\title{
Gastrotricha - not only in sediments: new epiphytic species of Chaetonotida from the Jubilee Greenhouse of the Botanical Garden in Kraków
}

\author{
Małgorzata KOLICKA \\ Department of Animal Taxonomy and Ecology, Institute of Environmental Biology, \\ Adam Mickiewicz University, Umultowska 89, 61-614 Poznań, Poland. \\ Email:kolicka@amu.edu.pl \\ urn:lsid:zoobank.org:author:550BCAA1-FB2B-47CC-A657-0340113C2D83
}

\begin{abstract}
Although Gastrotricha have previously been recorded in bottom sediments of greenhouses as well as in micro-reservoirs of Bromeliaceae, palm houses provide a more specific microhabitat for these animals that often originate from different regions of the world. This paper presents an investigation of gastrotrich assemblages associated with aquatic plants. Eight species of the epiphytic chaetonotids were found in the Jubilee Greenhouse of the Botanical Garden in Kraków (Poland), including three species new to science, Chaetonotus (Chaetonotus) invitatus sp. nov., C. (Hystricochaetonotus) horridus sp. nov. and $C$. (H.) inaequabilis sp. nov. Two other species are new to Poland, C. (C.) paucisquamatus Kisielewski, 1991 and C. (Zonochaeta) cestacanthus Balsamo, 1990, both recorded here for the first time outside their terra typica. These observations confirm that greenhouses and palm houses provide many ecological niches and favourable conditions for the development of a number of unintentionally introduced species which cannot be found outside their original climate conditions.
\end{abstract}

Keywords. Alien species, Chaetonotus, new species, new records, palm house.

Kolicka M. 2019. Gastroticha - not only in sediments: new epiphytic species of Chaetonotida from the Jubilee Greenhouse of the Botanical Garden in Kraków. European Journal of Taxonomy 511: 1-100.

https://doi.org/10.5852/ejt.2019.511

\section{Introduction}

The beginning of the $20^{\text {th }}$ century can be described as a period of very dynamic growth of urban areas throughout the world. This process is directly connected not only with the growing number of areas covered by compact housing but also with globalisation and the unification of environments (Ignatieva 2010). Palm houses and greenhouses are a frequent and common element in many major European cities. Many such structures were built as early as in the $18^{\text {th }}$ and $19^{\text {th }}$ centuries, and they hosted exhibitions of exotic vegetation species and ornamental elements (e.g., volcanic lava, boulders, logs), which were often brought from different natural environments (Britton 1896; Ignatieva 2010). New, modern palm houses and greenhouses were also created in the $20^{\text {th }}$ and $21^{\text {st }}$ centuries, using plant species from own agriculture, botanical stores or exchanges between palm houses. Regardless of the type of greenhouse, many animals species (both local and foreign) could have been brought in a random and uncontrolled manner together with the plants, seeds, soil, litter and other components of the exhibitions (e.g., Kolicka 
et al. 2015). Palm houses provide these accidentally introduced organisms with specific conditions for colonisation and habitation that are different from outside anthropic habitats, e.g., municipal parks or squares (e.g., Duggan \& Duggan 2011; Zawierucha et al. 2013). Due to the high temperatures and humidity kept at a constant level, they create favourable conditions for the formation of stable and numerous populations of invertebrates which function in an unchanged form for many years (e.g., Kolicka et al. 2013). Because of that, palm houses and greenhouses are often regarded as 'tropical islands' in a moderate climate (e.g., Zawierucha et al. 2013). These 'islands', as habitats that are distant and isolated from their natural counterparts and other greenhouses, could be a perfect place for research on newly introduced, alien communities of species and the new areas they occupy as well as on variability within and among isolated populations separated from their source habitats.

Studies on palm house gastrotrichs have previously been conducted in Poznań, Łódź (Poland) and Copenhagen (Denmark) (Kolicka et al. 2013; Kolicka 2014, 2016), and these microinvertebrates seem to be a constant element of these artificial habitats. However, previous research always concerned the bottom sediments or microreservoirs formed in the axils of Bromeliaceae. Species of Gastrotricha are components of benthic, epibenthic and epiphytic communities. All these habitats need to be the subjects of conducted analyses, as otherwise a false conclusion might be reached that greenhouse faunas do not reflect all the types of environments that these animals occupy in natural conditions. In inland waters, gastrotrichs are a common, abundant group of invertebrates, crucial in meiofauna communities of all types of aquatic and semi-aquatic ecosystems (e.g., Kisielewski 1997a). In nature, they are an important element of the benthic communities (they occur in particularly large abundance in bottom sediments that are very rich in organic matter) as well as of the epiphytic fauna (e.g., Balsamo \& Todaro 2002; Balsamo et al. 2014).

Taxonomic studies of Gastrotricha have so far mainly focused on the species of benthic communities, both from greenhouses and natural environments. Investigations focusing only on communities of submerged plant fauna remain scarce (e.g., Kisielewski 1981, 1991; Nesteruk 2000, 2004, 2010, 2011). However, analyses of bottom sediments from reservoirs or stations with a rich aquatic vegetation reveal a much higher abundance and species richness of gastrotrichs (e.g., Kisielewski 1986). This may be caused by mixing sediment and vegetation faunas or it may be linked with an increased production of organic matter from decaying plants. Analyses of mixed material (collected, for example, by using a net from the surface of the bottom and submerged plants) also indicate a large number of recorded species (e.g., Balsamo et al. 2014). Nonetheless, comparative studies on the gastrotrichofauna of submerged plants and bottom sediments show distinct differences in species composition and the dominance structure of various taxa. The number of common taxa between these two habitats is low, the dominant taxa are different, and the species number and diversity are higher in bottom sediments than in aquatic plants (Nesteruk 2004, 2011).

In my research, I have focused on analysing the composition of the gastrotrich epiphytic fauna forming in an anthropic habitat of the Jubilee Greenhouse of the Botanical Garden in Kraków (Poland). I would like to see whether this artificial habitat provides favourable conditions for Gastrotricha communities and to compare the results of this observation with previous data on palm house chaetonotids from bottom sediments as well as from microreservoirs formed in the axils of bromeliads (Kisielewski 1991; Kolicka et al. 2013, Kolicka 2014, 2016).

\section{Material and methods}

\section{Study area}

Samples were collected at the Jubilee Greenhouse of the Botanical Garden in Kraków $\left(50^{\circ} 03^{\prime} 38^{\prime \prime} \mathrm{N}\right.$, $19^{\circ} 57^{\prime} 30^{\prime \prime}$ E). This greenhouse was built in the years 1959-1966 in the southern part of the Botanical 
Garden of Jagiellonian University. The Jubilee Greenhouse comprises 8 departments, viz. the section of the palm house, of carnivorous plants, of aquatic and semi-aquatic plants, of useful tropical plants, of cycads, of desert and semi-desert plants and the nursery section. The research area was the aquatic and semi-aquatic plant section, with large water reservoirs (Fig. 1). These reservoirs with bottom sediments are an exposition place for many plants and some small, ornamental fish species. The submerged plants in this tank come from seeds imported from natural habitats, exchanged between palm houses or from the Botanical Garden's own nursery, whereas the fish come from aquarium shops. Most of the vegetation is cultivated directly in the bottom sediments, but some of the plant species grow in pots immersed in the reservoirs. Manure is added to these pots twice a year. The reservoirs are cleaned once a year, the plants are at that time transferred to a tank in the nursery section, while the water and half of the sediments are exchanged for new ones. The sediments in the aquatic reservoir and pots come from the local area whereas the fresh water for the tank is taken from a municipal water supply. The temperature in this section does not fall below $23^{\circ} \mathrm{C}$ during the year.

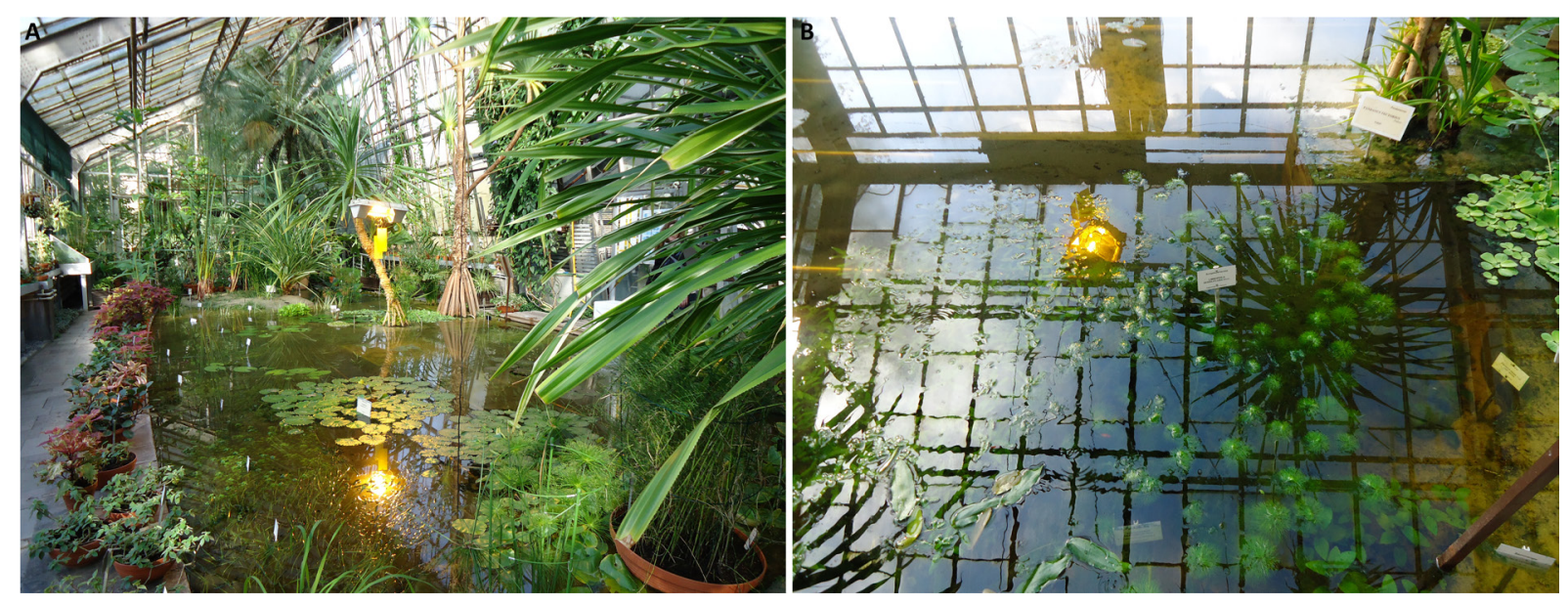

Fig. 1. Study area. A. The inside of Jubilee Greenhouse at the Botanical Garden in Kraków. B. Sampling site.

\section{Sampling and documentation}

Samples of aquatic plants were taken two times (15 November 2013 and 17 April 2014) from water reservoirs at the Jubilee Greenhouse of the Botanical Garden in Kraków. During both sampling sessions, the material was collected at the same spots from three stations within the reservoirs. However, between these sessions the plant arrangement was changed and the samples were collected from different plants during the first and second sampling (see Table 1). Samples of submerged vegetation were collected by picking the plants and squeezing water out of them thoroughly into a container, rinsing and squeezing them one more time, and then picking fresh, non-squeezed plants and placing them in a $1000 \mathrm{~cm}^{3}$ container. Water plant samples were collected using the standard method for gastrotrichofauna research due to the limited effectiveness of other methods (Kisielewski 1997a). Within 5 days of collecting the material, a total of $5 \mathrm{~cm}^{3}$ of water from the vegetation was analysed under an Olympus SZ51 stereo microscope. All specimens were observed, photographed and documented alive under an Olympus BX41 compound microscope (Tokyo, Shinjuku, Japan) equipped with phase contrast and an Array Artcam 300 digital camera (Tokyo, Shinjuku, Japan). Morphometric characters were measured in cellSens Entry 1.12 software (Olympus). All measurements are given in micrometres $(\mu \mathrm{m})$ and all formulas used are given as a percentage (\%) (Kisielewski 1981, 1991, 1997a; Hummon et al. 1992). 
Table 1. Sampling sites with specified aquatic plant species.

\begin{tabular}{ccc}
\hline Site & Session 1 (15 Nov. 2013) & Session 2 (17 Apr. 2014) \\
\hline I & Myriophyllum verticillatum L. & Myriophyllum verticillatum L. \\
II & Elodea nuttallii (Planch.) H.St.John & Myriophyllum verticillatum L. \\
III & Limnophila sessiliflora Blume & Elodea nuttallii (Planch.) H.St.John \\
\hline
\end{tabular}

\section{Morphological analyses}

Morphological characters were only measured if they were amenable to accurate measurement. Because of the generally low taxonomic usefulness of preserved gastrotrichs, each specimen was documented using a set of photomicrographs and each holotype was additionally documented with detailed schematic drawings (all deposited in the Natural History Collections at Adam Mickiewicz University, Poznań = NHC). The International Code of Zoological Nomenclature allows for such a documentation of types in article 73.1.4 (The International Commission on Zoological Nomenclature 1999), even if the documented specimen no longer exists. The taxon descriptions follow the convention of Hummon et al. (1992), in which the distance of a morphological character from the anterior end is expressed as percentage units (U) of the animal's total length. In the descriptions of new species in this paper, the measurements of width of different body sections were omitted because they would be strongly influenced by the pressure of the coverglass on the studied live specimens. The identification of gastrotrichs, their morphological study and terms follow Kisielewski (1981, 1991, 1997a) and Kolicka et al. (2016). The terms describing the shape of the furcal branches and furcal indentation follow Roszczak (1969). This paper uses the following formula to describe the distribution of scales:

$$
\text { Ratio of scale distribution }=\frac{\text { total number of longitudinal alternating rows of scales }}{\text { number of scales in central longitudinal rows }} \times 100 \%
$$

as well as the pharynx formulae according to Kisielewski (1991):

$$
\begin{array}{cc}
a=\frac{\text { width of anterior thickening }}{\text { pharynx length }} \times 100 \% & n=\frac{\text { width of pharyngeal narrowing }}{\text { pharynx length }} \times 100 \% \\
m=\frac{\text { width of middle pharynx }}{\text { pharynx length }} \times 100 \% & p=\frac{\text { width of posterior thickening }}{\text { pharynx length }} \times 100 \%
\end{array}
$$

and the pharynx-to-intestine length ratio according to Kolicka et al. (2016):

$$
I=\frac{\text { pharynx length }}{\text { intestine length }} \times 100 \%
$$

The use of these formulae allows for the objective comparison of these morphological features between different taxa and the demonstration of scale distribution and detailed pharynx shape in a numerical manner. The pharynx-to-intestine length ratio helps estimate the age of specimens, thus avoiding misclassification by analysing juvenile, subadult and adult individuals together. Juvenile and subadult specimens have a significantly higher I-ratio than adults, usually for representatives of Chaetonotus at $>70 \%$ and $55 \%-70 \%$, respectively. In this paper, the following abbreviations were used: $\mathrm{D}=$ dorsal; DL $=$ dorsolateral; $\mathrm{L}=$ lateral; $\mathrm{LV}=$ ventrolateral; $\mathrm{V}=$ ventral, sensu Kolicka et al. (2016, see $\mathrm{S} 1$ and S2).

\section{Results}

The analysed material consisted of 208 specimens belonging to three genera, two subgenera and nine species, including three species that are new to science, namely Chaetonotus (Chaetonotus) invitatus sp. nov., C. (Hystricochaetonotus) inaequabilis sp. nov. and C. (H.) horridus sp. nov. Two other species 
recorded at the Jubilee Greenhouse of the Botanical Garden in Kraków turned out to be new to Poland; the first species, C. (C.) paucisquamatus Kisielewski, 1991, was described from and is only known from Brazil; the second newly reported species, C. (Zonochaeta) cestacanthus Balsamo, 1990, was described from Italy and was previously recorded only in that country. Another species that was found, namely $C$. (H.) hystrix Mečnikow, 1865, is well known in Poland and is considered as a taxon with a worldwide distribution. The last two of the recorded species were identified as Lepidodermella aff. squamata (Dujardin, 1841) and Heterolepidoderma aff. majus Remane, 1927. These taxa were defined as species with an unclear taxonomic rank because they corresponded well with the original description, but possessed a single character that differed from previous records (see the 'Remarks' section for these species). Live euglenids were present inside the intestines of 4 out of 208 specimens (see Kisielewska et al. 2015). In all the samples, rotifers (representatives of Monogononta and Bdelloidea), ostracods and rare polychaetes were observed as accompanying fauna.

Phylum Gastrotricha Mečnikow, 1865

Order Chaetonotida Remane, 1925 [Rao \& Clausen 1970]

Suborder Paucitubulatina d'Hondt, 1971

Family Chaetonotidae Gosse, 1864 (sensu Leasi \& Todaro 2008)

Subfamily Chaetonotinae Gosse, 1864 (sensu Kisielewski 1991)

Genus Chaetonotus Ehrenberg, 1830

\section{Type species}

Trichoda larus Müller, 1773 (= Chaetonotus larus (Müller, 1773)).

\section{Terra typica}

Denmark.

\section{Remarks on genus}

This is a polyphyletic taxon, with only one apparently monophyletic subgenus (Chaetonotus (Zonochaeta) Remane, 1927); it encompasses 175 nominal freshwater species and 44 nominal marine species (Kånneby et al. 2012, 2013; Todaro 2018). Present in benthic, interstitial, periphytic and rarely semiplanktonic habitats (Kisielewski 1997a).

Subgenus Chaetonotus s. str. Ehrenberg, 1830

\section{Type species}

Trichoda larus Müller, 1773 (= Chaetonotus larus (Müller, 1773)).

\section{Terra typica}

Denmark.

\section{Remarks on subgenus}

This is clearly a polyphyletic subgenus in terms of molecular data (Kieneke et al. 2008; Kånneby et al. 2012, 2013); it encompasses 84 nominal freshwater and 4 nominal marine species (Kieneke \& SchmidtRhaesa 2015; Todaro 2018). Present in benthic, interstitial, periphytic and rarely also in semi-planktonic habitats (Kisielewski 1997a). 
Chaetonotus (Chaetonotus) invitatus sp. nov. urn:1sid:zoobank.org:act:5350662C-4565-4EB6-96B0-4742ED038286

Figs 2-11, A1-A2; Tables 2, A1-A2

\section{Diagnosis}

Slender, bottle-shaped, body measuring from 174.6 to $194.7 \mu \mathrm{m}$ in length. Head five-lobed, cephalion, epipleurae and hypopleurae clearly demarcated in head outline. Hypostomium kidney-shaped with horn-like protuberances anterolaterally and pair of reinforcements near anterior edge. Two additional plates beyond posterior hypostomium edge. Ocellar granules absent. In mouth ring, two weak cuticular teeth arising from anterior pharynx region. All scales one-lobed, with shallow to deep posterior notches, keeled and spined. Scales distributed in 23-25 single longitudinal rows $(5-7 \mathrm{D}+4 \mathrm{DL}+6 \mathrm{~L}+4 \mathrm{LV}+4 \mathrm{~V})$ with 25-27 scales in central row. Scales strongly differing morphologically in body areas. Scales located close to one another and with overlapping edges on furcal base and furcal appendages. Spines basally bent and thick, subsequently strongly and gradually tapering towards hair-like end, ventral spines hairlike along entire length. Lateral spines more strongly curved than dorsal and dorsolateral ones. Length of spines gradually increases from dorsal, dorsolateral, lateral and ventrolateral surfaces towards ventral surface and from head towards widest trunk region. Dorsally on posterior trunk region, two or three scales with longer and thicker spines. Dorsally and dorsolaterally on posterior trunk region, on furcal base and furcal appendages, scales with shorter spines, with rudimentary spines or without any spine. Dorsolaterally on furcal appendages, one pair of scales with long, rigid and spike-like spines reaching to furca inner indentation. Furcal appendages with two pairs of scales with long, thick parafurcal spines tapering to their ends. Ventral interciliary field covered with semirectangular plates on pharyngeal region and one-lobed, keeled scales on intestine region. Four pairs of ventral interciliary field terminal scales. Pharynx narrow, with anterior and posterior dilatations. Intestine straight without anterior section differing in form and morphology.

\section{Etymology}

From the Latin 'invitatus' = 'invited', referring to the artificial place to which it was transferred.

\section{Material examined}

\section{Holotype}

POLAND • adult; Kraków, Botanical Garden, Jubilee Greenhouse, site 1; 5003'38" N, 1957'30" E; 15 Nov. 2013; M. Kolicka leg.; NHC-GCCI-20-1-25/h (photomicrographs, also in the author's collection).

\section{Paratypes}

POLAND • 24 adults, 5 subadults, 5 juveniles; same collection data as for holotype; NHC-GCCI-20-26$100 / \mathrm{p}$ (photomicrographs, also in the author's collection).

\section{Description}

Habitus. Chaetonotus (Chaetonotus) invitatus sp. nov. has a slender, bottle-shaped body (Figs 2, 5). The head is wide and the neck constriction is strongly marked. The neck gradually tapers to the beginning of the trunk (ca U38) (Figs 2, 5). The trunk is only slightly wider than the head and gradually dilates from ca U39 to ca U59, where it is at its maximum width. Then it gradually tapers slightly towards a weakly demarcated furcal base (from U85) (Fig. 2). The furcal indentation is parabolic in shape. The furcal branches are set apart and point slightly outwards (Figs $6 \mathrm{G}-\mathrm{H}, 8$ ). The adhesive tubes are long, slightly bent, narrow and very gradually taper slightly towards their ends. The adhesive tube ends are blunt (Figs 2, 6G-H, 8). 
$\cup$

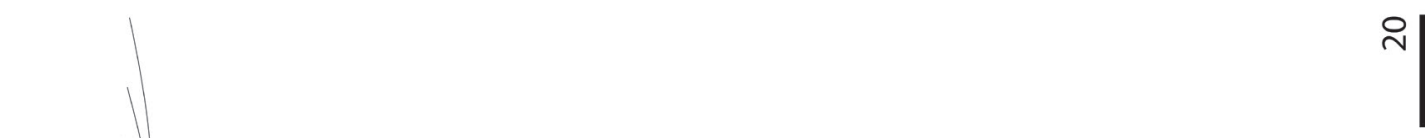

$\infty$

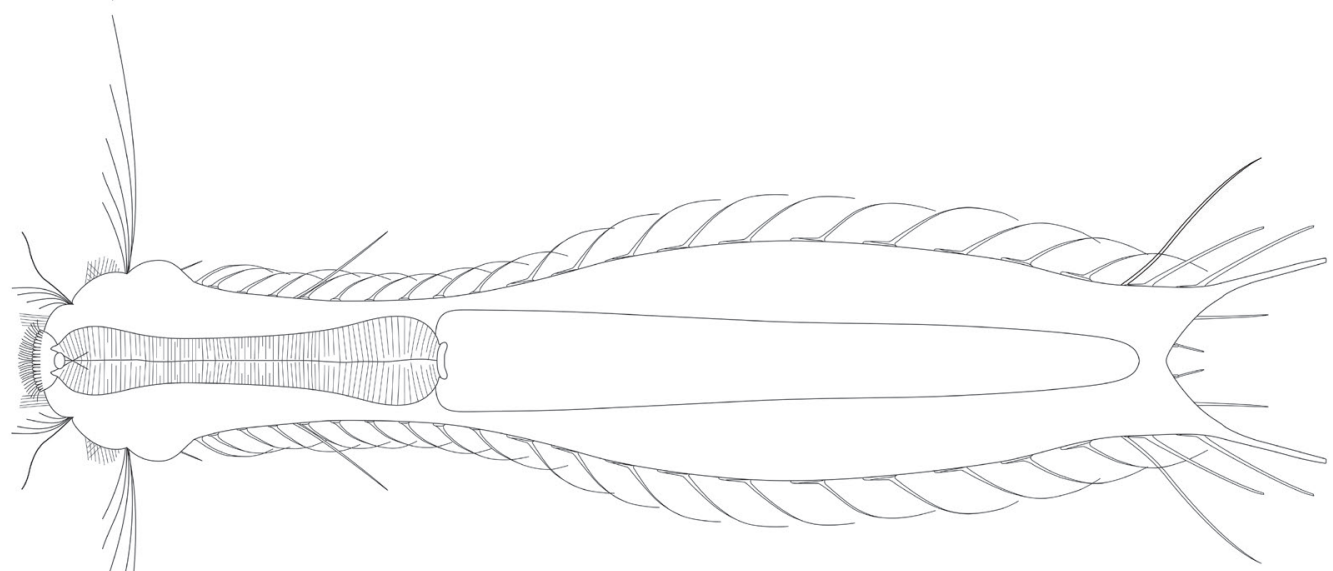



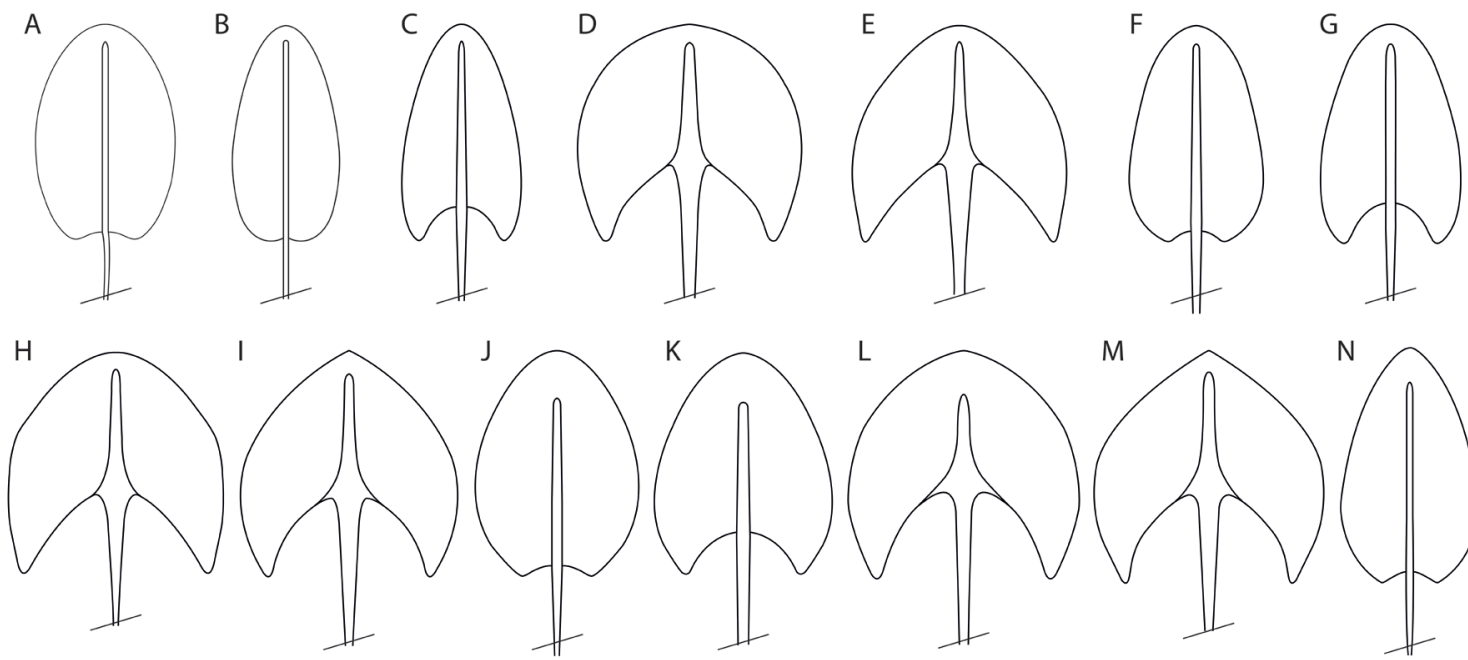

$\mathrm{K} / \mathrm{L}$

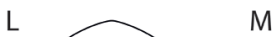

$\mathrm{M}$
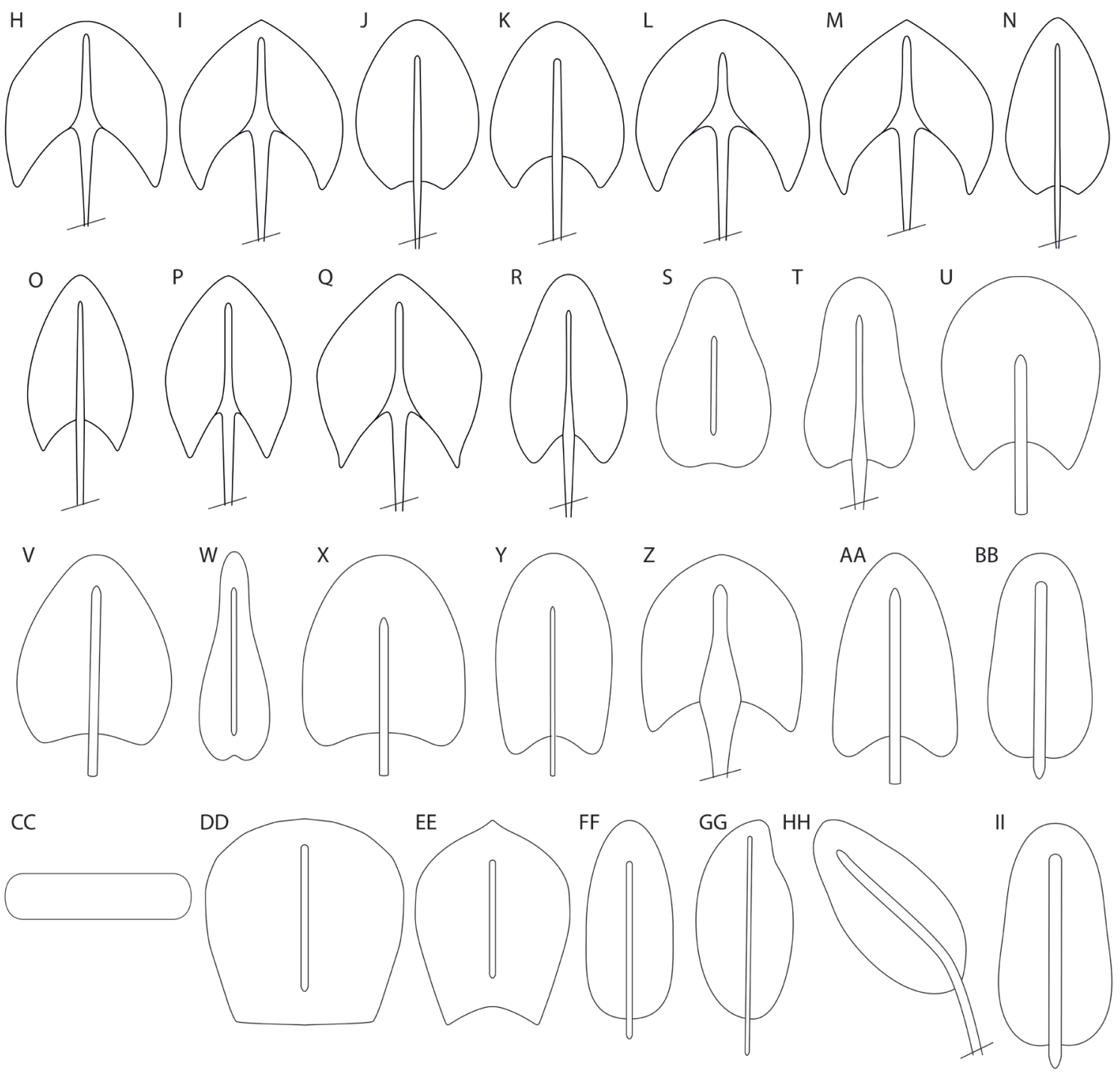

Fig. 3. Chaetonotus (Chaetonotus) invitatus sp. nov. Schematic drawings of the scales. A. Head anteriormost dorsal scale (scale 1). B. Head dorsal scale (scale 2). C. Head dorsolateral scale (scale 3). D. Head lateral and ventrolateral scale (scale 4). E. Head ventral scale (scale 5). F. Anterior neck dorsal scale (scale 6). G. Anterior neck dorsolateral scale (scale 7). H. Anterior neck lateral and ventrolateral scale (scale 8). I. Anterior neck ventral scale (scale 9). J. Posterior neck dorsal scale (scale 10). K. Posterior neck dorsolateral scale (scale 11). L. Posterior neck lateral and ventrolateral scale (scale 12). M. Posterior neck ventral scale (scale 13). N. Trunk dorsal scale (scale 14). O. Trunk dorsolateral scale (scale 15). P. Trunk lateral and ventrolateral scale (scale 16). Q. Trunk ventral scale (scale 17). R. Scale 18. S. Scale 19. T. Scale 20. U. Scale 21. V. Scale 22. W. Scale 23. X. Scale 24. Y. Scale 25. Z. Scale 26. AA. Scale 27. BB. Scale 28. CC. Scale 29. DD. Scale 30. EE. Scale 31. FF. Scale 32. GG. Scale 33. HH. Scale 34. II. Scale 35. 
HEAD. The head is five-lobed, long and parabolic. The cephalion (U1-U7) is long and wide, it is visible on the dorsal head surface as an inverted, rounded triangle. It is clearly demarcated in the body outline and its dorsal edge is free and does not adhere to the head surface (Fig. 7A-B). The pleurae are large, convex and clearly demarcated in the head outline, the hypopleurae are only slightly larger than the epipleurae (Fig. 2). Between the epipleurae and hypopleurae, deep notches are present. The epipleurae (U3-U7) are located on the dorsal, dorsolateral, lateral and ventrolateral surfaces, whereas the hypopleurae (U8U12) cover the dorsal, dorsolateral, lateral, ventrolateral and ventral surfaces in such a manner that their greatest portion is located on the ventral side. The hypostomium is kidney-shaped and has two horn-like protuberances placed anterolaterally and a pair of strong reinforcements near its anterior edge (U3-U6) (Figs 2C, 6B). One pair of additional plates is located posterolaterally to the hypostomium, at U6-U7. These plates are wide and short and their lateral edges extend to the edges of the ventral epipleurae (Fig. 6B). Two pairs of cephalic ciliary tufts are present. The anterior tufts emerge laterally between the cephalion edge and the dorsal edge of the epipleurae (at U3). The anterior tufts consist of 5 cilia which are bent and short, and their length increases from the first to the last cilium (Table A1). The posterior tufts have 5 cilia each and emerge laterally between the epipleurae and the hypopleurae (at U7-U8). Cilia in the posterior tufts are long and nearly straight and their length increases from the first cilium to the last, long cilium (Table A1). Ocellar granules are absent. The mouth ring is located terminally at $\mathrm{U} 1-\mathrm{U} 3$, is wide and has long, strong finger-like reinforcements as well as very long cuticular inner hairs (Figs 2, 9A-B). Inside the mouth ring, two small and weak cuticular teeth arising from the anterior pharynx region are present (Fig. 9B-C). Suboral bristles emerge in three pairs of tufts, laterally to the mouth ring, near the lateral edges of the hypostomium and in lines below the additional hypostomium plates (Fig. 2C).

SCALES. The body is covered with one-lobed scales that adhere along their entire surface to the cuticle (Figs 3, 6-7). The scales have a straight keel and are egg-shaped with very weak posterior notches to very deep posterior notches. The scales are distributed in 23-25 longitudinal alternating rows
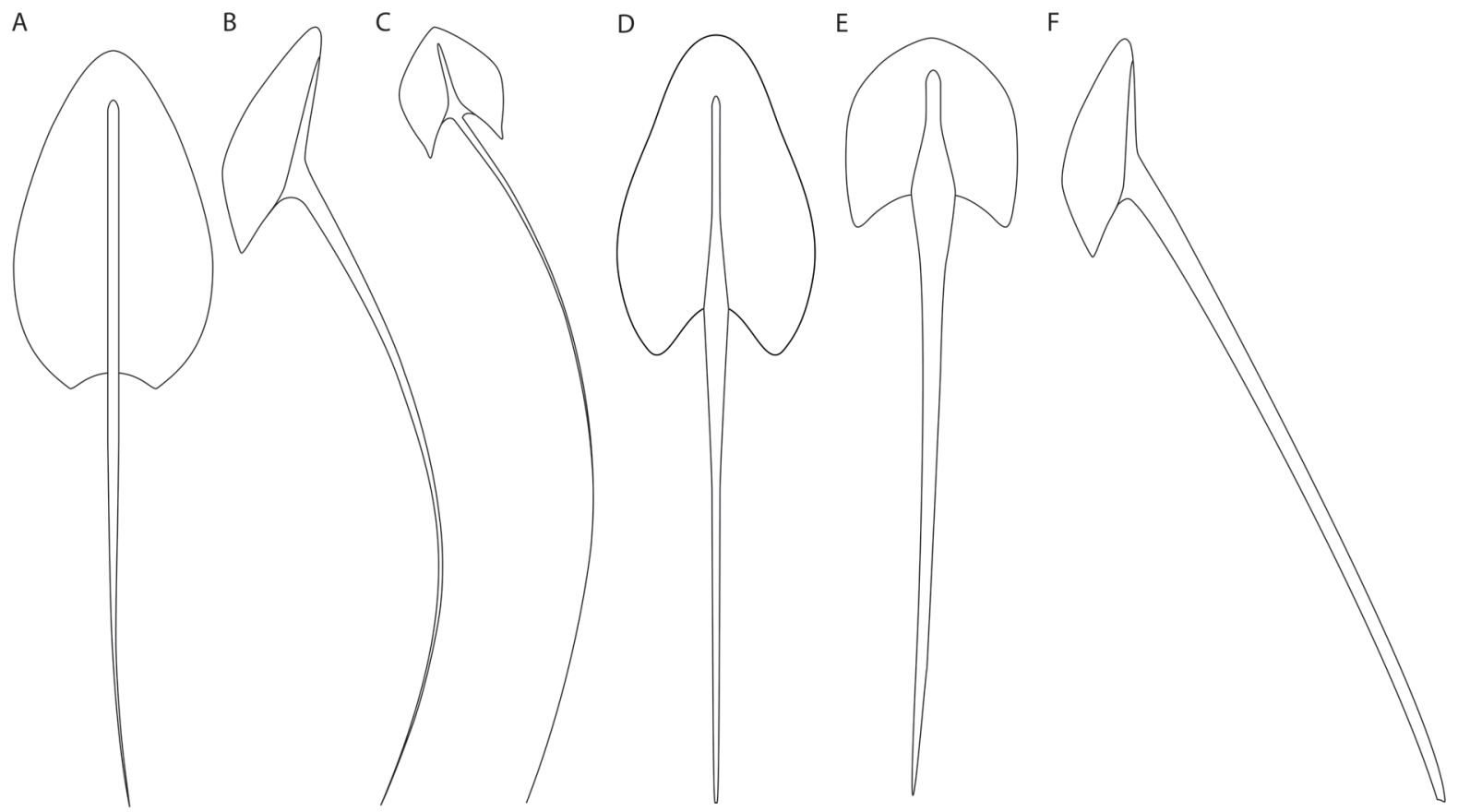

Fig. 4. Chaetonotus (Chaetonotus) invitatus sp. nov. Schematic drawings of the spine types. A. Dorsal and dorsolateral spine type. B. Lateral and ventrolateral spine type. C. Ventral spine type. D. Scale 18 spine type. E. Dorsolateral furcal appendage spine type. F. Parafurcal spine type. 
Table 2. Main morphometric characters of Chaetonotus (Chaetonotus) invitatus sp. nov. $\mathrm{N}=$ number of specimens analysed; Range $=$ the smallest and the largest structure found among all specimens measured. All measurements in micrometers $(\mu \mathrm{m})$.

\begin{tabular}{cccc}
\hline Characters & N & Holotype & Range of adult paratypes \\
\hline Body length & 23 & 193.18 & $174.64-194.66$ \\
Furca length & 22 & 33.17 & $31.14-34.45$ \\
Adhesive tube length & 22 & 18.97 & $16.39-19.20$ \\
Number of scales in central longitudinal row & 25 & 27 & $25-27$ \\
Total noumber of longitudinal alternating & 25 & 25 & $23-25$ \\
rows of scales & 22 & $1.94-4.94 \times 1.91-4.23$ & $1.58-5.19 \times 1.60-4.91$ \\
Head scales length $\times$ width & 22 & $2.55-6.29 \times 3.02-5.71$ & $2.08-7.09 \times 2.46-6.44$ \\
Neck scales length $\times$ width & 22 & $3.57-8.78 \times 2.79-5.97$ & $2.84-9.38 \times 2.22-7.39$ \\
Trunk scales length $\times$ width & 22 & $3.88-24.11$ & $3.31-26.39$ \\
Head spines length & 22 & $6.37-27.41$ & $5.03-31.86$ \\
Neck spines length & 22 & $10.09-31.06$ & $7.84-34.26$ \\
Trunk spines length & 22 & 8.43 & $7.58-9.47$ \\
Mouth ring diameter & 23 & 56.84 & $51.02-59.64$ \\
Pharynx length & & &
\end{tabular}
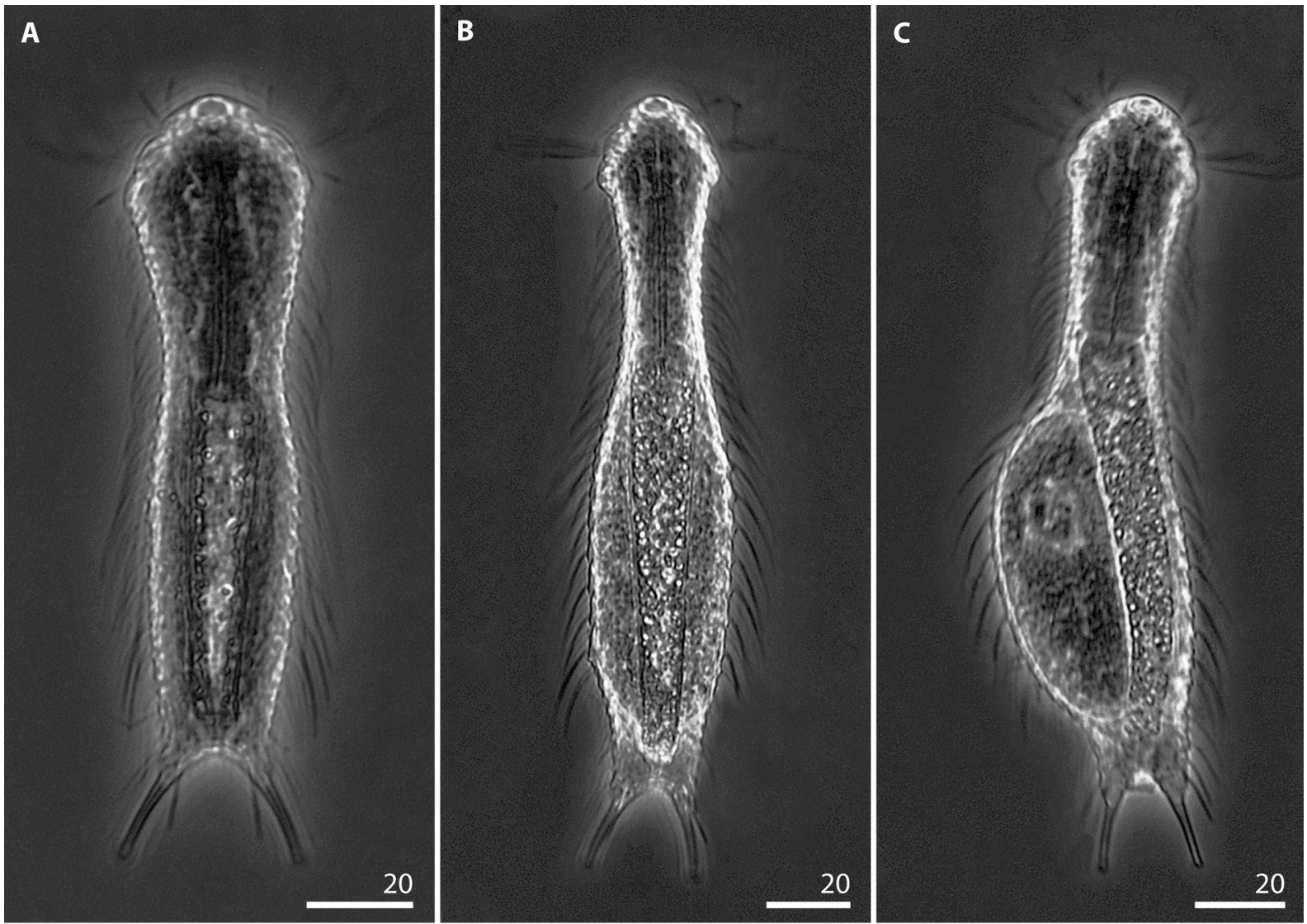

Fig. 5. Chaetonotus (Chaetonotus) invitatus sp. nov. Habitus. Phase contrast microphotographs. A. Juvenile specimen. B. Adult specimen. C. Specimen with mature egg. 

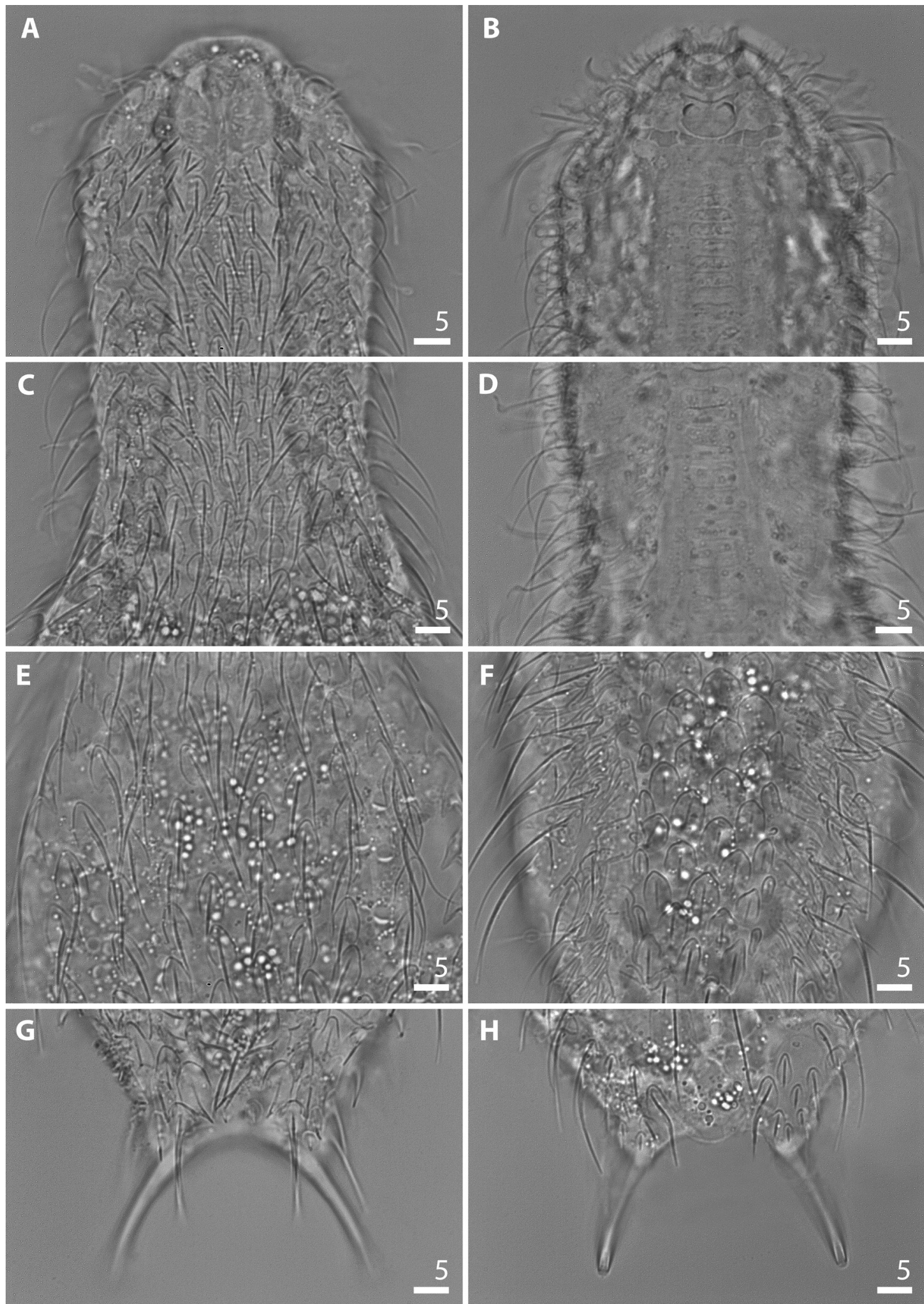

Fig. 6. Chaetonotus (Chaetonotus) invitatus sp. nov. Bright field microphotographs. A. Head, dorsal view. B. Head, ventral view. C. Neck, dorsal view. D. Neck, ventral view. E. Trunk, dorsal view. F. Trunk, ventral view. G. Furca base and furcal appendages, dorsal view. H. Furca base and furcal appendages, ventral view. 
$(5-7 \mathrm{D}+4 \mathrm{DL}+6 \mathrm{~L}+4 \mathrm{LV}+4 \mathrm{~V})$ with $25-27$ scales in the central row. The longitudinal rows of scales run straight and are arranged in parallel to one another from the top of the head to the widest body region. Dorsally and dorsolaterally on the posterior trunk region, furca base and furcal appendages, the scales are arranged in rounded arcs and in a rosette (Figs 2, 7C-D, 8A). The scales are located close to one another, but on the head, neck and anterior and central trunk part they do not overlap. The edges of the scales overlap only on the furcal base and furcal appendages (Figs 2, 8A). The scales show morphological diversity throughout the particular body regions in terms of shape and size (Fig. A1). The head anteriormost scales are situated near the posterior edge of the cephalion. These scales are oval with shallow posterior notches (scale 1; Fig. 3A). The remaining head dorsal scales (scale 2; Fig. 3B) are more elongated and have shallower posterior notches. The head dorsolateral scales (scale 3; Fig. 3C) become shorter than the dorsal scales and have deeper posterior notches. The head lateral and ventrolateral scales (scale 4; Fig. 3D) become more semi-rounded, shorter and wider than the dorsolateral ones and possess deep posterior notches, whereas the ventral scales are smaller, wide and have more pointed anterior edges (scale 5; Fig. 3E). On the neck, the scales are shorter and wider than the scales on the head area (scales 6-9; Fig. 3F-I) and their size gradually increases towards the trunk region (scales 10-13; Fig. 3J). The neck dorsal scales (scales 6 and 10; Fig. 3F, J) are egg-shaped and possess weak posterior notches. The neck dorsolateral scales (scales 7 and 11; Fig. 3G, K) become gradually larger than the dorsal scales and have deeper posterior notches. The neck lateral and ventrolateral scales (scales 8 and 12; Fig. 3H, L) become more semi-rounded and deeply posteriorly notched. They are wider and gradually larger than the dorsolateral ones, whereas the ventral scales (scales 9 and 13; Fig. 3I, M) are
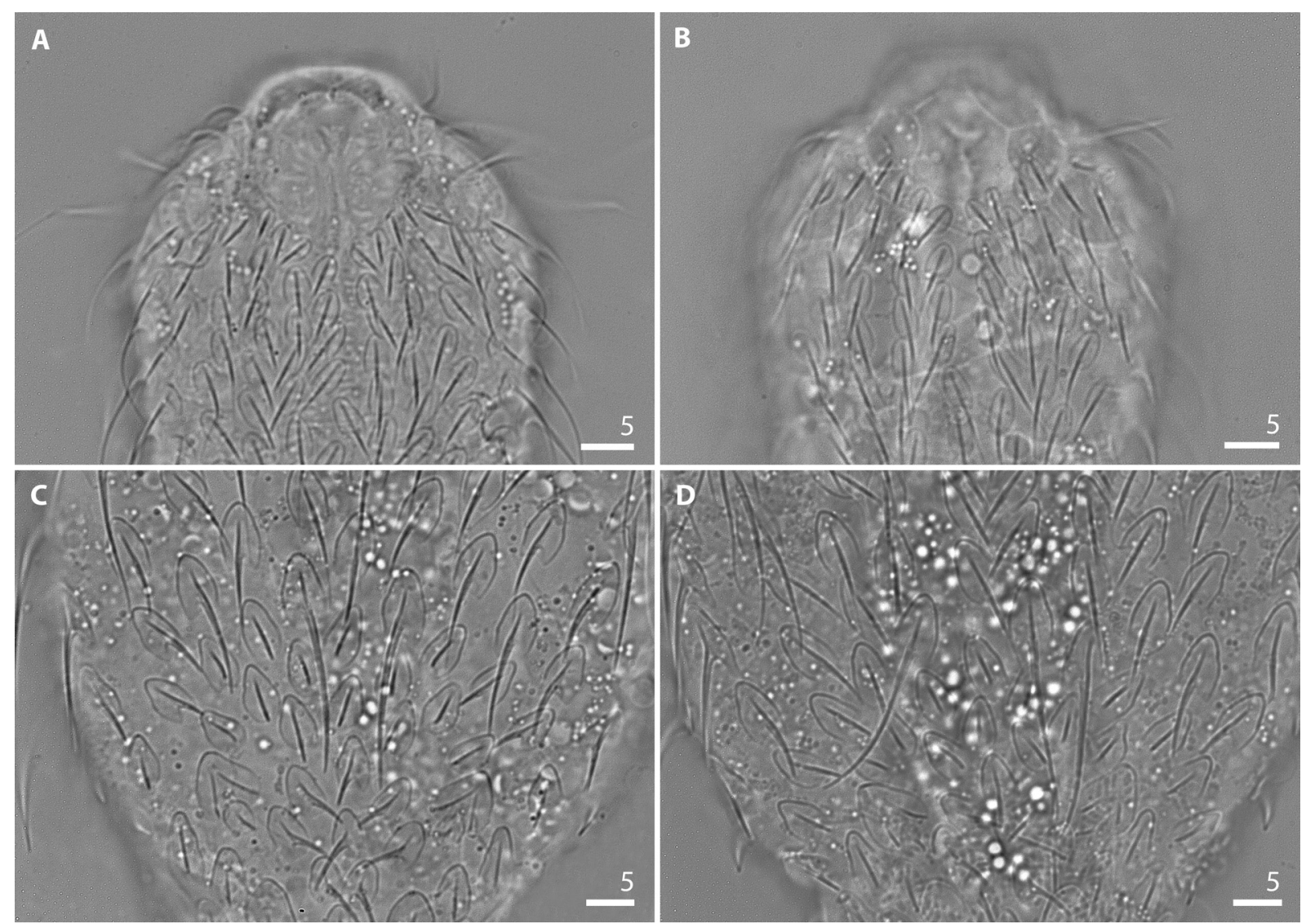

Fig. 7. Chaetonotus (Chaetonotus) invitatus sp. nov. Bright field microphotographs. A. Detail of dorsal head view of adult specimen. B. Detail of dorsal head view of juvenile specimen. C. Dorsal view of posterior trunk region of specimen with two scales 17. D. Dorsal view of posterior trunk region of specimen with three scales 17. 
smaller, wide and have more pointed anterior edges (Fig. 2C). The trunk dorsal scales (scale 14; Fig. 3N) from the anterior to posterior trunk part are egg-shaped, but with a more tapered anterior edge than the neck scales. These scales have weak posterior notches. The trunk dorsolateral scales (scale 15; Fig. 3O) become gradually larger than the dorsal scales and have deeper posterior notches. The trunk lateral and ventrolateral scales (scale 16; Fig. 3P) become more oval, gradually larger and wider than the dorsolateral ones, have a more pointed anterior edge and possess deep posterior notches. The trunk ventral scales (scale 17; Fig. 3Q) are smaller, shorter and wider, have more pointed anterior edges and a very deep posterior notch (Figs 2A, 6F). The scales in the ventral longitudinal row located closest to the ciliary band are distinctly smaller than the other scales and their anterior edge is oriented towards the bands at an angle of ca $40^{\circ}$ (Figs 2C, 6B, D, F, H). Dorsally on the trunk posterior region (at U73-U77), two or three slightly larger scales with deeper posterior notches and much longer and stronger spines are present (scale 18; Fig. 3R). Near the scales with longer and stronger spines and posteriorly to them (at U75-U80), smaller, trifle pear-shaped scales are located with weak posterior notches, straight keels and without spines (scale 19; Fig. 3S). Subsequently, on U80-U85, dorsally on the posterior trunk region, 8 scales, that are triangle-shaped with strongly rounded edges, with clear posterior notches and a straight keel and spine, are situated (scale 20; Fig. 3T). On the dorsal posterior trunk region, one pair of small, semirounded scales with a straight keel and a short, straight spine is located in the notch of a pair of double keeled scales with trunk sensory bristles (at U82-U83) (scale 21; Fig. 3U). Dorsolaterally on the posterior trunk region and furcal base, two pairs of small semi-triangular scales with strongly rounded edges and shallow posterior notches, straight keels and straight rudimental spines are present (at U84-

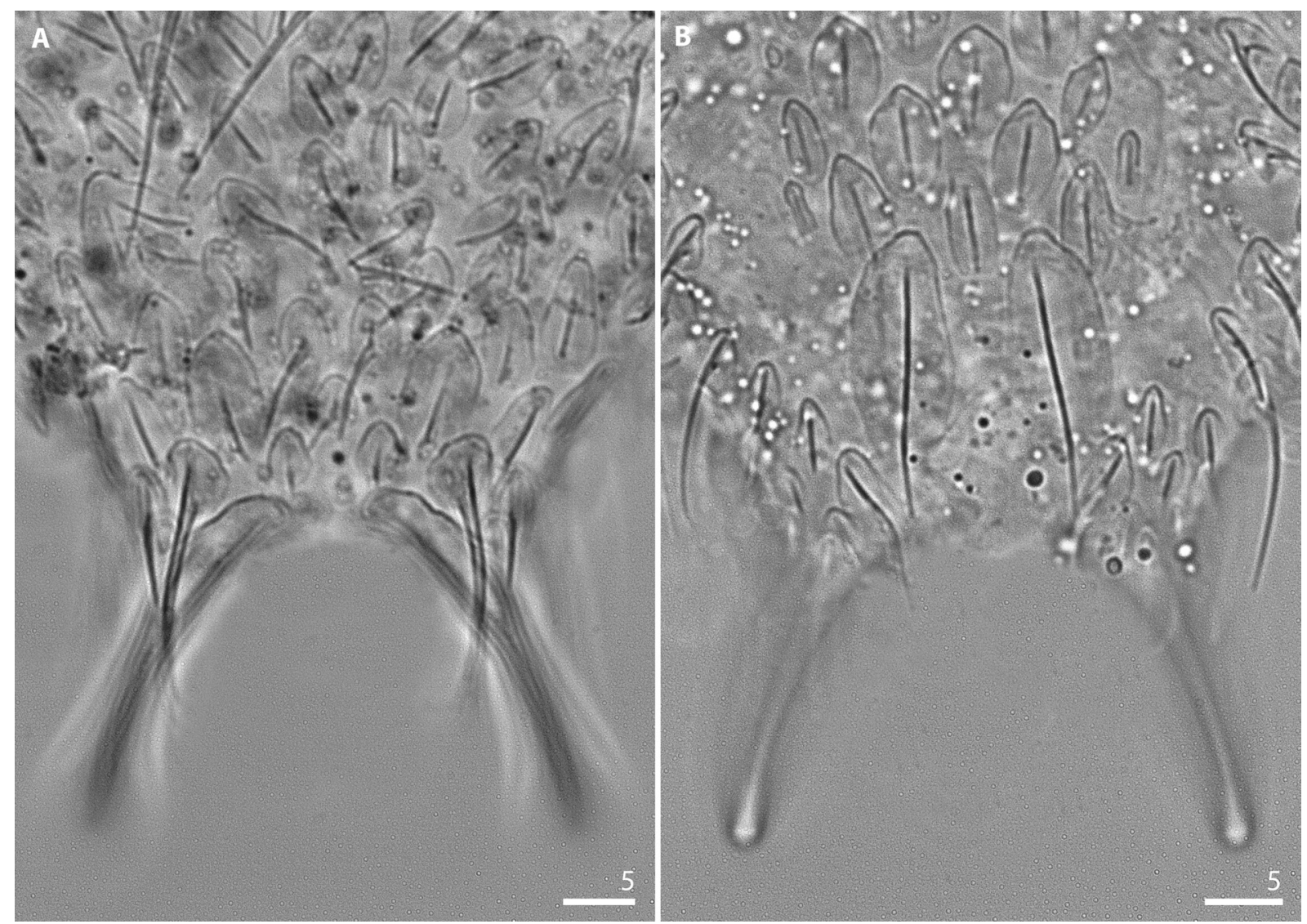

Fig. 8. Chaetonotus (Chaetonotus) invitatus sp. nov. Bright field microphotographs. A. Dorsal view of the posterior trunk region, furca base and furcal appendage scales. B. Ventral view of the posterior trunk region, furca base and furcal appendage scales. 
U87) (scale 22; Fig. 3V). Laterally on the posterior trunk region and on the furcal base, at U82-U88, two pairs of narrow, elongated pear-shaped scales with very weak posterior notches are present. These scales have long straight keels but are not spined (scale 23; Fig. 3W). Dorsally on the furcal base and furcal appendages at U85-U88, three semi-rounded scales with weak posterior notches, straight keels and short spines are present (scale 24; Fig. 3X). Laterally to them (to scales 24), on the dorsal furcal base, one pair of large $(5.4-9.1 \times 3.2-5.3 \mu \mathrm{m})$, oval scales with a shallow posterior notch, straight keel and a short, straight spine is situated (at U84-U87) (scale 25; Fig. 3Y). Dorsolaterally on the furcal appendages at U87-U89, one pair of large, rounded scales with prominent posterior notches is present (scale 26; Fig. 3Z). These scales have straight keels and long, rigid spines. Laterally to this pair of scales (to scales 26) at U88-U89, two pairs of small $(2.6-6.1 \times 1.8-4.1 \mu \mathrm{m})$, oval-shaped scales with a shallow indentation and straight keels and spines are present (scale 27; Fig. 3AA). On the lateral surface of the furcal appendage, two pairs of scales with parafurcal spines are present. The first pair is located at U88-U89 and the second one, i.e. the last pair of furcal lateral scales, is located at U90-U91. Both pairs are similar in shape to the posterior trunk scales (Figs 2, 6G). Ventrolaterally and ventrally on the furcal appendages and furcal base, two pairs of small $(2.2-5.3 \times 1.4-2.8 \mu \mathrm{m})$ oval scales without any posterior notches are present (at U85-U88). These scales have straight keels and straight rudimentary spines (scale 28; Fig. 3BB).

SPINES. All spines emerging from the posterior scale region have no lateral denticles. The dorsal, dorsolateral (Fig. 4A), lateral and ventrolateral (Fig. 4B) spines are basally bent and thick, and subsequently strongly and gradually taper towards the slightly bent hair-like ends. The spines arising from the lateral,
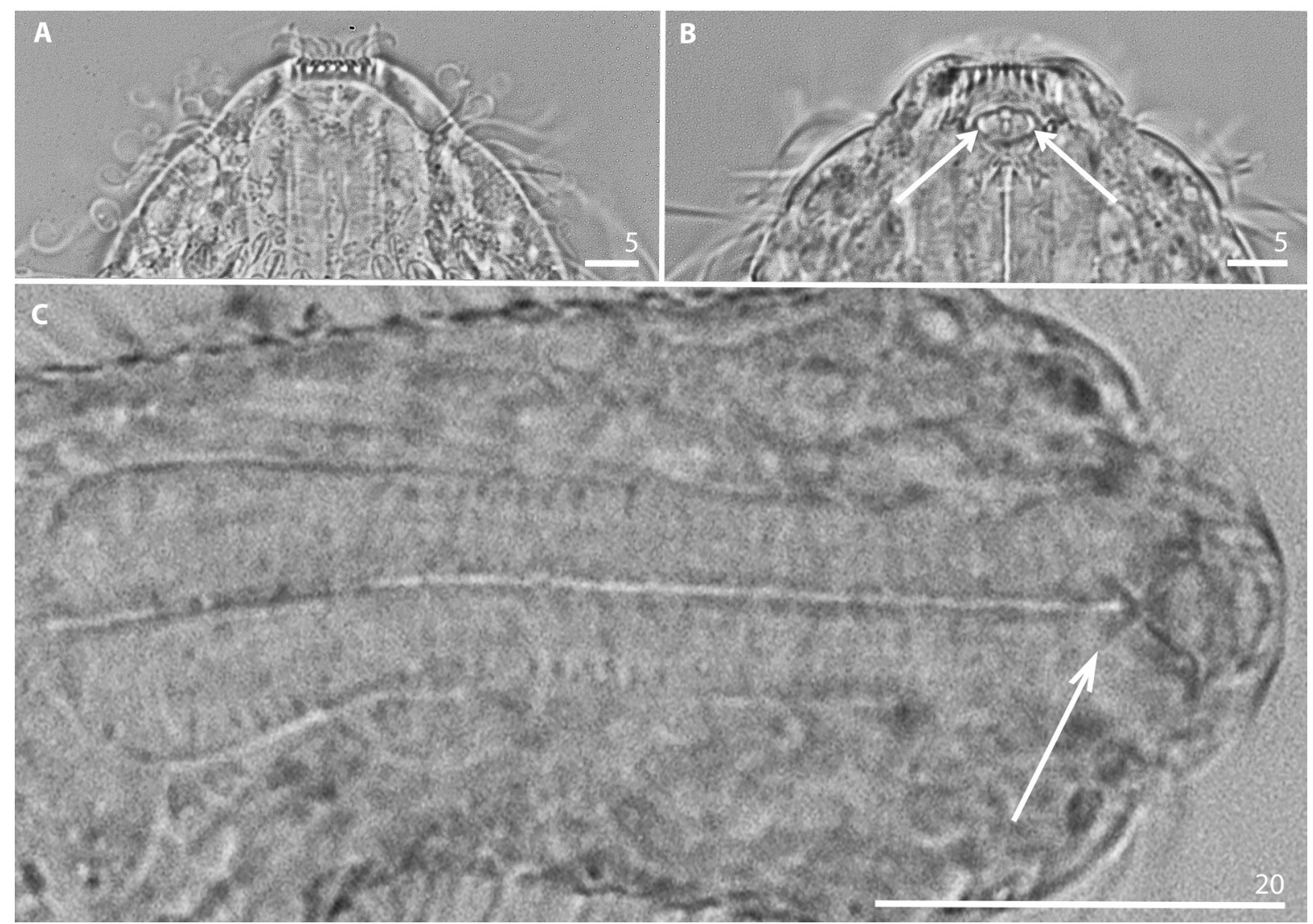

Fig. 9. Chaetonotus (Chaetonotus) invitatus sp. nov. Adult specimen. Bright field microphotographs. A. Detail of the mouth ring, dorsal view. B. Detail of the mouth ring, internal view. C. Detail of the pharynx. 
ventrolateral and ventral scales are much more strongly bent than the dorsal and dorsolateral spines. The ventral scale spines are hair-like along their entire length (Fig. 4C). The length of the spines gradually increases from the head towards the widest body region (from 3.9-24.1 to $10.1-31.1 \mu \mathrm{m}$ ). Then the length of the dorsal spines gradually shortens to the posterior trunk region. Moreover, the length of the spines gradually increases from the dorsal surface, along the dorsolateral, lateral, ventrolateral and ventral surfaces towards the ciliary bands (head: from 1.6-7.4 to $13.3-26.4 \mu \mathrm{m}$; neck: from $5.0-10.7$ to 15.9-31.9 $\mu \mathrm{m}$; trunk: from 7.8-16.5 to 19.6-34.3 $\mu \mathrm{m}$ ) (Table A1). On the dorsal posterior trunk region, two or three spines of different types are present (arising from scales 18). These spines are much longer $(16.6-20.0 \mu \mathrm{m})$ and stronger than the other dorsal spines and taper to blunt ends (Figs 2A, 6C-D). The spines arising from the dorsal and dorsolateral posterior trunk and furcal base scales (namely from scales $20,22,24,27)$ are thick and straight, tapering to blunt ends (Fig. 4D). The posteriormost lateral trunk spines $(16.1-25.1 \mu \mathrm{m})$ do not vary in length from the other lateral spines in the posterior trunk region. From the dorsolateral furcal appendage scales (scale 26) arise very long (14.5-18.4 $\mu \mathrm{m})$, thick, rigid, basally bent and spike-like spines that extend to the inner furcal indentation (Figs 2A, 4E, 6G, 8A). These spines taper slightly to pointed ends. Two pairs of parafurcal spines, emerging from the lateral scales of the furcal appendages (at U88-U89 and at U90-U91), are thicker and longer $(11.3-13.5 \mu \mathrm{m}$ ) than the other lateral body spines (Fig. 4F). These spines are basally bent and taper slightly towards their pointed ends (Figs 6G, 8A).

DORSAL SENSORY BRISTLES. This species has three pairs of dorsal sensory bristles. The first pair is located on the head, directly between the lateral edge of the cephalion and the epipleurae (at U4), and emerges from small, round papillae. The second pair of sensory bristles is located on the neck (U19) and emerges

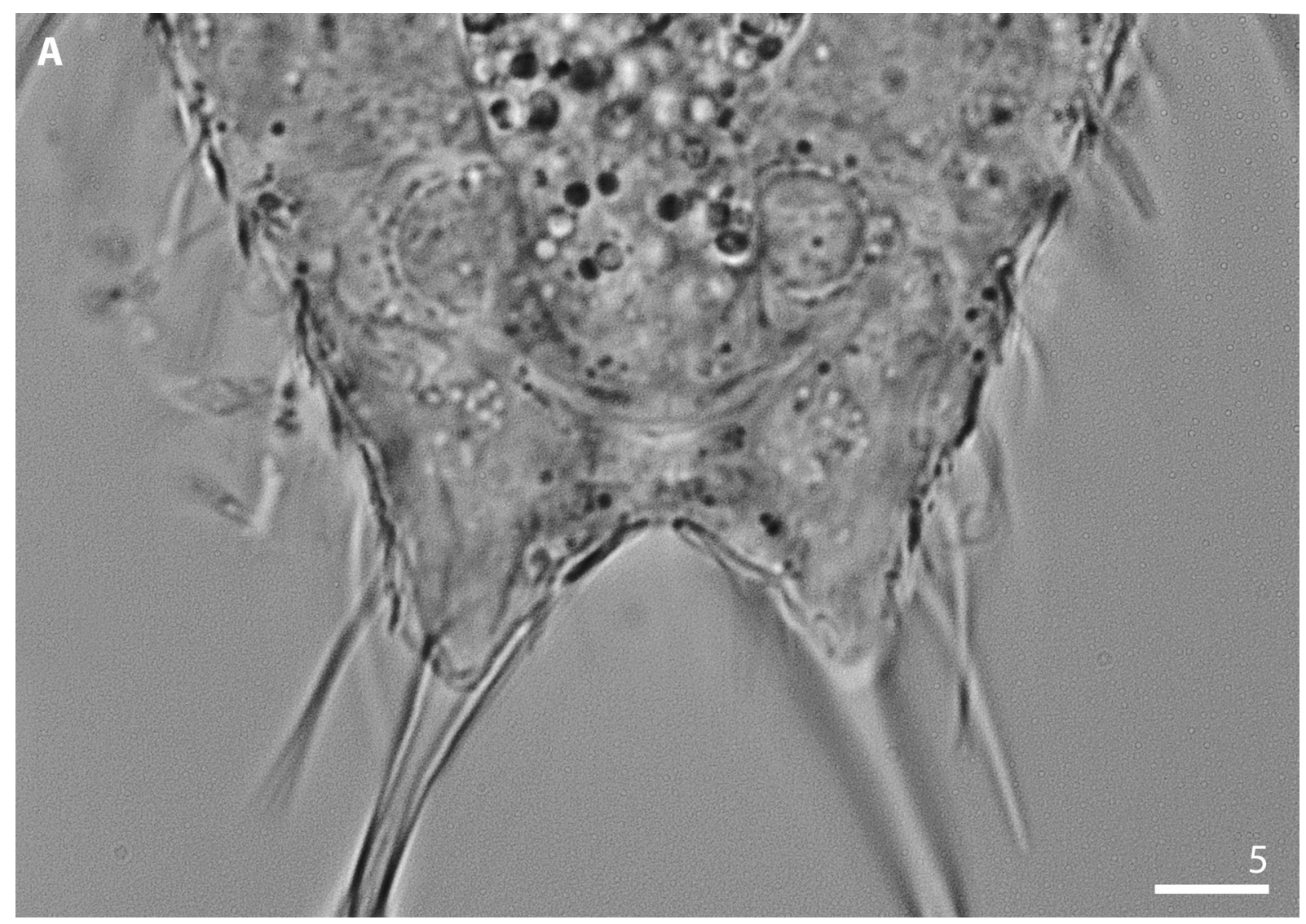

Fig. 10. Chaetonotus (Chaetonotus) invitatus sp. nov. Detail of internal morphology. Bright field microphotography. X-organ. 
from small, rounded papillae. The third posterior pair of sensory bristles emerges from the doublekeeled scales located on the posterior trunk region at U81-U83. These scales are shaped like triangles with strongly rounded edges and a deep posterior notch. The keels of these scales are slightly bent, not connected and pass into rudimentary spines (Figs 2A, 8A).

VENTRAL CILIARY BANDS AND VENTRAL INTERCILIARY FIELD. Longitudinal ventral ciliary bands begin at U8 and run back to U86 (Figs 2C, 6B, D, F, H). On the head, at ca U8-U10, the ciliary bands are merged and lie close to the hypopleurae. The ventral interciliary field scales are distributed in single (on the pharyngeal region) and 5-7 (on the intestinal region) longitudinal alternating rows, with 29-33 scales in the central row, including 15-18 plate-like scales and 14-17 one-lobed scales. The entire pharyngeal region (from U10 to U31) is covered with short, wide plates (scale 29; Fig. 3CC) and their size gradually increases from the anterior to the posterior end (from 1.0-1.7 $\times 1.9-3.5 \mu \mathrm{m}$ to $2.6-5.2 \times 7.1-11.4 \mu \mathrm{m}$ ). On the intestinal region, one-lobed scales with overlapped edges are present (from U32 to U84). On the anterior part of the intestinal region the scales are semi-rectangular in shape, have weak keels and their posterior edges are straight, without posterior notches (scale 30, Fig. 3DD). Towards the furcal base the keels become more pronounced and on the edges of the anterior scales small, horn-like perturbances begin to appear; the posterior edges become notched (scale 31; Fig. 3EE). The last alternating row of interciliary field scales is of a different type, i.e., they are oval in shape without posterior notches, have straight keels and present rudimentary spines (scale 32; Fig. 3FF). The longitudinal row of ventral field scales closest to the ventral ciliary bands has significantly smaller and narrower scales than in the central rows. The first pair of terminal scales on the ventral interciliary field is large $(14.8-17.1 \times 6.6-8.1)$ and located at U84-U87. They are oval, asymmetrical in shape, possess a straight keel and a straight,

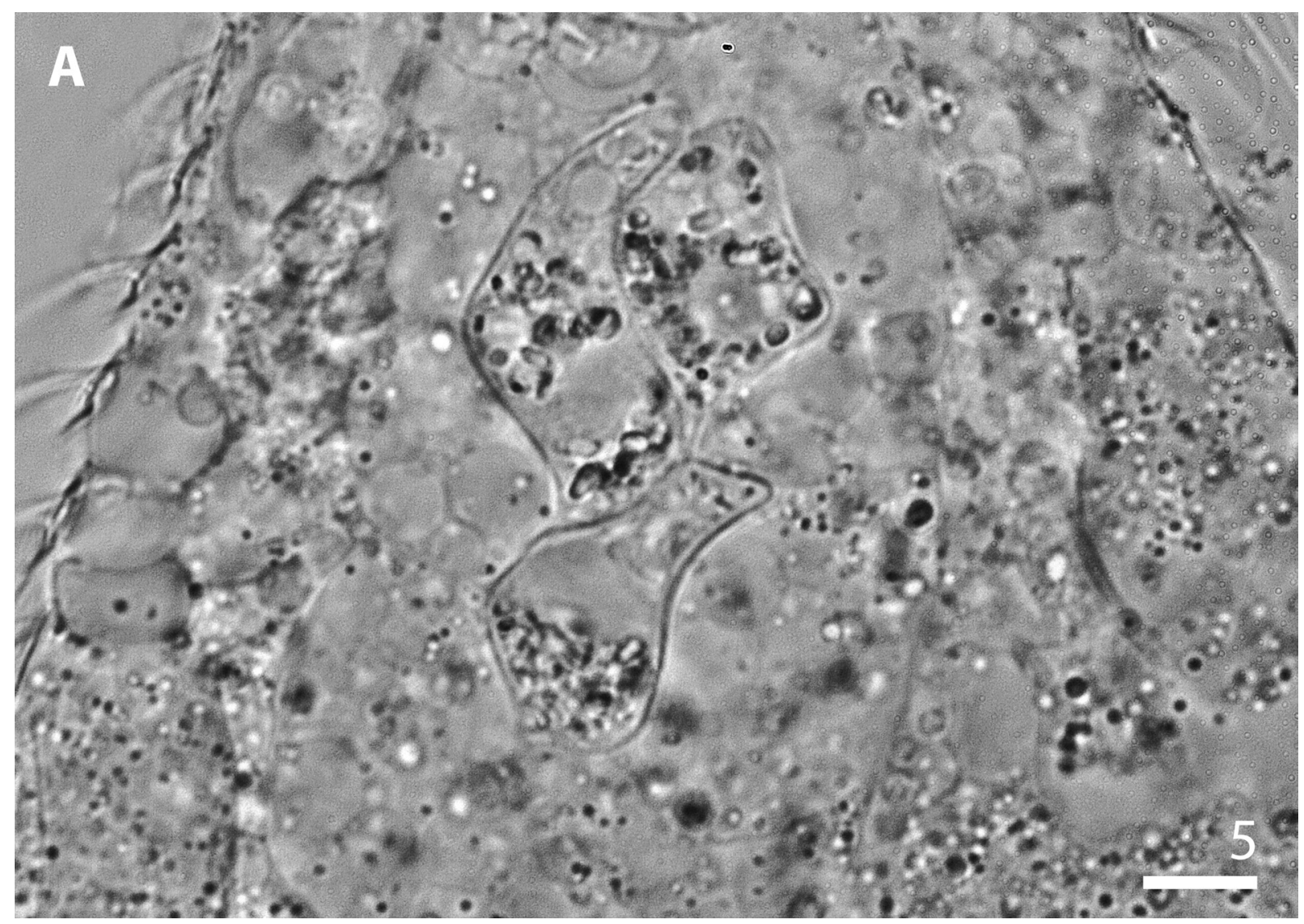

Fig. 11. Chaetonotus (Chaetonotus) invitatus sp. nov. Adult specimen. Bright field microphotography. Living euglenids inside intestine. 
thick spine (scale 33; Fig. 3GG). The second pair of terminal scales on the ventral interciliary field is located on the furcal appendages (at U86-U88). These scales are oval in shape, have long, straight keels and thick, curved spines reaching to the internal furcal indentation (scale 34; Fig. 3HH). The first and second pairs slightly overlap. The third (at U87-U88) and fourth (at 88-U89) pairs are definitely small $(2.0-4.8 \times 1.3-3.0 \mu \mathrm{m})$, egg-shaped, are located on the furcal appendages, and have straight keels and rudimentary spines (scale 35; Fig. 3II).

INTERNAL MORPHOLOGY. The pharynx (from U2 to U31) is narrow and has marked anterior and posterior dilatations. The posterior dilatation is stronger than the anterior one (Fig. 9C). In the anterior dilatation, weak cuticular reinforcements are located in the form of two straight, connected rods (at U4). The pharynx is connected through the pharyngeal-intestinal junction by the straight intestine (running from U32 to U86). The pharyngeal-intestinal junction is clearly demarcated, short and wide (U32) (Fig. 2B). The intestine does not have a separate, different anterior section. The X-organ of this species (observed in one specimen) is located at U84-U86 near the terminal part of the intestine. It is bilobed, built from two extensions enveloped in a thin coat and connected by a thinner band located below the intestine end, at the ventral surface (Fig. 10). The extensions have a granular appearance. The thin coat and the cellular bridge connecting the extensions have a smooth and homogeneous structure. The sperm packets of this species were not observed.

\section{Remarks}

Because of the long pharynx in relation to the length of the body and intestine, the pharynx-intestine ratio (I) has high values in this species. Juvenile and subadult specimens have a pharynx-intestine ratio (I) higher than $65 \%$, rather than higher than $55 \%$, as is usually observed in other species. In juvenile specimens, the first head scales from each dorsal longitudinal row are located under the free dorsal cephalion edges, whereas in adults they are nto located under the cephalion but below their dorsal edges (Fig. 7A-B). Of the 25 reported adults, one individual had a large, developing egg (Fig. 5C) and another possessed a distinct X-organ (Fig. 10). Four specimens had live, motile euglenids inside their intestine (Fig. 11) and were listed in an earlier paper as Chaetonotus (Chaetonotus) sp. 1 (Kisielewska et al. 2015).

\section{Differential diagnosis}

Of all the 92 currently known nominal representatives of the subgenus Chaetonotus (Chaetonotus) Ehrenberg, 1830, C. (C.) invitatus sp. nov. most closely resembles C. (C.) maximus Ehrenberg, 1830, C. (C.) microchaetus Preobrajenskaja, 1926, C. (C.) similis Zelinka, 1889, C. (C.) heterospinosus Balsamo, 1978, C. (C.) laroides Marcolongo, 1910 and C. (C.) polyspinosus Greuter, 1917. Of all 32 species belonging to the subgenus Hystricochaetonotus Schwank, 1990, C. (H.) trispinosus Balsamo, 1990 seems to be the most similar to the newly described taxon, whereas of all the currently known 22 nominal representatives of the subgenus $C$. (Primochaetus) Kisielewski, 1997b, the new species most closely resembles C. (P.) mutinensis Balsamo, 1978. Chaetonotus (C.) maximus, C. (C.) microchaetus, C. (C.) similis, C. (C.) heterospinosus, C. (C.) laroides, C. (C.) polyspinosus and C. (P.) mutinensis are the most similar to the newly described species in terms of: body shape similarity, range of body length, range of pharynx length, range of adhesive tube length, presence of a scale of a different type on the dorsal and dorsolateral surfaces on the furcal base, presence of rigid, long spines on the furcal appendages and a similar type of terminal scales on the ventral interciliary field. Chaetonotus $(H$.) trispinosus was selected for comparison with $C$. (C.) invitatus sp. nov. due to its similarity in terms of having three larger scales with longer and stronger spines present on the dorsal posterior trunk region, length variation of large spines on different body sides and by the presence of scales of a different type on the dorsal and dorsolateral surfaces of the furcal base. Despite the fact that these eight species have the highest number of common features with the newly described species, they are significantly different from $C$. (C.) invitatus sp. nov. - most strikingly by scale type and shape variation, spine types 
and length variation. Comparisons between the new species and the most morphologically similar taxa are summarised in Table A2. Taxa chosen for the differential diagnosis often occur in different regions of the world and are presented very differently by various researchers. Thus, a different description/ specification or taxonomic classification of theoretically the same species may suggest that we are dealing with a very large range of plasticity of these taxa or with a larger number of undiagnosed, separate species. To avoid any doubts in comparisons with $C$. (C.) invitatus sp. nov., only the original descriptions of these species and three of the most detailed papers with morphological data were used (Balsamo 1983; Schwank 1990; Kisielewski 1997a). For information regarding C. (P.) mutinensis, only original data are considered in the differential diagnosis.

Chaetonotus (Chaetonotus) paucisquamatus Kisielewski, 1991

Figs 12-13; Table 3

Chaetonotus (Chaetonotus) paucisquamatus Kisielewski, 1991: 40-42, figs 47-50.

\section{Locus typicus}

Brazil.

\section{Material examined}

POLAND • 1 adult; Kraków, Botanical Garden, Jubilee Greenhouse, site 1; 5003'38" N, 1957'30" E; 15 Nov. 2013; M. Kolicka leg.; NHC (photomicrographs, also in the author's collection).
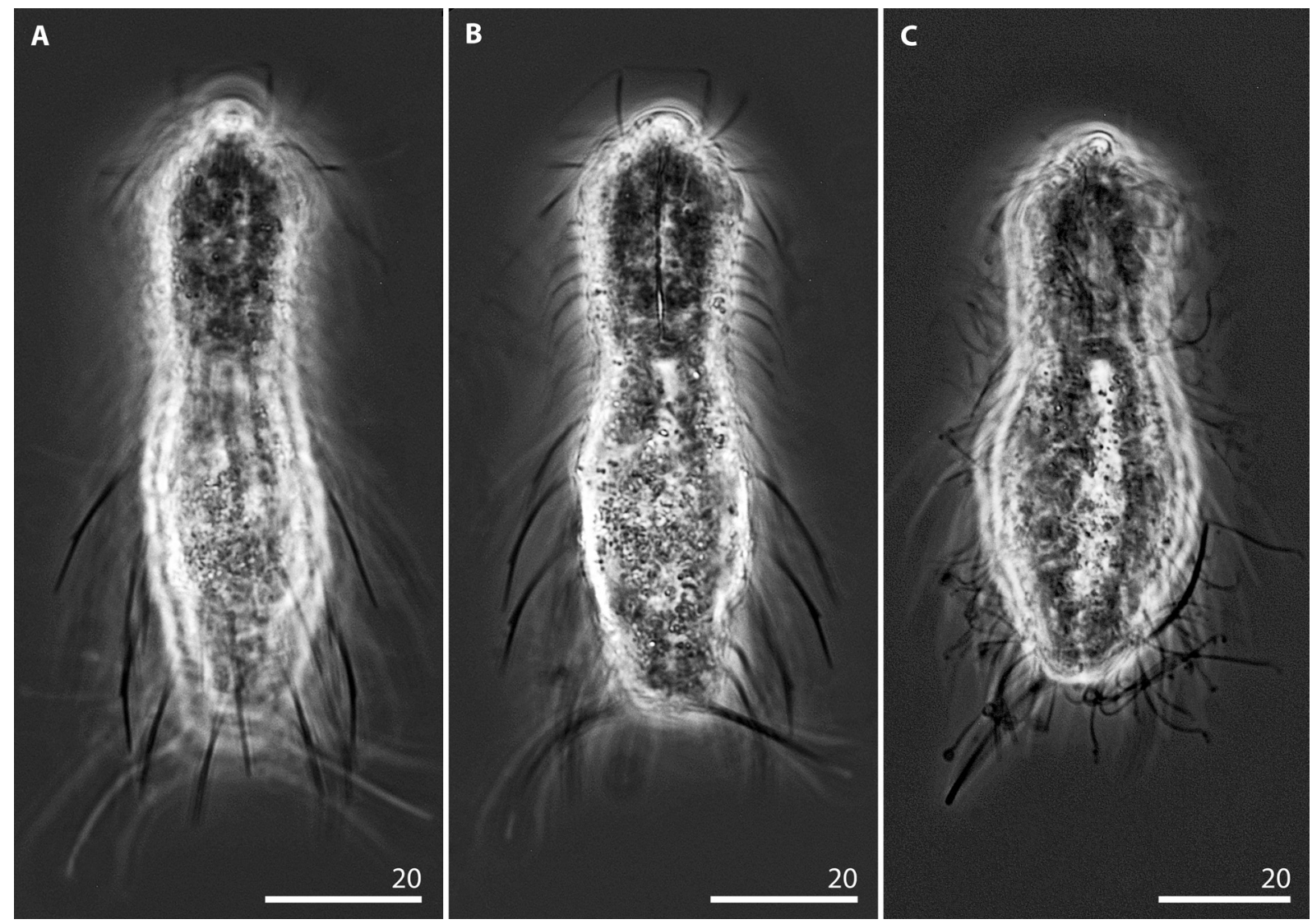

Fig. 12. Chaetonotus (Chaetonotus) paucisquamatus Kisielewski, 1991. Adult specimen. Phase contrast microphotographs. A. Dorsal body view. B. View of internal morphology. C. Ventral body view. 
Table 3. Main morphometric characters of Chaetonotus (Chaetonotus) paucisquamatus Kisielewski, 1991. All measurements in micrometers $(\mu \mathrm{m}) . \mathrm{NA}=$ data not available.

\begin{tabular}{|c|c|c|}
\hline Characters & According Kisielewski (1991) & Adult specimen \\
\hline Body length & $121.00-154.00$ & 114.76 \\
\hline Furca length & NA & 36.74 \\
\hline Adhesive tube length & $25.00-40.00$ & 27.82 \\
\hline Number of scales in central longitudinal row & 9 (head and neck: 5 ; trunk: 4) & 14 (head and neck: 9; trunk: 5) \\
\hline Total number of longitudinal alternating rows of scales & 9 & 9 \\
\hline Length of cephalic cilia (anterior tuft) & NA & $9.49-21.98$ \\
\hline Length of cephalic cilia (posterior tuft) & NA & $12.97-24.34$ \\
\hline Head scales length $\times$ width & NA & $3.09-4.37 \times 3.13-4.14$ \\
\hline Neck scales length $\times$ width & NA & $4.62-6.56 \times 3.90-6.26$ \\
\hline Trunk scales length $\times$ width & $8.00-12.50 \times 10.00$ & $7.31-13.33 \times 7.01-11.72$ \\
\hline Head dorsal spines length & NA & $1.24-4.03$ \\
\hline Head ventral spines length & NA & $6.28-8.49$ \\
\hline Neck dorsal spines length & $4.00-4.50$ & $4.18-14.70$ \\
\hline Neck ventral spines length & NA & $9.83-20.06$ \\
\hline Trunk dorsal spines length & $23.00-35.00$ & $23.70-26.70$ \\
\hline Trunk ventral spines length & NA & $20.86-24.29$ \\
\hline Length of rearmost lateral spines & $12.00-21.50$ & 19.05 \\
\hline Neck dorsal sensory bristles length & NA & 19.96 \\
\hline Posterior dorsal sensory bristles length & NA & 23.36 \\
\hline $\begin{array}{l}\text { Number of scales in central longitudinal row on ventral } \\
\text { interciliary field }\end{array}$ & NA & 13 \\
\hline $\begin{array}{l}\text { Total number of longitudinal alternating rows of scales } \\
\text { on ventral interciliary field }\end{array}$ & NA & 7 \\
\hline Ventral interciliary field scales length $\times$ width & NA & $2.83-4.62 \times 2.20-3.18$ \\
\hline Terminal ventral interciliary field scales length $\times$ width & NA & $7.41 \times 4.02$ \\
\hline Mouth ring diameter & $3.20-3.50$ & 3.39 \\
\hline Pharynx length & $27.50-34.00$ & 30.81 \\
\hline Intestine length & NA & 52.90 \\
\hline
\end{tabular}

\section{Distribution}

This species was previously known only from Brazil, namely from water reservoirs, silt sediments and aquatic vegetation (Kisielewski 1991).

\section{Remarks}

The specimen found in the Jubilee Greenhouse in Kraków is consistent with the detailed description of Chaetonotus (Chaetonotus) paucisquamatus Kisielewski, 1991. The presence of only one specimen does not allow for a thorough comparison and for conclusions to be drawn; however, the individual observed in Poland differed slightly from the original description by: its smaller body size (Table 3); a larger number of scales in the central longitudinal row than in the original description (Table 3); the presence of thin, rounded scales on the ventral interciliary field, increasing in size and isolation from the cuticle towards the posterior trunk region, where the scales possessed weak keels; and the presence of one pair of elongated, elliptical and keeled ventral terminal scales. These differences may result from 

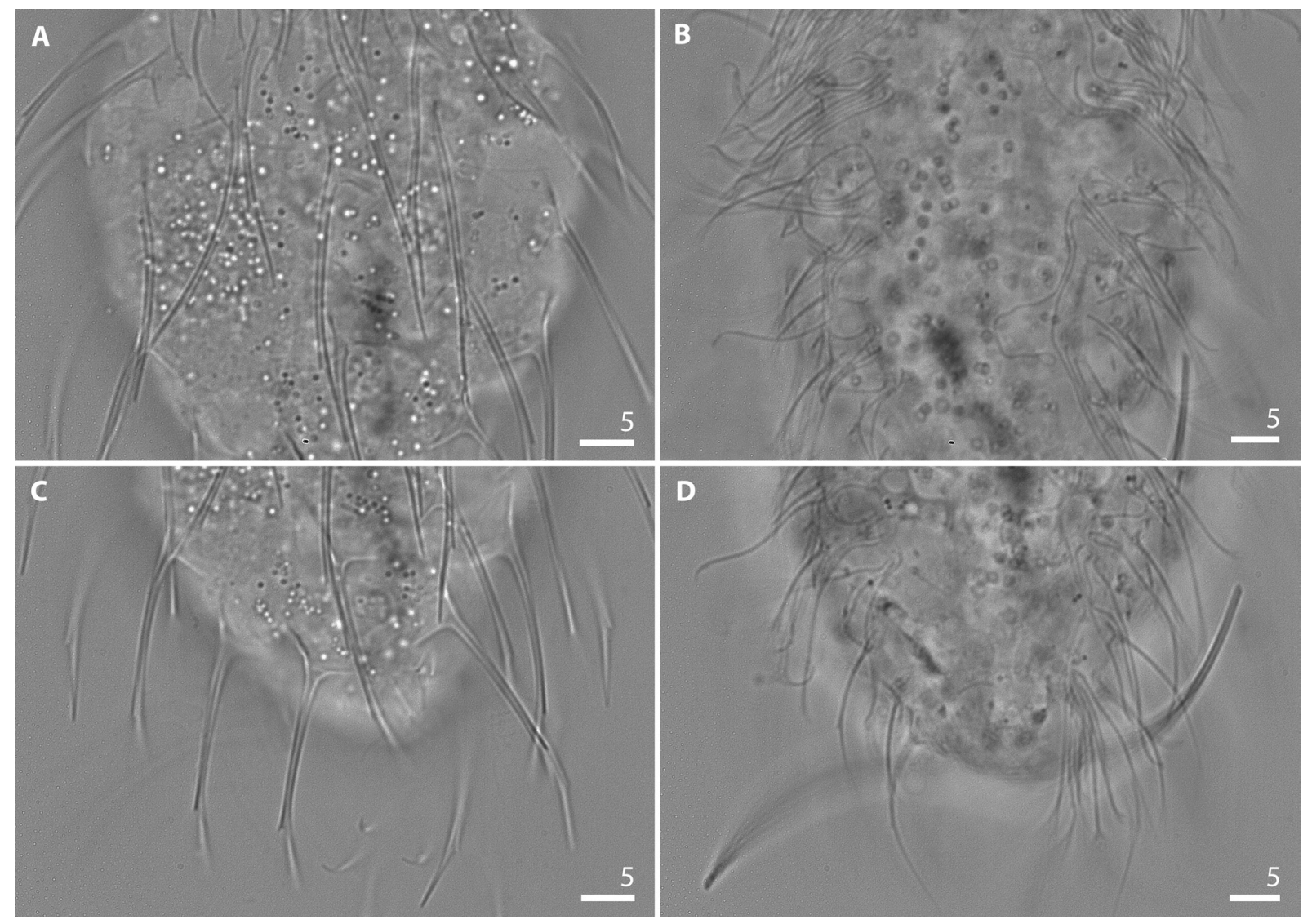

Fig. 13. Chaetonotus (Chaetonotus) paucisquamatus Kisielewski, 1991. Adult specimen. Bright field microphotographs. A. Anterior trunk, dorsal view. B. Anterior trunk ventral view. C. Posterior trunk dorsal view. D. Posterior trunk, ventral view.

phenotypic variation caused, e.g., by different developing conditions. Due to the lack of any differences in the other taxonomic characteristics, there are no grounds to conclude that the recorded individual represents a separate species.

Subgenus Hystricochaetonotus Schwank, 1990

\section{Type species}

Chaetonotus hystrix Mečnikow, 1865.

\section{Terra typica}

Russia.

\section{Remarks on subgenus}

A polyphyletic subgenus in terms of molecular data (Kånneby et al. 2013), it encompasses 28 nominal freshwater species and 10 marine species (Todaro 2018). Present in benthic and periphytic habitats (e.g., Kisielewski 1997a). 
Chaetonotus (Hystricochaetonotus) hystrix Mečnikow, 1865

Figs 14-15

Chaetonotus hystrix Mečnikow, 1865: 451, fig. 7.

\section{Locus typicus}

Russia.

\section{Material examined}

POLAND • 21 adults, 3 subadults, 7 juveniles; Kraków, Botanical Garden, Jubilee Greenhouse, sites $1-3 ; 50^{\circ} 03^{\prime} 38^{\prime \prime}$ N, 1957'30" E; 17 Apr. 2014; M. Kolicka leg.; NHC (photomicrographs, also in the author's collection).

\section{Distribution}

Chaetonotus (Hystricochaetonotus) hystrix Mečnikow, 1865 is considered a cosmopolitan and common species recorded worldwide from highly differing habitats (lakes with different trophic structures, mountain springs, fertile ponds, peat bogs, brackish estuarine waters) (Kisielewski 1991). Outside Europe, it is known from Brazil (Kisielewski 1991), Israel (Kisielewski 1997b), Japan (Saito 1937) and Paraguay (Daday 1905).
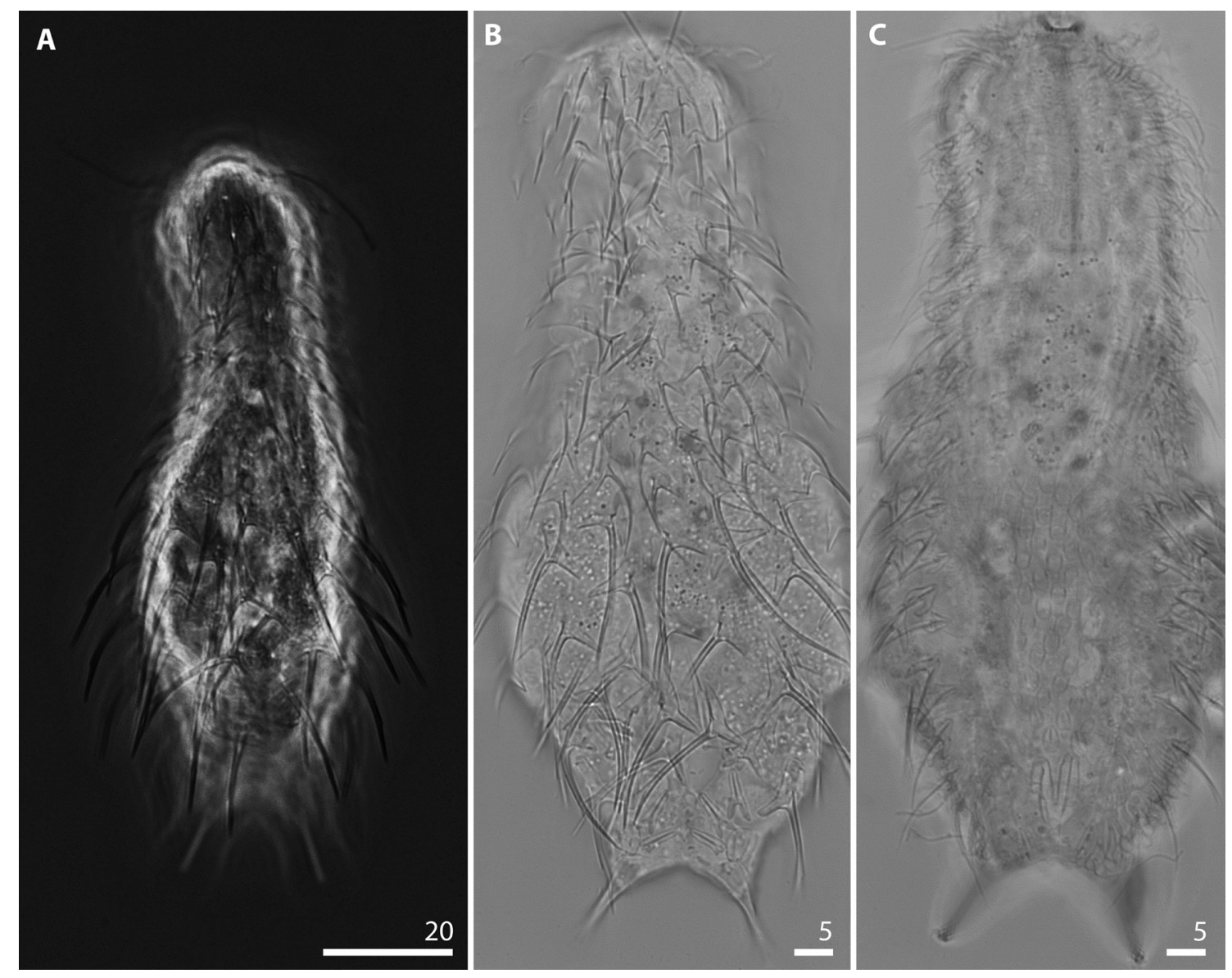

Fig. 14. Chaetonotus (Hystricochaetonotus) hystrix Mečnikow, 1865. Adult specimen. A. Habitus, phase contrast microphotograph. B. Dorsal scales, bright field microphotograph. C. Ventral scales, bright field microphotograph. 


\section{Remarks}

The specimens examined here correspond very well with the original description (Figs 14-15). All their morphometric characteristics are within the ranges given in the literature for this species (Rudescu 1967; Roszczak 1969; Balsamo 1983; Schwank 1990; Kisielewski 1984, 1997b). The total body length of adult specimens varied from 107.4 to $128.6 \mu \mathrm{m}$; length of pharynx was between 27.6

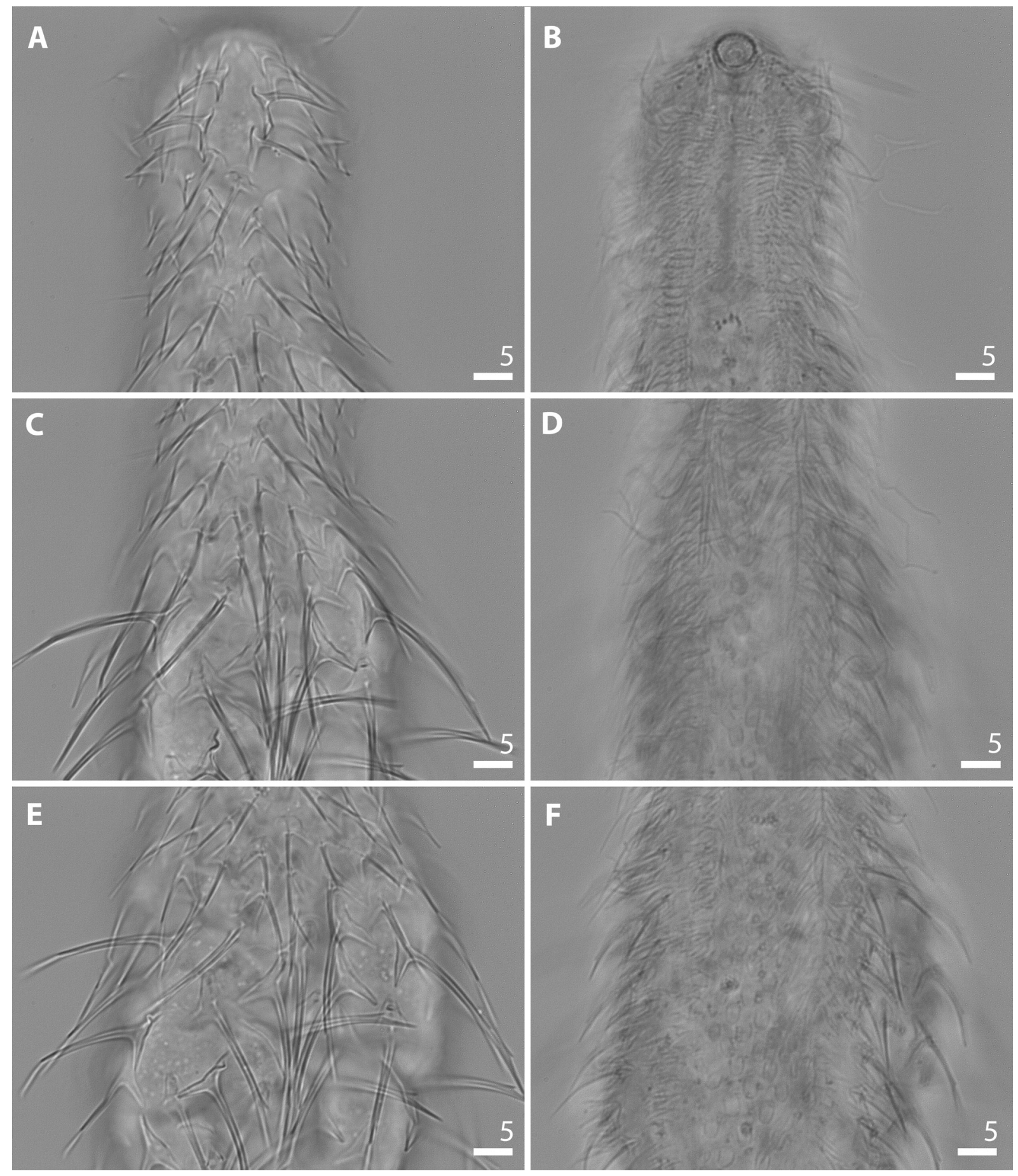

Fig. 15. Chaetonotus (Hystricochaetonotus) hystrix Mečnikow, 1865. Adult specimen. Bright field microphotographs. A. Head dorsal spines. B. Head ventral spines. C. Neck and trunk dorsal spines. D. Neck and trunk ventral spines. E. Trunk dorsal spines. F. Trunk ventral spines. 
and $32.7 \mu \mathrm{m}$; length of intestine from 56.1 to $81.9 \mu \mathrm{m}$; there were $15-17$ total longitudinal rows of scales $(5-7 \mathrm{D}+2 \mathrm{DL}+2 \mathrm{~L}+4 \mathrm{LV}+2 \mathrm{~V})$, with $13-17$ scales in the central row. The total body length of juvenile specimens varied from 86.9 to $105.4 \mu \mathrm{m}$; length of pharynx was between 28.6 and $32.4 \mu \mathrm{m}$; length of intestine from 37.9 to $52.6 \mu \mathrm{m}$; there were 13-17 total longitudinal rows of scales $(5-7 \mathrm{D}+2 \mathrm{DL}+2 \mathrm{~L}+2-4 \mathrm{LV}+2 \mathrm{~V})$, with $13-17$ scales in the central row. Among the adults, two had a large, developing egg, while one had an X-organ and two packages of sperm.

Chaetonotus (Hystricochaetonotus) horridus sp. nov. urn:lsid:zoobank.org:act:478175BF-E4D8-48BC-AE73-2032127AB69D

Figs 16-25, A3-A6; Tables 4, A3-A4

\section{Diagnosis}

Stocky body, measuring from 107.8 to $134.0 \mu \mathrm{m}$ in length. Head five-lobed, cephalion narrow, hypopleurae slightly larger in size than epipleurae. All cephalic plates weakly demarcated in head outline. Hypostomium small, rectangular in shape. Ocellar granules absent. Almost all scales three-lobed and keeled. Scales distributed in 15-21 total longitudinal rows $(3 \mathrm{D}+2-4 \mathrm{DL}+4-6 \mathrm{~L}+4 \mathrm{LV}+2-4 \mathrm{~V})$, with 13-15 scales in central row. Scales strongly differ morphologically in various body areas. On dorsal trunk area, large scales with very long, thick spines with a strong, very prominent lateral denticle. Two pairs of posteriormost trunk lateral scales with long, thick spines with strong lateral denticle. Remaining scales with simple, shorter and thinner spines or on central dorsal trunk area and on furcal appendages with rudimentary spines or without spines. Parafurcal spines absent. Spines on ventral surface hair-like, with narrow, delicate lamellae along entire length. Entire ventral interciliary field covered with plate-like scales. Three pairs of ventral interciliary field terminal scales. Pharynx wide, with pronounced anterior and posterior dilatations. Intestine straight without anterior section differing in form and morphology.

\section{Etymology}

From the Latin 'horridus' = 'hairy', referring to the very long and strong trunk spines.

\section{Material examined}

\section{Holotype}

POLAND • adult; Kraków, Botanical Garden, Jubilee Greenhouse, site 1; 5003'38" N, 1957'30" E; 15 Nov. 2013; M. Kolicka leg.; NHC-GCHH-22-1-25/h (photomicrographs, also in the author's collection).

\section{Paratypes}

POLAND -80 adults, 30 subadults, 9 juveniles; same locality as holotype; sites 1-3; 15 Nov. 2013 and 17 Apr. 2014; M. Kolicka leg.; NHC-GCHH-22-21-60/p (photomicrographs, also in the author's collection).

\section{Description}

HaBitus. Chaetonotus (Hystricochaetonotus) horridus sp. nov. has a stocky body that is slightly bottleshaped (Figs 16, 19). Its head is only slightly wider than the neck and the neck constriction is weakly demarcated. The neck gradually tapers from the head (from U17) to the beginning of the trunk (ca U31). The trunk is slightly wider than the head and gradually dilates from ca U32 to ca U59, where it is at its maximum width. Then it gradually tapers towards the narrow furcal base (from U79) (Figs 16, 19). The furcal base is clearly demarcated and narrow. The furcal indentation is V-shaped. The furcal branches are set widely apart and point outwards to the widest trunk region (Figs 16, 19). The adhesive tubes are straight, fairly thick and slightly tapered towards the blunt ends (Figs 16, 19). 


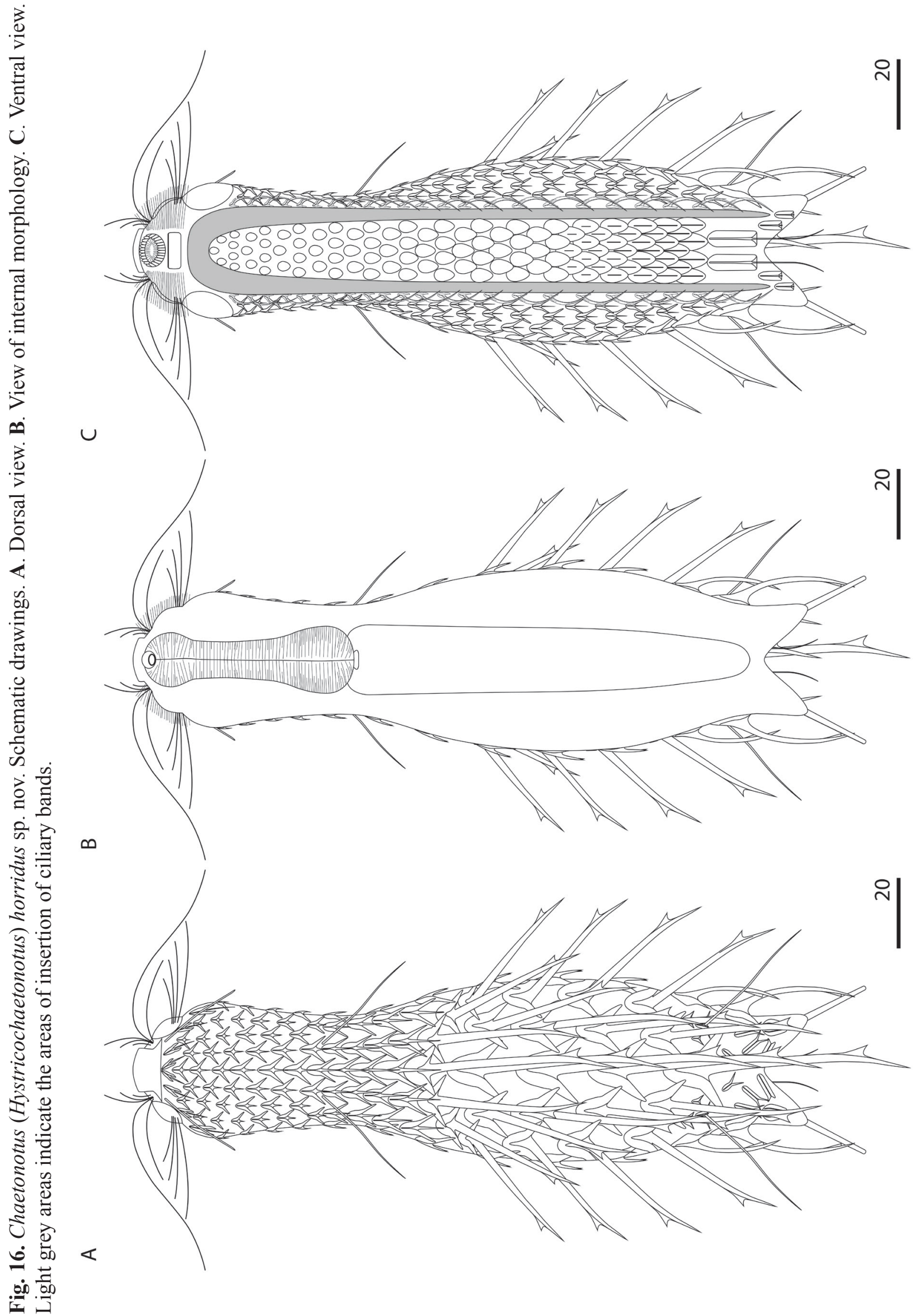



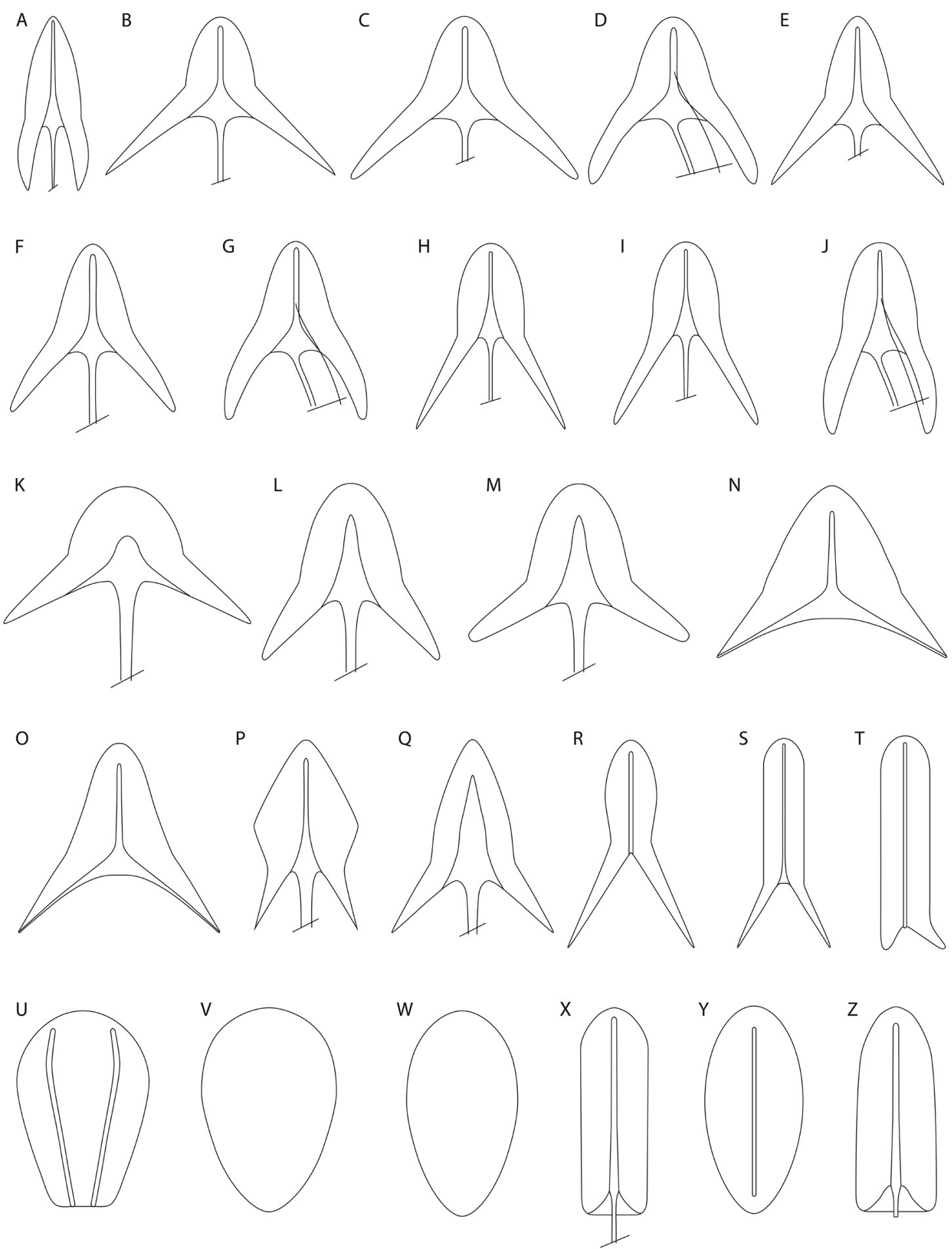

Fig. 17. Chaetonotus (Hystricochaetonotus) horridus sp. nov. Schematic drawings of the scales. A. Head anteriormost scale (scale 1). B. Head dorsal scale (scale 2). C. Head dorsolateral, lateral and ventrolateral scale (scale 3). D. Head ventral scale (scale 4). E. Neck dorsal scale (scale 5). F. Neck dorsolateral, lateral and ventrolateral scale (scale 6). G. Neck ventral scale (scale 7). H. Trunk dorsal scale (scale 8). I. Trunk dorsolateral, lateral and ventrolateral scale (scale 9). J. Trunk ventral scale (scale 10). K. Scale 11. L. Scale 12. M. Scale 13. N. Scale 14. O. Scale 15. P. Scale 16. Q. Scale 17. R. Scale 18. S. Scale 19. T. Scale 20. U. Scale 21. V. Scale 22. W. Scale 23. X. Scale 24. Y. Scale 25. Z. Scale 26 . 
HEAD. The head is five-lobed, short and semicircular in shape. The cephalion (U1-U4) is narrow, short, with straight dorsal edge. It adheres to the head along its entire length and rapidly extends near the dorsal edge (Fig. 20A). The epipleurae (U4-U7) are slightly arched and weakly demarcated in the head outline. They are located on the dorsal, dorsolateral and lateral sides and are slightly visible on the ventrolateral head side. The hypopleurae (U8-U14) are slightly larger in size than the epipleurae and located entirely on the ventrolateral and ventral head sides (Figs 16, 20A-B). They are not visible in dorsal body view. On the dorsal head surface, between the lateral edges of the cephalion and epipleurae there is a prominent space, their edges meeting only in the cephalion extension place. Deep notches are present between the cephalion and epipleurae and between the epipleurae and hypopleurae. The hypostomium (U6-U7) is short, rectangular, with a slightly reinforced anterior edge (Figs 16C, 20B). Two pairs of cephalic ciliary tufts are present. The anterior tufts emerge in the area between the cephalion and epipleurae on the dorso-terminal head surface (ca U3) and consist of 5 cilia. The anteriormost cephalic cilium is very short and the length of the cilia in the anterior tuft gradually increases from the anteriormost to the fourth cilium. The fourth cilium in the anterior tufts is very long, the longest in both pairs of tufts, while the fifth, posteriormost cilium is much shorter. The posterior tufts (at U6-U7) have 4 cilia each and emerge on the ventral head side, above the anterior edge of the hypopleurae. The length of the cilia in the posterior tuft gradually increases from the anteriormost to the fourth cilium. Ocellar granules are not present. The mouth ring is large, wide and located subterminally at U2-U5. It has very strong, long reinforcements and long inner hairs (Figs 16C, 20B). Suboral bristles are located in two tufts located beneath and laterally to the mouth ring and reaching beyond the hypostomium end (between U3 and U7).

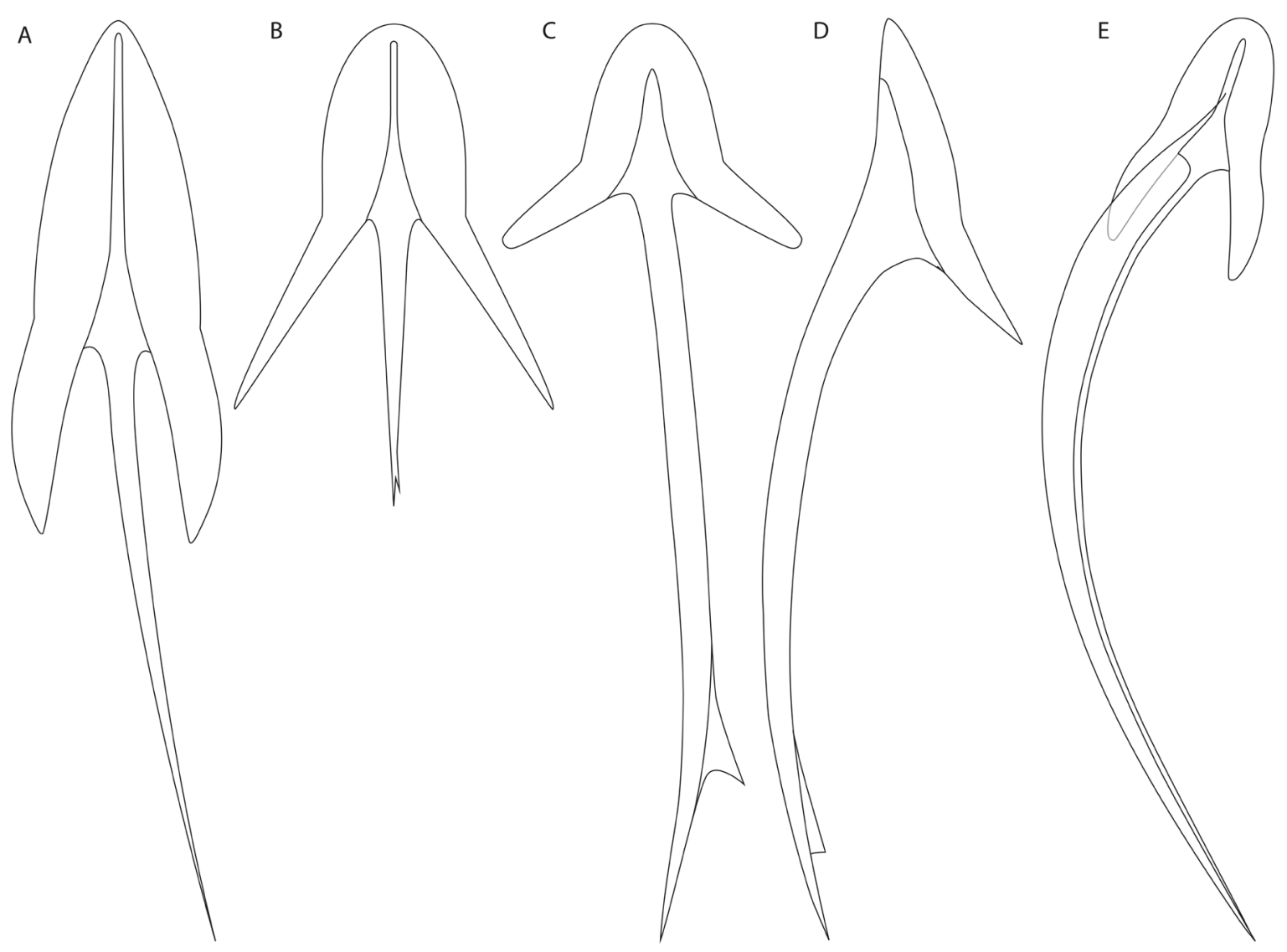

Fig. 18. Chaetonotus (Hystricochaetonotus) horridus sp. nov. Schematic drawings of the spine types. A. First type of spines. B. Second type of spines. C. Third type of spines. D. Fourth type of spines. E. Fifth type of spines. 
SCALES. The entire body, except for one pair of scales on the furcal appendages, is covered with threelobed scales that adhere to the cuticle along their entire surface (Fig. A6). All scales have a strong keel and are shaped like triangles. The scales are distributed in 15-21 total longitudinal alternating rows $(3 \mathrm{D}+2-4 \mathrm{DL}+4-6 \mathrm{~L}+4 \mathrm{LV}+2-4 \mathrm{~V})$, with $13-15$ scales in the central row. The central longitudinal rows of scales begin on the head directly beneath the posterior edge of the cephalion. On the head and anterior neck region the scales are located far from one another, on the posterior neck and anterior trunk region the scales are located gradually closer, but still at a distance to the other scales and not juxtaposed. The dorsolateral, lateral, ventrolateral and ventral trunk scales are located at a distance from the other scales, whereas the dorsal trunk scales and scales on the furcal appendages have slightly overlapping posterolateral edges (Fig. 20). The head anteriormost scales are situated near the posterior edge of the cephalion and epipleurae. The dorsal anterior scales are located aslant, whereas the dorsolateral scales are arranged parallel to the longitudinal body axis. These scales are elongated and their central lobes are long, trilobed and have very long keels. Their posterolateral lobes are slightly separated, narrow, slanted downward and create a narrow, deep V-shaped posterior scale notch (scale 1; Fig. 17A). The remaining scales of the head are significantly wider. The central lobes of these scales become shorter and simultaneously the posterolateral lobes become slightly longer, whereas their keels are shorter. The posterolateral lobes are directed diagonally downward and laterally; they create a deep and wide posterior scale notch (scale 2; Fig. 17B). The anterior neck scales become gradually longer than the head scales. Their central lobes become longer and the posterolateral lobes are more separated and directed more downward and create a wide and deep V-shaped posterior scale notch (scale 5; Fig. 17E). From the neck towards the trunk, the scale size gradually increases (from $2.8-3.5 \times 2.4-3.2$ to $5.2-6.4 \times 5.1-5.9 \mu \mathrm{m}$ ). All of the anterior trunk scales and dorsolateral, lateral, ventrolateral and ventral trunk scales on the
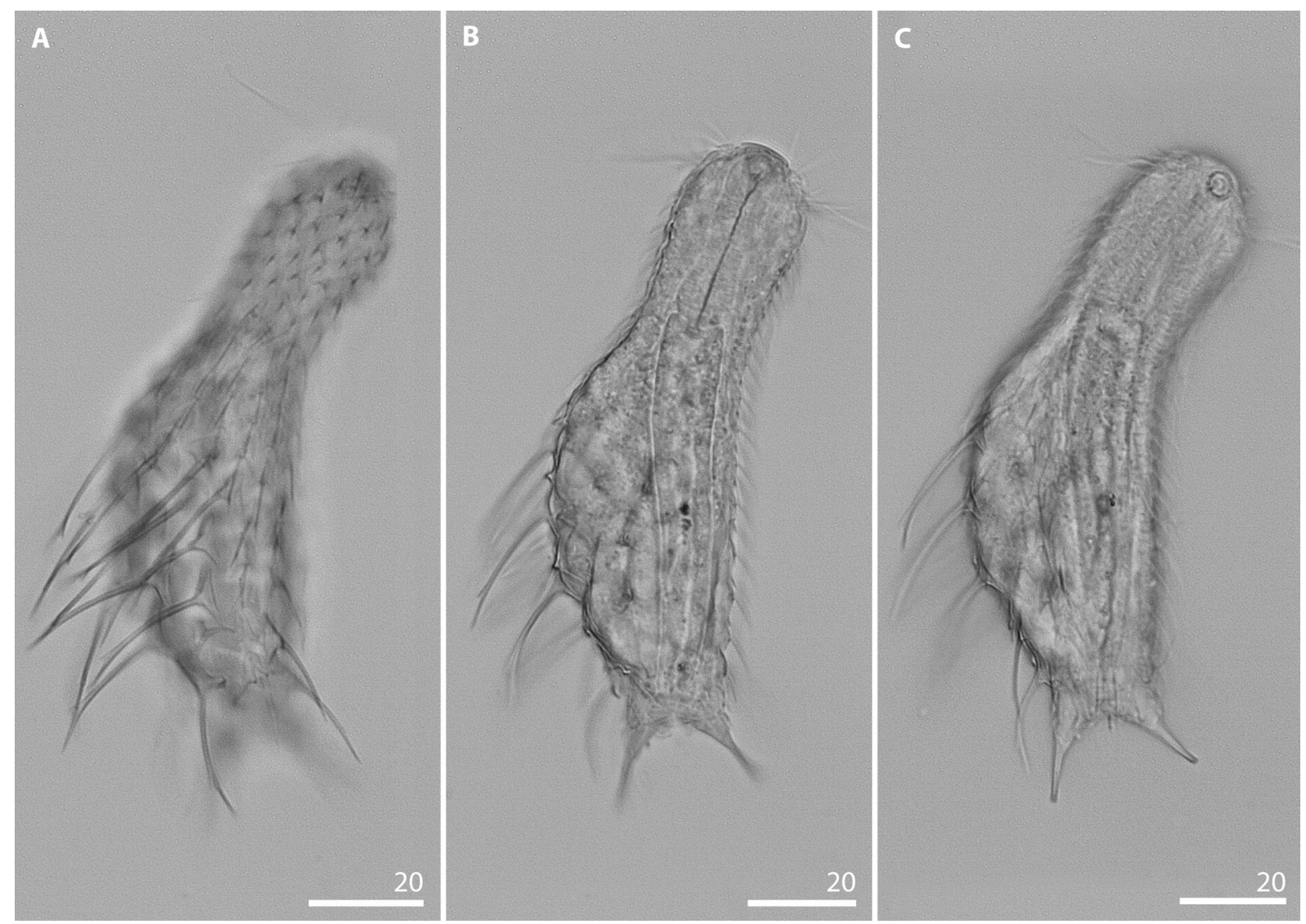

Fig. 19. Chaetonotus (Hystricochaetonotus) horridus sp. nov. Adult specimen. Bright field microphotographs. A. Dorsal body view. B. View of internal morphology. C. Ventral body view. 
central and posterior body region have a wide and rounded anterior central lobe and clear, separate, long, narrow and sharp posterolateral lobes. The posterolateral lobes are directed diagonally downward and are slightly lateral; they create a deep V-shaped posterior scale notch (scale 8; Fig. 17H). The size of these scales increases from the anterior trunk region to the widest body region (from 3.0-4.1 $\times 2.1-3.3$ to 5.6-9.7 $\times 4.68-8.43 \mu \mathrm{m}$ ) (Figs 20,23). Dorsally and dorsolaterally from ca U37 to U73 and dorsally to U81, larger and thick, different scales are located with very long and strong spines (Figs 16, 20, 22). The first of the different, larger scales from each longitudinal dorsal and dorsolateral row are triangular in shape, their central lobes are short, wide and pass seamlessly into posterolateral lobes that are directed very wide apart. The posterior edge of this scale is almost straight and only very narrowly notched. Its keel starts from the half-length of the central lobe and is very pronounced and high, strongly triangular in shape (scale 11; Fig. 17K). The subsequent large scales (located from U41 to U73) are triangular in shape, with rounded edges, and their central lobes are longer and have longer keels. The posterolateral lobes of these scales are more rounded, directed slightly more downward and create a wide V-shaped posterior scale notch (scale 12; Fig. 17L). The posteriormost scale of the dorsal and dorsolateral large scales with long, strong spines is located in the central longitudinal row of scales at U78 to U81 (Figs 17A, 19A, 22B). This scale is wide and its central and posterolateral lobes are rounded. The posterior edge of this scale is almost straight and only very narrowly notched. Its keel is very pronounced and high, strongly triangular in shape (scale 13; Fig. 17M). Anteriorly to the double keeled scales with trunk dorsal sensory bristles, on the dorsal and dorsolateral trunk region, three pairs of keeled and spineless scales are located at U73-U77. Two of these three pairs are located more anteriorly and laterally than the third pair and are triangular in shape, their posterolateral lobes are weakly separated, and their keels are strong and reach from the anterior part of the central lobes to the ends of the

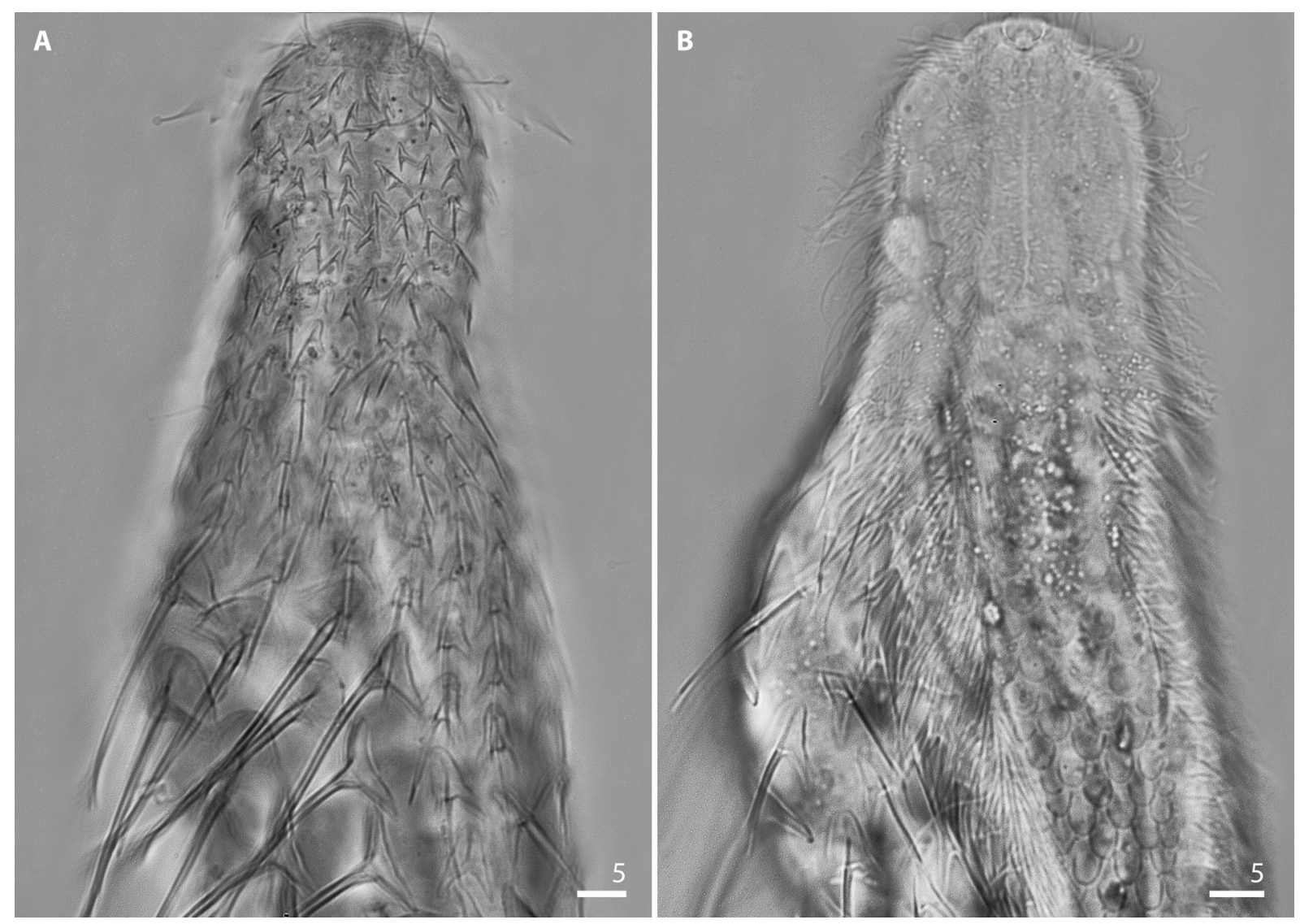

Fig. 20. Chaetonotus (Hystricochaetonotus) horridus sp. nov. Adult specimen. Bright field microphotographs. A. Scales, dorsal view. B. Scales, ventral view. 
posterolateral lobes. The posterior notches of these scales are shallow and semicircular (scale 14; Fig. 17N). The third pair of these scales, located at U75-U77, is wider and possesses shallower posterior notches (scale 15; Fig. 17O). On the lateral surface of the posterior trunk region, one pair of the second to last trunk scales is located at U69-U75. These scales are large and have a long, wide, and anteriorly clearly pointed central lobes with strongly rounded lateral edges. Their posterolateral lobes are clearly separated from the central lobes, are long and have sharp edges. These posterolateral lobes are directed diagonally downward (scale 16; Fig. 17P). The scales have strong keels and strong, long spines. Posteriorly to them, on the posterior trunk region and furcal base, the last pair of trunk lateral scales is situated at U76-U82. This pair of scales is large $(7.4-11.7 \times 5.3-8.9 \mu \mathrm{m})$; its scales have a long, wide and anteriorly strongly pointed central lobes and straight posterolateral lobes that are triangular. The posterolateral lobes of these scales are directed diagonally wide apart, downward and laterally, creating a wide and shallow $\mathrm{V}$-shaped posterior scale notch. These scales have a very strong keel and strong, long spines (scale 17; Fig. 17Q). One pair of small $(2.2-7.0 \times 1.6-4.5 \mu \mathrm{m})$ three-lobed scales, shaped like triangles with strongly rounded anterior lobes and with straight, narrow and long posterolateral lobes, is located diagonally on the dorsal surface of the furcal base (at U81-U83). These scales have long, thin keels and are spineless. Their posterior edge notches are V-shaped and very deep (scale 18; Fig. 17R). Two pairs of three-lobed, elongated and narrow scales are located on the dorsal surface of the furcal base and furcal appendages (at U82-U86). These scales have wide and rounded central lobes and straight, narrow posterolateral lobes located diagonally downward which create narrow, deep V-shaped posterior
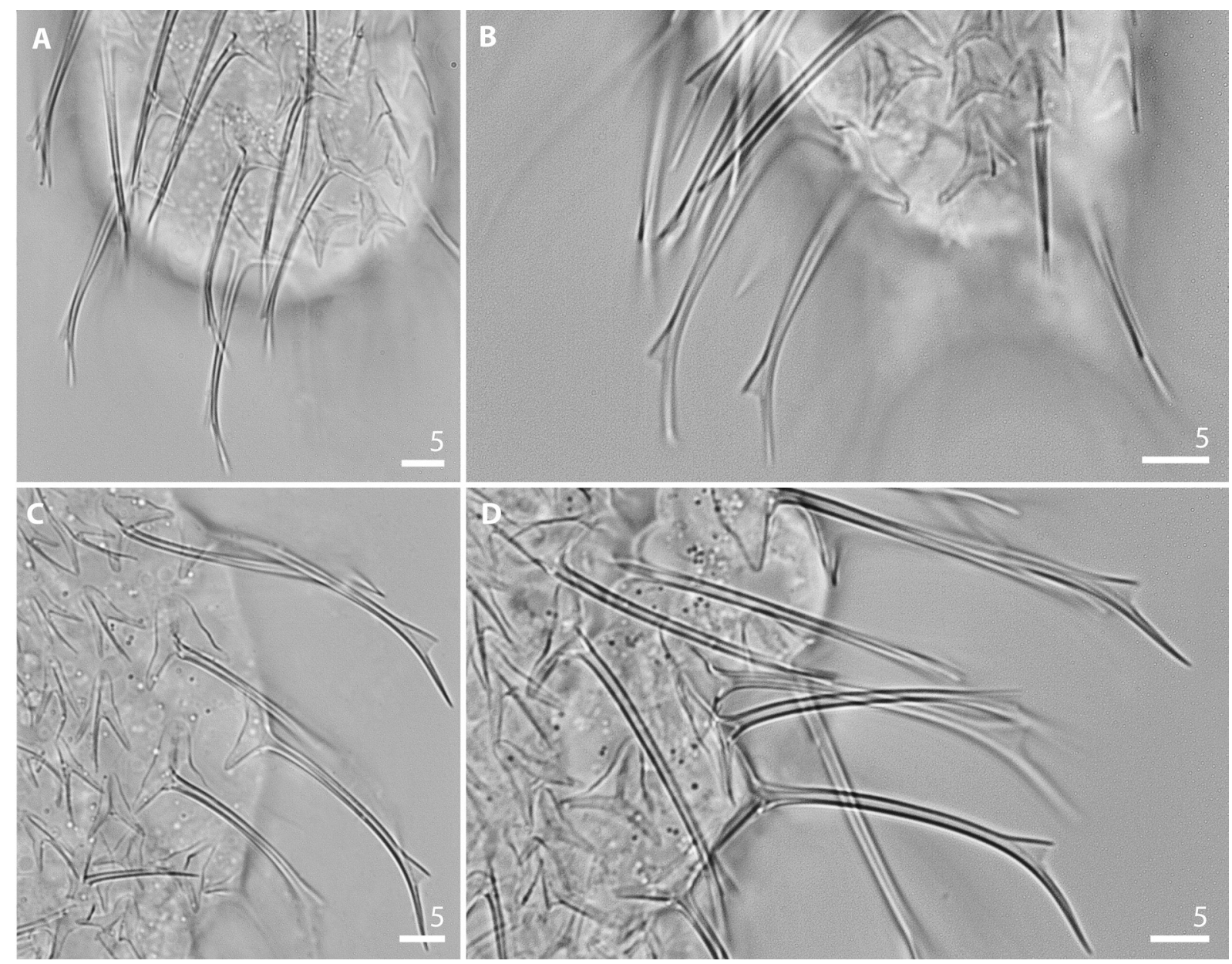

Fig. 21. Chaetonotus (Hystricochaetonotus) horridus sp. nov. Adult specimen. Bright field microphotographs. A. Trunk spines, dorsal view. B. Trunk spines, dorsolateral view. C-D. Trunk spines, lateral view. 
scale notches. Their keels are long and thin and the scales are spineless (Fig. 22B). The scales are diagonally arranged and directed towards the central body axis (scale 19; Fig. 17S). One pair of slightly three-lobed, narrow, asymmetrical scales is located on the dorsal surface of the furcal appendages. These scales are shaped like strongly elongated ovals, with a slightly triangular posterior notch. This pair of scales has long keels running along their length and does not have a spine (scale 20; Fig. 17T). They are located at U86-U88, slightly diagonally to the central body axis. Dorsolaterally at the furcal appendages, one pair of scales with two keels is located (at U86-U89). These scales are oval in shape and do not have any posterior notches or spines. Their keels are long and slightly bent (scale 21; Fig. 17U). The edges of the furcal appendage scales are slightly overlapping (Fig. 22). The size of the scales gradually decreases slightly from the dorsal, dorsolateral, lateral, ventrolateral and ventral surfaces towards the ciliary bands (head: from 3.2-5.2 ×3.2-6.2 to $2.2-4.1 \times 2.1-3.9 \mu \mathrm{m}$; neck: from 4.5-6.4 $\times 4.1-5.9$ to $2.8-4.6 \times 2.4-4.1$ $\mu \mathrm{m}$, trunk: from 5.3-9.7 $\times 4.1-8.4$ to $3.0-5.5 \times 2.1-4.6 \mu \mathrm{m})$ (Table A3). Furthermore, the edges of the dorsolateral, lateral, ventrolateral and ventral scales gradually become slightly more rounded towards the ciliary bands as compared to the edges of the dorsal scales (Figs 16, 20). Scales arranged in the ventral longitudinal row located closest to the ciliary bands are smaller than the scales of the other rows, and their anterior edge is oriented towards the bands at an angle of ca $20^{\circ}$.
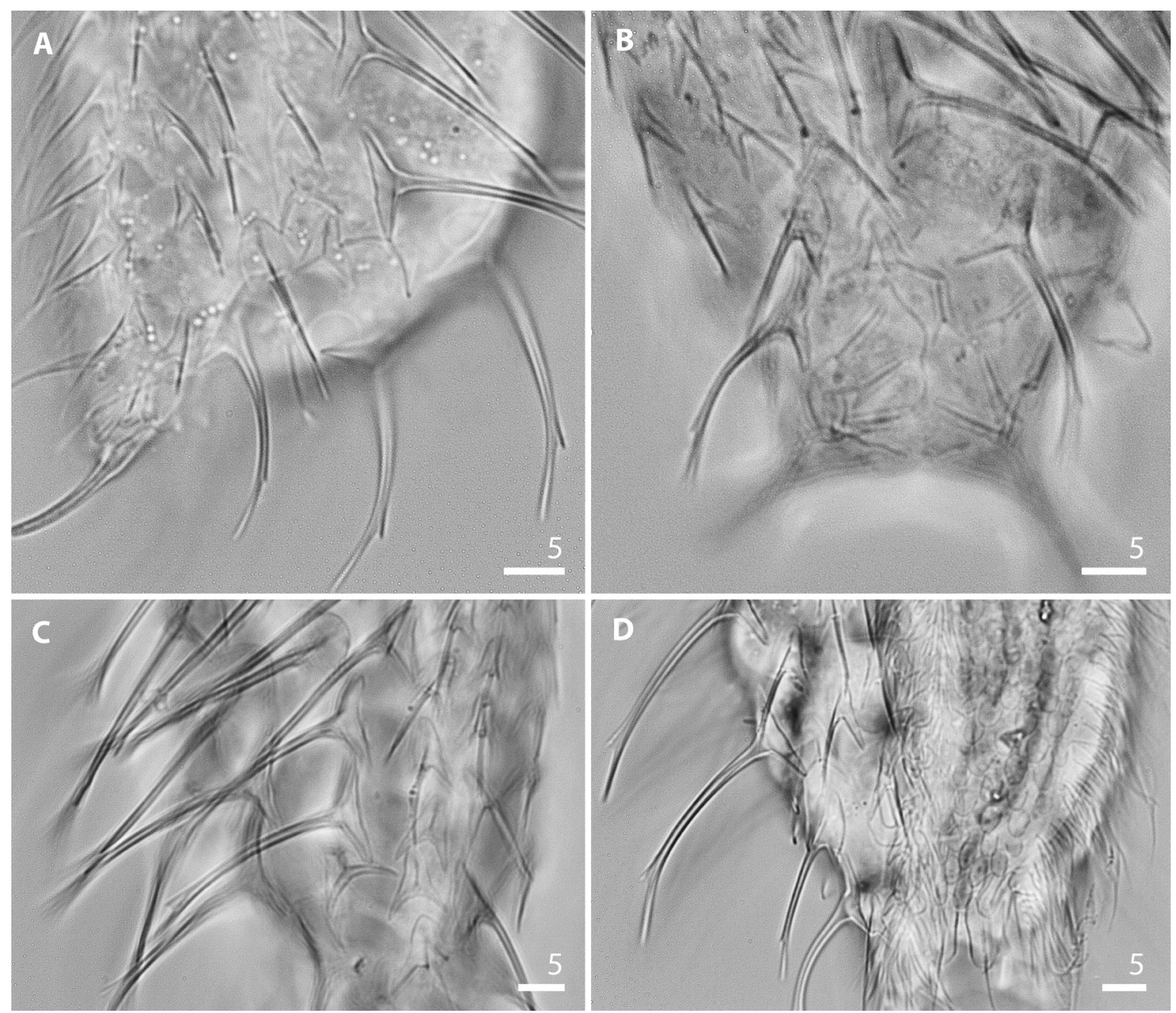

Fig. 22. Chaetonotus (Hystricochaetonotus) horridus sp. nov. Adult specimen. Bright field microphotographs. A. Posterior trunk, furca base and furcal appendage, scales lateral view. B. Posterior trunk, furca base and furcal appendage scales, dorsal view. C. Central and posterior trunk scales, dorsal view. D. Posterior trunk, furca base and furcal appendage scales, ventral view. 
Table 4. Main morphometric characters of Chaetonotus (Hystricochaetonotus) horridus sp. nov. $\mathrm{N}=$ number of specimens analysed; Range $=$ the smallest and the largest structure found among all specimens measured. All measurements in micrometers $(\mu \mathrm{m})$; all indicators given as a percentage $(\%)$ and italicized.

\begin{tabular}{cccc}
\hline Characters & N & Holotype & $\begin{array}{c}\text { Range of adult } \\
\text { paratypes }\end{array}$ \\
\hline Body length & 70 & 131.69 & $107.77-134.01$ \\
Furca length & 70 & 25.51 & $21.74-25.90$ \\
Adhesive tube length & 70 & 12.43 & $9.67-13.04$ \\
Number of scales in central longitudinal row & 81 & 15 & $13-15$ \\
Total number of longitudinal alternating rows of scales & 81 & 21 & $15-21$ \\
Head scales length $\times$ width & 15 & $2.82-5.23 \times 2.66-5.20$ & $2.17-5.30 \times 2.05-6.20$ \\
Neck scales length $\times$ width & 15 & $3.24-6.37 \times 2.75-5.91$ & $2.77-6.37 \times 2.35-5.91$ \\
Trunk scales length $\times$ width & 15 & $3.49-13.43 \times 2.62-13.37$ & $3.03-13.43 \times 2.12-13.37$ \\
Head spines length & 15 & $1.86-13.73$ & $0.44-13.78$ \\
Neck spines length & 15 & $15.054-32.630$ & $13.699-32.653$ \\
Localization of lateral denticle on head spines & 15 & $5.12-16.49$ & $2.45-16.49$ \\
Localization of lateral denticle on neck spines & 15 & $25.502-29.323$ & $19.818-29.448$ \\
Trunk spines length & 15 & $7.88-19.58$ & $4.97-19.54$ \\
Localization of lateral denticle on trunk spines & 15 & $21.053-31.124$ & $21.053-32.937$ \\
Long trunk spines length & 15 & $16.65-31.75$ & $11.59-34.14$ \\
Localization of lateral denticle on trunk long spines spines & 15 & $23.039-31.937$ & $17.969-34.785$ \\
Length of trunk posteriormost pair of lateral spines & 15 & 20.09 & $13.87-20.09$ \\
Localization of lateral denticle on trunk posteriormost pair of & 15 & 31.210 & $24.942-34.785$ \\
lateral spines & 70 & 6.45 & $5.48-7.04$ \\
Mouth ring diameter & 70 & 33.20 & $27.03-33.58$ \\
\hline Pharynx length & & & \\
\hline
\end{tabular}

SPINES. In this species, five main types of spines may be distinguished (Fig. 18). The first type of spine bends slightly along its entire length and tapers towards the end, without lateral denticles. This type of spine emerges from the anteriormost head dorsal scales (Fig. 18A). The second type of spine is basally bent, tapering towards their ends, with a weak lateral denticle. These spines emerge from the dorsal, dorsolateral, lateral and ventrolateral head, neck and anterior trunk region scales and laterally and ventrolaterally on the remaining scales of the trunk part (Fig. 18B). The length and thickness of the spines gradually increase from the head towards the widest body region (ca U59) (from 1.8-13.7 to 7.9-19.6 $\mu \mathrm{m}$ ). Moreover, their length gradually increases towards the ventrolateral surface (head: from 0.4-5.6 to 0.7-6.1 $\mu \mathrm{m}$; neck: from 2.5-8.3 to 3.4-10.1 $\mu \mathrm{m}$; trunk: 5.0-11.1 to 5.7-17.0 $\mu \mathrm{m}$ ) (Table A3). The third type of spine is very long and thick, straight, with a prominent, deeply notched lateral denticle. The spines emerge from large (scales 11, 12 and 13), thick dorsal and dorsolateral trunk scales (from ca U37 to ca U73), are the longest $(18.9-35.5 \mu \mathrm{m})$ and thickest body spines and have the most prominent lateral denticle (Fig. 18C). From scales 13, located on the posterior trunk region (at U78-U81), arise the last long dorsal and dorsolateral long spines (Fig. 21). These spines are slightly shorter than the preceding long spines and their lateral denticle is less prominent $(18.9-27.2 \mu \mathrm{m})$. The fourth type of spine is long, thick, slightly bent and with a clearly marked lateral denticle (Fig. 18D). This type of spine arises from the second to posteriormost trunk pair of lateral scales located at U69-U75 and from the posteriormost trunk pair of lateral scales located at U76-U82 (Fig. 22A-B). The posteriormost pair of trunk spines is longer $(13.9-20.1 \mu \mathrm{m})$ and thicker than the second to posteriormost pair of lateral 


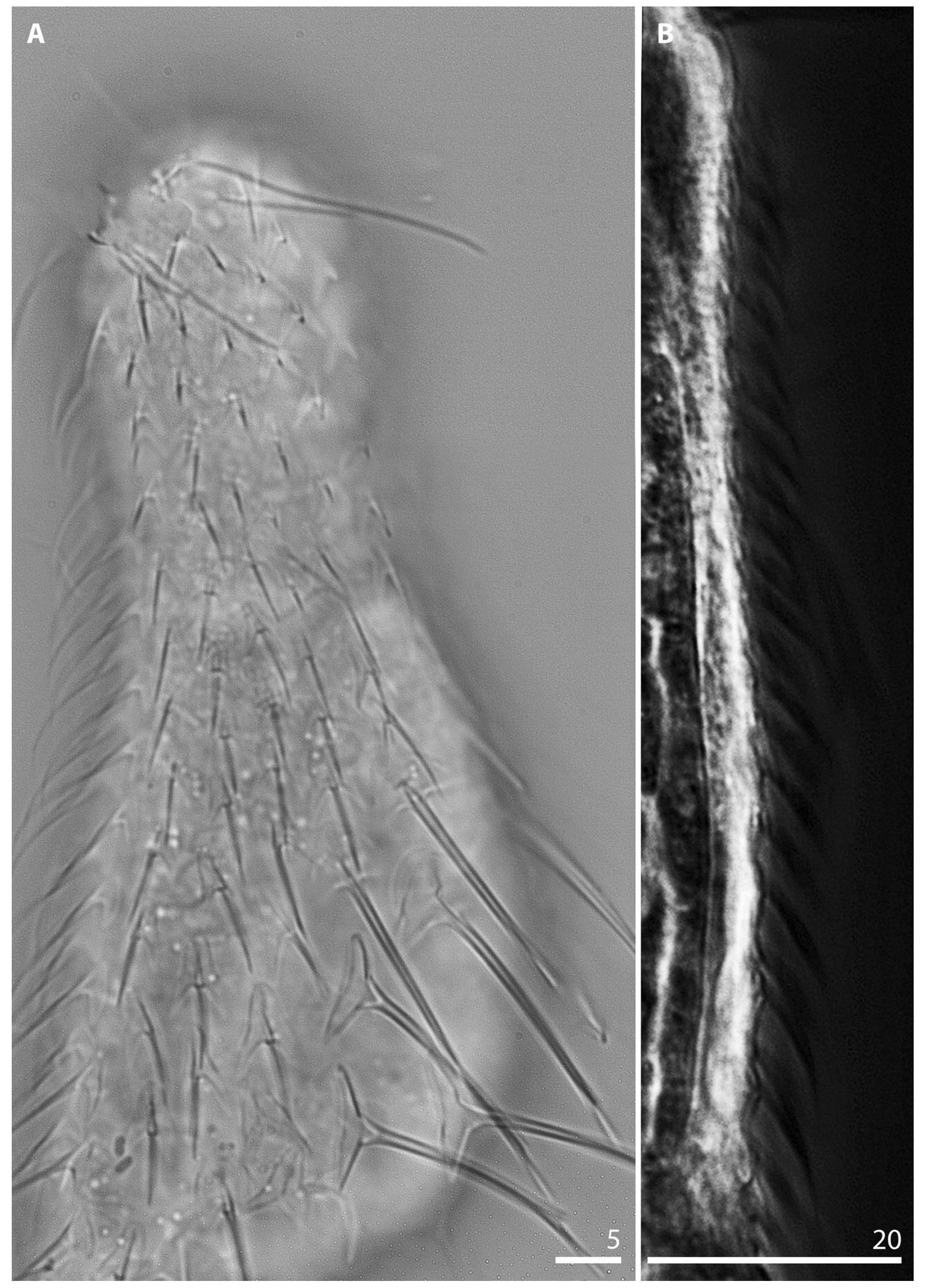

Fig. 23. Chaetonotus (Hystricochaetonotus) horridus sp. nov. Adult specimen. A. Spines lateral view, bright field microphotograph. B. Spines with lamellae, phase contrast microphotograph. 

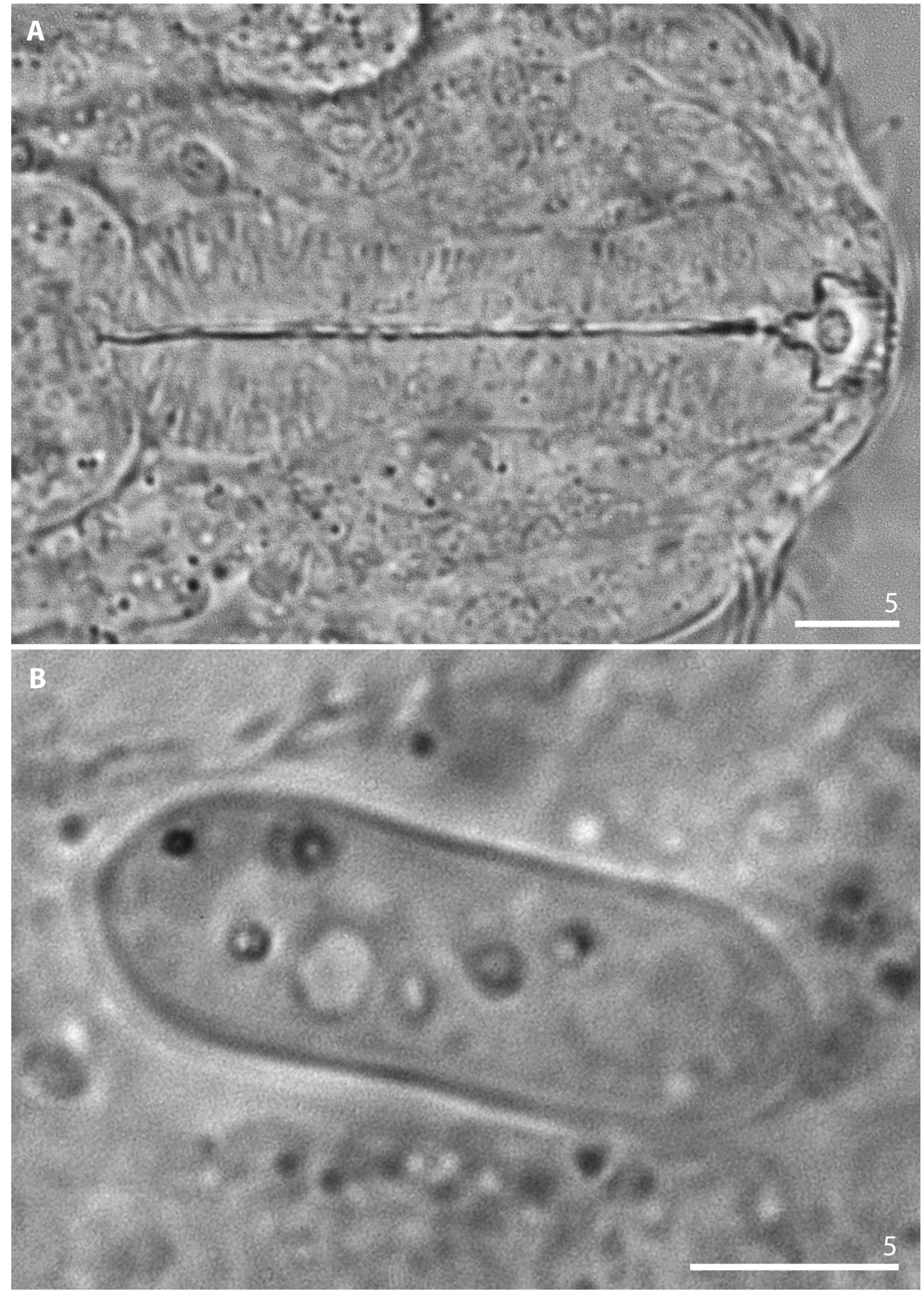

Fig. 24. Chaetonotus (Hystricochaetonotus) horridus sp. nov. Adult specimen. Bright field microphotographs. A. Detail of pharynx. B. Crescent-like formation inside body integument. 
spines $(11.6-16.7 \mu \mathrm{m})($ Table A3), and their lateral denticles are more prominent and deeply notched (Fig. 22A-B). The fifth type are long $(7.2-19.5 \mu \mathrm{m})$, thin, hair-like spines with narrow, delicate lamellae along their entire length. These spines arise on the ventral surface, from scales arranged in one pair of longitudinal rows located closest to the ciliary bands (Fig. 18E). The lamellae are the widest here, ca one-third of the length of the spine, and taper towards the end of the spines (Fig. 21B).

DoRsAl SENSORY BRISTLES. This species has three pairs of dorsal sensory bristles (Fig. 16A). The first, anterior pair is located on the dorsal surface of the head at U5, beyond the dorsolateral cephalion edges, whereas the second pair of sensory bristles is located on the dorsal surface of the posterior neck region at U27. The first and the second pairs emerge from small, spherical papillae. The third, posterior pair of sensory bristles is located dorsally and dorsolaterally on the posterior trunk and emerges from the three-lobed, double-keeled scales at U76-U79. The keels of these scales are connected in the centre of the scales, and the scales are shaped like double, sharp triangles with long, narrow posterolateral lobes set very wide apart and a double, deep posterior notch (Figs 16A, 22B).

VeNTRAL CILIARY BANDS AND VENTRAL INTERCILIARY FIELD. On the ventral surface, the longitudinal ciliary bands begin at U8 and run back to U87 (Fig. 16C). On the head region (from ca U8 to ca U11) the ciliary bands are merged (Fig. 16C) and subsequently are divided into two separate bands arranged parallel to one another. The entire ventral interciliary field is covered by plate-like scales. They are distributed in 7 longitudinal rows with 14-23 scales in the central row (Figs 16C, 19C, 22D). The ventral interciliary field anterior scales are partially recessed on the cuticle and isolation from the cuticle increases towards the posterior body part. The anterior scales are rounded to inverted egg-shaped (scale
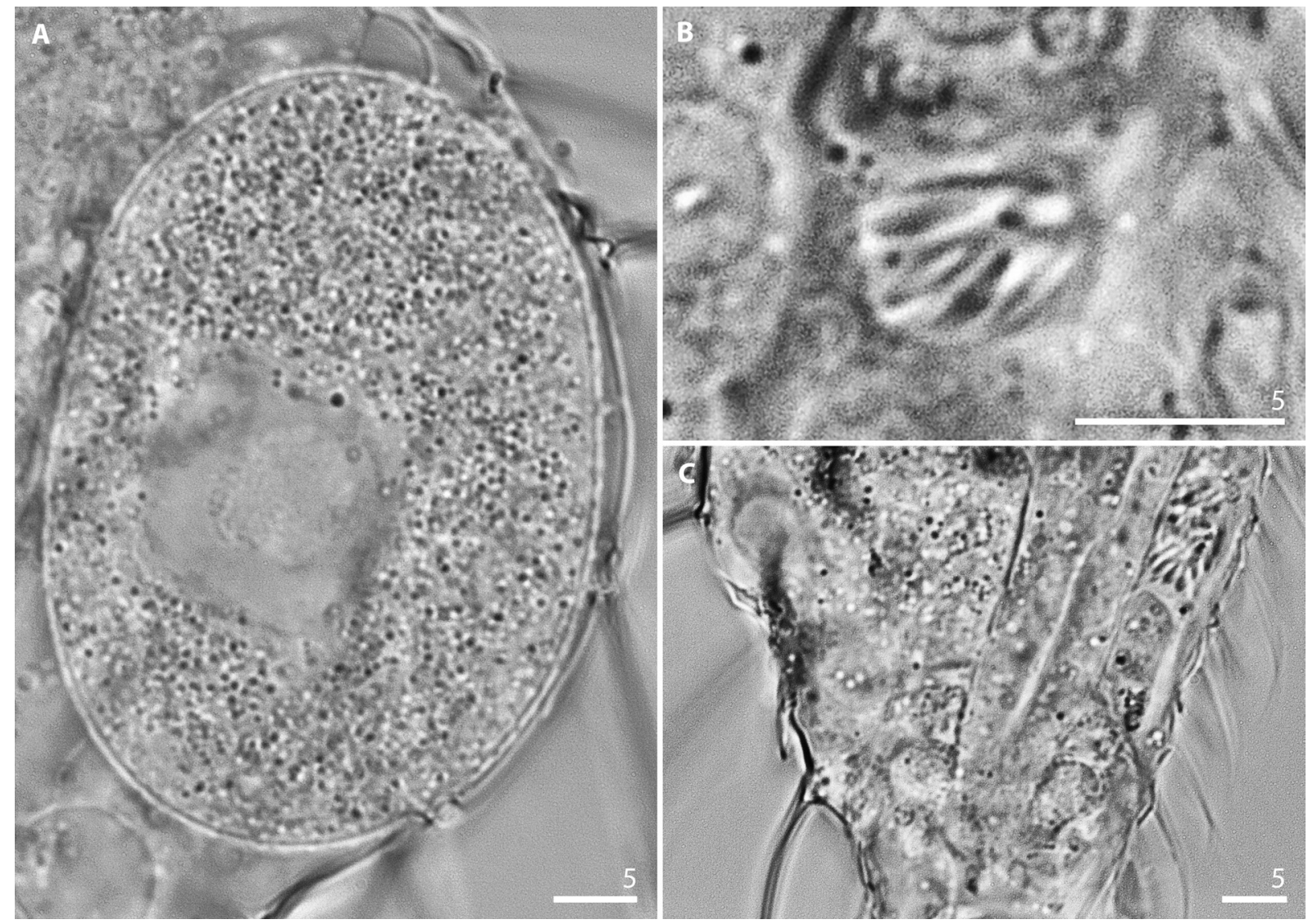

Fig. 25. Chaetonotus (Hystricochaetonotus) horridus sp. nov. Detail of the internal morphology. Bright field microphotographs. A. Mature egg. B. Sperm pocket. C. X-organ and sperm pocket. 
22; Figs 17V, 20B), and towards the posterior body region the scales become gradually larger and more elongated (scales 23-24; Fig. 17W-X). The posterior ventral interciliary field region scales (at U73U79) are elongated, oval in shape, and have straight and thin keels (Figs 20F, 22D). From the anterior to posterior body region, the distances between the scales decrease, and beyond half the trunk length the scales start to overlap (Fig. 20D, F). Three pairs of ventral interciliary field terminal scales are present. The first pair (at U79-U85) is elongated and rectangular, with rounded anterior edges (scale 25; Fig. 17Y). They have a long, narrow keel and a long, thin and straight spine extending beyond the internal furcal indentation. The second and third pairs (at U86-U89) are elongated and rectangular, with rounded anterior edges (scale 26; Fig. 17Z). These pairs have long, narrow keels and possess short, rudimentary spines that only slightly extend towards the posterior scale edge (Fig. 22D).

INTERNAL MORPHOLOGY. The pharynx (from U2 to U30) is wide and has distinct, marked, rounded anterior and posterior dilatations. The posterior dilatation is wider than the anterior one (Fig. 24A). The pharynx is connected through the pharyngeal-intestinal junction to a straight intestine, running from U30 to U84. The pharyngeal-intestinal junction is clearly demarcated, short and narrow (U31). The X-organ of this species (observed in five specimens) is located at U83-U86 near the terminal part of the intestine. It is bilobed, built from two extensions enveloped in a thin coat and connected by a thinner band located below the intestine, at the ventral side. The extensions and the thin coat and the cellular bridge connecting the extensions have a grain-like structure (Fig. 25C). The pair of sperm packets of this species are circular in shape and contain spermatozoids ( $8-16$ per packet) in the form of a short rod. The pair is located at U60-U62 on both sides, juxtaposed to the intestine. When only a single sperm pocket is present, it is irregular in shape, less compact and contains 8-16 spermatozoids. Unpaired sperm pockets, when present, are located at U64-U66, very near the internal trunk wall (Fig. 25C).

\section{Remarks}

The total body length of juvenile specimens of Chaetonotus (Hystricochaetonotus) horridus sp. nov. varied from 88.8 to $122.9 \mu \mathrm{m}$; length of pharynx between 27.6 and $34.2 \mu \mathrm{m}$; length of intestine from 36.4 to $58.2 \mu \mathrm{m}$; there were $15-21$ total longitudinal rows of scales $(3 \mathrm{D}+2-4 \mathrm{DL}+4-6 \mathrm{~L}+4 \mathrm{LV}+2-4 \mathrm{~V})$, with 11-15 scales in the central row. Out of 69 adults, nine had a large, developing egg, one had a developing egg, an X-organ and a single sperm packet, one had an X-organ and a single sperm packet, whereas two others had an X-organ and two sperm packets and the next one only had a single sperm packet; one had large, crescent-like formations inside the integuments (Fig. 25B) and another had diffuse formations (in both case probably some kind of parasitic structures).

\section{Differential diagnosis}

Of all 32 species belonging to the subgenus Hystricochaetonotus Schwank, 1990, Chaetonotus (H.) horridus sp. nov. most closely resembles C. (H.) acanthophorus Stokes, 1888, C. (H.) balsamoae Kisielewski, 1997, C. (H.) euhystrix Schwank, 1990 and C. (H.) novenarius Greuter, 1917 (Table A4). Chaetonotus $(H$.) acanthophorus shares the following characters with $C$. (H.) horridus sp. nov.: long and strong spines on the dorsal and dorsolateral trunk surfaces; two strong and long anteriormost lateral trunk spines. Chaetonotus $(H$.) balsamoae and $C$. (H.) novenarius were selected for comparison with the new species due to their similarity in possessing very long and strong spines with strong, prominent lateral denticles on the dorsal trunk surface. Chaetonotus $(H$.) euhystrix was selected for comparison with the new species due to its similarity in possessing very long and strong spines with strong, prominent lateral denticles on the dorsal and dorsolateral trunk surfaces; a large mouth ring; a similar number of scales in the central longitudinal row of scales; and type of covering of the ventral interciliary field. Despite the fact that among all of the hitherto known species in this subgenus, those listed above have the highest number of common features with $C$. $(H$.) horridus sp. nov., they are significantly different from it - most strikingly by scale type and shape, spine length variation, as well as arrangements of the long trunk dorsal spines and lateral denticle type. In order to avoid any doubts in comparisons with 
the new species, only the original descriptions of these species and three of the most detailed papers with morphological data were used (Balsamo 1983; Schwank 1990; Kisielewski 1997a). Comparisons between the new species and the most morphologically similar taxa have been summarised in Table A4.

Chaetonotus (Hystricochaetonotus) inaequabilis sp. nov. urn:lsid:zoobank.org:act:82BC94AE-15DD-4A5D-A727-B34013BC6B7A

Figs 26-32, A7; Tables 5, A5-A6

\section{Diagnosis}

Stocky body, measuring from 98.2 to $108.5 \mu \mathrm{m}$ in length. Head five-lobed, cephalion narrow, epipleurae and hypopleurae small. All cephalic plates weakly demarcated in head outline. Hypostomium small, rectangular in shape. Ocellar granules absent. Almost all scales three-lobed. Scales distributed in 15-17 total longitudinal rows $(5-7 \mathrm{D}+2 \mathrm{DL}+2 \mathrm{~L}+4 \mathrm{LV}+2 \mathrm{~V})$, with 12-13 scales in central row. Scales strongly differ morphologically in various body areas. Nine significantly larger scales on dorsal trunk area with very long, thick spines with a strong lateral denticle. Two pairs of posteriormost trunk lateral scales with long, thick spines with strong lateral denticle. Remaining scales with simple, shorter and thinner spines, or with rudimentary spines, or without spines on central dorsal trunk area and on furcal appendages. Scales with parafurcal spines absent. Spines on ventral surface hair-like, with narrow, delicate lamellae along entire length. Entire ventral interciliary field covered with small scales. Four pairs of ventral interciliary field terminal scales. Pharynx wide, with pronounced anterior and posterior dilatations. Intestine straight without anterior section differing in form and morphology.

\section{Etymology}

From the Latin 'inaequabilis' = 'heterogeneous', referring to the very numerous types of scales on the body.

\section{Type material}

\section{Holotype}

POLAND • adult; Kraków, Botanical Garden, Jubilee Greenhouse, site 2; 5003'38" N, 1957'30" E; 15 Nov. 2013; M. Kolicka leg.; NHC-GCHI-23-1-25/h (photomicrographs, also in the author's collection).

\section{Paratypes}

POLAND -6 adults; same locality as holotype; sites 2-3; 15 Nov. 2013 and 17 Apr. 2014; M. Kolicka leg.; NHC-GCHI-23-26-60/p (photomicrographs, also in the author's collection).

\section{Description}

HaBitus. Chaetonotus (Hystricochaetonotus) inaequabilis sp. nov. has a stocky body (Figs 26, 29). Its head is only slightly wider than the neck, and the neck constriction is weakly demarcated. The neck gradually tapers from the head (from U20) to the beginning of the trunk (ca U30) (Figs 26, 29). The trunk is slightly wider than the head and gradually dilates from ca U31 to ca half of its length (U56), where it is at its maximum width. Then it gradually tapers towards the narrow furcal base (from U84) (Figs 26, 29). The furcal base is clearly demarcated and narrow. The furcal indentation is V-shaped. The furcal branches are set narrowly apart and point slightly outwards (Figs 26, 29). The adhesive tubes are relatively short in comparison to the whole body length (Table 5), straight, fairly thick and not tapered towards the blunt ends (Figs 26, 29).

HEAD. The head is five-lobed, short and semicircular in shape. The cephalion (U1-U3) is narrow, short and straight, on the dorsal body side. It adheres to the head along its entire length and rapidly extends 
$\dot{0}$

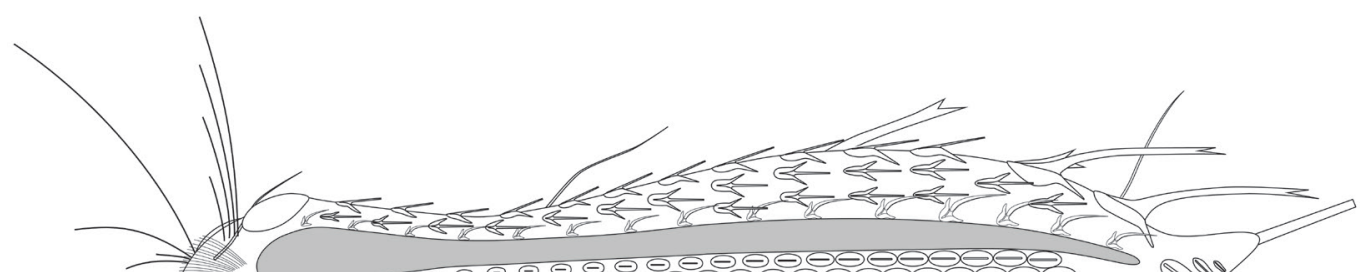

(0)

$\cup$

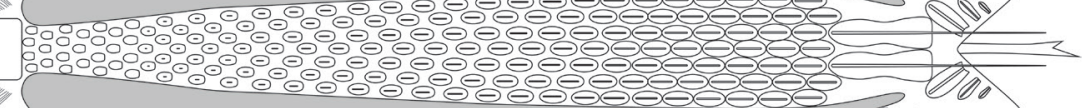
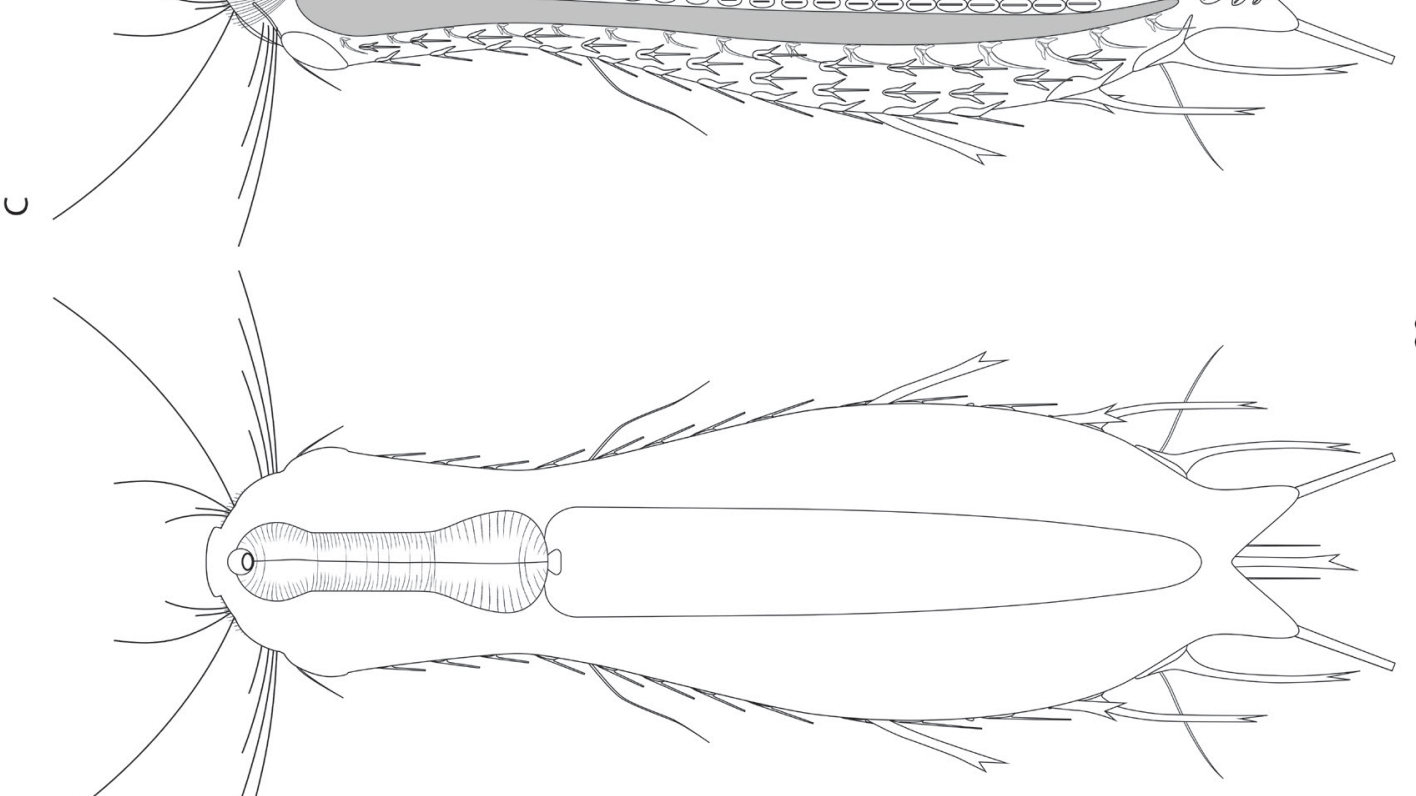

오
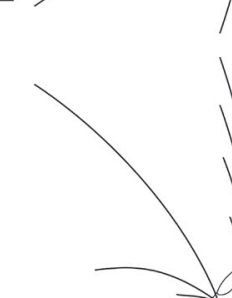

$\varangle$

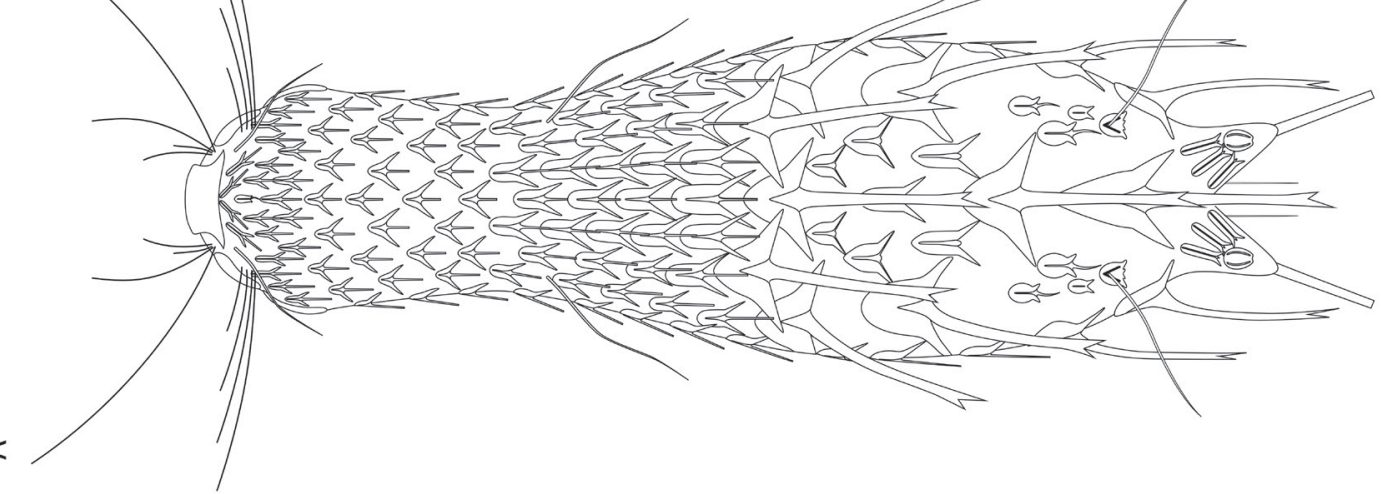



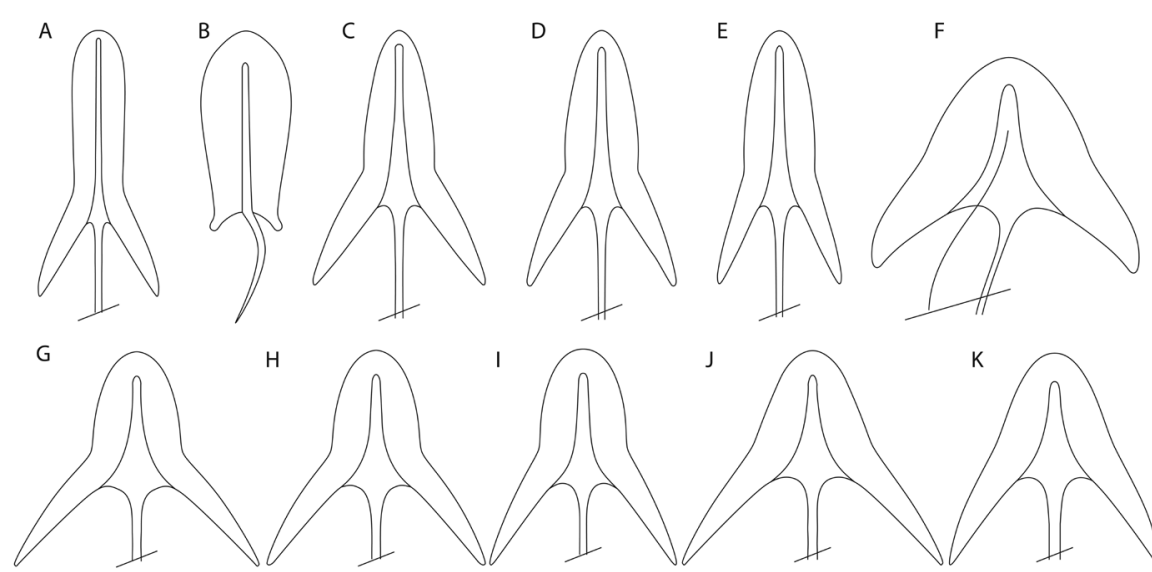

$\mathrm{H}$
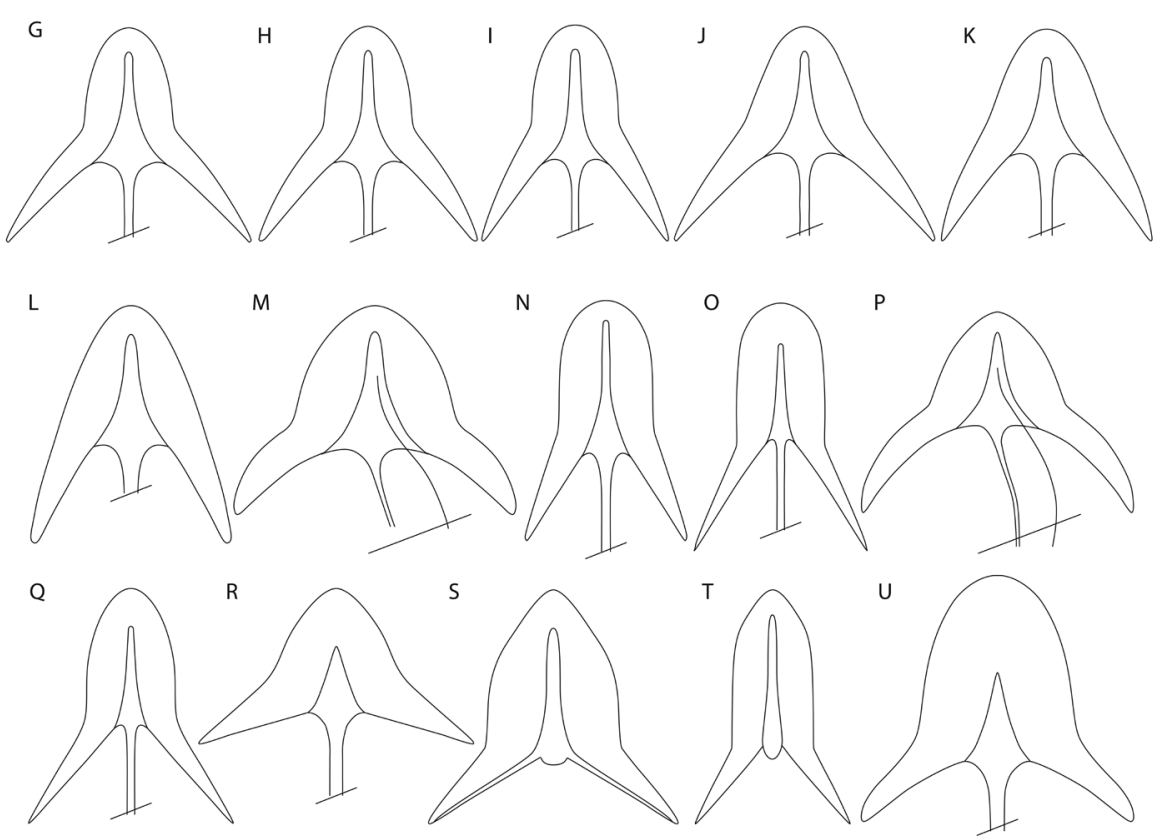

$R S$
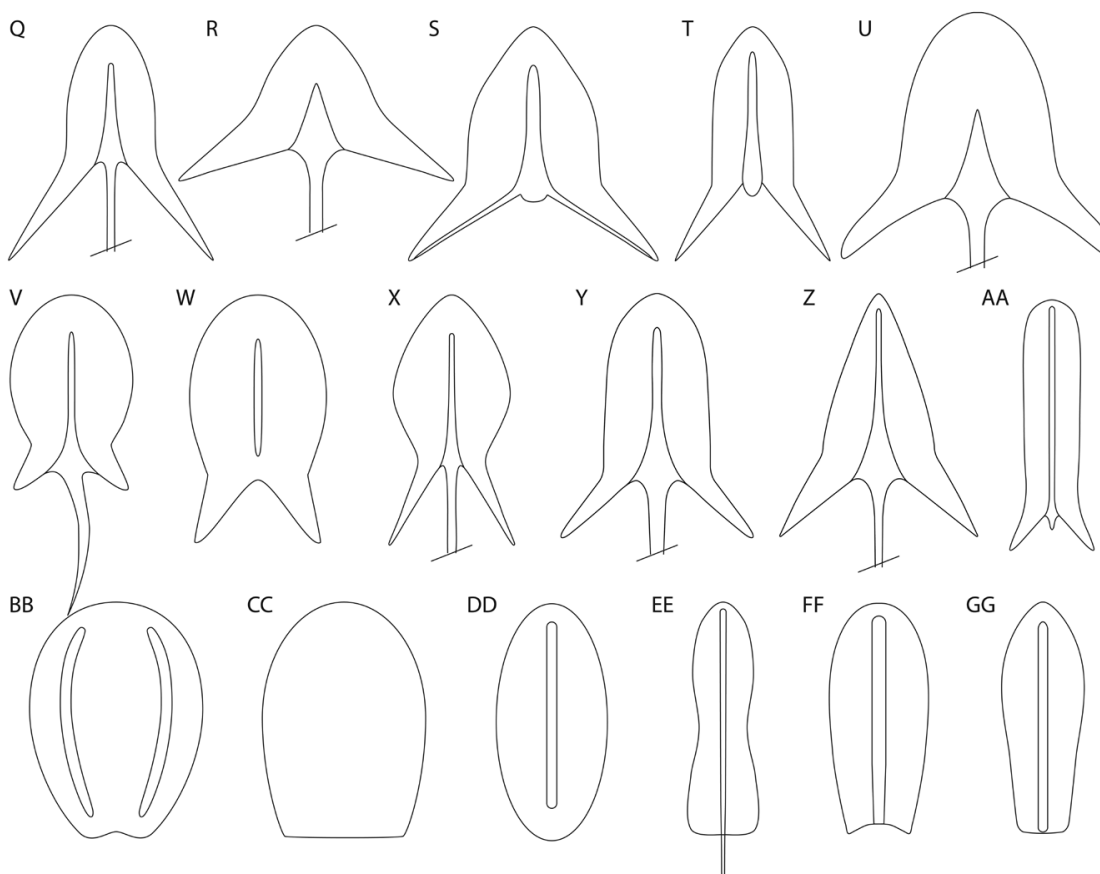

Fig. 27. Chaetonotus (Hystricochaetonotus) inaequabilis sp. nov. Schematic drawings of the scales. A. Head anteriormost scale (scale 1). B. Head anteriormost central scale (scale 2). C. Anterior head dorsal scale (scale 3). D. Anterior head dorsolateral and lateral scale (scale 4). E. Anterior head ventrolateral scale (scale 5). F. Head ventral scale (scale 6). G. Posterior head dorsal scale (scale 7). H. Posterior head dorsolateral and lateral scale (scale 8). I. Posterior head ventrolateral scale (scale 9). J. Anterior neck dorsal scale (scale 10). K. Neck dorsolateral and lateral scale (scale 11). L. Neck ventrolateral scale (scale 12). M. Neck ventral scale (scale 13). N. Posterior neck dorsal scale (scale 14). O. Anterior trunk dorsal, dorsolateral, lateral and ventrolateral scale (scale 15). P. Trunk ventral scale (scale 16). Q. Posterior trunk dorsal, dorsolateral, lateral and ventrolateral scale (scale 17). R. Scale 18. S. Scale 19. T. Scale 20. U. Scale 21. V. Scale 22. W. Scale 23. X. Scale 24. Y. Scale 25. Z. Scale 26. AA. Scale 27. BB. Scale 28. CC. Scale 29. DD. Scale 30. EE. Scale 31. FF. Scale 32. GG. Scale 33. 
Table 5. Main morphometric characters of Chaetonotus (Hystricochaetonotus) inaequabilis sp. nov. $\mathrm{N}=$ number of specimens analysed; Range $=$ the smallest and the largest structure found among all specimens measured. All measurements in micrometers $(\mu \mathrm{m})$; all indicators given as a percentage $(\%)$ and italicized.

\begin{tabular}{cccc}
\hline Characters & N & Holotype & Range of adult paratypes \\
\hline Body length & 5 & 107.91 & $98.16-108.49$ \\
Furca length & 5 & 20.96 & $20.08-22.05$ \\
Adhesive tube length & 5 & 10.05 & $9.92-10.50$ \\
Number of scales in central longitudinal row & 5 & 14 & $14-15$ \\
Total number of longitudinal alternating rows of scales & 5 & 19 & $19-21$ \\
Head scales length $\times$ width & 5 & $1.87-5.22 \times 1.49-4.86$ & $1.49-5.91 \times 1.23-5.01$ \\
Neck scales length $\times$ width & 5 & $2.39-6.45 \times 2.77-5.21$ & $2.07-6.65 \times 2.40-5.37$ \\
Trunk scales length $\times$ width & 5 & $2.82-11.04 \times 3.31-13.03$ & $2.28-11.39 \times 2.24-13.03$ \\
Head spines length & 5 & $0.34-11.42$ & $0.27-12.03$ \\
Neck spines length & 5 & $1.76-12.41$ & $1.62-13.60$ \\
Trunk spines length & 5 & $3.32-14.62$ & $3.09-15.23$ \\
Trunk long spines length & 5 & $11.61-21.61$ & $10.16-21.61$ \\
Localization of lateral denticle on trunk long spines spines & 5 & $10.288-17.399$ & $8.780-17.958$ \\
Length of trunk posteriormost pair of lateral spines & 5 & 13.69 & $11.42-14.02$ \\
Localization of lateral denticle on trunk posteriormost pair & 5 & 13.587 & $12.610-15.149$ \\
of lateral spines & 5 & 6.04 & $5.14-7.07$ \\
Mouth ring diameter & 5 & 28.05 & $26.21-28.29$ \\
Pharynx length & 5 & &
\end{tabular}

laterally near the dorsal edge (Figs 26A, 31A). The epipleurae (U3-U7) are small, narrow, slightly arched and weakly demarcated in the head outline. They are visible on the dorsal, dorsolateral and lateral head sides. The hypopleurae (U7-U12) are similar in size to the epipleurae and located entirely on the ventrolateral and ventral head sides (Fig. 26). On the dorsal head surface, between the lateral edges of the cephalion and epipleurae, is a prominent space; their edges meet only in the cephalion extension place. Deep notches are present between the cephalion and epipleurae and between the epipleurae and hypopleurae. The hypostomium (U6-U8) is small, rectangular, with a slightly reinforced anterior edge (Figs 26C, 31B). Two pairs of cephalic ciliary tufts are present. The anterior tufts emerge in the area between the cephalion and epipleurae on the dorso-terminal head surface (at U2-U3) and consist of four cilia. The anteriormost cilium in both anterior tufts is fairly short. The second cilium is short, shorter than the anteriormost one. The third cilium is longer than either of the preceding cilia. The fourth, last cilium in the anterior tufts is very long, the longest in both pairs of tufts. The posterior tufts (at U6-U7) have four straight cilia each and emerge on the ventral head surface, above the anterior edge of the hypopleurae. The length of the cilia in the posterior tuft gradually increases from the anteriormost to the fourth cilium. Ocellar granules are not present. The mouth ring is large and subterminal at U2-U5. It has very strong, granular cuticular reinforcements and short inner hairs (Figs 26C, 29C). Suboral bristles are located in two tufts located beneath and laterally to the mouth ring and reaching half the length of the lateral hypostomium edges (between U5 and U7).

SCALEs. The entire body, except for one pair of scales on the furcal appendages, is covered with threelobed scales that adhere to the cuticle along their entire surface (Fig. A7). All scales have a strong, triangular keel and are shaped like triangles with a deep posterior notch. The scales are distributed in $15-17$ total longitudinal alternating rows $(5-7 \mathrm{D}+2 \mathrm{DL}+2 \mathrm{~L}+4 \mathrm{LV}+2 \mathrm{~V})$, with $12-13$ scales in the central 


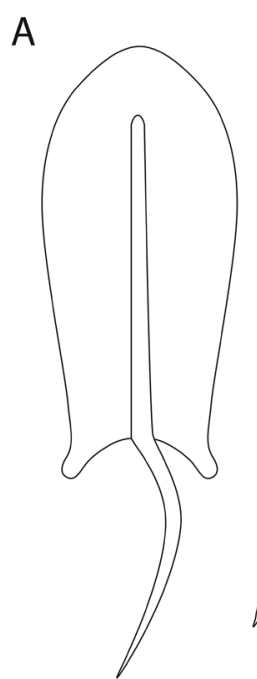

D

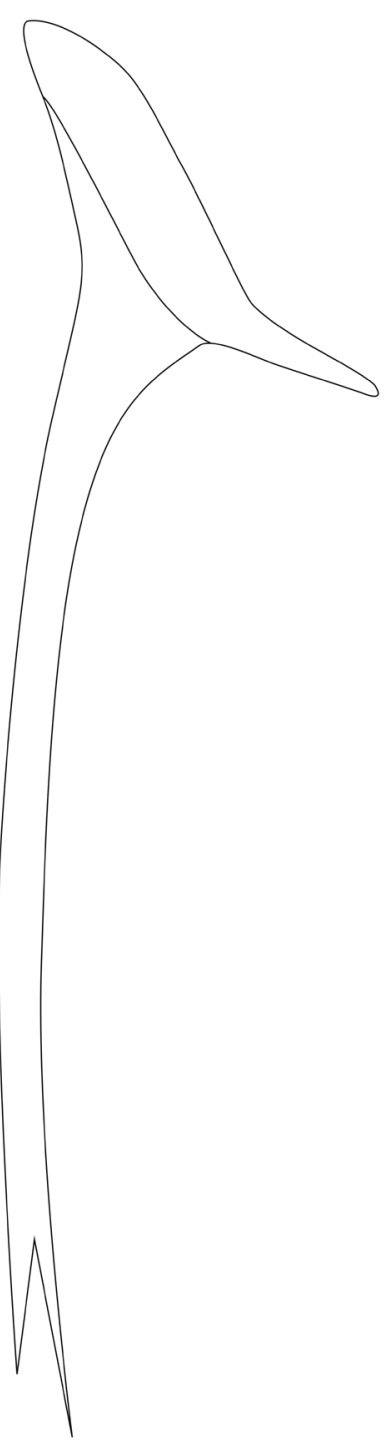

B
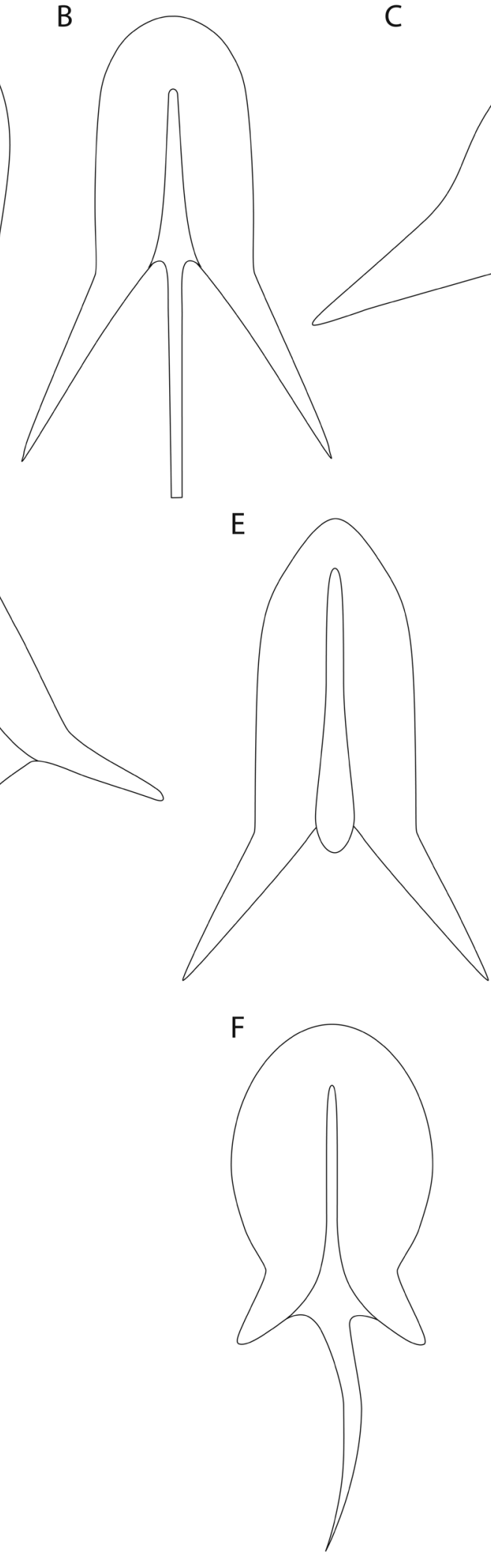

C
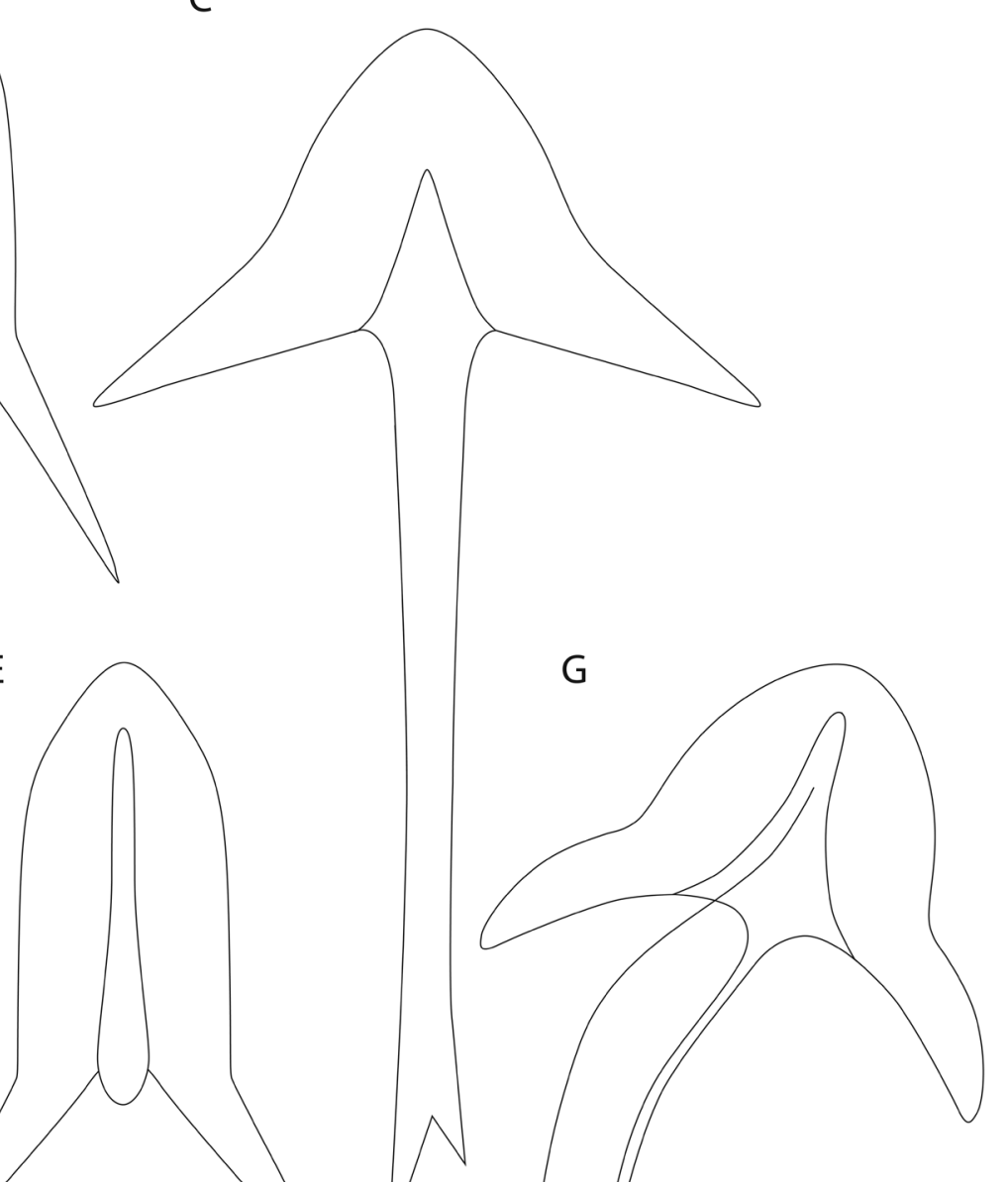

G

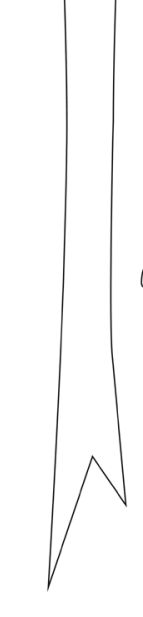

Fig. 28. Chaetonotus (Hystricochaetonotus) inaequabilis sp. nov. Schematic drawings of the spine types. A. First type of spines. B. Second type of spines. C-D. Third type of spines. E-F. Fourth type of spines. G. Fifth type of spines. 
row. The longitudinal rows of scales begin on the head directly beneath the posterior edge of the cephalion, epipleurae and hypopleurae. The scales show a strong diversity in size and shape between the various parts of the body. On the head and anterior neck region the scales are located far from each other, while on the posterior neck and anterior trunk region the scales become gradually juxtaposed but do not overlap. The dorsolateral, lateral, ventrolateral and ventral trunk scales are juxtaposed, whereas the dorsal trunk scales and scales on the furcal appendages have overlapping posterolateral edges (Fig. 30). The head anteriormost scales are situated near the posterior edge of the cephalion and epipleurae. The dorsal anterior scales are located aslant, whereas the dorsolateral scales are arranged parallel to the longitudinal body axis. These scales are elongated, their central lobes are long and wide, and they have very long keels. The posterolateral lobes are narrow, slanted downward and create a narrow, deep V-shaped posterior scale notch (scale 1; Fig. 27A). The central anteriormost head scales are located at U5-U6, beneath the aslant arranged scales, are smaller, more rounded and have weaker separate posterolateral lobes (scale 2; Fig. 27B). The remaining scales of the head are wider. The central lobes of these scales become shorter, and simultaneously the posterolateral lobes become slightly longer, whereas their keels are shorter. The posterolateral lobes are directed diagonally downward and laterally and create a deep and wide posterior scale notch (scales 3 and 7; Fig. 27C, G). The anterior neck scales are shorter than the head scales. Their central lobes are wide and short. Their posterolateral lobes are weaker and separate from the central lobes (scale 10; Fig. 27J). The subsequent neck scales become larger but relatively narrower than the preceding neck scales (Table A5). Their central lobes are wide, with strongly rounded anterior edges, whereas their postero-lateral lobes are more separated and directed more downward and create a deep V-shaped posterior scale notch (scale 14; Fig. 27N). The posterolateral lobes of the dorsolateral, lateral and ventrolateral scales of the head and neck become gradually more
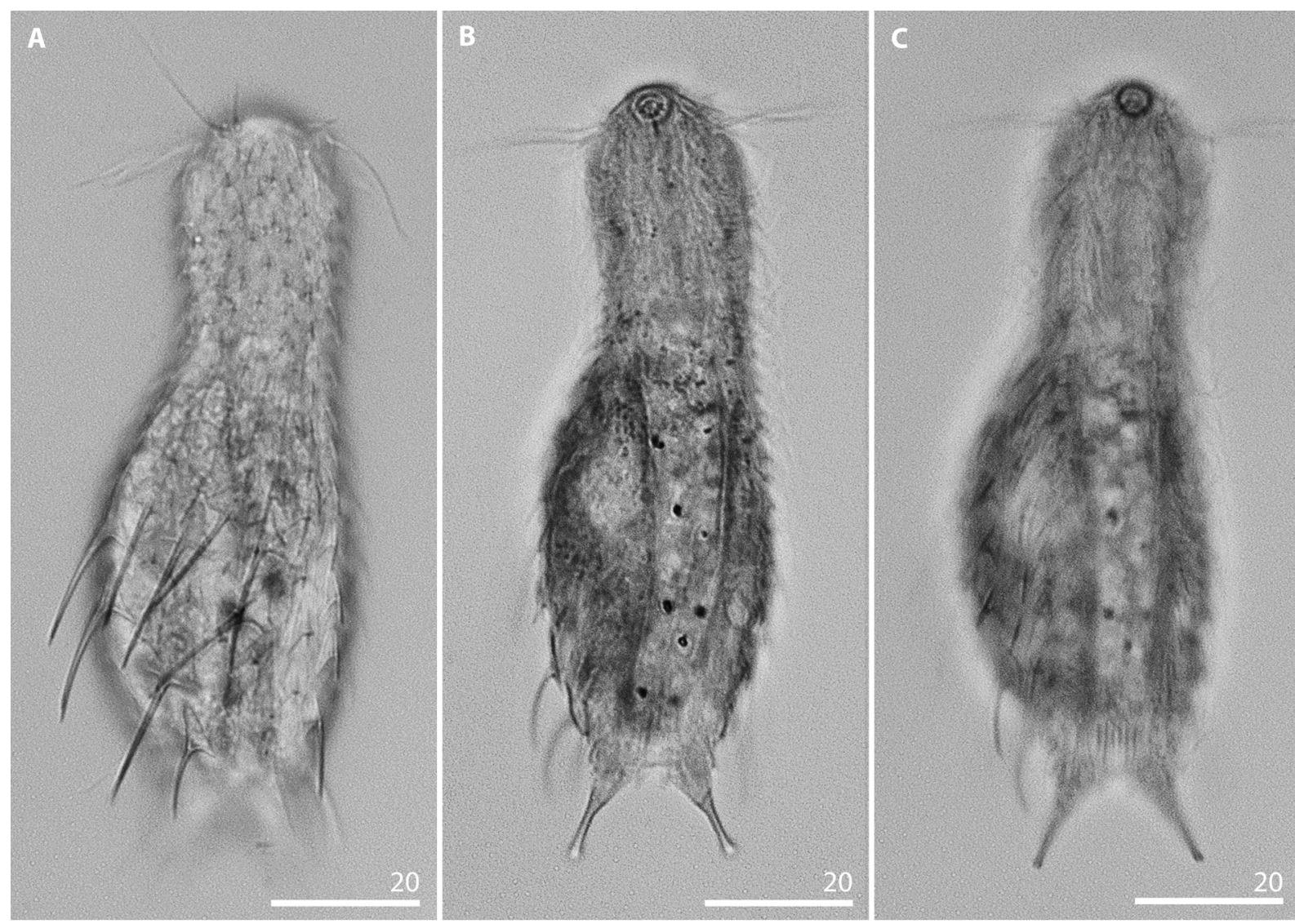

Fig. 29. Chaetonotus (Hystricochaetonotus) inaequabilis sp. nov. Adult specimen. Bright field microphotographs. A. Dorsal body view. B. View of internal morphology. C. Ventral body view. 


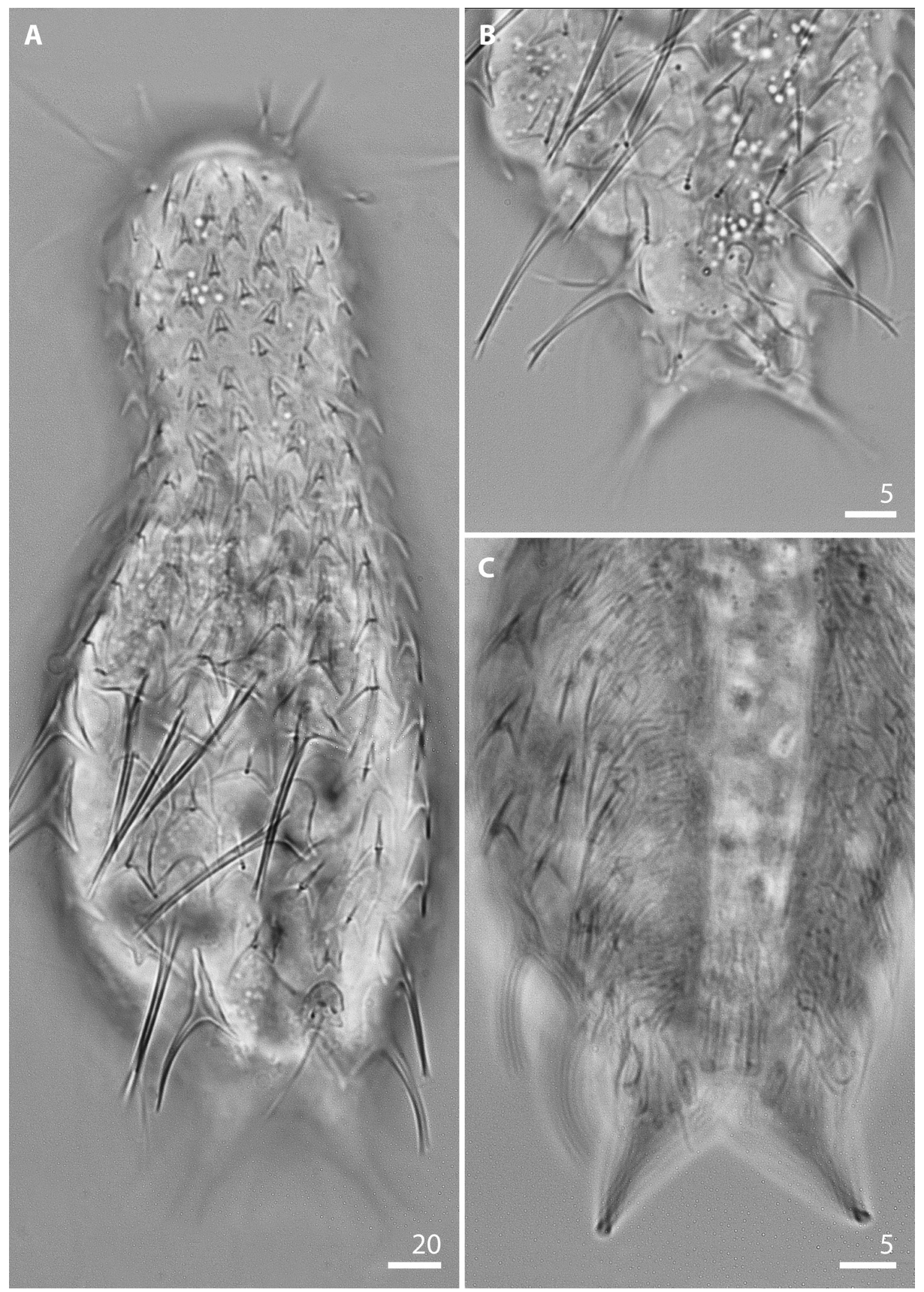

Fig. 30. Chaetonotus (Hystricochaetonotus) inaequabilis sp. nov. Adult specimen. Bright field microphotographs. A. Scales, dorsal view. B. Posterior trunk region, furca base and furcal appendage scales, dorsal view. C. Posterior trunk region, furca base and furcal appendage scales, ventral view. 
directed downward towards the ciliary bands as compared to the dorsal scales (scales 3-14; Fig. $27 \mathrm{C}-\mathrm{N}$ ). From the neck towards the trunk, the size of the scales gradually increases (from 2.1$2.5 \times 2.4-2.9$ to $4.2-5.4 \times 5.1-6.5 \mu \mathrm{m})$. The anterior trunk scales have a wide and rounded anterior central lobe and clearly separate, long, narrow and sharp posterolateral lobes. The posterolateral lobes are directed diagonally downward and slightly laterally, and they create a deep, narrow V-shaped posterior scale notch (scale 15; Fig. 270). The dorsolateral, lateral and ventrolateral trunk scales, arranged from the central to posterior trunk region (U50 to U83), become gradually larger than the anterior trunk scales (from 2.3-7.1 $\times 2.7-5.1$ to $3.5-8.8 \times 4.1-7.1 \mu \mathrm{m}$ ) and they have a more pointed anterior edge of the central lobe and longer, more sharp posterolateral lobes directed more apart and diagonally downward (scale 17; Fig. 27Q). Dorsally, on the central trunk part (at U47-U57), five different scales with very long and strong spines are located in one transverse row. These scales are very large $(6.4-13.0 \times 5.2-$ $8.3 \mu \mathrm{m})$ and very thick. They are triangular, their central lobes are short, wide and pass seamlessly into wide, posterolateral lobes directed very far apart. The posterior edges of these scales are almost straight and only very narrowly notched. Their keels start from the half length of the central lobes and are very pronounced, strongly triangular in shape (scale 18; Fig. 27R). Directly beneath the row of large scales, two pairs of smaller scales with long keels and spiny processes are located (at ca U55-U61). These scales are triangular, have longer central lobes with pointed anterior edges and narrower posterolateral lobes directed slightly more downward (scale 19; Fig. 27S). Posteriorly to these scales, at the centre of the dorsal trunk region, three scales with long keels and spiny processes are located (at U60-U68). These scales are narrower and have longer central lobes than the preceding scales. Their posterolateral
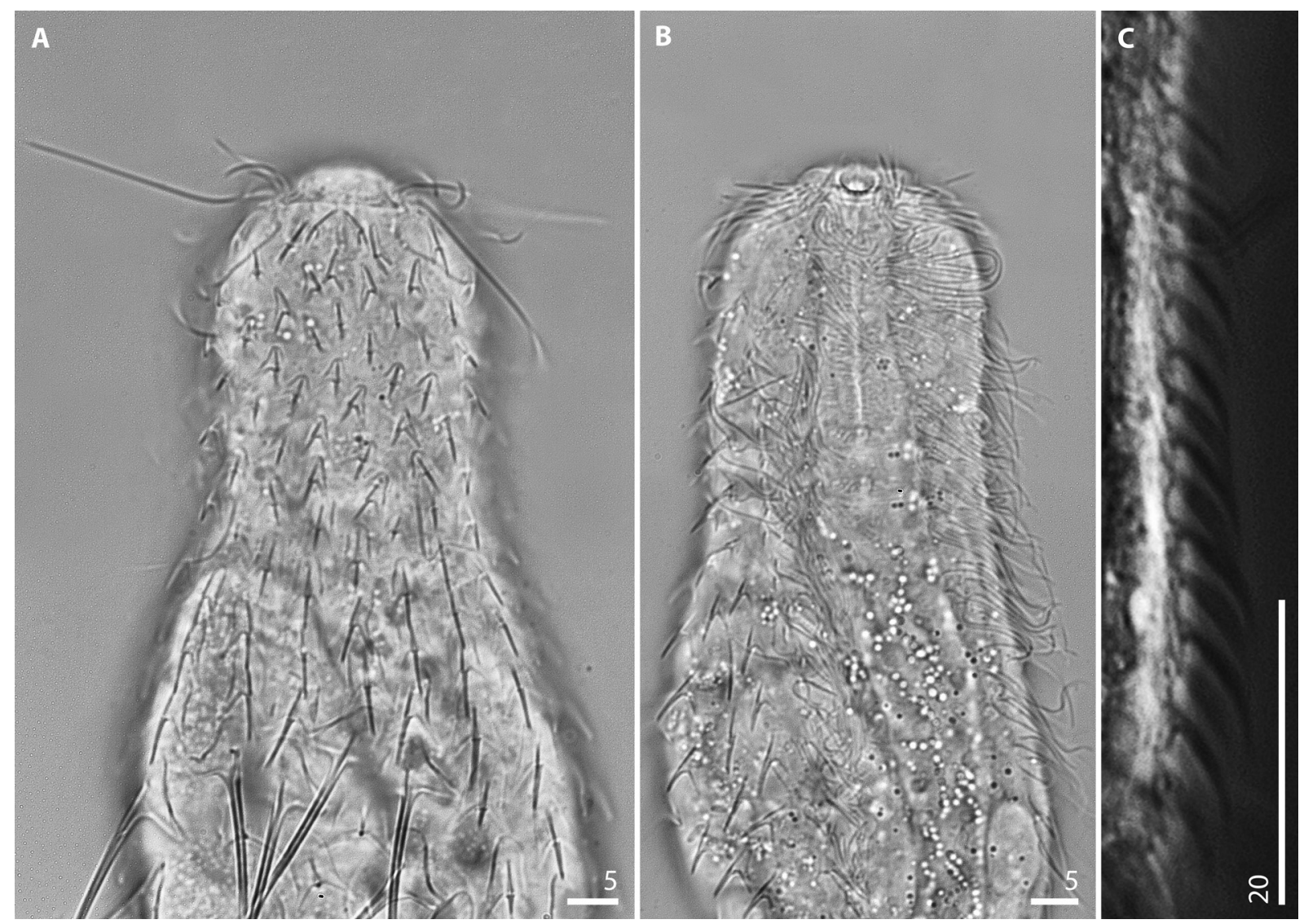

Fig. 31. Chaetonotus (Hystricochaetonotus) inaequabilis sp. nov. Adult specimen. A. Head, neck, anterior and central trunk spines, dorsal view, bright field microphotograph. B. Head, neck, anterior and central trunk spines, ventral view, bright field microphotograph. C. Ventrolateral spines with lamellae, phase contrast microphotograph. 
lobes are directed clearly downward, creating a V-shaped posterior scale notch (scale 20; Fig. 27T). Laterally to these three scales and posteriorly to the transverse row with wide, large scales, another pair of large scales with very long and strong spines is located (at U60-U66). These scales have longer central lobes, narrower posterolateral lobes directed more downward (7.3-9.2 $\times 7.2-9.5 \mu \mathrm{m})$ and more rounded edges than the preceding large scales (scale 21; Fig. 27U). In the central dorsal longitudinal row, at U67-U74, a single scale of the same type as the large scales from the transverse row at U55-U59 is present (scale 18; Fig. 27R). Laterally to it, at U70-U74, two pairs of smaller scales are located, with one pair after another in the longitudinal row. These scales have a long and strongly rounded central lobe and clearly separated, short and wide posterolateral lobes (Fig. 30B). Of these two scale pairs, the pair situated below (U72-U74) is larger than the upper pair (U70-U72) (scale 22; Fig. 27V). On the posterior trunk region laterally to these rounded scales, directed above the double-keeled scales with trunk dorsal sensory bristles, one pair of small $(3.3-4.9 \times 2.2-3.3 \mu \mathrm{m})$ scales is arranged at U74-U75 (scale 23; Fig. $27 \mathrm{~W}$ ). These scales have a strongly rounded central lobe and posterolateral lobes that are weakly separated from the central lobes, wide, short and directed downward, creating a V-shaped posterior notch. Their keels are strong but short and pass into short spines which do not extend to the posterior edge of the scales. On the lateral surface of the posterior trunk region, one pair of second to last trunk scales is located (at U71-U78). These scales are large $(7.4-11.4 \times 4.1-6.1 \mu \mathrm{m})$ and have a long, wide, strongly rounded and clearly pointed anterior central lobe. Their postero-lateral lobes are strongly separated from the central lobe and have long, narrow and sharp edges that are directed diagonally downward. These scales have strong keels and strong, long spines (scale 24; Fig. 27X). Posteriorly to them, the last pair of trunk lateral scales is situated at the furcal base (at U78-U84). This pair of scales is large $(6.4-10.8 \times 4.9-8.3 \mu \mathrm{m})$; these scales have a long, wide and strongly anteriorly rounded central

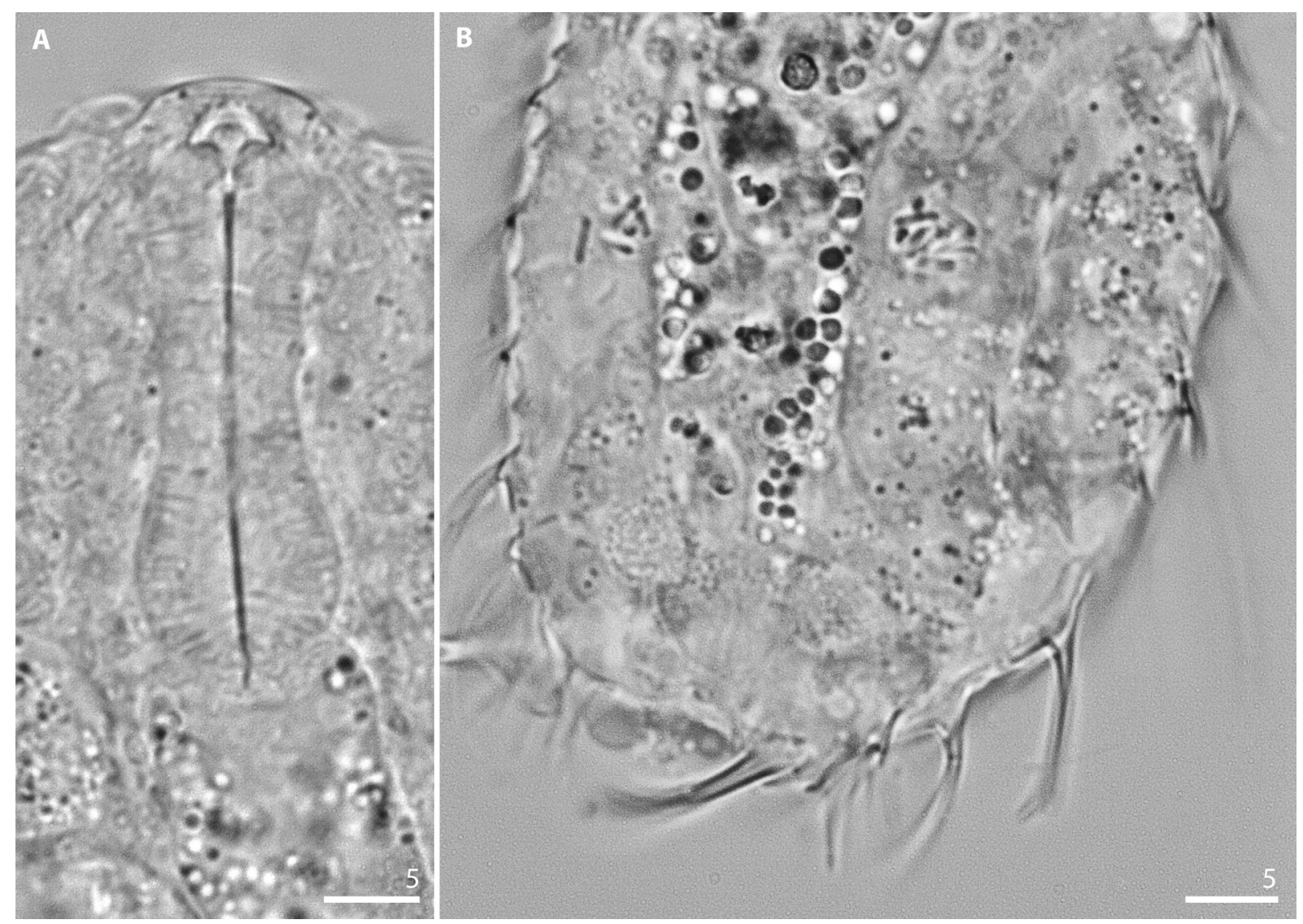

Fig. 32. Chaetonotus (Hystricochaetonotus) inaequabilis sp. nov. Adult specimen. Bright field microphotographs. A. Detail of pharynx. B. X-organ and sperm pockets. 
lobe with a very strong and high keel and strong, long spines and short, narrow posterolateral lobes. The posterolateral lobes of these scales are directed diagonally wide apart, downward and laterally, creating a wide and shallow V-shaped posterior scale notch (scale 25; Fig. 27Y). On the dorsal posterior trunk region and furcal base, at U76-U83, one median large scale that is different in type is located. This scale is triangular, has a long and pointed central lobe with a long keel and a long, strong spine, and clearly separate, relatively short postero-lateral lobes directed diagonally downwards (scale 26; Fig. 27Z). On the dorsal surface of the furcal appendages (at U84-U89), three pairs of three-lobed, elongated and narrow scales with long central and short posterolateral lobes are present. These scales have a long keel with a spiny process (scale 27; Fig. 27AA). Dorsolaterally and laterally to the furcal appendages (at U88-U90), one pair of scales with two long and slightly bent keels is present. These scales are oval in shape and have very shallow posterior notches (scale 28; Fig. 27BB). The edges of the scales on the furcal appendage are slightly overlapping (Fig. 30B). The size of the scales gradually decreases from the dorsal, dorsolateral and lateral surfaces towards the ventrolateral surface. The scales in the ventral longitudinal row located closest to the ciliary bands are short and wide, their central lobes are short and their posterolateral lobes are weakly separated. From the head to the widest body region the length of the posterolateral lobes of these scales, as well as their separation from the central lobes, gradually increase. The notches of the posterior edges of these scales are semicircular in shape. The ventral scales are much smaller than the scales of the other rows and their anterior edge is oriented towards the bands at an angle of ca $20^{\circ}$.

SPINES. In this species, five main types of spines may be distinguished (Fig. 28). The first type are basally bent spines tapering towards the end, without any lateral denticle (Fig. 28A). These spines emerge from single, central anteriormost head scales located at U5-U6 (Figs 27A, 31A) and from two pairs of dorsal posterior trunk region scales located at U70-U74 (scale 12) (Fig. 27A). The second type are simple spines that do not taper towards the blunt ends and are without any lateral denticle (Fig. 28B). These spines emerge from the dorsal, dorsolateral, most of the lateral and ventrolateral head, neck and anterior trunk region scales and dorsolaterally, laterally and ventrolaterally on the remaining trunk part scales. The length and thickness of the spines gradually increase from the head top towards the widest body region (from 0.3-12.0 to 3.1-15.2 $\mu \mathrm{m}$ ) (ca U57). Moreover, their length gradually decreases towards the ventrolateral surface (head: from $0.5-3.1$ to $0.3-2.4 \mu \mathrm{m}$; neck: from 2.1-5.7 to 1.6-4.4 $\mu \mathrm{m}$; trunk: from 3.9-8.2 to 3.1-7.1 $\mu \mathrm{m}$ ) (Table A5). The third type are very long (11.4-21.6 $\mu \mathrm{m})$ and thick, straight spines with a prominent lateral denticle (Fig. 28C). Together, nine dorsal spines and four (two pairs) lateral spines of this type are present. Five of them arise from large dorsal trunk scales located in one transverse row at U47-U57 (scale 18) (Figs 29A, 31A-B). The next two spines arise from one pair of dorsal trunk scales located at U60-66 (scale 21) (Figs 29A, 31A-B). The eighth of these long spines arises from the central dorsal scale located at U67-U74 (scale 18) (Figs 29A, 31A-B). This spine is the longest $(11.4-21.6 \mu \mathrm{m})$ and the thickest body spine and it has the most prominent lateral denticle. The ninth and last of these long dorsal spines arises from the central dorsal scale located at the posterior trunk region and on the furcal base (at U84-U89) (scale 26) (Fig. 31A-B). This spine is slightly shorter than the preceding long spine (11.4-14.2 $\mu \mathrm{m}$ ). The two pairs of long lateral spines arise from the trunk second to posteriormost pair of lateral scales (at U71-U78) (scale 24) and from the trunk posteriormost pair of lateral scales (at U78-U84) (scale 25; Figs 28D, 31A-B). The posteriormost pair is longer (11.4$14.0 \mu \mathrm{m})$ and thicker than the second to posteriormost pair of lateral spines $(10.1-12.7 \mu \mathrm{m}$ long). The fourth type are short, simple spines (Fig. 28E) or spiny processes without any lateral denticle (Fig. 28F). These spines arise from the central dorsal trunk scales located at U55-U59 and U60-U68 (Fig. 31A), from one pair of trunk dorsal scales located at U74-U75, above the double-keeled scales with the dorsal sensory bristle, and from three pairs of elongated scales located on the dorsal and dorsolateral surface of the furcal appendages at U84-U89 (Fig. 31A). The fifth type are long (7.3-15.2 $\mu \mathrm{m}$ ), thin and hair-like, with narrow, delicate lamellae along their entire length (Fig. 28G). These spines arise on the ventral 
surface, from scales arranged in one pair of a longitudinal row located closest to the ciliary bands. The lamellae on these spines are widest near the spine base and gradually taper towards the end of the spine (Fig. 31C).

DorSAL SENSORY BRISTLES. This species has three pairs of dorsal sensory bristles (Fig. 26A). The first, anterior pair is located on the dorsal surface of the head at U5, beyond the dorsolateral cephalion edges, where the second pair of sensory bristles is located on the dorsal surface of the posterior neck at U31. The first and the second pairs emerge from small, spherical papillae. The third, posterior pair of sensory bristles is located dorsolaterally on the posterior trunk region and furcal base and emerges from the small three-lobed scales with two strong keels situated at U77-U79. These scales have keels which are connected in the centre of the scales and have a strongly rounded, wide central lobe and short, weakly separated posterolateral lobes. These scales have a double, shallow posterior notch (Fig. 31A).

VENTRAL CILIARY BANDS AND VENTRAL INTERCILIARY FIELD. On the ventral surface, the longitudinal ciliary bands begin at U9 and run back to U82 (Fig. 29C). The ciliary bands are wide, and wider on the head region than on other parts of the body. The entire ventral interciliary field is covered with thin, small scales. They are distributed in seven longitudinal rows, with 21-25 scales in the central row (Figs 30C, 31B). The ventral interciliary field anterior scales are partially recessed on the cuticle and isolation from the cuticle increases towards the posterior body part. On the anterior region the scales have an oval shape with a straight posterior edge and are located far from each other (scale 29; Fig. 27CC). Towards the posterior body region the scales become gradually larger (from $1.4-1.9 \times 0.6-1.1$ to $3.8-5.2 \times 2.7-$ $4.1 \mu \mathrm{m}$ ), more elongated and with a rounded posterior edge (scale 30; Fig. 27DD). The anterior scales are keelless and spineless, but towards the trunk posterior region the keels on the scales become more distinct and the distance between the scales decreases (Figs 26C). Four pairs of ventral interciliary field terminal scales are present. The first pair (at U76-U85) is elongated and has a narrowing halfway along the length of the scale (Fig. 30C). They have a long, narrow keel and a long, thin and straight spine extending beyond the internal furcal indentation (scale 31; Fig. 27EE). The second pair (at U84-U87) is elongated, has a pointed anterior edge and gradually tapers to the posterior end. This pair has long, narrow keels and is spineless (scale 32; Fig. 27FF). The third (at U87-U88) and fourth (at U88-U89) pairs are small, elongated and oval-shaped, with a shallow posterior notch (scale 33; Fig. 27GG). They have a long, straight keel and are spineless. The second, third and fourth pairs of ventral interciliary field terminal scales are situated at the furcal appendages.

INTERNAL MORPHOLOGY. The pharynx (from U3 to U29) is wide and has distinct, marked, rounded anterior and posterior dilatations. The posterior dilatation is wider than the anterior one (Fig. 32A). The pharynx is connected through the pharyngeal-intestinal junction to a straight intestine, running from U29 to U84. The pharyngeal-intestinal junction is clearly demarcated, short and narrow (U29-U30). The X-organ of this species (observed in one specimen) is located at U80-U83 near the terminal part of the intestine. It is bilobed, built from two extensions enveloped in a thin coat and connected by a thinner band located behind the intestine at the ventral side. The extensions, the thin coat and the cellular bridge connecting the extensions have have a grain-like structure. The pair of sperm packets of this species are circular in shape and contain spermatozoids (12 per packet) in the form of a short rod. They are located at U62-U64 on both sides, juxtaposed to the intestine (Fig. 32B).

\section{Remarks}

Juvenile specimens of Chaetonotus (Hystricochaetonotus) inaequabilis sp. nov. were not observed; furthermore, specimens with large, developing eggs were not present. Out of seven adults, one had an $\mathrm{X}$-organ and two had sperm packets. 


\section{Differential diagnosis}

Within the subgenus Hystricochaetonotus, Chaetonotus (H.) inaequabilis sp. nov. most closely resembles C. (H.) enormis Stokes, 1887, C. (H.) schlitzensis Schwank, 1990, C. (H.) octonarius Stokes, 1887, C. (H.) novenarius Greuter, 1917, C. (H.) aemilianus Balsamo, 1978, C. (H.) ferrarius Schwank, 1990, C. (H.) spinulosus Stokes, 1887 and C. (H.) longispinosus Stokes, 1887. All of these species were chosen for comparison because they possess a set of similar features such as: range of body length; body shape; presence of very long spines on dorsal and/or dorsolateral trunk surfaces; presence of lateral denticle only on the long spines (for $C$. (H.) ferrarius see Table A6); and absence of parafurcal spines. Moreover, $C$. $(H$.) enormis is similar to the new species in having two pairs of furcal base lateral spines which are longer and stronger than the remaining lateral spines. Chaetonotus $(H$.) schlitzensis, C. (H.) octonarius, C. (H.) novenarius, C. (H.) aemilianus, C. (H.) ferrarius and C. (H.) spinulosus share with $C$. $(H$.) inaequabilis sp. nov. the presence of scales without spines or with spiny processes on the central dorsal trunk region. Chaetonotus $(H$.) novenarius and $C$. (H.) aemilianus also possess the same number of scales with long spines as the newly described species. Despite the fact that among the hitherto known species in this subgenus, those listed above have the highest number of common features with the newly described species, they are significantly different from $C$. (H.) inaequabilis sp. nov. - most strikingly by size, type, and shape of the scale coverage as well as the arrangement of scales with long spines. In order to avoid any doubts in comparisons with the new species, only the original descriptions of these species and three of the most detailed papers with morphological data were used (Balsamo 1983; Schwank 1990; Kisielewski 1997a). Comparisons between the new species and the morphologically most similar taxa are summarised in Table A6.

\section{Subgenus Zonochaeta Remane, 1927}

\section{Type species}

Chaetonotus succinctus Voigt, 1902.

\section{Terra typica}

Germany.

\section{Remarks on subgenus}

This is the only subgenus of Chaetonotus that seems to be monophyletic in terms of molecular data (Kånneby et al. 2013); it encompasses 13 nominal freshwater species (Todaro 2018). It is present in benthic and periphytic habitats (e.g., Kisielewski 1997a).

Chaetonotus (Zonochaeta) cestacanthus Balsamo, 1990

Figs 33-34; Table 6

Chaetonotus (Zonochaeta) cestacanthus Balsamo, 1990: 168, fig. 4.

\section{Locus typicus}

Italy.

\section{Material examined}

POLAND • 3 adults, 1 juvenile; Kraków, Botanical Garden, Jubilee Greenhouse, sites 1-2; 5003'38' N, 1957'30" E; 15 Nov. 2013 and 17 Apr. 2014; M. Kolicka leg.; NHC-GCZC-24-1-10 (photomicrographs, also in the author's collection). 


\section{Distribution}

Chaetonotus (Z.) cestacanthus Balsamo, 1990 was originally described from Italian lakes, namely Lake Chiusi and Lake Bolsena (Balsamo 1990), and next recorded from the volcanic Lake Nemi, also in Italy (Balsamo \& Fregni 1995). It has not previously been listed outside of this country.
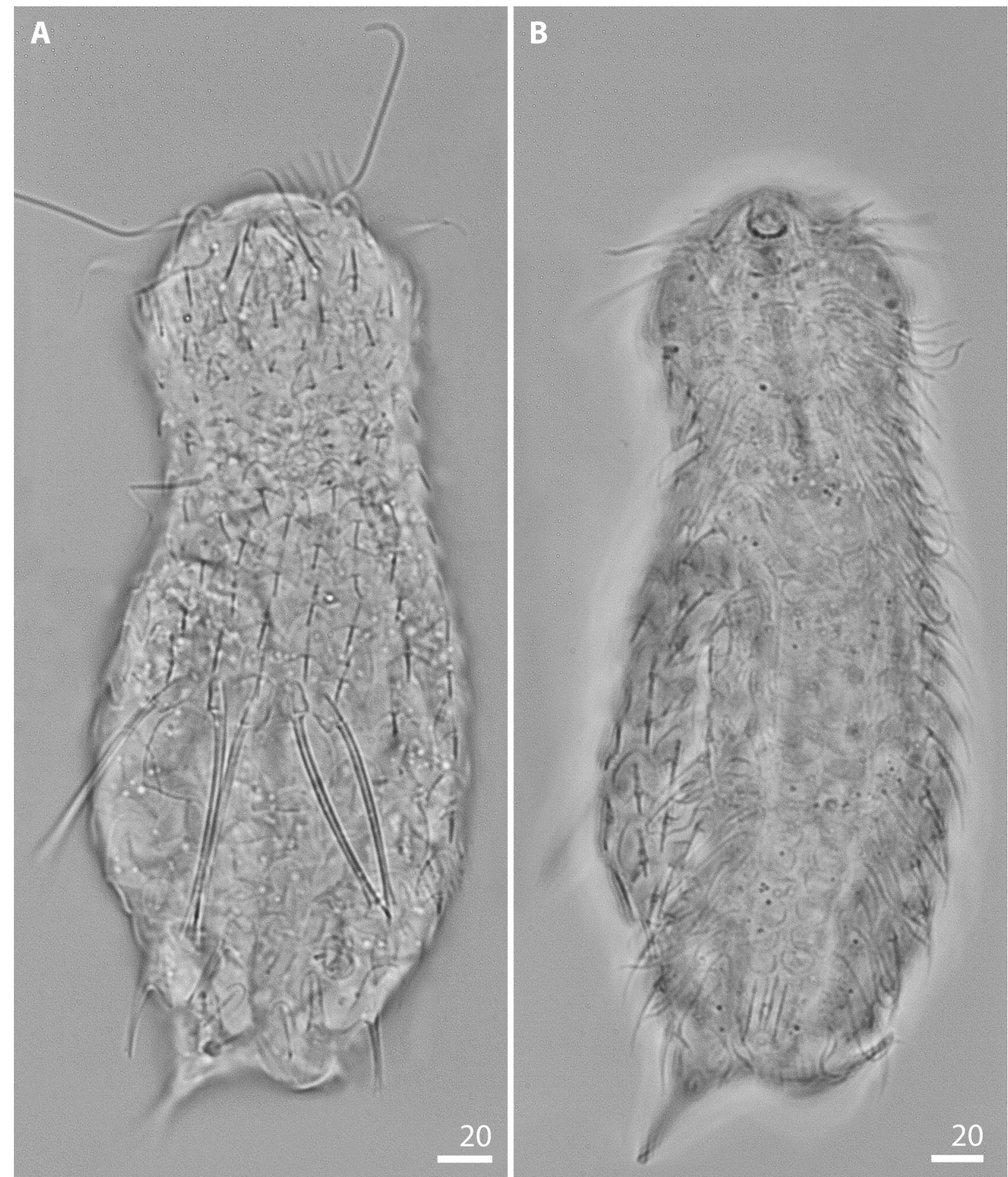

Fig. 33. Chaetonotus (Zonochaeta) cestacanthus Balsamo, 1990. Adult specimen. Bright field microphotographs. A. Scales and spines, dorsal view.

B. Scales and spines, ventral view. 

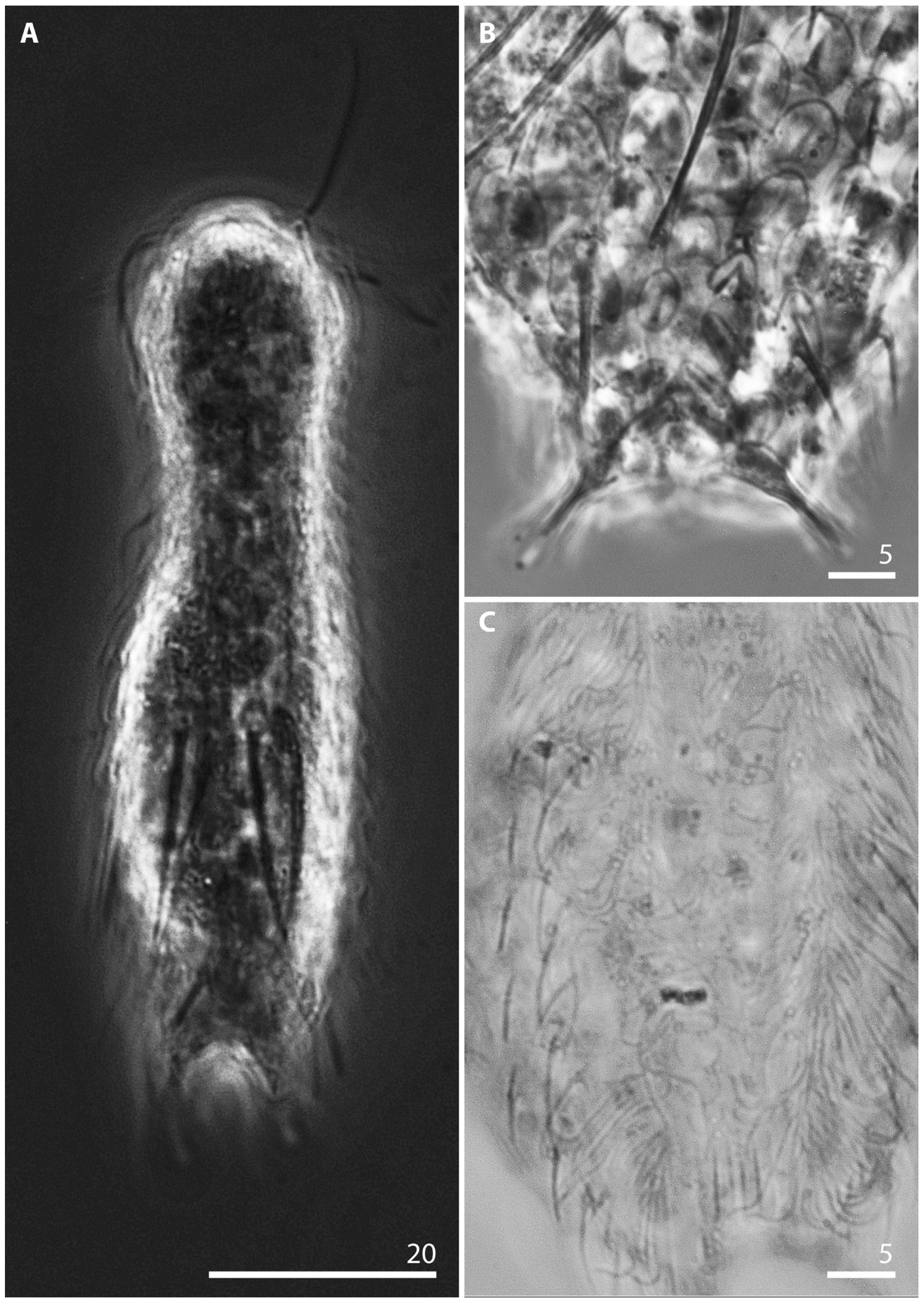

Fig. 34. Chaetonotus (Zonochaeta) cestacanthus Balsamo, 1990. Adult specimen. A. Habitus, phase contrast microphotograph. B. Posterior trunk region, furca base and furcal appendages, dorsal view, phase contrast microphotograph. C. Posterior trunk region, furca base and furcal appendages, dorsal view, bright field microphotograph. 
Table 6 (continued on next page). Main morphometric characters of Chaetonotus (Zonochaeta) cestacanthus Balsamo, 1990. $\mathrm{N}=$ number of specimens analysed; $\mathrm{NA}=$ data not available; Range = the smallest and the largest structure found among all specimens measured. All measurements in micrometers $(\mu \mathrm{m})$.

\begin{tabular}{|c|c|c|c|c|}
\hline Characters & $\begin{array}{l}\text { According to } \\
\text { Balsamo (1990) }\end{array}$ & $\mathbf{N}$ & Range of adult specimens & Juvenile specimen \\
\hline Body length & $64.50-80.00$ & 3 & $87.19-89.11$ & 70.12 \\
\hline Furca length & $8.50-11.00$ & 3 & $14.91-15.77$ & 15.05 \\
\hline Adhesive tube length & NA & 3 & $7.50-8.13$ & 8.06 \\
\hline $\begin{array}{c}\text { Number of scales in central } \\
\text { longitudinal row }\end{array}$ & $13-14$ & 3 & 14 & 13 \\
\hline $\begin{array}{l}\text { Total number of longitudinal } \\
\text { alternating rows of scales }\end{array}$ & 15 & 3 & 15 & 13 \\
\hline Length of cephalic cilia (anterior tuft) & $\begin{array}{l}(8.50-10.50)- \\
(18.50-20.0)\end{array}$ & 3 & $(7.85-8.11)-(20.89-22.46)$ & $7.34-18.16$ \\
\hline $\begin{array}{l}\text { Length of cephalic cilia } \\
\text { (posterior tuft) }\end{array}$ & $8.50-10.50$ & 3 & $(8.24-9.55)-(11.73-16.54)$ & $8.15-11.37$ \\
\hline Head scales length $\times$ width & $3.50-4.20 \times 2.50-3.20$ & 3 & $\begin{array}{c}(2.98-3.19)-(4.67-5.02) \times \\
(2.18-2.34)-(3.63-3.83)\end{array}$ & $2.89-4.22 \times 2.09-3.32$ \\
\hline Neck scales length $\times$ width & $3.00 \times 2.80$ & 3 & $\begin{array}{c}(2.56-2.91)-(4.19-4.67) \times \\
(2.77-3.19)-(4.10-4.31)\end{array}$ & $2.34-3.83 \times 2.67-3.86$ \\
\hline Trunk scales length $\times$ width & $6.50-8.70 \times 5.30-6.50$ & 3 & $\begin{array}{c}(3.89-4.05)-(9.46-9.59) \times \\
(3.26-3.91)-(7.20-7.85)\end{array}$ & $3.68-5.94 \times 3.10-4.72$ \\
\hline $\begin{array}{l}\text { Scales with long dorsal spines } \\
\text { length } \times \text { width }\end{array}$ & $3.70-4.60 \times 3.20-3.70$ & 3 & $\begin{array}{c}(4.24-4.78)-(4.69-4.95) \times \\
(2.89-3.30)-(3.19-3.53)\end{array}$ & $4.19-4.81 \times 3.22-3.46$ \\
\hline $\begin{array}{l}\text { Median and dorsolateral scales with } \\
\text { long spines on posterior trunk region } \\
\text { length } \times \text { width }\end{array}$ & $6.00 \times 4.00-6.00$ & 3 & $\begin{array}{c}(5.68-6.70)-(5.86-7.19) \times \\
(5.22-5.88)-(5.42-6.47)\end{array}$ & $5.03-5.72 \times 4.41-4.76$ \\
\hline $\begin{array}{l}\text { Double keeled scales on furcal } \\
\text { appendages length } \times \text { width }\end{array}$ & NA & 3 & $4.36-4.93 \times 4.04-4.51$ & $3.85 \times 3.52$ \\
\hline Head dorsal spines length & $1.30-2.30$ & 3 & $(0.39-0.51)-(3.17-4.61)$ & $0.34-3.97$ \\
\hline Head ventral spines length & $2.00-7.80$ & 3 & $(3.02-3.81)-(6.14-6.54)$ & $2.84-5.79$ \\
\hline Neck dorsal spines length & $1.30-2.30$ & 3 & $(0.31-0.37)-(2.66-2.74)$ & $0.27-2.30$ \\
\hline Neck ventral spines length & $2.00-7.80$ & 3 & $(6.23-6.82)-(7.28-7.79)$ & $6.08-7.14$ \\
\hline Trunk dorsal spines length & $1.30-2.30$ & 3 & $(2.34-2.49)-(2.81-2.92)$ & $2.12-2.92$ \\
\hline Trunk ventral spines length & $2.00-7.80$ & 3 & $(7.47-8.06)-(9.16-10.12)$ & $7.36-9.69$ \\
\hline Long dorsal spines length & $13.50-17.80$ & 3 & $19.69-20.61$ & 18.28 \\
\hline $\begin{array}{l}\text { Median spine on posterior trunk } \\
\text { region length }\end{array}$ & $9.30-11.00$ & 3 & $8.20-9.66$ & 7.8 \\
\hline $\begin{array}{c}\text { Dorsolateral spines on posterior trunk } \\
\text { region length }\end{array}$ & $7.20-8.70$ & 3 & $7.18-7.69$ & 6.61 \\
\hline Head dorsal sensory bristles length & NA & 3 & $9.47-11.21$ & 10.29 \\
\hline Neck dorsal sensory bristles length & $8.70-10.20$ & 3 & $12.95-14.29$ & 12.7 \\
\hline $\begin{array}{l}\text { Posterior dorsal sensory } \\
\text { bristles length }\end{array}$ & $8.70-10.20$ & 3 & $14.23-15.62$ & 13.94 \\
\hline $\begin{array}{l}\text { Number of scales in central } \\
\text { longitudinal row on ventral } \\
\text { interciliary field }\end{array}$ & $25-26$ & 3 & $25-26$ & 23 \\
\hline $\begin{array}{l}\text { Total number of longitudinal } \\
\text { alternating rows of scales on ventral } \\
\text { interciliary field }\end{array}$ & 2 & 3 & 2 & 2 \\
\hline
\end{tabular}


Table 6 (continued). Main morphometric characters of Chaetonotus (Zonochaeta) cestacanthus Balsamo, 1990.

\begin{tabular}{ccccc}
\hline Characters & $\begin{array}{c}\text { According to } \\
\text { Balsamo (1990) }\end{array}$ & N & Range of adult specimens & Juvenile specimen \\
\hline $\begin{array}{c}\text { Ventral interciliary field scales } \\
\text { length } \times \text { width }\end{array}$ & $2.50-2.60 \times 2.80-3.00$ & 3 & $\begin{array}{c}(1.93-2.26)-(3.28-3.72) \times \\
(2.26-3.25)-(4.59-4.66)\end{array}$ & $1.72-3.16 \times 2.04-4.05$ \\
$\begin{array}{c}\text { Terminal ventral interciliary field } \\
\text { scales I pair length } \times \text { width }\end{array}$ & $7.60 \times 2.7$ & 3 & $7.25-8.04 \times 2.24-2.80$ & $6.63 \times 2.43$ \\
$\begin{array}{c}\text { Terminal ventral interciliary field } \\
\text { scales II pair length } \times \text { width }\end{array}$ & & 3 & $3.10-3.50 \times 1.43-1.89$ & $2.79 \times 1.39$ \\
Mouth ring diameter & NA & 3 & $3.79-3.95$ & 3.82 \\
Pharynx length & $20.70-27.00$ & 3 & $23.26-24.09$ & 24.28 \\
Intestine length & NA & 3 & $45.24-46.70$ & 30.51 \\
\hline
\end{tabular}

\section{Remarks}

The original description of C. (Z.) cestacanthus is very detailed (Balsamo 1990) and specimens found in the Jubilee Greenhouse in Kraków correspond well with it. However, the present specimens differ from the original data in being slightly larger (Table 6) and in having three pairs of dorsal sensory bristles instead of two (the additional pair arising on the head, near the dorsal cephalion edge); the first scales of the dorsal longitudinal rows, located near the cephalion and epipleurae, are more elongated and have longer spines than the remaining head scales in comparison to the original description and figures (Figs 33-34); the ventrolateral and ventral scales are similar to the dorsal ones (Fig. 33B), and dorsolaterally on the furcal appendages they have one pair of double-keeled scales, rounded in shape, with shallow posterior notches (Fig. 34B).

Chaetonotus (Zonochaeta) cestacanthus has previously been recorded only as an element of benthic assemblages in sandy sediments, as well as in sediments rich in detritus, at a station with rich vegetation (Balsamo 1990; Balsamo \& Fregni 1995). There have been no reports of this taxon being found in epiphytic or other periphyton communities, although their presence in samples collected near rich aquatic vegetation may suggest that $C$. (Z.) cestacanthus could also survive in this habitat type.

Genus Heterolepidoderma Remane, 1927

\section{Type species}

Ichthydium ocellatum Mečnikow, 1865 (= Heterolepidoderma ocellatum (Mečnikow, 1865)).

\section{Terra typica}

Russia.

\section{Remarks on genus}

This is regarded as a polyphyletic genus (Kieneke et al. 2008; Kånneby et al. 2013), which encompasses 22 nominal freshwater species and 10 nominal marine species. It is present in benthic, interstitial and periphytic habitats.

Heterolepidoderma aff. majus Remane, 1927

Fig. 35

Heterolepidoderma majus Remane, 1927: 313-315, fig. 10. 


\section{Locus typicus}

Germany.

\section{Material examined}

POLAND • 8 adults; Kraków, Botanical Garden, Jubilee Greenhouse, sites 1-2; 5003'38" N, 1957'30" E; 15 Nov. 2013; M. Kolicka leg.; NHC (photomicrographs, also in the author's collection).

\section{Distribution}

Nominal Heterolepidoderma majus Remane, 1927 is a species that is widely distributed in Europe, inter alia reported from: Bulgaria (Valkanov 1937), France (Kisielewski 1997a), Germany (Remane 1927), Great Britain (Martin 1990), Poland (e.g., Roszczak 1936; Kisielewska \& Kisielewski 1986a, 1986b, 1986c), Russia (Tretjakova 1989) and Romania (Rudescu 1967); it has also been reported from Argentina (Grosso \& Drahg 1984), Brazil (Kisielewski 1991), Canada (Schwank 1990) and Japan (Sudzuki 1971).
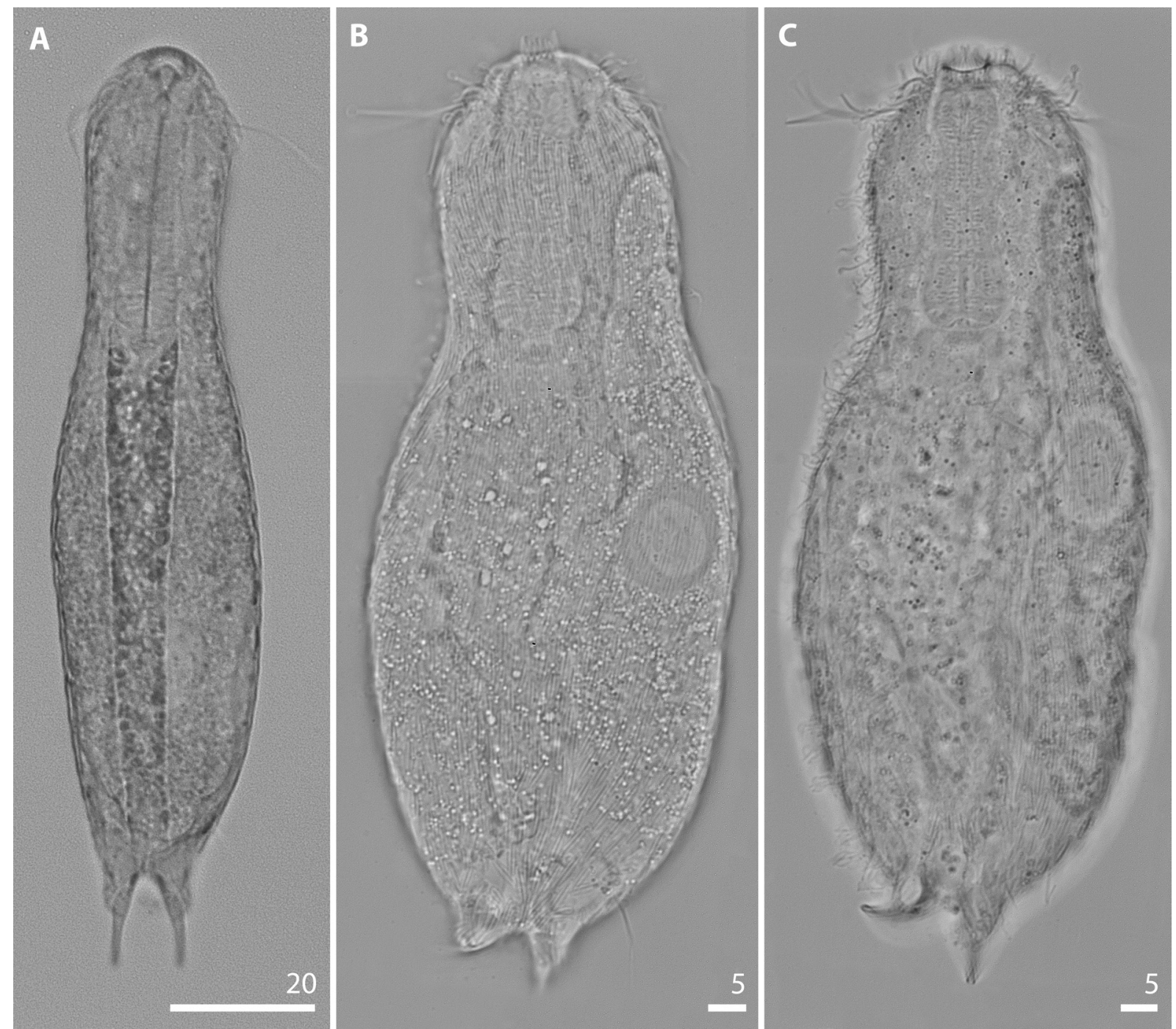

Fig. 35. Heterolepidoderma aff. majus Remane, 1927. Adult specimen. Bright field microphotographs. A. Habitus. B. Dorsal view. C. Ventral view. 


\section{Remarks}

The body length of adult specimens of Heterolepidoderma aff. majus Remane, 1927 varied from 111.1 to $131.4 \mu \mathrm{m}$; length of pharynx was between 31.9 and $40.3 \mu \mathrm{m}$; intestine length from 60.7 to $72.6 \mu \mathrm{m}$; $53-57$ total longitudinal rows of scales $(19-21 \mathrm{D}+10 \mathrm{DL}+8 \mathrm{~L}+8-10 \mathrm{LV}+8 \mathrm{~V})$, with $23-27$ scales in the central row (Fig. 35).

In a previous paper, these specimens were reported as Heterolepidoderma majus Remane, 1927 (Kisielewska et al. 2015). However, although the specimens seemed to fall within the range of variability as reported by Schwank (1990) and Kisielewski (1997a), the presence of one pair of scales with four keels, nearly parallel to one another, did not allow, after a thorough analysis, the identification of the specimens from the Jubilee Greenhouse as representatives of the nominal species H. majus. The question of the species affinities of these individuals demands further analyses and studies of intra- and interspecific variability within Heterolepidoderma.

Genus Lepidodermella Blake, 1933

\section{Type species}

Chaetonotus squamatus Dujardin, 1841 (= Lepidodermella squamata (Dujardin, 1841)).

\section{Terra typica}

France.

\section{Remarks on genus}

This polyphyletic genus (Kånneby et al. 2012, 2013) comprises 12 nominal freshwater species and one nominal marine species. It is present in benthic, interstitial and periphytic habitats.

\section{Lepidodermella aff. squamata (Dujardin, 1841)}

Fig. 36

Chaetonotus squamatus Dujardin, 1841: 664, fig. 18.

\section{Locus typicus}

France.

\section{Material examined}

POLAND • 2 adults; Kraków, Botanical Garden, Jubilee Greenhouse, site 2; 5003'38" N, 1957'30" E; 15 Nov. 2013; M. Kolicka leg.; NHC (photomicrographs, also in the author's collection).

\section{Distribution}

Lepidodermella squamata is a widely distributed species or, more precisely, in the light of the current data, it represents sets of cryptic or morphologically similar species noted in Europe, inter alia reported from Bulgaria (Valkanov 1937), Germany (Remane 1935-36), Great Britain (Martin 1981), Italy (Mola 1932), Poland (Roszczak 1936; Kisielewska \& Kisielewski 1986a, 1986b, 1986c), Romania (Rudescu 1967), Sweden (Kånneby 2011) and Switzerland (Greuter 1917); also reported from Argentina (Grosso \& Drahg 1984), Australia (Hochberg 2005), Brazil (Kisielewski 1991), Canada (Schwank 1990), East Africa (Daday 1910), India (Naidu \& Rao 2004), Israel (Kisielewski 1999), Japan (Sudzuki 1971), South Korea (Lee \& Chang 2000), the United States (Bryce 1924) and Uruguay (Cordero 1918). 


\section{Remarks}

Lepidodermella squamata (Dujardin, 1841) is one of the four earliest described gastrotrich species (Balsamo et al. 2014). This taxon is distributed worldwide and is very common in very different habitats (from freshwater and brackish psammon to micro-reservoirs in bromeliad leaves); however, in light of molecular data and on the basis of morphological evidence, it constitutes not one but at least a few morphologically very similar species, i.e., a complex of pseudocryptic or cryptic species (Fregni et al. 1998; Kånneby et al. 2012).

Both of the specimens reported here corresponded well with the original species description (Dujardin 1841) and with later records and the emended descriptions by Balsamo (1983) and Kisielewski (1984, 1997a) (Fig. 36). A detailed discussion of the shape of the scales and comparisons between the studied specimens and $L$. squamata in the literature are considerably impeded by the noticeable differences in the shape and distribution of the scales that were presented by various authors and by intraspecific variability (e.g., Rudescu 1967; Roszczak 1969; Balsamo 1983; Schwank 1990; Kisielewski 1997a), but the type and shape of the scales in the main covering remain consistent with Balsamo (1983)
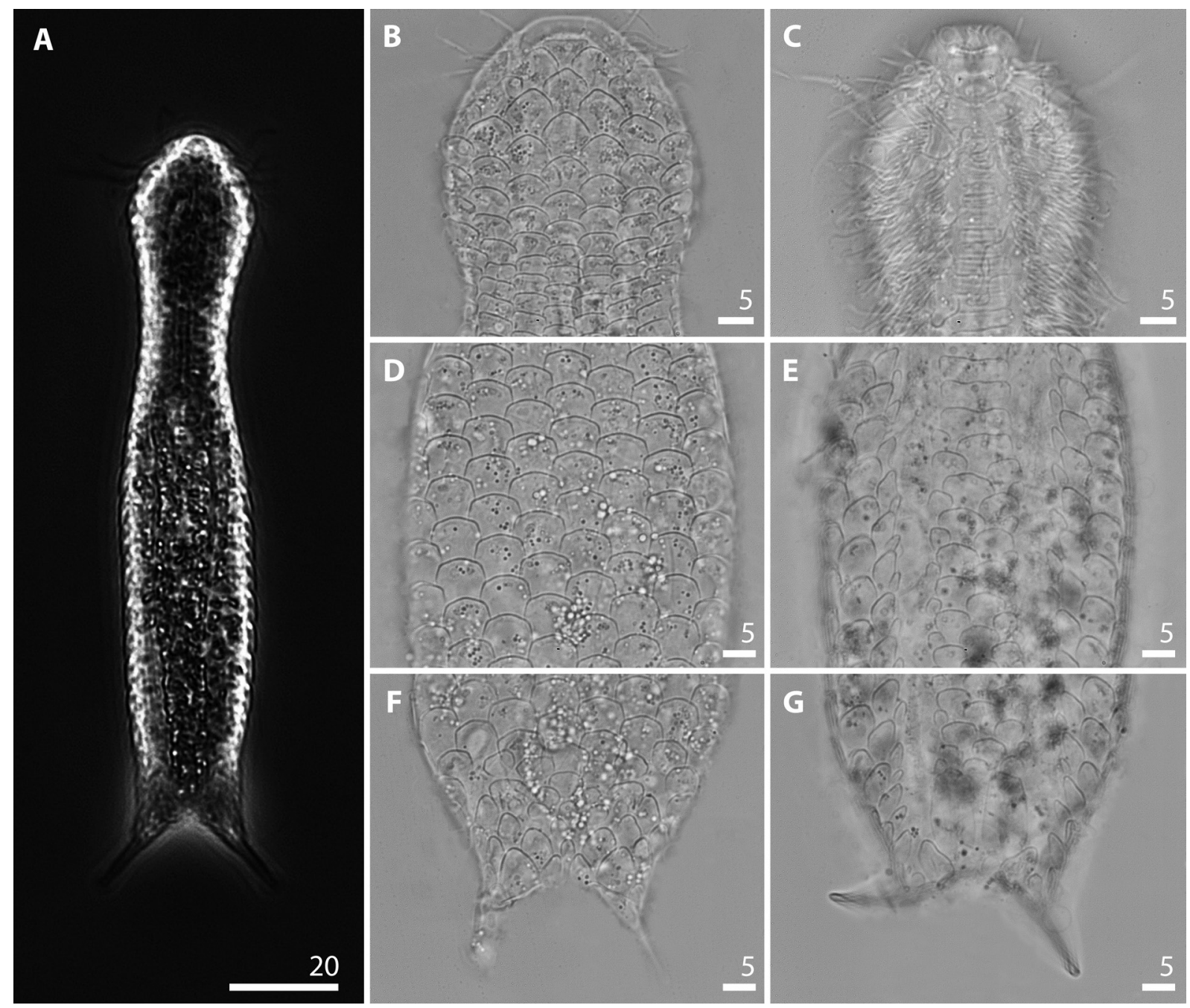

Fig. 36. Lepidodermella aff. squamata (Dujardin, 1841). Adult specimen. A. Habitus, phase contrast microphotograph. B-G. Bright field microphotographs. B. Head, dorsal view. C. Head, ventral view. D. Trunk, dorsal view. E. Trunk, ventral view. F. Posterior trunk region, furca base and furcal appendages, dorsal view. G. Posterior trunk region, furca base and furcal appendages, ventral view. 
and Kisielewski (1984, 1997a). All of the main morphometric characteristics of L. aff. squamata are within the range given in the literature (Rudescu 1967; Roszczak 1969; Balsamo 1983; Schwank 1990; Kisielewski 1984, 1997a). The body length of studied adult specimens varied from 146.2 to $153.5 \mu \mathrm{m}$; the length of the pharynx from 45.7 to $47.3 \mu \mathrm{m}$; the intestine length from 75.5 to $82.1 \mu \mathrm{m}$; there were 19 total longitudinal rows of scales $(5 \mathrm{D}+4 \mathrm{DL}+4 \mathrm{~L}+4 \mathrm{LV}+2 \mathrm{~V})$, with $29-31$ scales in the central row. The main clear differences between the studied specimens and L. squamata are the possession of one pair of scales with keels and rudimental but rigid spines on the dorsolateral area of the furcal appendages. Scales with keels or spines were listed neither in the original description nor in the main taxonomic reports on L. squamata; thus, I could not determine that the specimens undoubtedly belonged to this nominal taxon. Moreover, the present specimens possessed three pairs of dorsal sensory bristles, but this features cannot be a valid diagnostic character, since it was omitted in the original description and most previous works.

\section{Discussion}

The epiphytic species found in the Jubilee Greenhouse in Kraków increase the number of Gastrotricha known from Poland to 105 and those known from palm houses to 24 species (see Kolicka 2016). This is also the first recorded presence of gastrotrichs in aquatic plants in an artificial habitat. It is worth emphasising that these chaetonotids were found on vegetation cultivated from seeds or small seedling shoots in reservoirs that were cleaned on a yearly basis, including a partial replacement of the bottom sediment. The species composition changed between the first and second sample collections. The presence of different species could have been caused by two factors, namely the reservoir cleaning which took place between the collection of the samples and the change of plant species arrangement. Perhaps some of the gastrotrich species did not survive the seasonal cleaning and replacement of sediments, or some new taxa from the second sample collection were ones that were unintentionally imported into the Jubilee Greenhouse or were present on different plant species brought from another part of the reservoir. Observations of epiphytic gastrotrichs and species community changes may increase our knowledge of the colonisation abilities of Gastroticha because they suggest three ways of inhabitation of specific plants: 1) the gastrotrichs were brought in their resting egg stages on seeds or seedlings to the reservoir and survived the transfer to the nursery tank during the annual cleaning procedure; 2) gastrotrichs were introduced to the reservoir with the bottom sediments, they grew in abundance and subsequently they also moved to the submerged plants from the benthic communities; 3 ) the resting eggs of various gastrotrich species were brought yearly to the reservoirs in uncontrolled ways and some taxa found appropriate conditions to live in the bottom sediments while others were able to live only on aquatic vegetation.

Kisielewski (1990) suggested that submerged plants were the last freshwater habitat to be colonised by gastrotrichs after their expansion from marine waters. Possible routes of gastrotrich transfer from sediments to aquatic plants or from aquatic plants to sediments remain unconfirmed. Chaetonotids, as small benthic or epibenthic invertebrates without any free-swimming life stages, possess very limited abilities to actively move long distances. However, the active movement of Gastrotricha into vegetation rooted in a reservoir bottom does not seem to be impossible. On the other hand, transport by the water column itself seems to be a task requiring external factors in the form of water tides or larger, more actively swimming animals which could drag the gastrotrichs or their eggs from the bottom sediments to the submerged plants. The very long spines on the trunk of Chaetonotus (Hystricochaetonotus) horridus sp. nov. and $C$. (H.) inaequabilis sp. nov., as well as the very long lateral to ventral spines in C. (C.) invitatus sp. nov., may be a crucial adaptation to an epibenthic or epiphytic lifestyle. The presence of a long spine could increase the likelihood of elevation from sediments to vegetation and allow this species to stay on submerged plants by increasing the bearing surface (Kisielewski 1991). 
The presence of as many as three species that are new to science and two newly recorded species in such a relatively well-studied country as Poland may suggest the foreign origin of the newly found taxa. Although we do not know the place of origin of the new species, the newly observed Chaetonotus (Chaetonotus) paucisquamatus Kisielewski, 1991 and C. (Zonochaeta) cestacanthus Balsamo, 1990 were previously known only from their terra typica in Brazil and Italy, respectively. Both regions have a relatively high annual temperature and more stable climatic conditions than those observed in natural Polish habitats (e.g., Hijmans et al. 2005). It is possible that these species were accidentally imported to the Jubilee Greenhouse along with the subsoil (potted plants, sand, peat or, less probably, in the manure) or with the water containing fish, and they found appropriate living conditions. It cannot be excluded that the resting eggs of these species are widely spread in a temperate climate zone via natural (air currents, surface runoffs, dispersion with larger animals) or anthropogenic (long-distance transport of goods and people) means, but do not find favourable conditions for development and/or the creation of a stable population (e.g., due to long, cold winters). On the other hand, the taxa recorded in the Kraków greenhouse were not found in any previously studied palm houses (see Kolicka et al. 2013; Kolicka 2014, 2016), which may suggest that the aquatic vegetation plays a crucial, habitat-forming role for these chaetonotids. This research could confirm that urban greenhouses may be considered as biodiversity hot-spots in a strongly industrialised world and that they provide conditions for communities composed of species from different habitats and world regions.

\section{Acknowledgements}

I thank Prof. Ziemowit Olszanowski and two anonymous reviewers for their kind advice and insightful and helpful comments regarding earlier versions of the manuscript. Special thanks to Małgorzata Kuźnik and Beata Starczewska for preparing the drawings of the new species and the figures used in this paper. I also sincerely thank Mrs. Dorota Wróbel and the staff of the Botanical Garden of Jagiellonian University in Kraków for their kindness and support during collection of the samples. My studies were supported by National Science Centre grant no. 2015/17/N/NZ8/01568 titled 'Gastrotricha in palm houses as a model for research on phenotypic variability and cryptic diversity.' I was also a beneficiary of the Adam Mickiewicz Foundation scholarship scheme.

\section{References}

Balsamo M. 1983. Gastrotrichi. In: Consiglio Nazionale delle Ricerche (ed.) Guide per il Riconoscimento delle Specie animali delle Acque interne italiane 20: 1-92.

Balsamo M. 1990. Gastrotrichs from Lakes Bolsena, Chiusi and Montepulciano (central Italy), with the description of four new species. Bolletino di Zoologia 57 (2): 165-178. https://doi.org/10.1080/11250009009355693

Balsamo M. \& Fregni E. 1995. Gastrotrichs from interstitial fresh water, with a description of four new species. Hydrobiologia 302: 163-175. https://doi.org/10.1007/BF00027040

Balsamo M. \& Todaro M.A. 2002. Gastrotricha. In: Rundle S.D., Robertson A.L \& Schmid-Araya J.M. (eds) Freshwater Meiofauna: Biology and Ecology: 45-61. Backhuys Publishers, Leiden.

Balsamo M., Grilli P., Guidi L. \& d'Hondt J.-L. 2014. Gastrotricha: biology, ecology and systematics: families Dasydytidae, Dichaeturidae, Neogosseidae, Proichthydiidae. In: Dumont H.J.F. (ed.) Identification Guides to the Plankton and Benthos of Inland Waters 24. Backhuys Publishers and Margraf Publishers, Weikersheim, Germany.

Britton N.L. 1896. Botanical Gardens. Science 4 (88): 284-293.

Bryce D. 1924. The Rotifera and Gastrotricha of Devils and Stump Lakes, North Dakota, USA. Journal of the Quekett Microscopical Club 15: 81-108. 
Cordero E.H. 1918. Notes sur les Gastrotriches. Physis 4: 241-244.

Daday E.V. von. 1905. Untersuchungen über die Süsswasser-Mikrofauna Paraguays. Zoology of Bulgaria 44: 72-86.

Daday E.V. von. 1910. Die Süßwasserfauna Deutsch-Ostafrikas. Zoologica 23: 56-59.

Duggan I.C. \& Duggan K.S. 2011. Are botanical gardens a risk for zooplankton invasions? Biological Invasions 13 (12): 2997-3003. https://doi.org/10.1007/s10530-011-9984-z

Dujardin F. 1841. Histoire naturelle des Zoophytes, Infusoires. Librairie Encyclopedique de Roret, Paris.

Fregni E., Balsamo M. \& Tongiorgi P. 1998. Interstitial gastrotrichs from lotic Italian fresh waters. Hydrobiologia 368: 175-187. https://doi.org/10.1023/A:1003250217483

Greuter A. 1917. Beiträge zur Systematik der Gastrotrichen in der Schweiz. Revue suisse de Zoologie 25: 35-76. Available from https://biodiversitylibrary.org/page/10710334 [accessed 28 Jan. 2019].

Grosso L.E. \& Drahg F. 1984. Gastrotricos dulceacuicolas de la provincia de Tucuman. II. Chaetonotus majestuosus n. sp. Acta Zoologica, Lilloana 37: 227-230.

Hijmans R.J., Cameron S.E., Parra J.L., Jones P.G. \& Jarvis A. 2005. Very high resolution interpolated climate surfaces for global land areas. International Journal of Climatology 25: 1965-1978.

https://doi.org/10.1002/joc.1276

Hochberg R. 2005. First record of Polymerurus (Gastrotricha, Chaetonotida) from Australia with the description of a new species from Queensland and of cuticular ultrastructure in $P$. nodicaudus. Invertebrate Biology 124: 119-130. https://doi.org/10.1111/j.1744-7410.2005.00014.x

Hummon W.D., Balsamo M. \& Todaro M.A. 1992. Italian marine Gastrotricha: I. Six new and one redescribed species of Chaetonotida. Bollettino di Zoologia 59: 499-516.

Ignatieva M. 2010. Design and future of urban biodiversity. In: Müller N., Werner P. \& Kelcey J.G. (eds) Urban Biodiversity and Design: 118-144. Blackwell Publishing, Chichester.

International Commission on Zoological Nomenclature. 1999. International Code of Zoological Nomenclature, Fourth Edition. The International Trust for Zoological Nomenclature, The Natural History Museum, London.

Kånneby T. 2011. New species and new records of freshwater Chaetonotida (Gastrotricha) from Sweden. Zootaxa 3115: 29-55.

Kånneby T., Todaro M.A. \& Jondelius U. 2012. A phylogenetic approach to species delimitation in freshwater Gastrotricha from Sweden. Hydrobiologia 683: 185-202.

https://doi.org/10.1007/s10750-011-0956-1

Kånneby T., Todaro M.A. \& Jondelius U. 2013. Phylogeny of Chaetonotidae and other Paucitubulatina (Gastrotricha: Chaetonotida) and colonization of aquatic ecosystems. Zoologica Scripta 42: 88-105. https://doi.org/10.1111/j.1463-6409.2012.00558.x

Kieneke A. \& Schmidt-Rhaesa A. 2015. Gastrotricha. In: Schmidt-Rhaesa A. (ed.) Handbook of Zoology 3. Gastrotricha and Gnathifera: 1-134. De Gruyter, Berlin, Boston.

Kieneke A., Riemann O. \& Ahlrichs W.H. 2008. Novel implications for the basal internal relationschips of Gastrotricha revealed by an analysis of morphological characters. Zoologica Scripta 37: 429-460. https://doi.org/10.1111/j.1463-6409.2008.00334.x

Kisielewska G. \& Kisielewski J. 1986a. Freshwater Gastrotricha of Poland. II. Gastrotricha from the seaside lakes in the Słowiński National Park. Fragmenta Faunistica 30: 183-182. 
Kisielewska G. \& Kisielewski J. 1986b. Freshwater Gastrotricha of Poland. III. Gastrotricha from the Białowieża Forest and the Białowieża Glade. Fragmenta Faunistica 30: 195-215.

Kisielewska G. \& Kisielewski J. 1986c. Freshwater Gastrotricha of Poland. V. Gastrotricha of alder woods. Fragmenta Faunistica 30: 235-250.

Kisielewska G., Kolicka M. \& Zawierucha K. 2015. Prey or parasite? The first observations of live Euglenida in the intestine of Gastrotricha. European Journal of Protistology 51: 138-141.

https://doi.org/10.1016/j.ejop.2014.12.003

Kisielewski J. 1981. Gastrotricha from raised and transitional peat bogs in Poland. Monografie Fauny Polski 11: 1-143.

Kisielewski J. 1984. Three new freshwater gastrotrichs of the genus Chaetonotus Ehrenberg (Chaetonotida) from Poland. Bulletin de l'Académie polonaise des Sciences, Série des Sciences biologiques 32: 293-301.

Kisielewski J. 1986. Freshwater Gastrotricha of Poland. VII. Gastrotricha of extremely eutrophicated water bodies. Fragmenta Faunistica 30: 267-295.

Kisielewski J. 1990. Origin and phylogenetic significance of freshwater psammic Gastrotricha. Stygologia 5: 87-92.

Kisielewski J. 1991. Inland-water Gastrotricha from Brazil. Annales Zoologici 43: 1-168.

Kisielewski J. 1997a. Brzuchorzęski (Gastrotricha). Fauna Stodkowodna Polski, Zeszyt 31: 1-157.

Kisielewski J. 1997b. On the subgeneric division of the genus Chaetonotus Ehrenberg (Gastrotricha). Annales Zoologici 46: 145-151.

Kisielewski J. 1999. A preliminary study of the inland-water Gastrotricha of Israel. Israel Journal of Zoology 45: 135-157.

Kolicka M. 2014. Gastrotricha Mečnikow, 1865 from Copenhagen Palm House - contribution to the knowledge of Lepidodermella intermedia Kånneby, Todaro \& Jondelius, 2012 (Chaetonotida, Gastrotricha). Zoosystema 34 (4): 713-722. https://doi.org/10.5252/z2014n4a1

Kolicka M. 2016. Gastrotrichs in bromeliads - newly recorded Chaetonotus (Hystricochaetonotus) furcatus Kisielewski, 1991 (Chaetonotida) from the Łódź Palm House. Zoosystema 38 (1): 141-155. https://doi.org/10.5252/z2016n1a5

Kolicka M., Kisielewski J., Nesteruk T. \& Zawierucha K. 2013. Gastrotricha from the Poznań Palm House - one new subgenus and three new species of freshwater Chaetonotida (Gastrotricha). Zootaxa 3717 (2): 231-279. https://doi.org/10.11646/zootaxa.3717.2.7

Kolicka M., Dziuba M.K., Zawierucha K., Kuczyńska-Kippen N. \& Kotwicki L. 2015. Palm house biodiversity hotspot or risk of invasion? Aquatic invertebrates: The special case of Monogononta (Rotifera) under greenhouse conditions. Biologia 70 (1): 94-103. https://doi.org/10.1515/biolog-2015-0012

Kolicka M., Dabert M., Dabert J., Kånneby T. \& Kisielewski J. 2016. Bifidochaetus, a new Arctic genus of freshwater Chaetonotida (Gastrotricha) from Spitsbergen revealed by an integrative taxonomic approach. Invertebrate Systematics 30: 398-419. https://doi.org/10.1071/IS16001

Leasi F. \& Todaro M.A. 2008. The muscular system of Musellifer delamarei (Renaud-Mornant, 1968) and other chaetonotidans with implications for the phylogeny and systematization of the Paucitubulatina (Gastrotricha). Biological Journal of the Linnean Society 94: 379-398.

https://doi.org/10.1111/j.1095-8312.2008.00974.x 
Lee J.M. \& Chang C.Y. 2000. Freshwater chaetonotid gastrotrichs in Korea. The Korean Journal of Systematic Zoology 16: 87-104.

Martin L.V. 1981. Gastrotrichs found in Surrey. Microscopy 34: 286-300.

Martin L.V. 1990. Further observations on gastrotrichs in Surrey and a provisional British list. Microscopy 36: 415-425.

Mečnikow E. 1865. Über einige wenig bekannte niedere Thierformen. Zeitschrift für Wissenschaftliche Zoologie 15: 450-463. Available from https://biodiversitylibrary.org/page/45004241 [accessed 28 Jan. 2019].

Mola P. 1932. Gastrotricha delle acque dolci italiane. International Review of Hydrobiology 26 (5-6): 397-423. https://doi.org/10.1002/iroh.19320260504

Naidu K.V. \& Rao G.C. 2004. The Fauna of India and the Adjacent Countries - Gastrotricha. Zoological Survey of India, Kolkata.

Nesteruk T. 2000. Epiphytic Gastrotricha - species composition and dominance. Acta Hydrobiologica 42: 53-57.

Nesteruk T. 2004. Benthic and epiphytic fauna of Gastrotricha in littoral of mesotrophic lake in ŁęcznaWłodawa Lakeland, Poland. Fragmenta Faunistica 47 (1): 1-6.

Nesteruk T. 2010. Species structure, density and biomass of gastrotrich fauna of elodeids in two lakes of different trophy. Teka Komisji Ochrony i Kształtowania Środowiska Przyrodniczego [Teka Commission of Protection and Formation of Natural Environment] 7: 280-289.

Nesteruk T. 2011. Comparison of gastrotrich fauna on elodeids and in bottom sediments of different trophic status (the region Polesie Lubelskie, Estern Poland). Oceonological and Hydrobiological Studies 40: 13-21. https://doi.org/10.2478/s13545-011-0012-9

Rao G.C. \& Clausen C. 1970. Planodasys marginalis gen. et. sp. nov. and Planodasyidae fam. nov. (Gastrotricha Macrodasyoidea). Sarsia 42: 73-82.

Remane A. 1927. Beiträge zur Systematik der Süsswassergastrotrichen. Zoologische Jahrbücher, Abteilung für Systematik, Ökologie und Geographie der Tiere 53: 269-320.

Remane A. 1935-1936. Gastrotricha und Kinorhyncha. In: Bronn H.G. (ed.) Klassen und Ordnungen des Tierreichs, Vol. 4, Section 2, Book 1, Part 2, Issues 1-2. Akademie Verlagsgesellschaft, Leipzig.

Roszczak R. 1936. Brzuchorzęski (Gastrotricha) zbiorników wodnych okolic Poznania. Sprawy, Poznańskie Towarzystwo Przyjaciót Nauk 9: 109-111.

Roszczak R. 1969. Brzuchorzęski (Gastrotricha) środkowej Wielkopolski. Prace Komisji Biologicznej 32: $1-92$.

Rudescu L. 1967. Gastrotricha. In: Fauna Republicii Socialiste Romania, Trochelminthes 2 (3). Academia Republicii Socialiste Romania, Bucharest.

Saito I. 1937. Neue und bekannte Gastrotrichen der Umgebung von Hiroshima (Japan). Journal of Science of the Hiroshima University 5: 245-265.

Schwank P. 1990. Gastrotricha. In: Schwoerbel J. \& Zwick P. (eds) Süsswasserfauna von Mitteleuropa, 3. Gastrotricha und Nemertini. Gustav Fischer Verlag, Stuttgart, Jena, New York.

Sudzuki M. 1971. Die das Kapillarwasser des Lückensystems bewohnenden Gastrotrichen Japans II. Bulletin of the Biogeographical Society of Japan 27 (5): 37-41.

Todaro M.A. 2018. Gastrotricha. Available from http://www.marinespecies.org/aphia.php?p=taxdetailsetid=2078 [accessed 2 Aug. 2018]. 
Tretjakova E.I. 1989. K poznaniju Fauny presnovodnych Gastrotrich evropejskoj Casti SSSR. Gosudarstvennyj Komitet SSSR po Narodnomu Obrazovaniju, Redkollegija Zhurnala. Biologieeskie Nauki (typescript, 21 pp, ID: udk 595.132).

Valkanov A. 1937. Über die Gastrotrichen Bulgariens. Zoologische Jahrbücher, Abteilung für Systematik, Ökologie und Geographie der Tiere 70: 171-176.

Zawierucha K., Szymkowiak P., Dabert M. \& Harvey M.S. 2013. First record of the schizomid Stenochrus portoricensis (Schizomida: Hubbardiidae) in Poland with DNA barcode data. Turkish Journal of Zoology 37: 357-361. https://doi.org/10.3906/zoo-1210-9

Manuscript received: 5 August 2018

Manuscript accepted: 13 December 2018

Published on: 2 April 2019

Topic editor: Rudy Jocqué

Desk editor: Danny Eibye-Jacobsen

Printed versions of all papers are also deposited in the libraries of the institutes that are members of the EJT consortium: Muséum national d'Histoire naturelle, Paris, France; Meise Botanic Garden, Belgium; Royal Museum for Central Africa, Tervuren, Belgium; Royal Belgian Institute of Natural Sciences, Brussels, Belgium; Natural History Museum of Denmark, Copenhagen, Denmark; Naturalis Biodiversity Center, Leiden, the Netherlands; Museo Nacional de Ciencias Naturales-CSIC, Madrid, Spain; Real Jardín Botánico de Madrid CSIC, Spain; Zoological Research Museum Alexander Koenig, Bonn, Germany. 


\section{Appendices}

Figs A1-A2: Chaetonotus (Chaetonotus) invitatus sp. nov.

Figs A3-A6: Chaetonotus (Chaetonotus) horridus sp. nov.

Fig. A7: Chaetonotus (Chaetonotus) inaequabilis sp. nov.

Tables A1-A2: Chaetonotus (Chaetonotus) invitatus sp. nov.

Tables A3-A4: Chaetonotus (Chaetonotus) horridus sp. nov.

Tables A5-A6: Chaetonotus (Chaetonotus) inaequabilis sp. nov. 

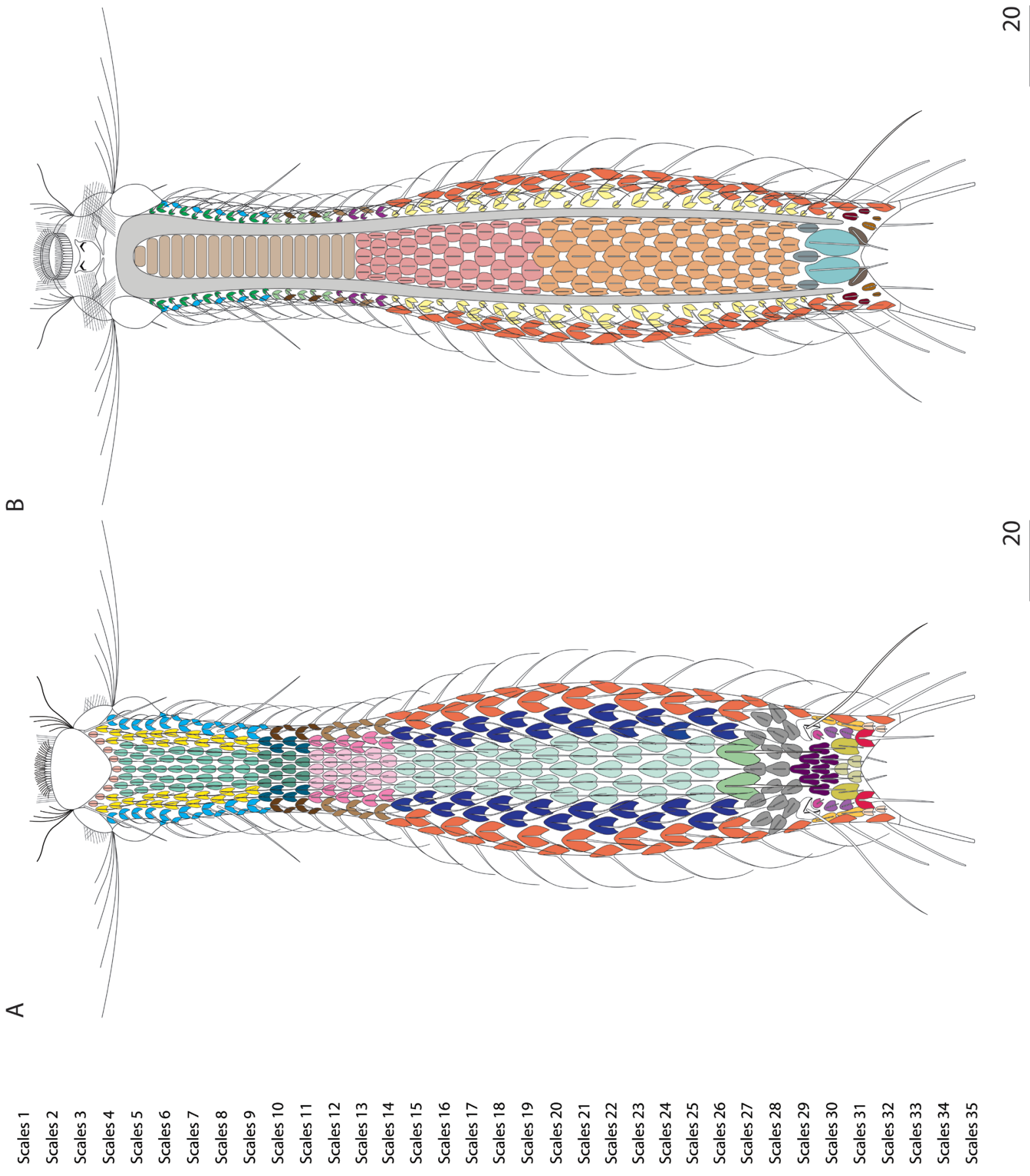

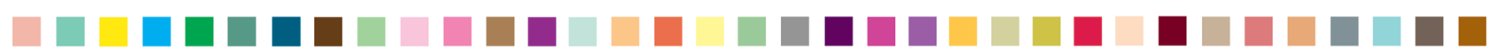

Fig. A1. Chaetonotus (Chaetonotus) invitatus sp. nov. Schematic drawings with various types of scales indicated. A. Dorsal body view. B.Ventral body view. Light grey areas indicate the areas of insertion of ciliary bands. 

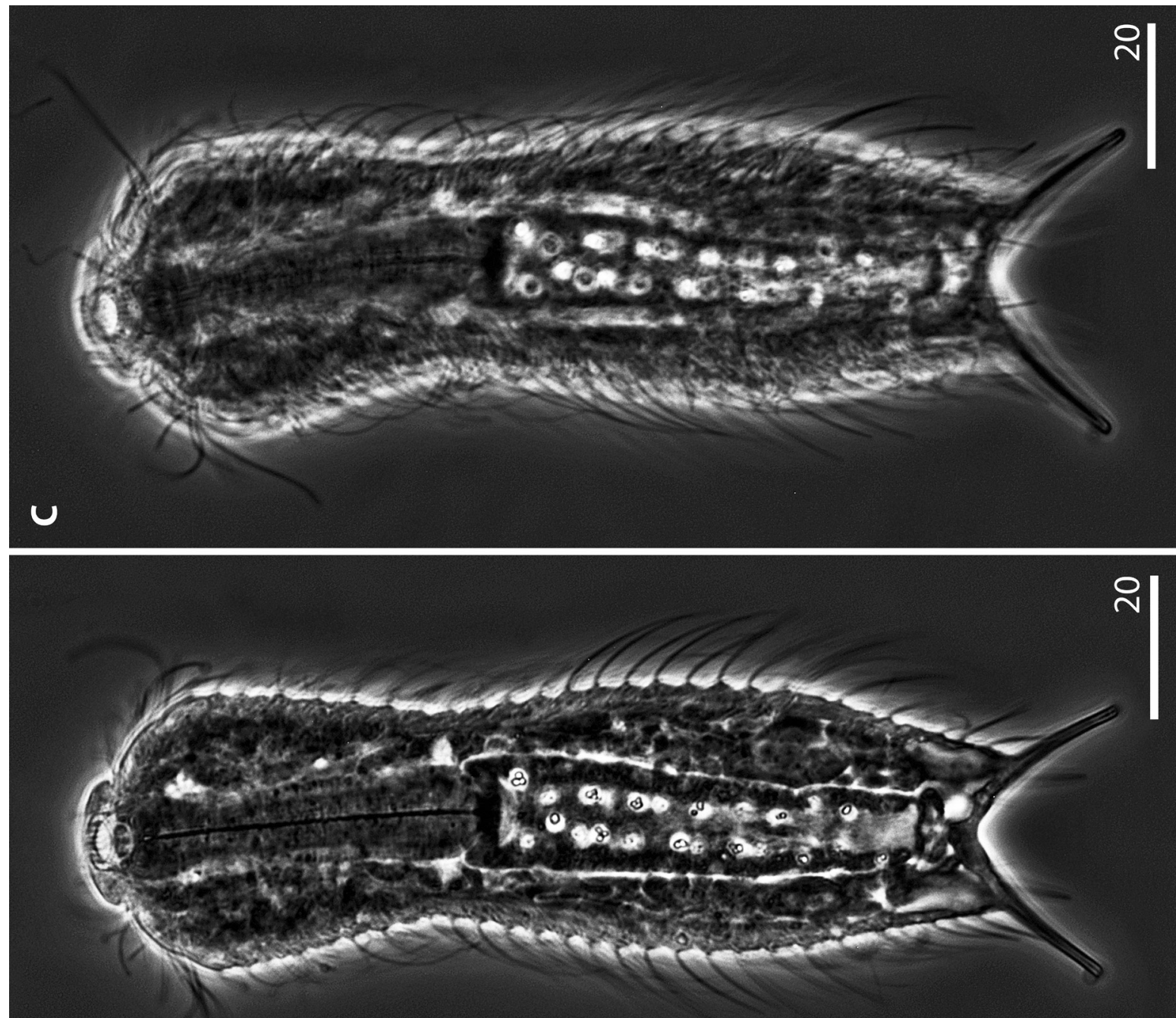

?

$\infty$

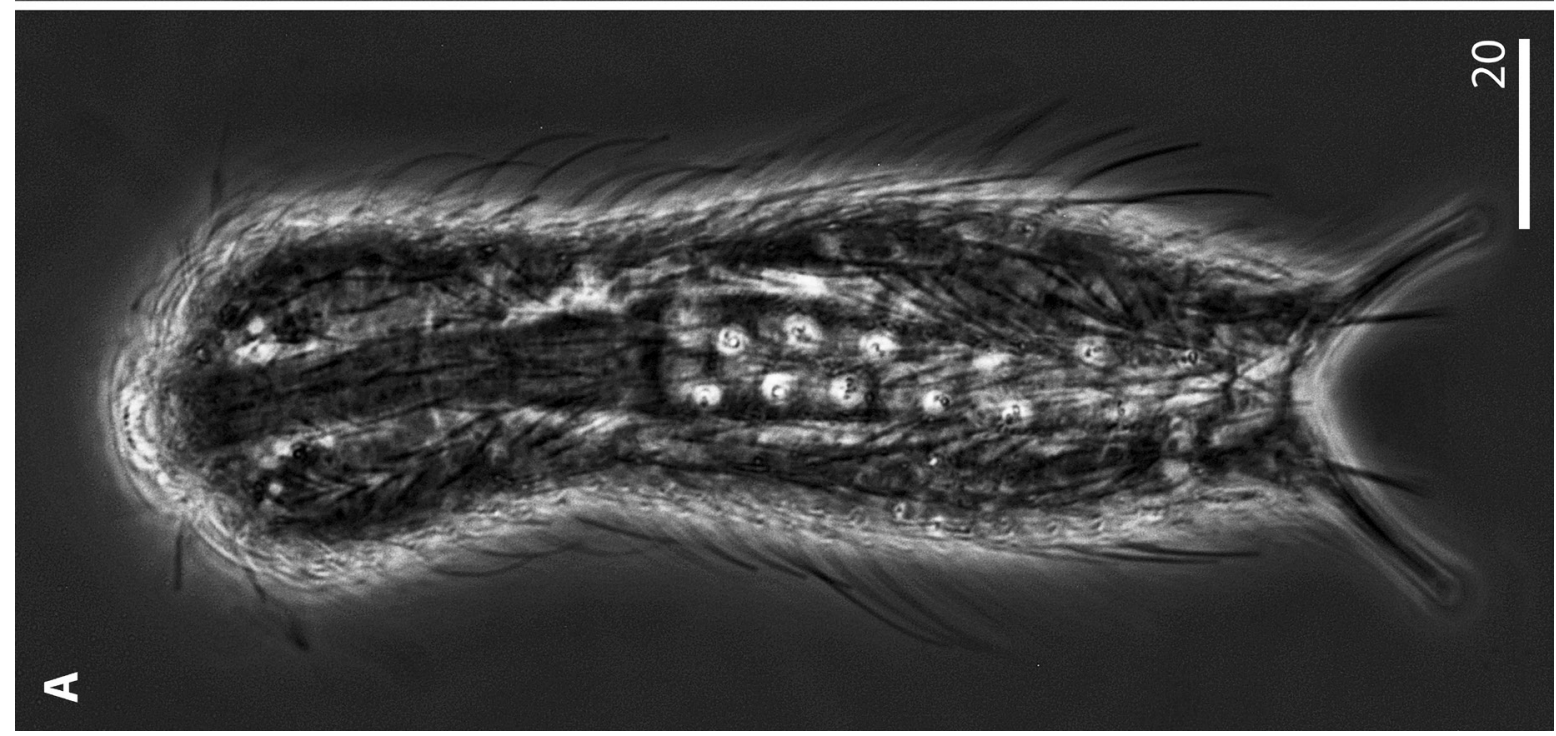

Fig. A2. Chaetonotus (Chaetonotus) invitatus sp. nov. Juvenile specimen. Phase contrast microphotographs. A. Dorsal body view. B. View of internal morphology. C. Ventral body view. 

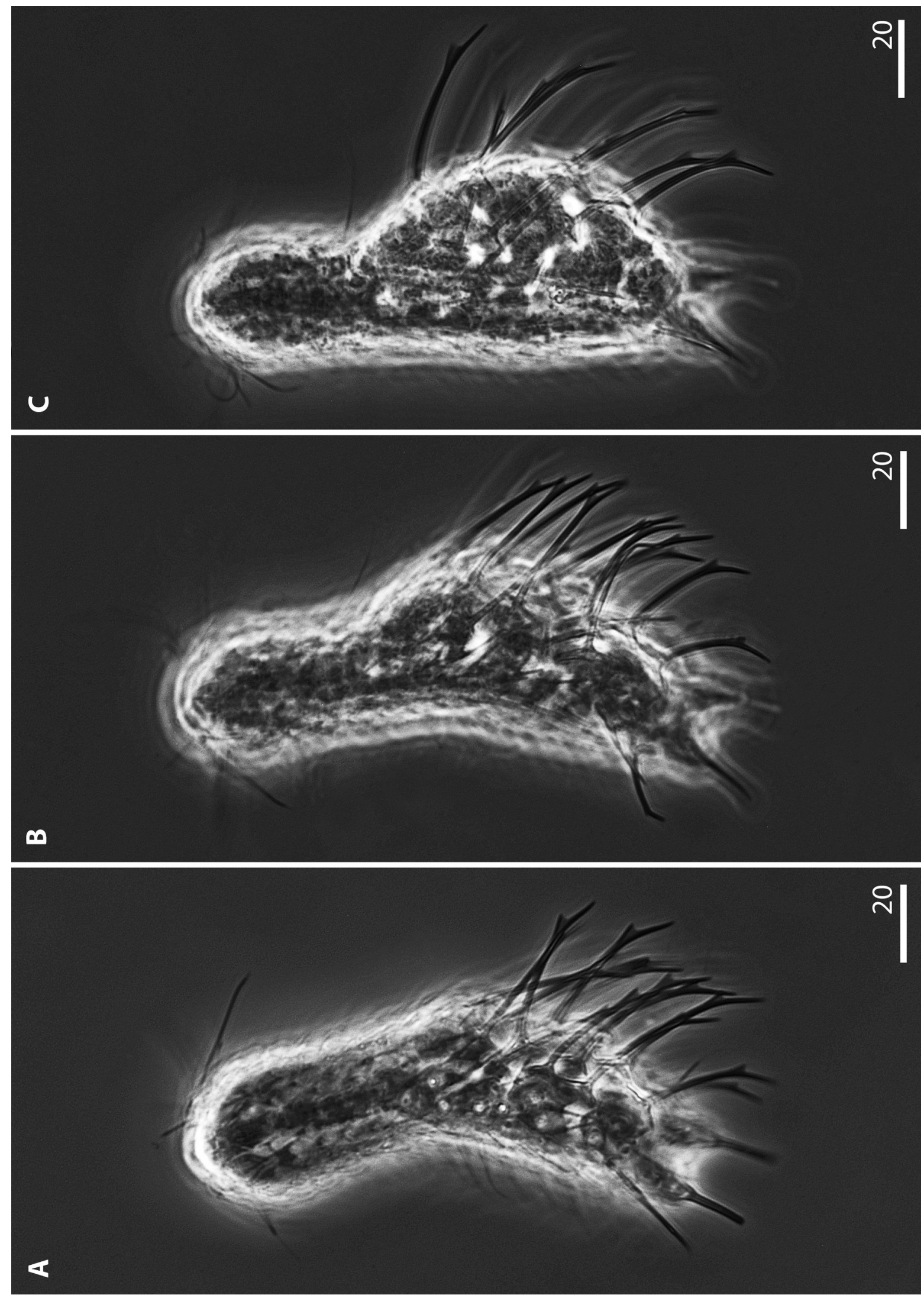

Fig. A3. Chaetonotus (Hystricochaetonotus) horridus sp. nov. Habitus. Phase contrast microphotographs. A. Juvenile specimen. B. Adult specimen. C. Specimen with mature egg. 

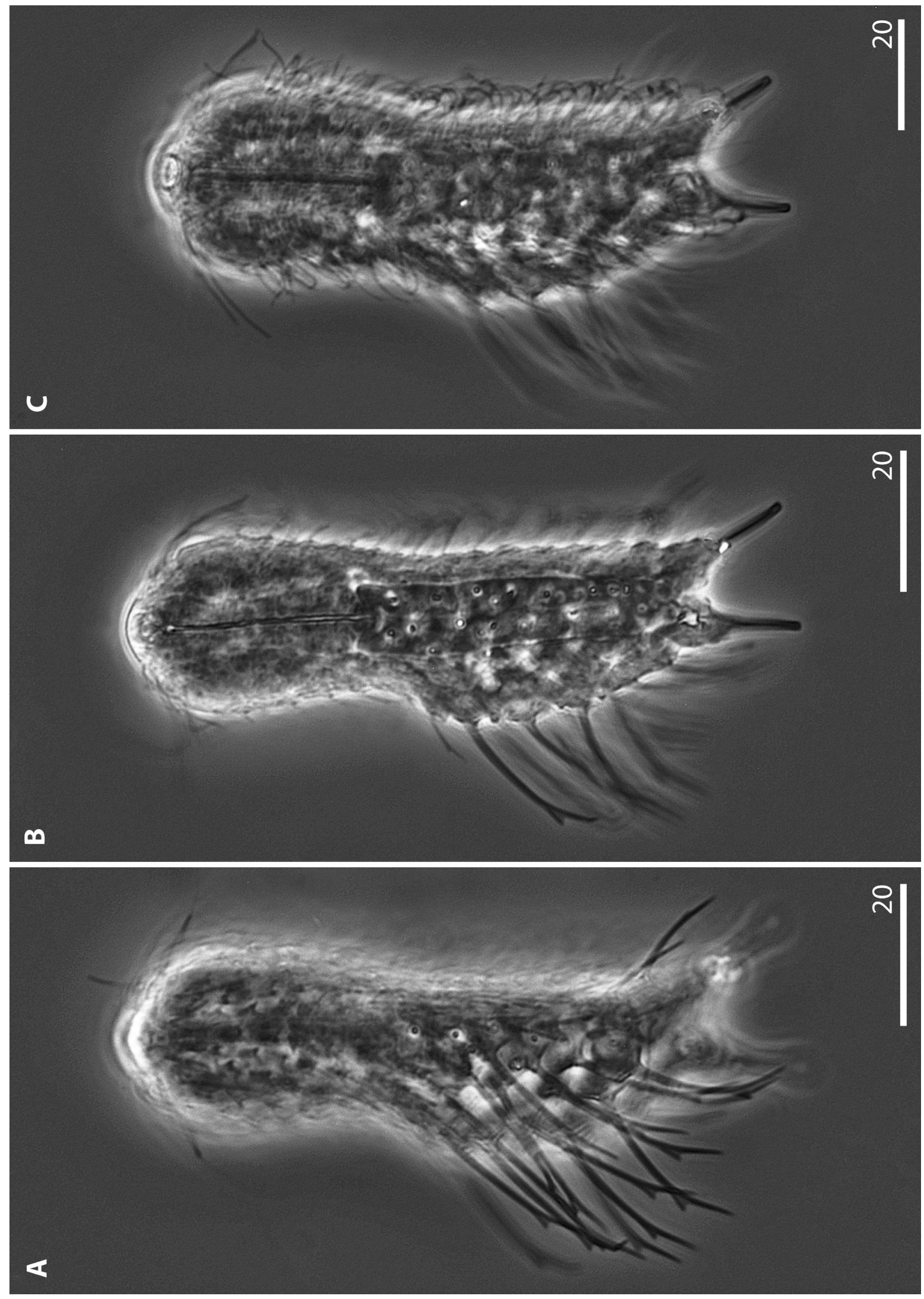

Fig. A4. Chaetonotus (Hystricochaetonotus) horridus sp. nov. Juvenile specimen. Phase contrast microphotographs. A. Dorsal body view. B. View of internal morphology. C. Ventral body view. 

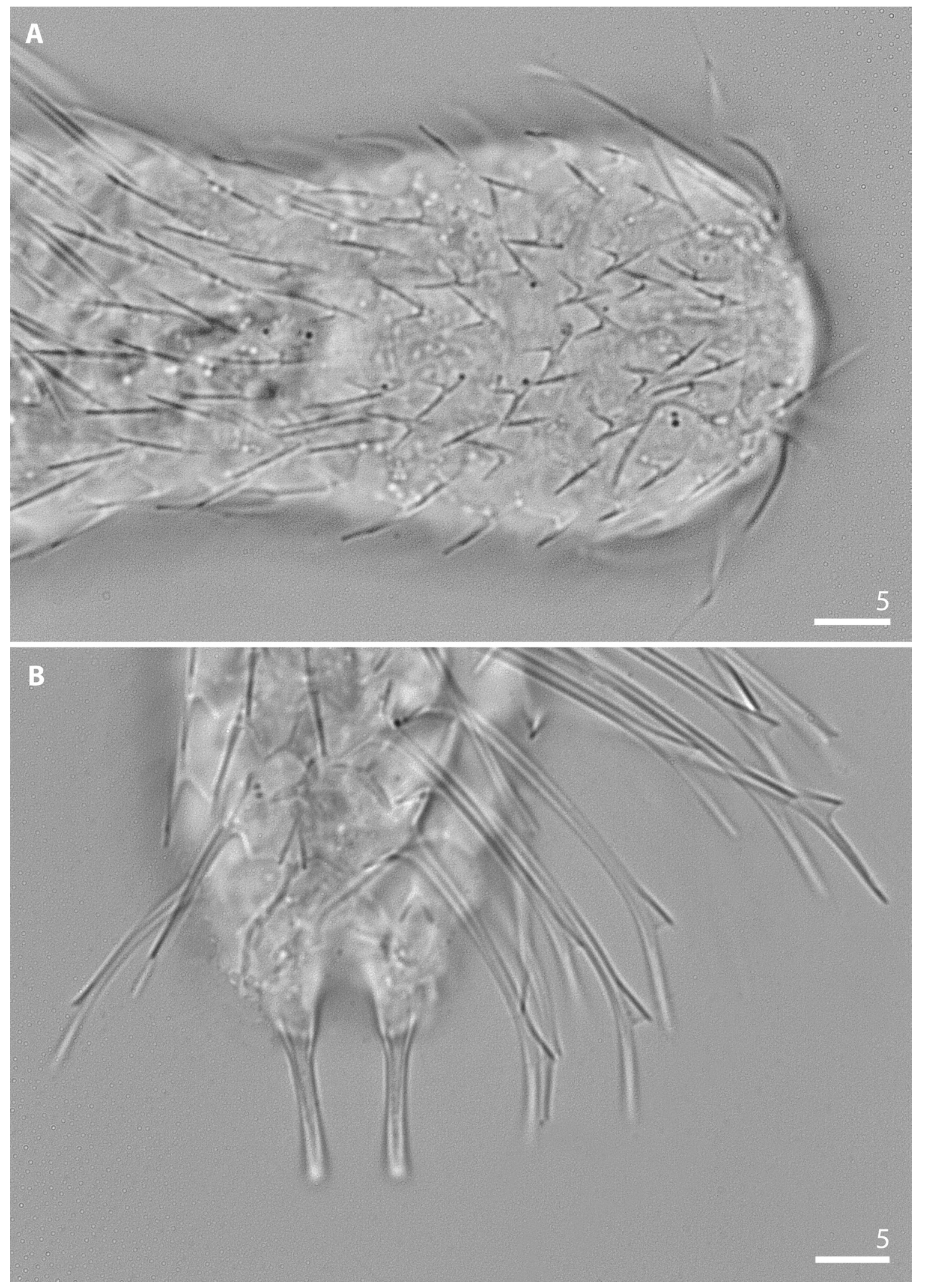

Fig. A5. Chaetonotus (Hystricochaetonotus) horridus sp. nov. Juvenile specimen. Bright field microphotographs. A. Head, neck and anterior trunk scales, dorsal view. B. Posterior trunk, furca base and furcal appendage scales and spines, dorsal view. 


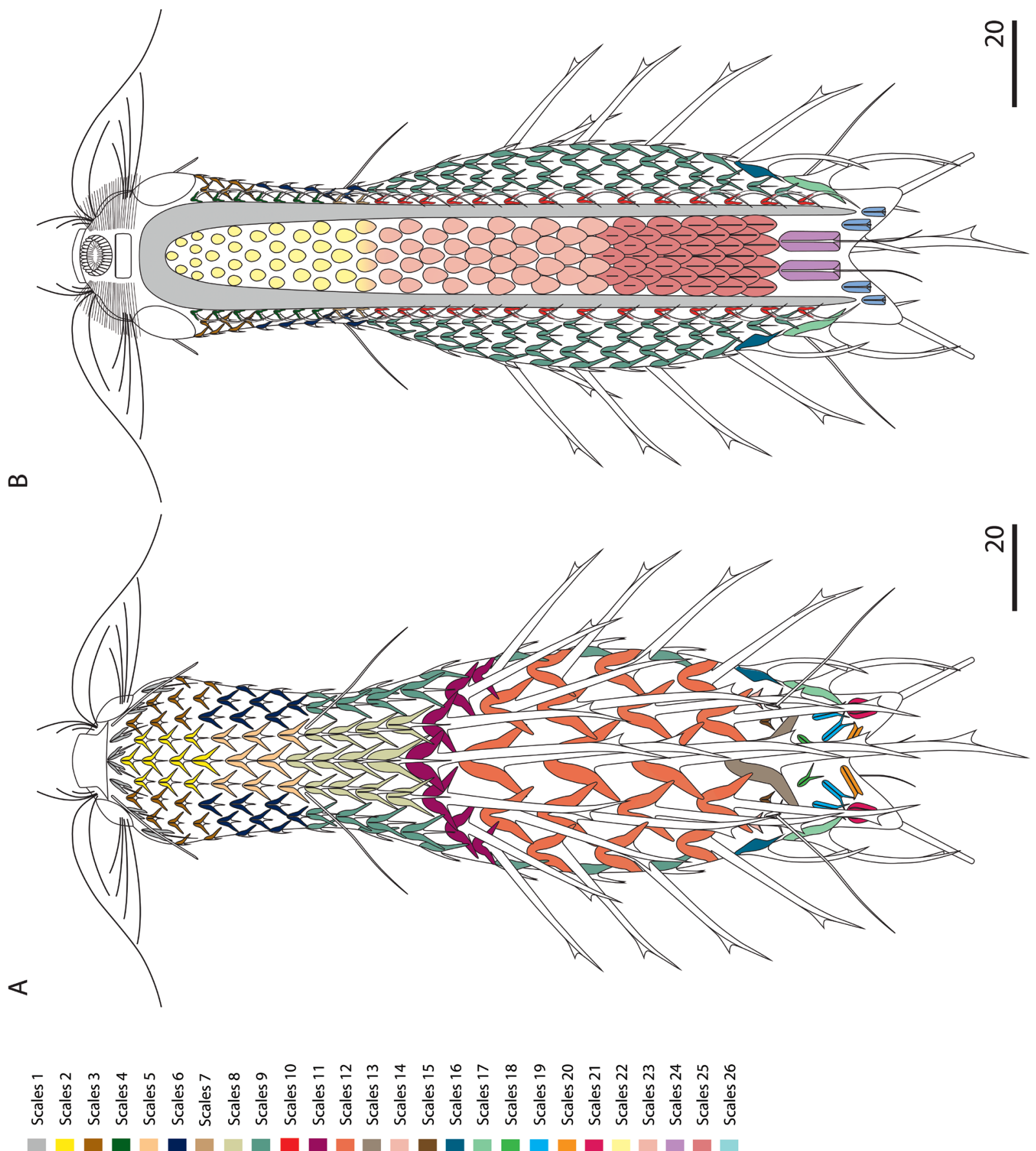

Fig. A6. Chaetonotus (Hystricochaetonotus) horridus sp. nov. Schematic drawings with various types of scales indicated. A. Dorsal body view. B. Ventral body view. Light grey areas indicate the areas of insertion of ciliary bands. 


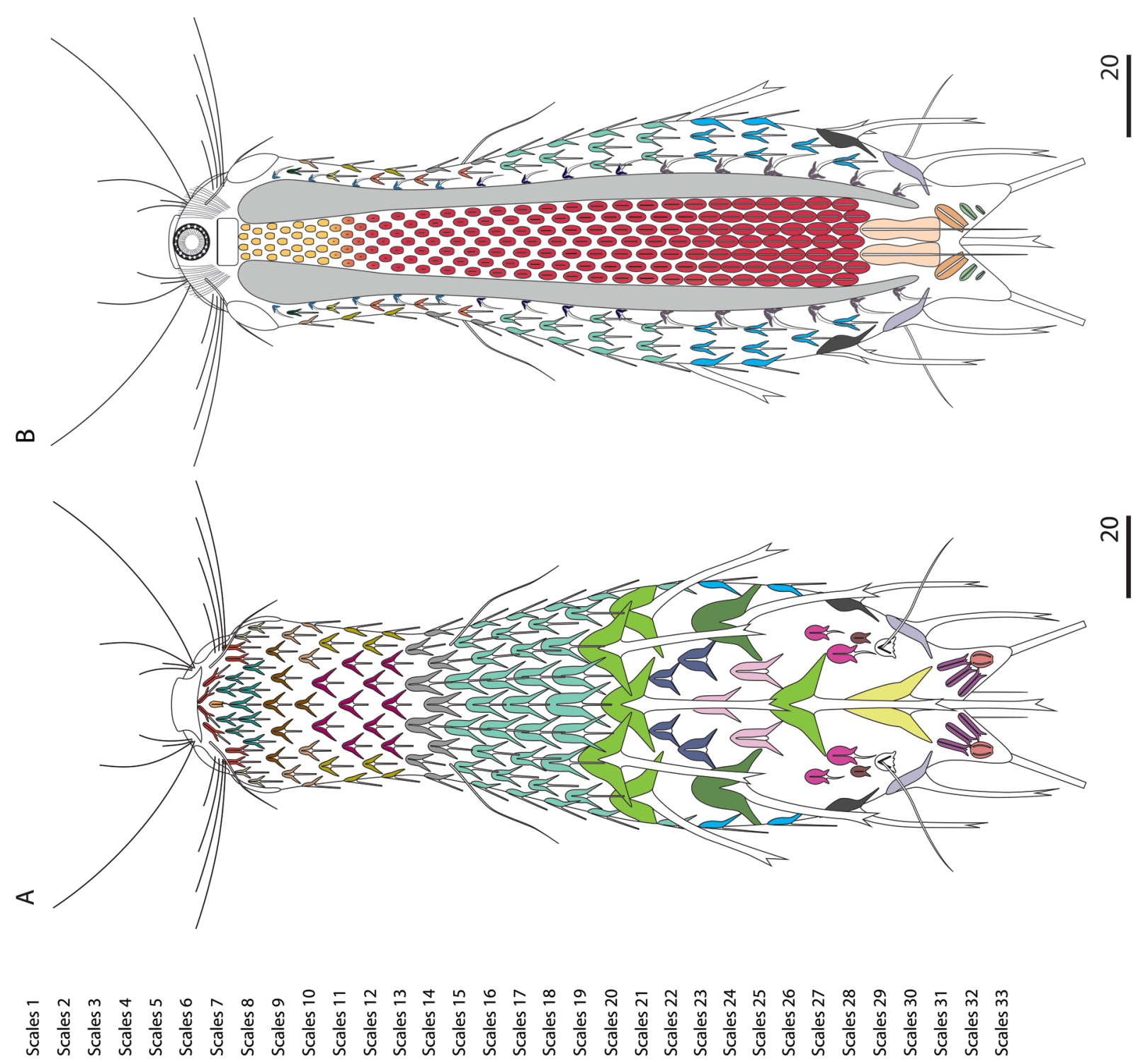

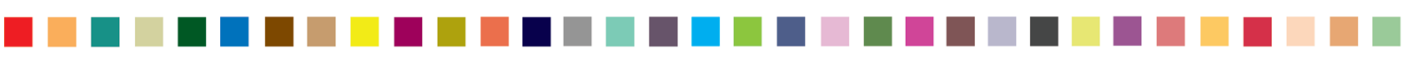

Fig. A7. Chaetonotus (Hystricochaetonotus) inaequabilis sp. nov. Schematic drawings with various types of scales indicated. A. Dorsal body view. B. Ventral body view. Light grey areas indicate the areas of insertion of ciliary bands. 


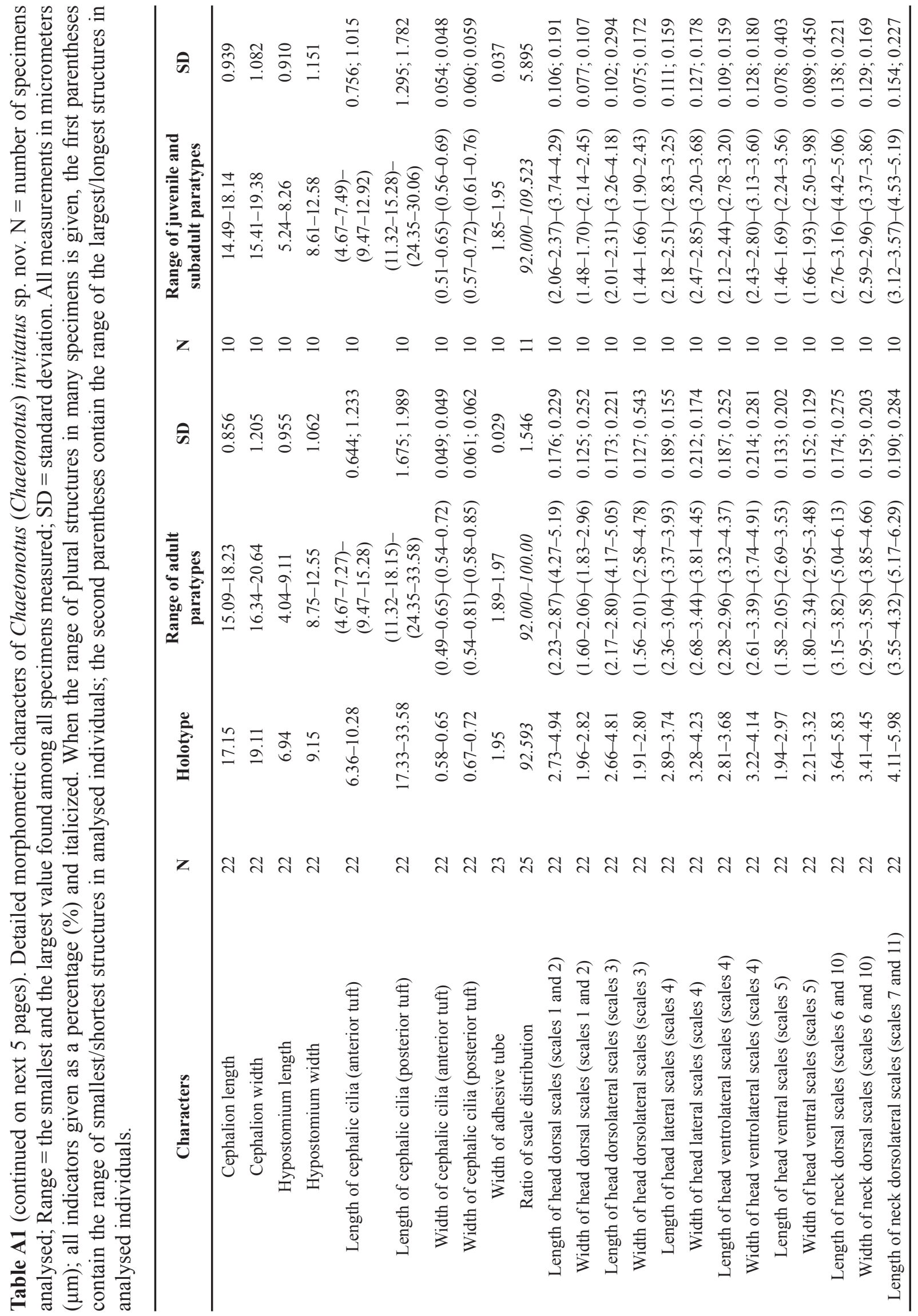




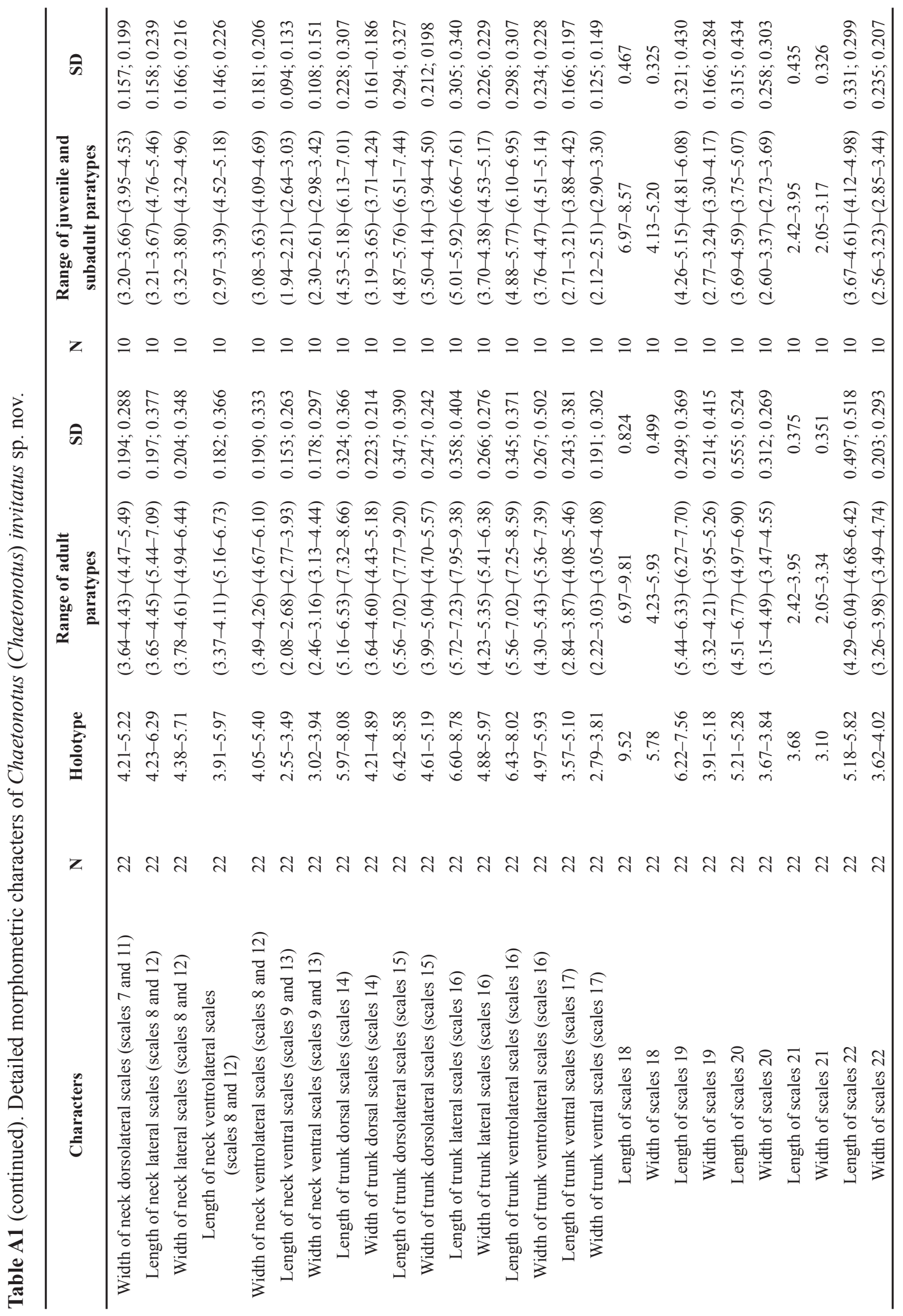




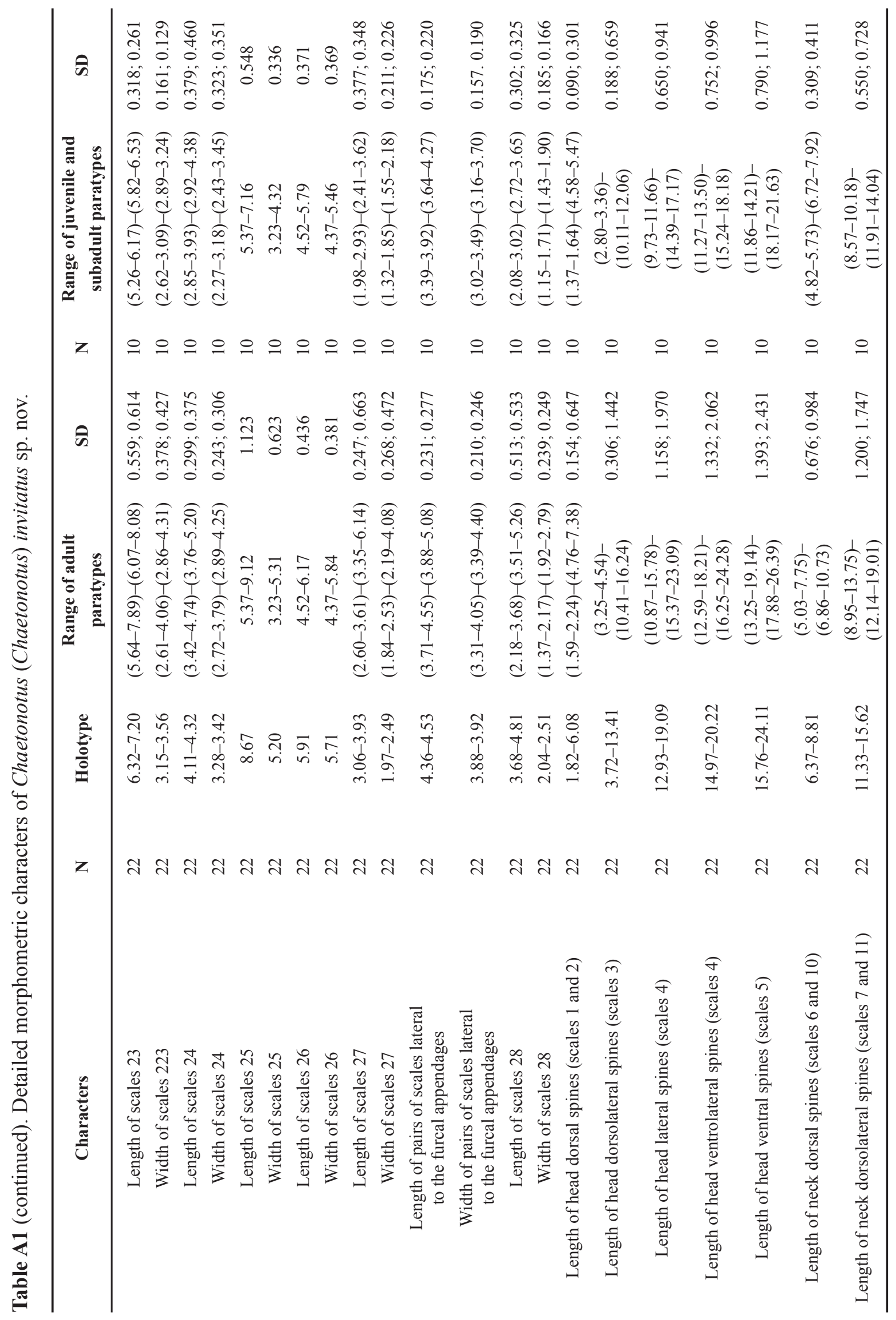




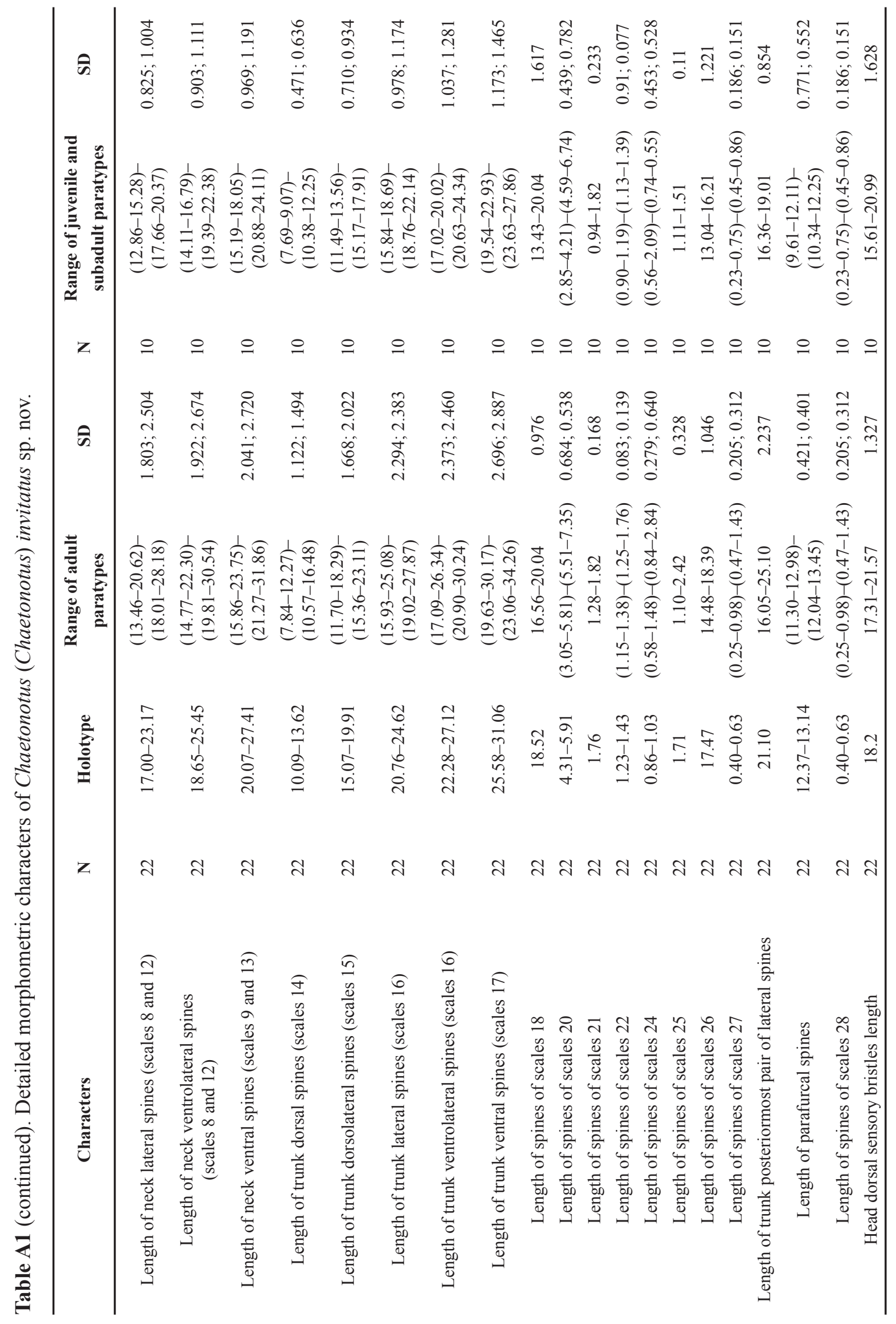




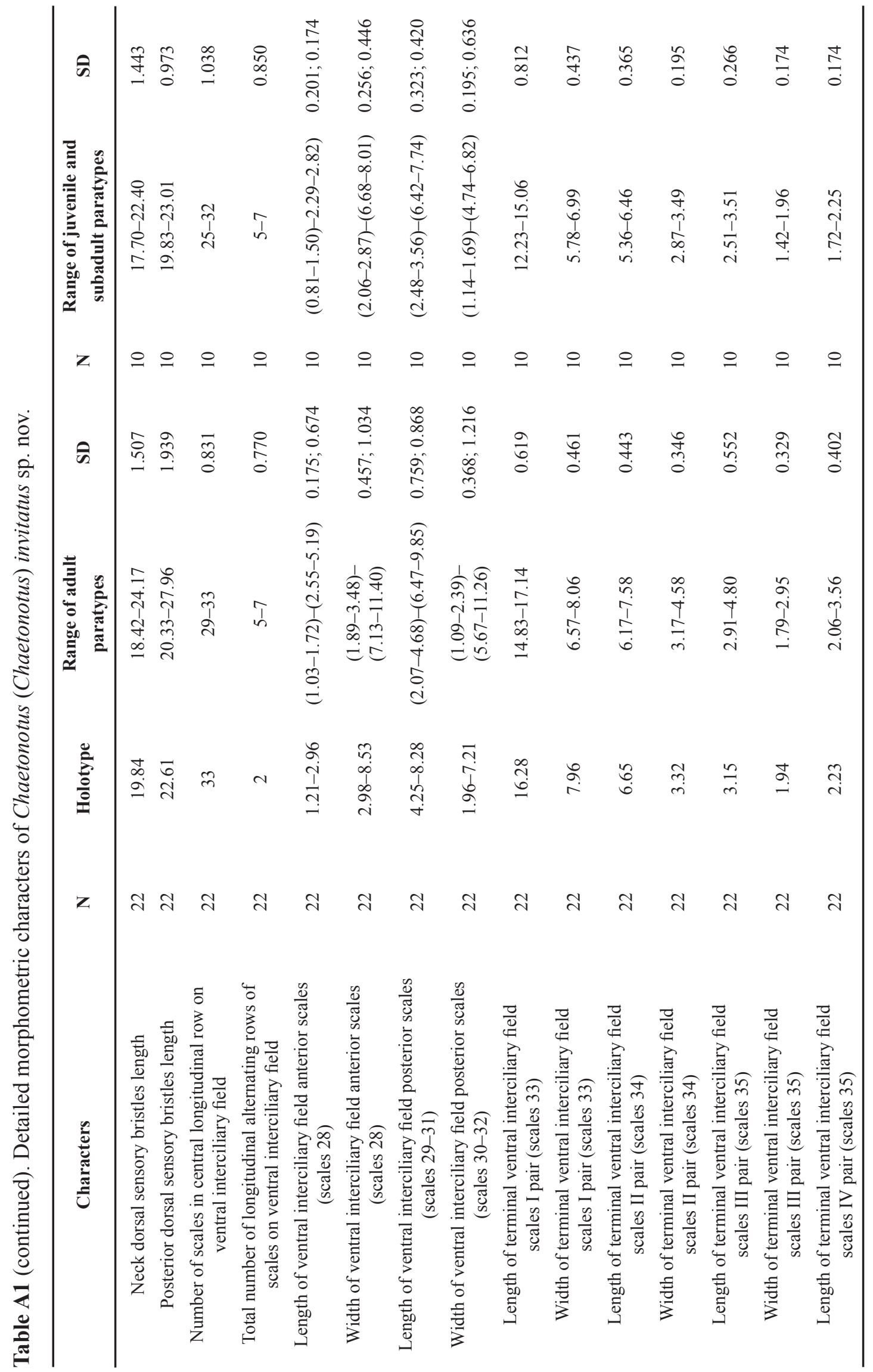




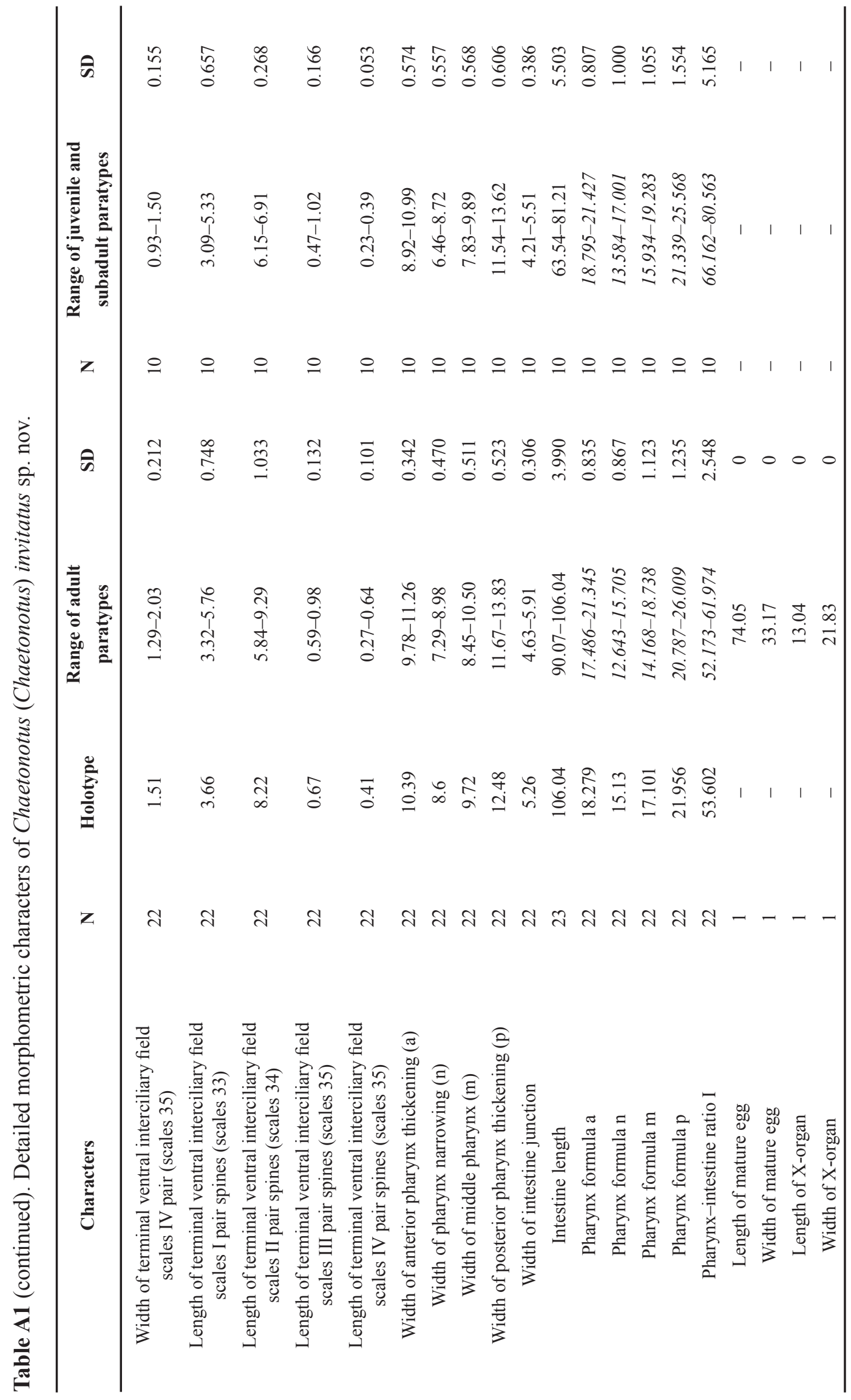




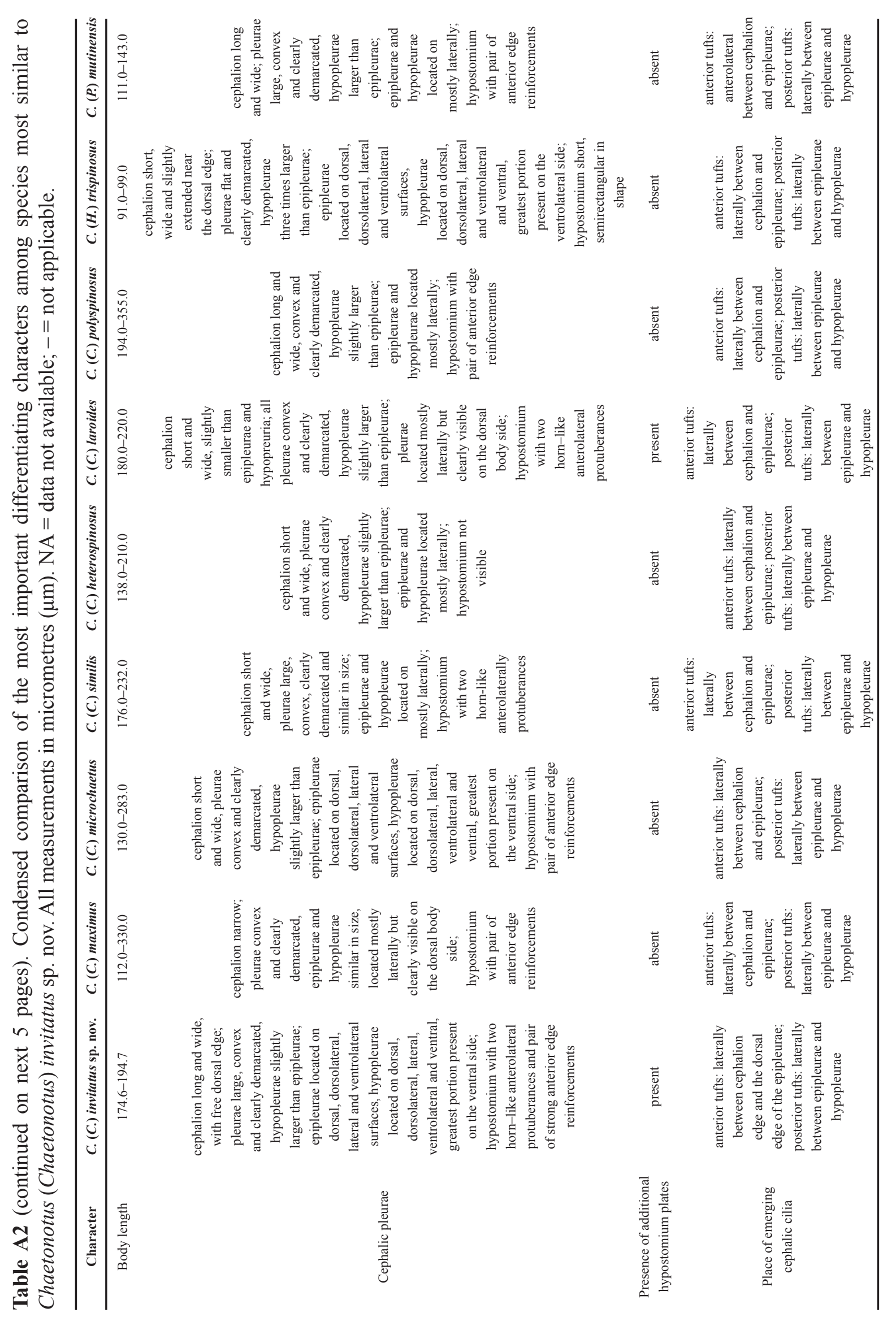




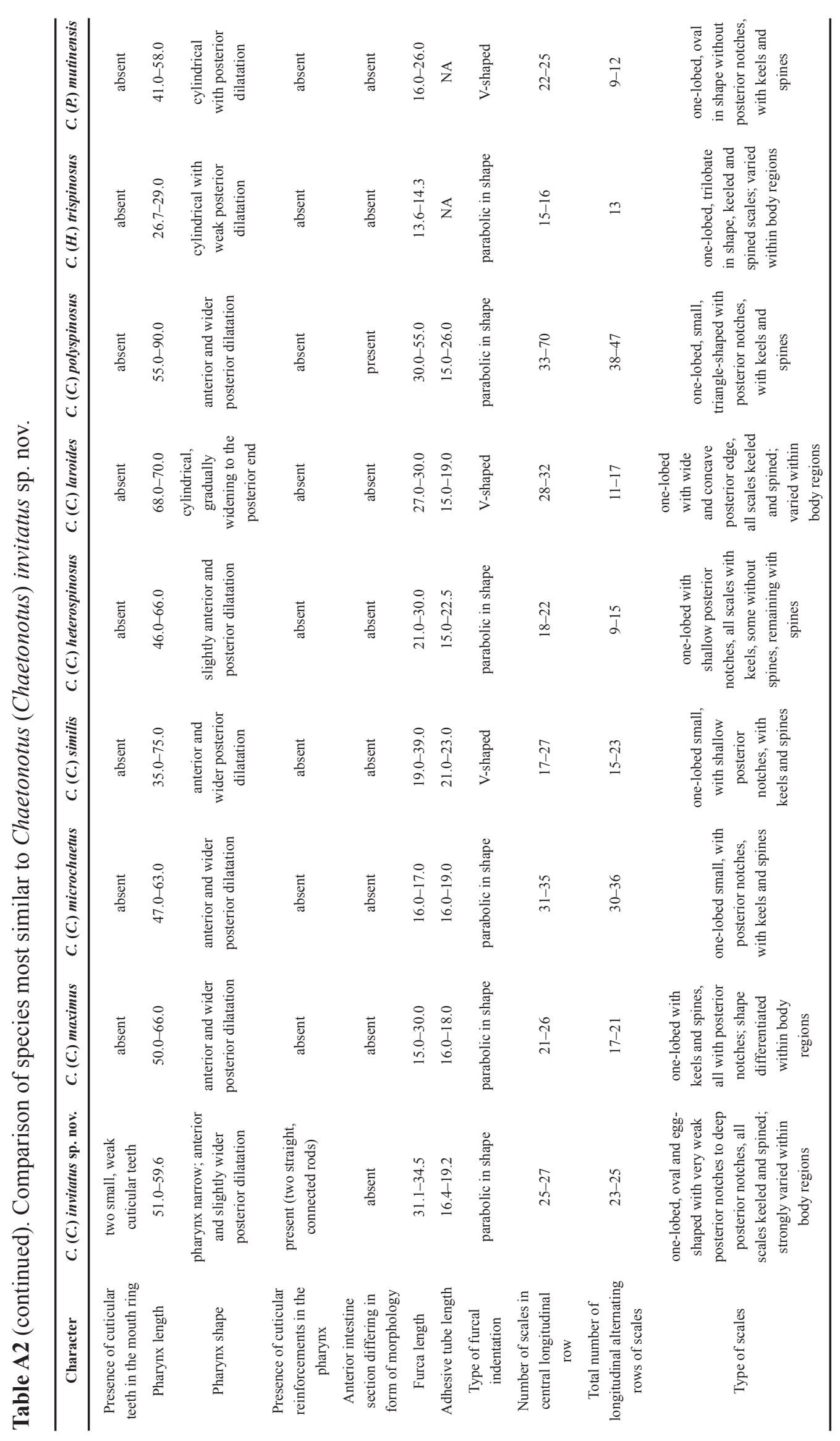




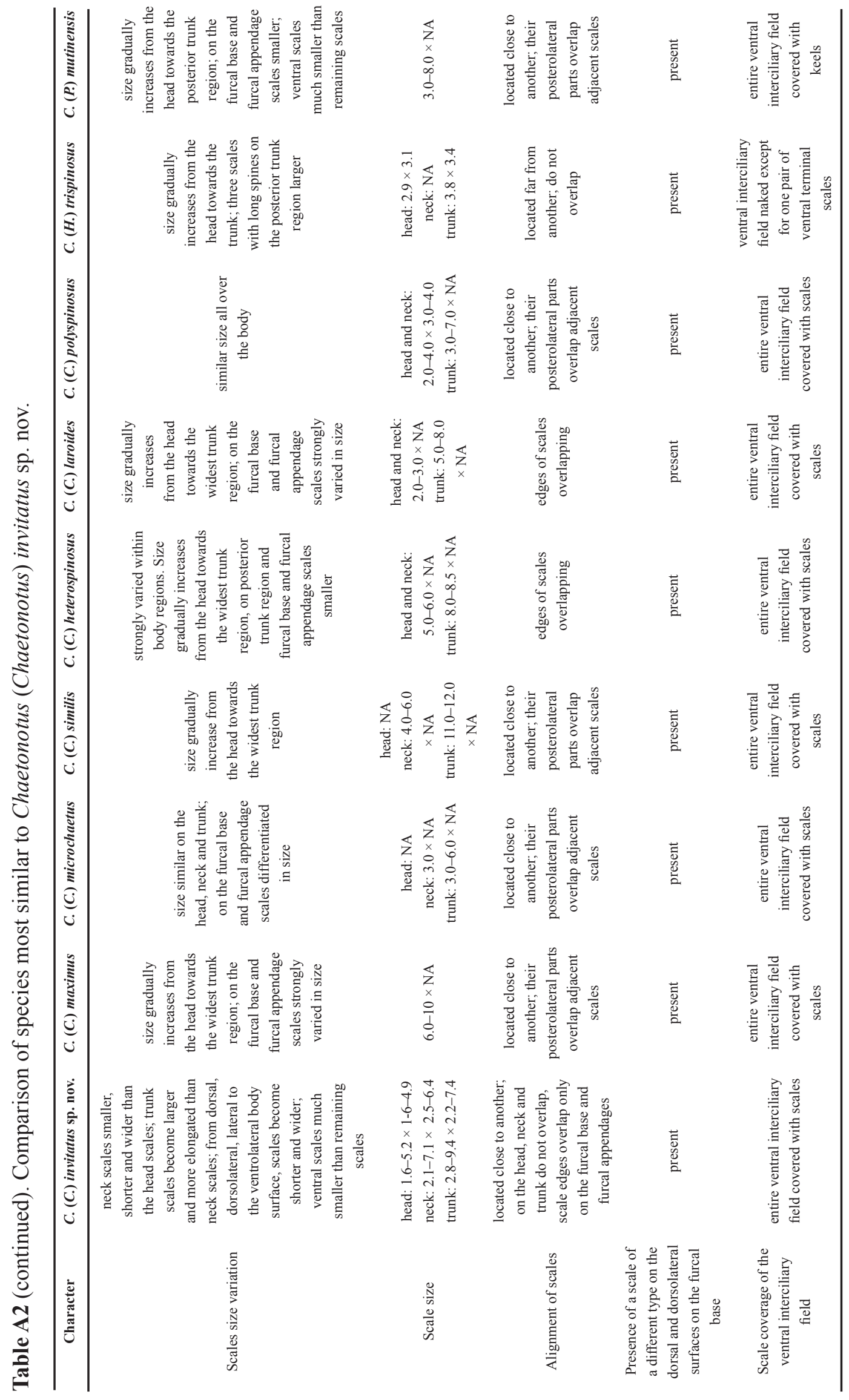




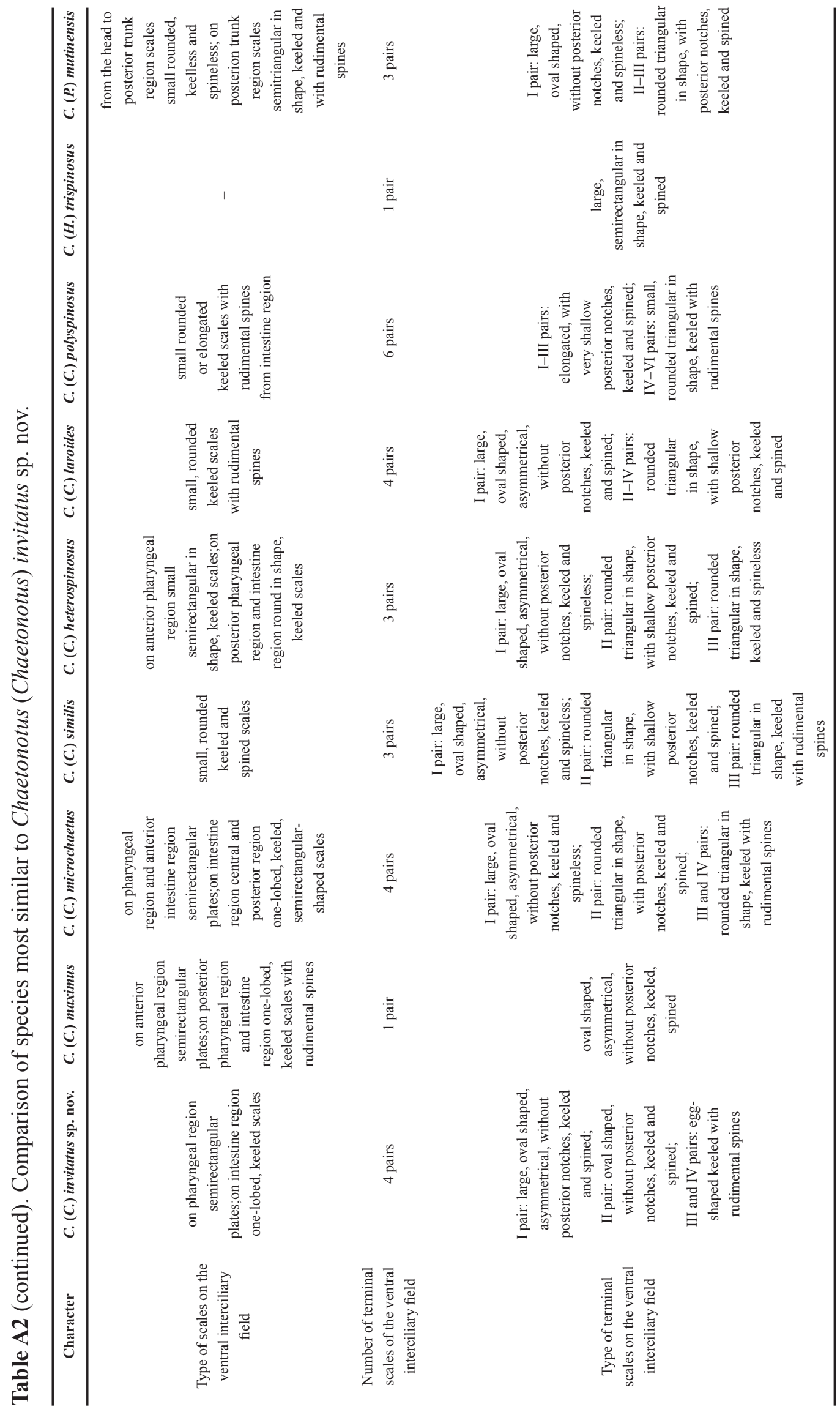




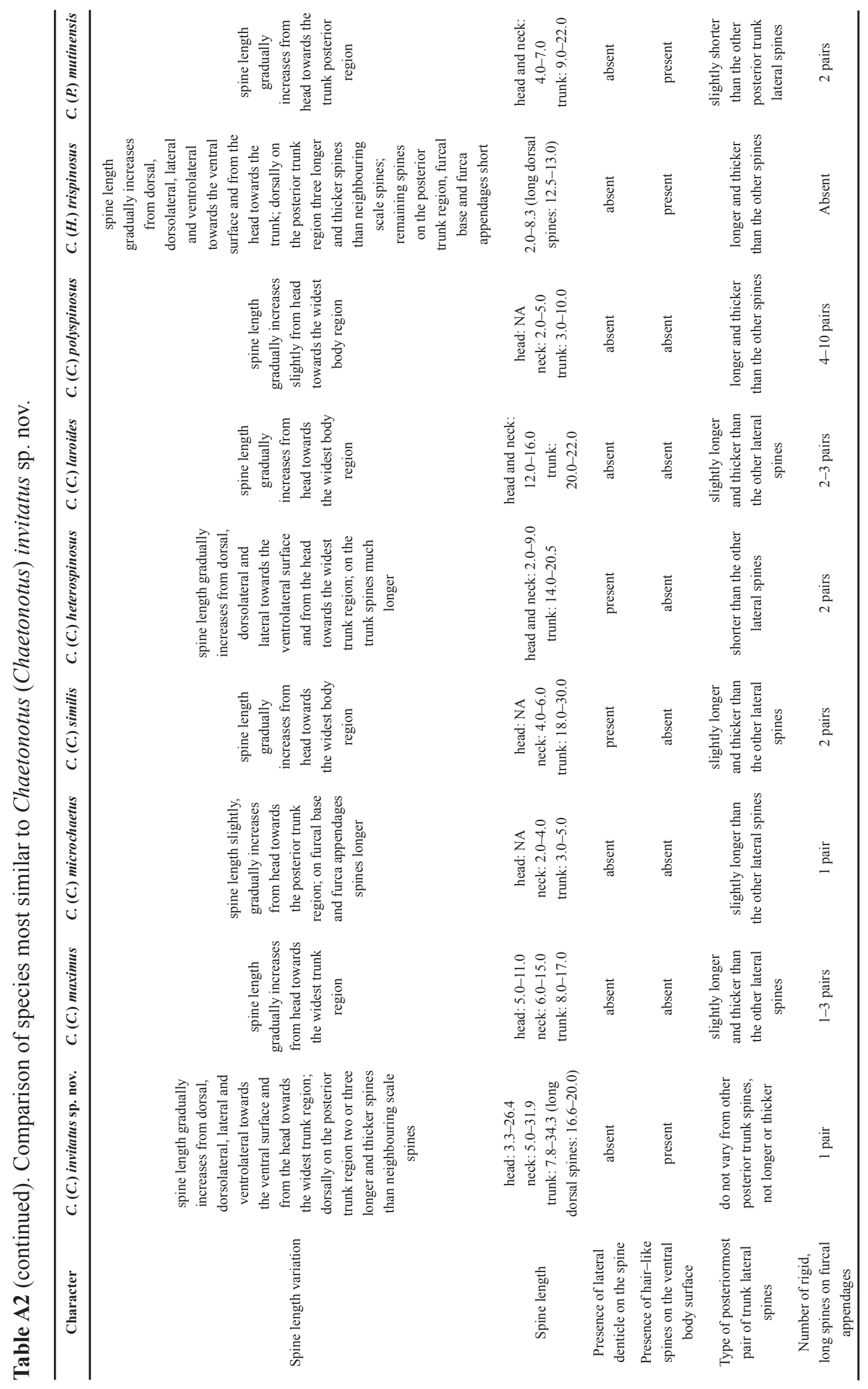




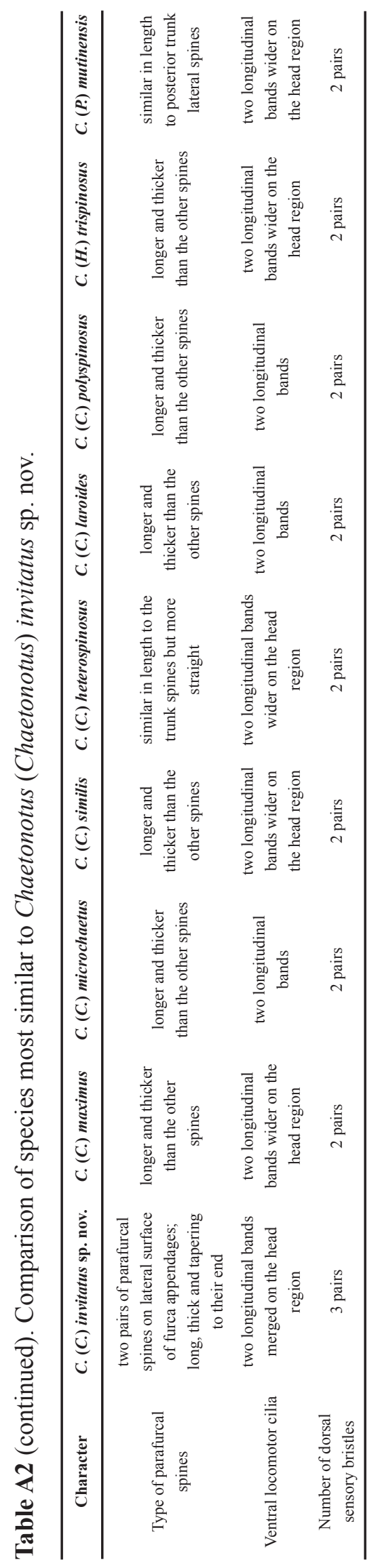




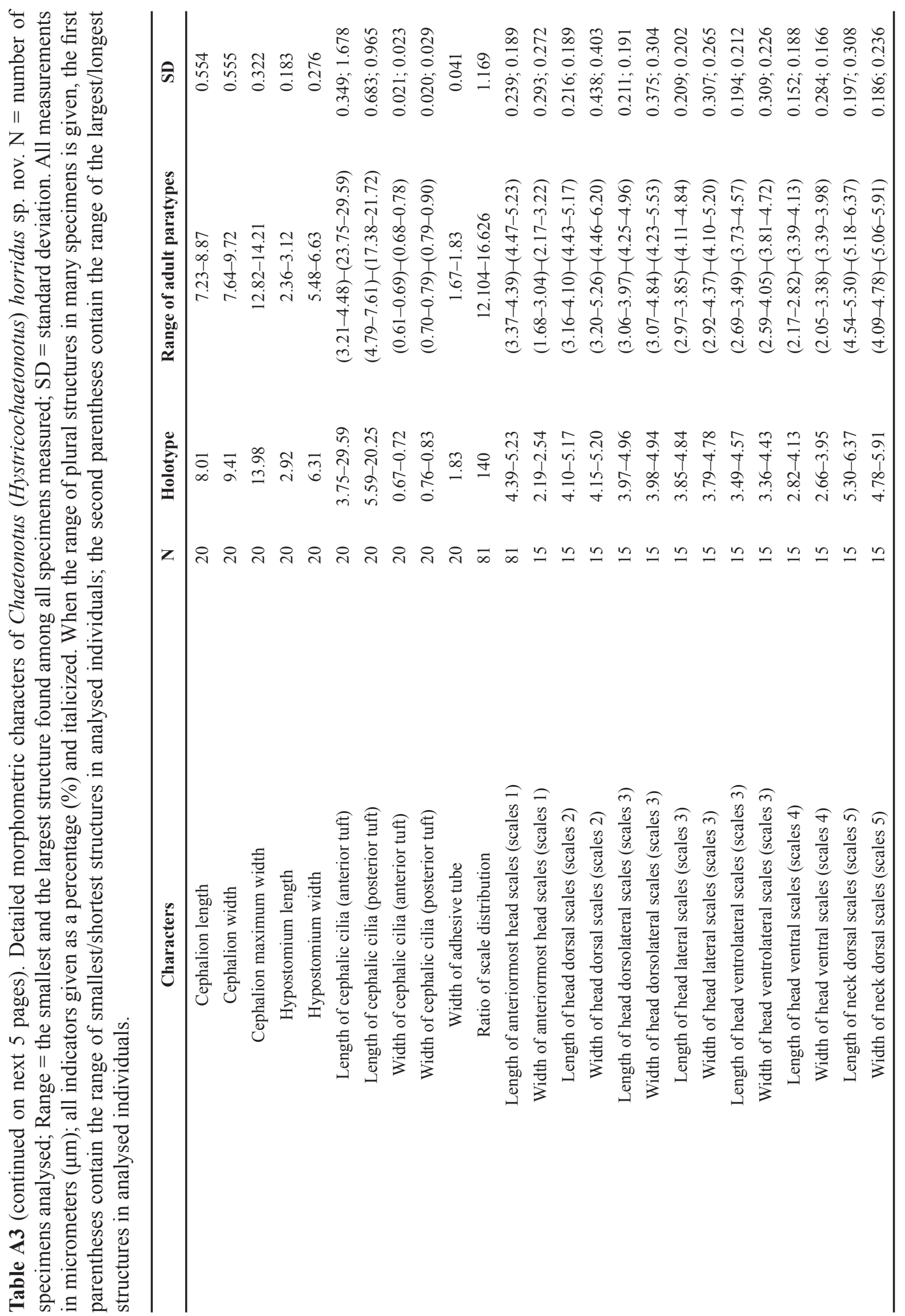




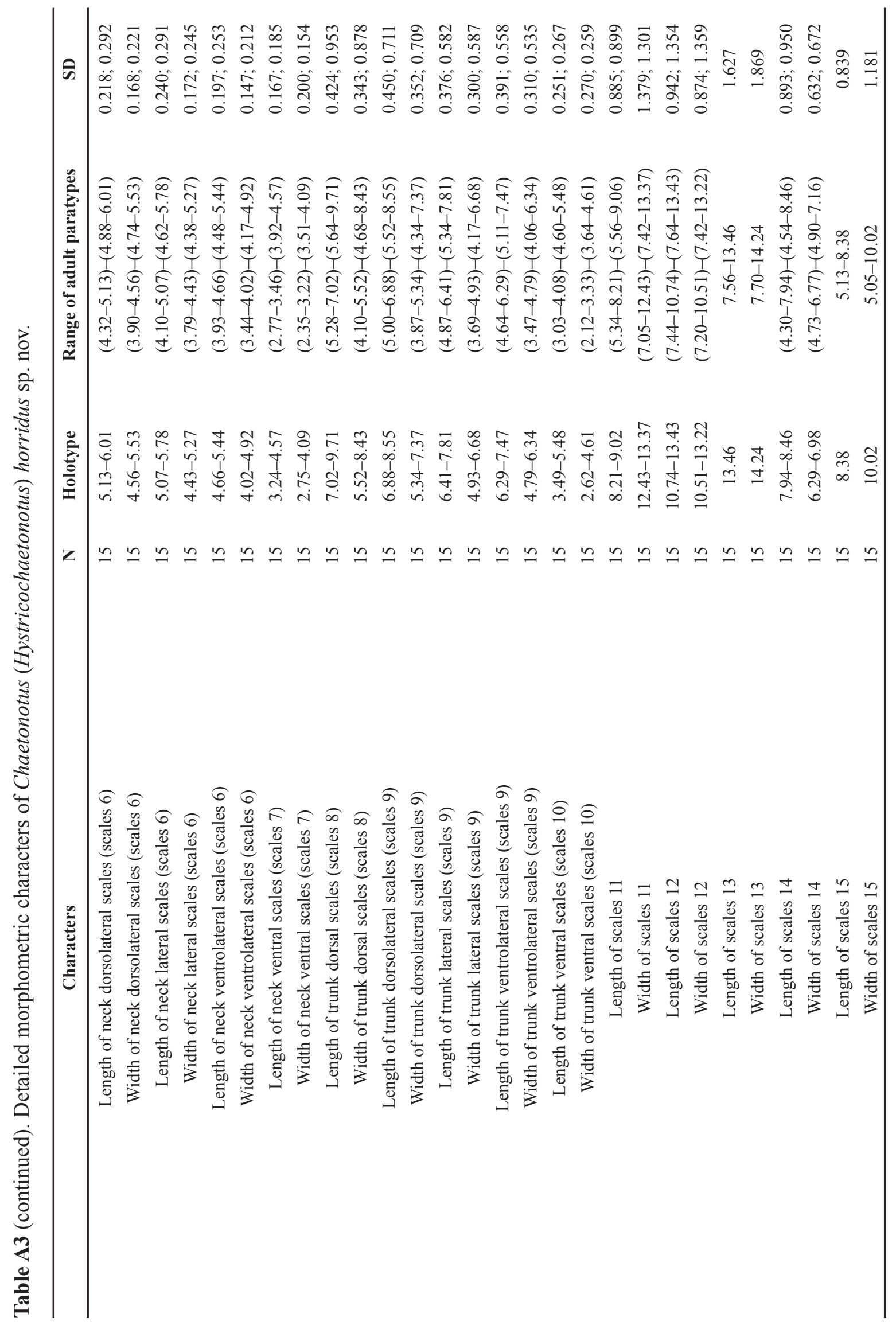




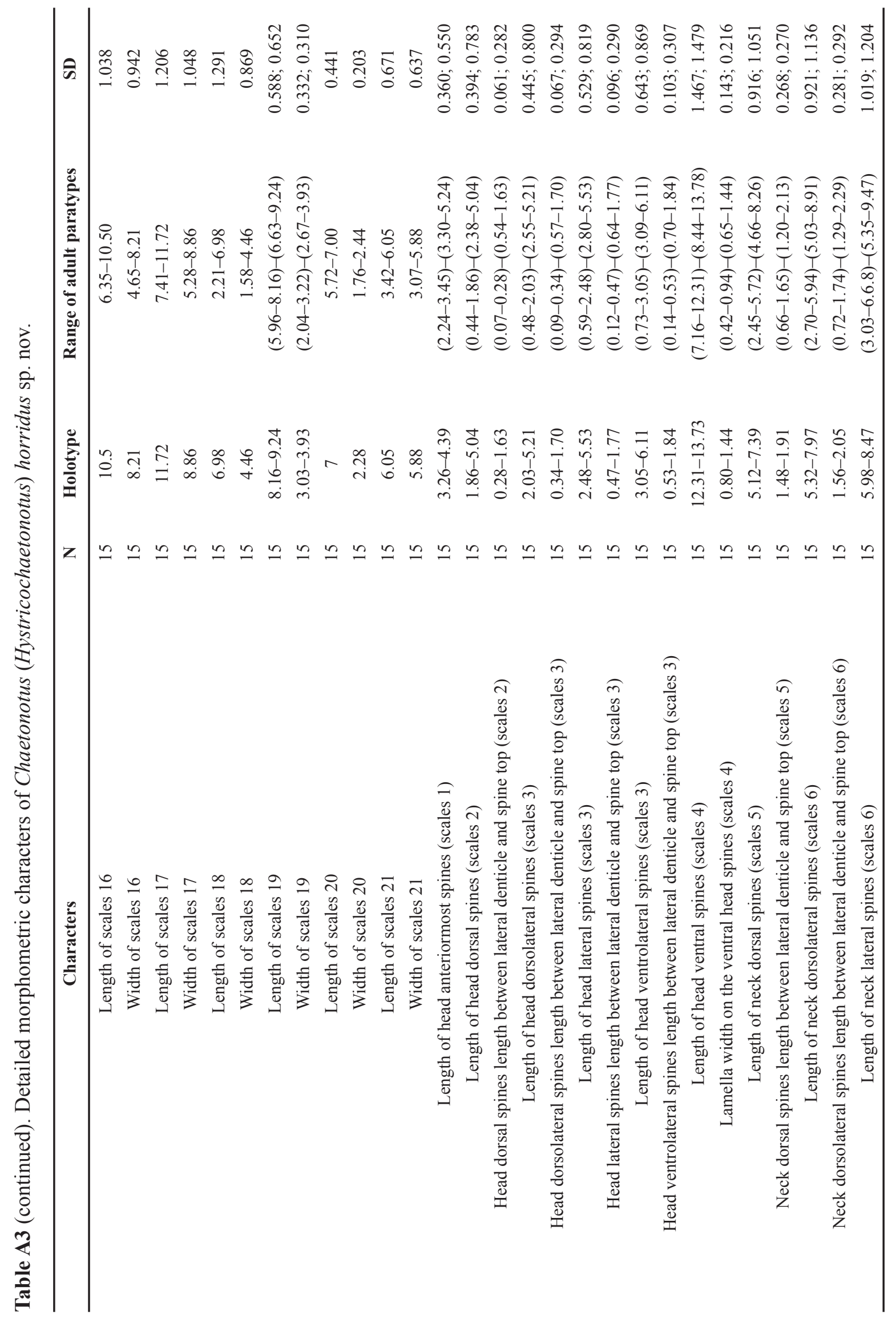




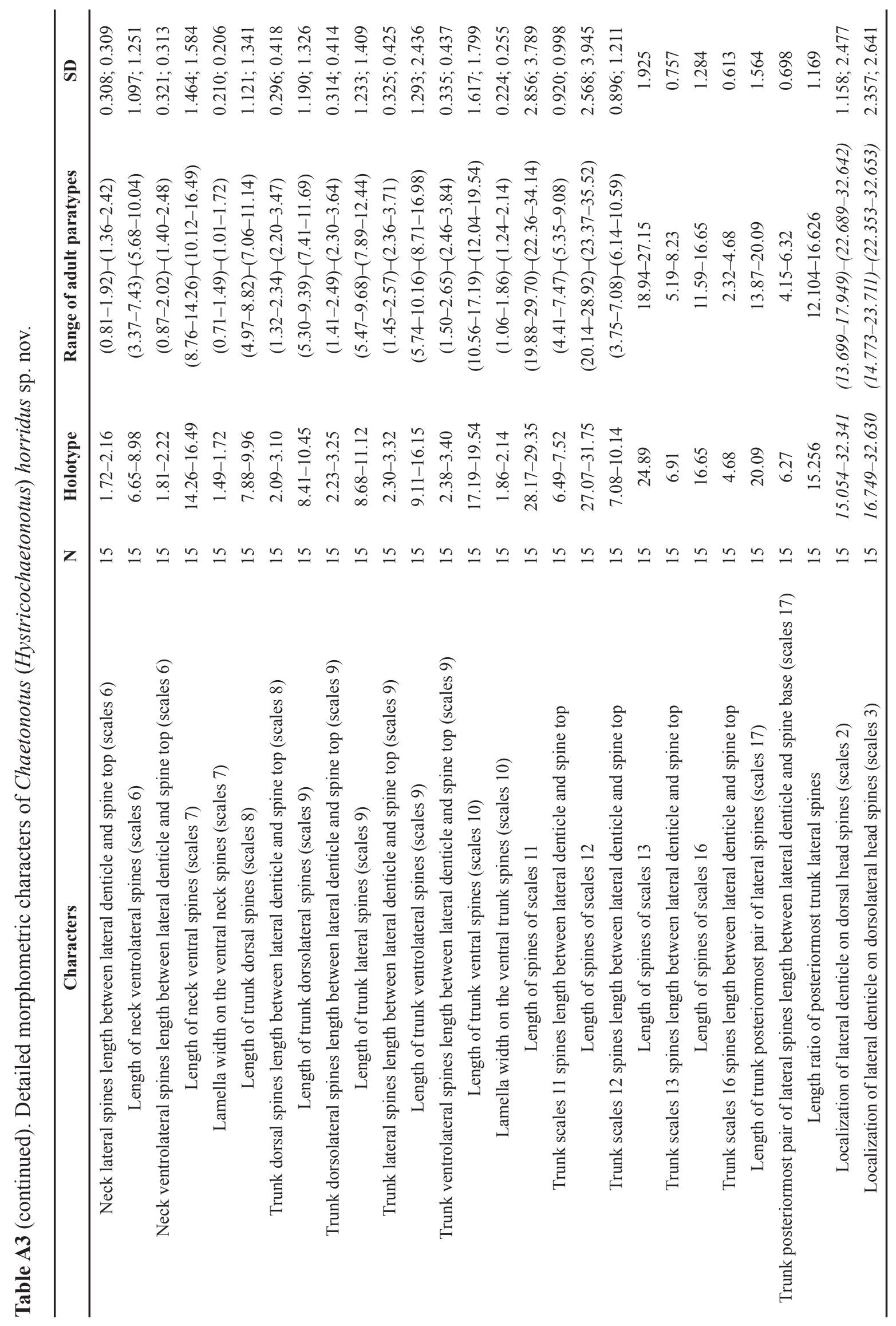




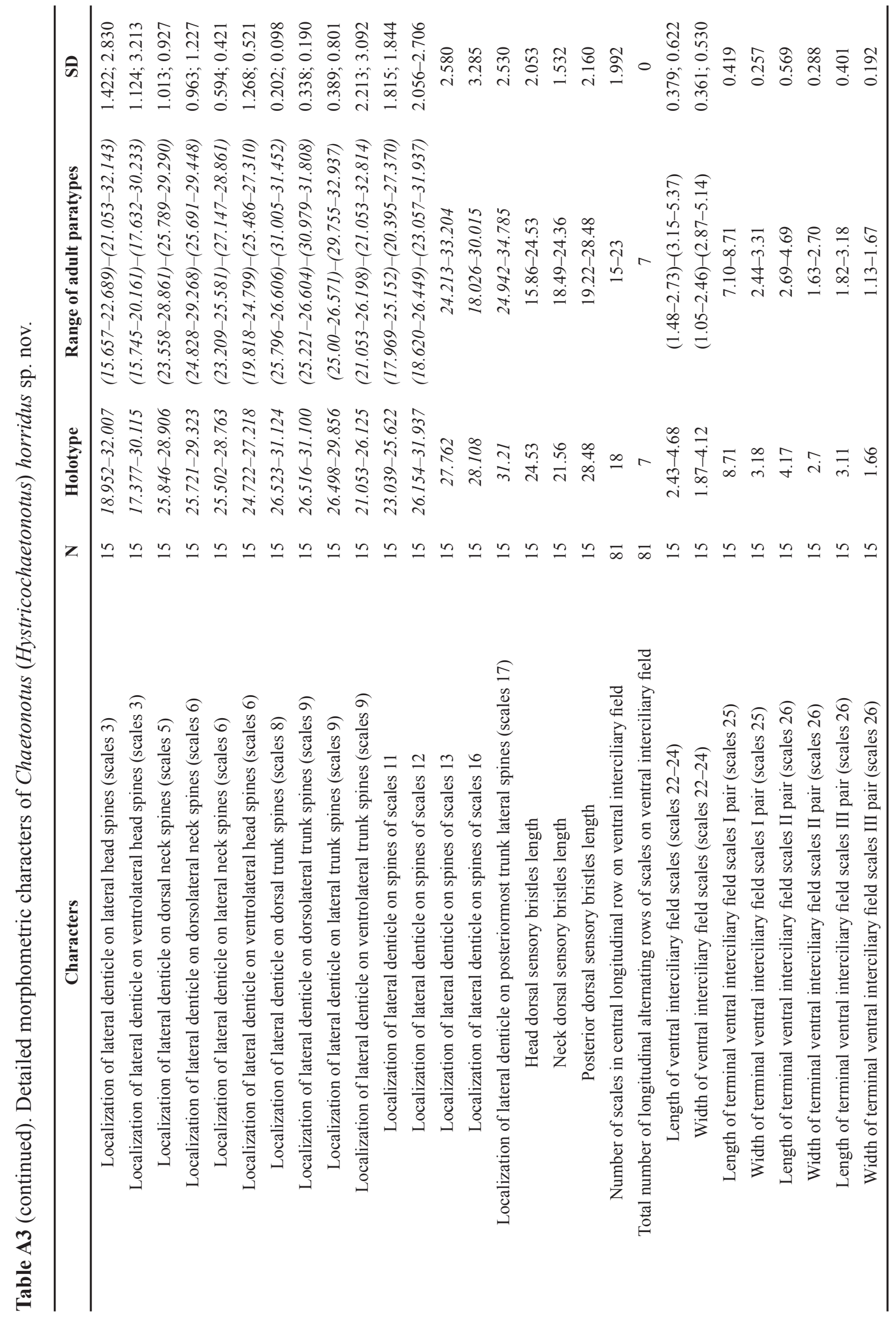




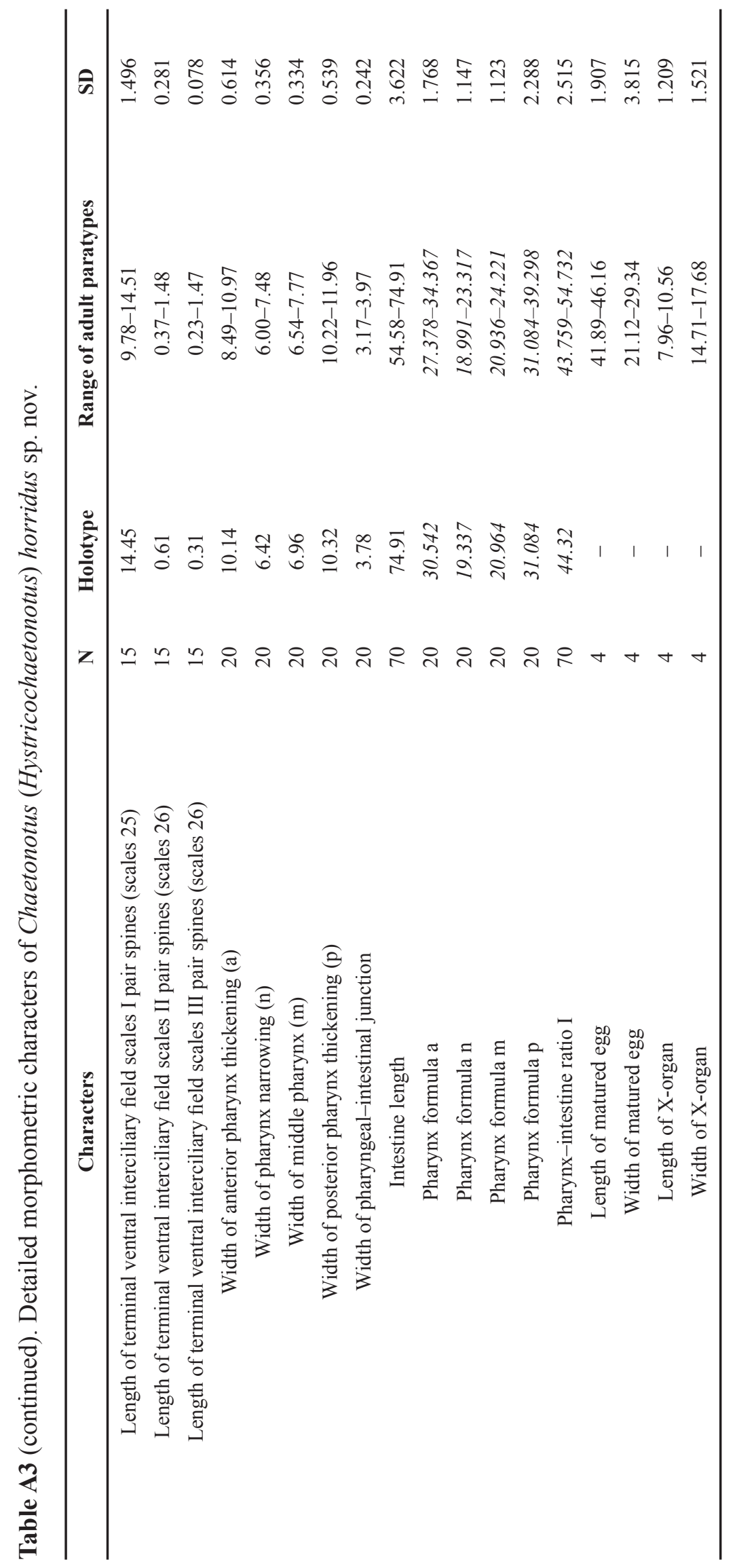




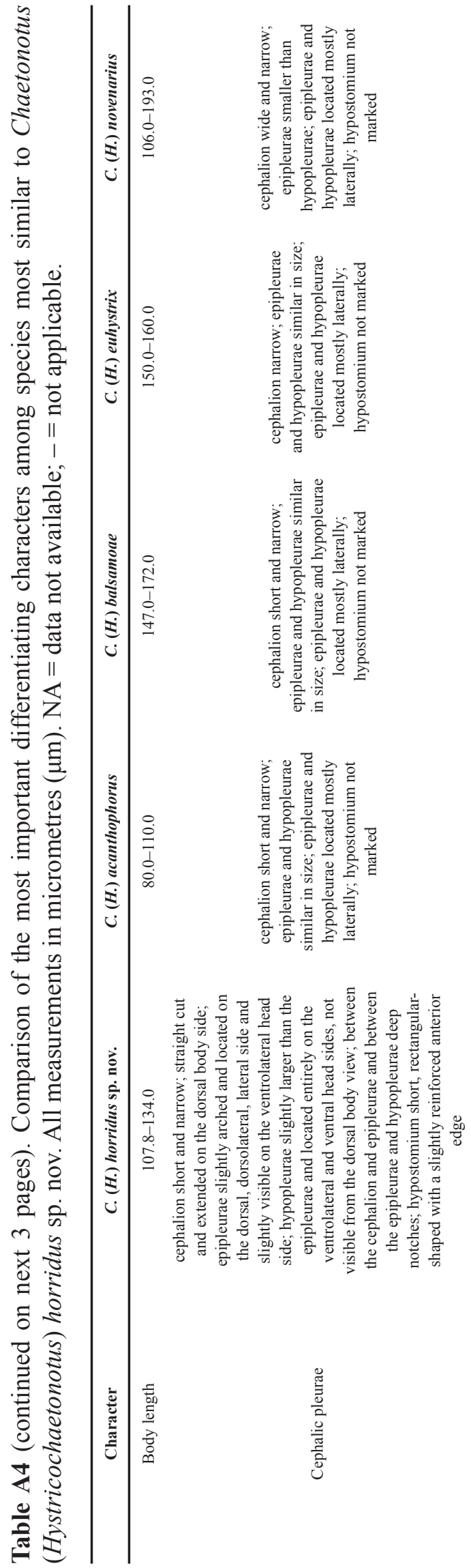

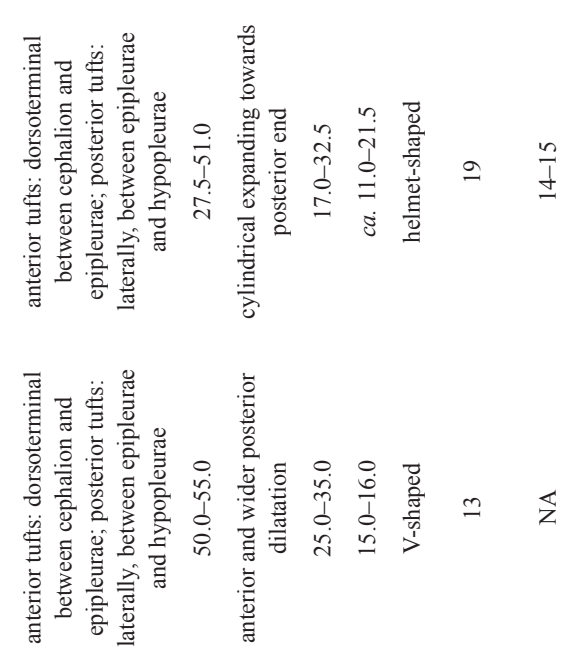

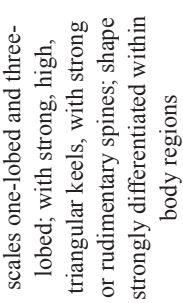
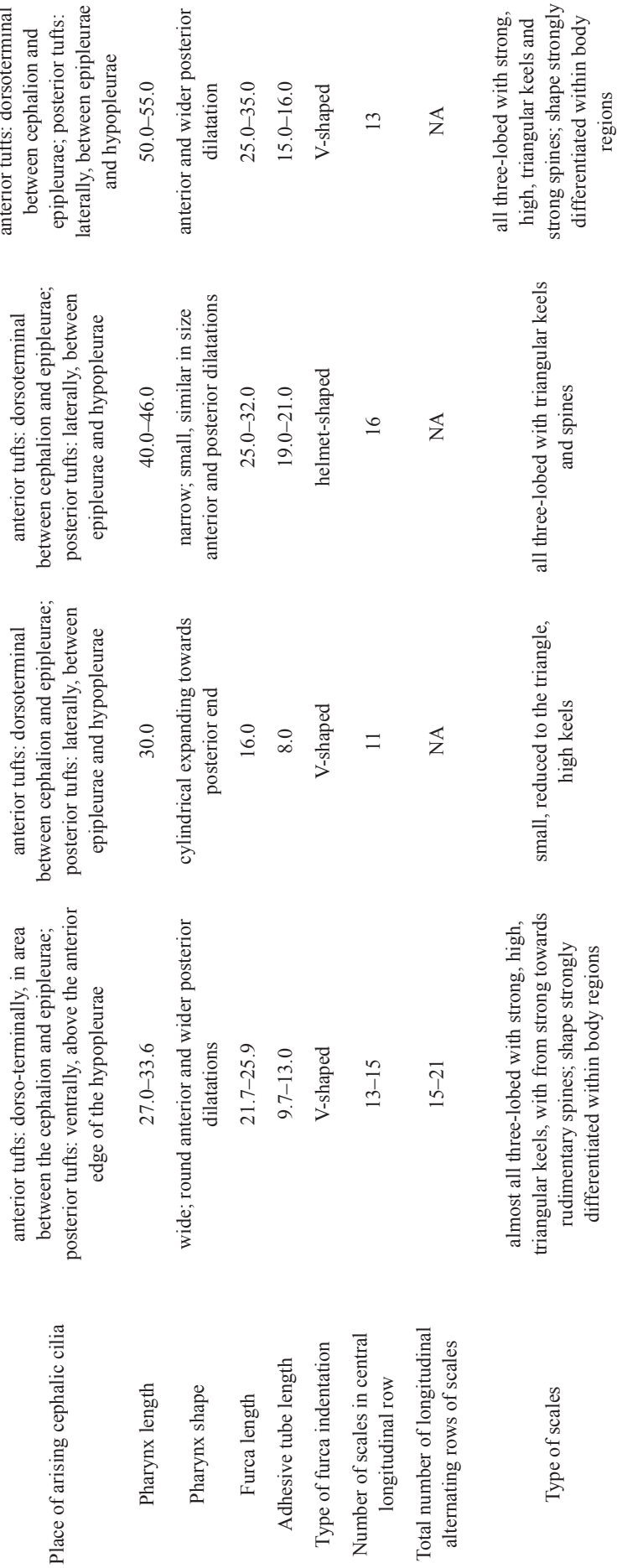


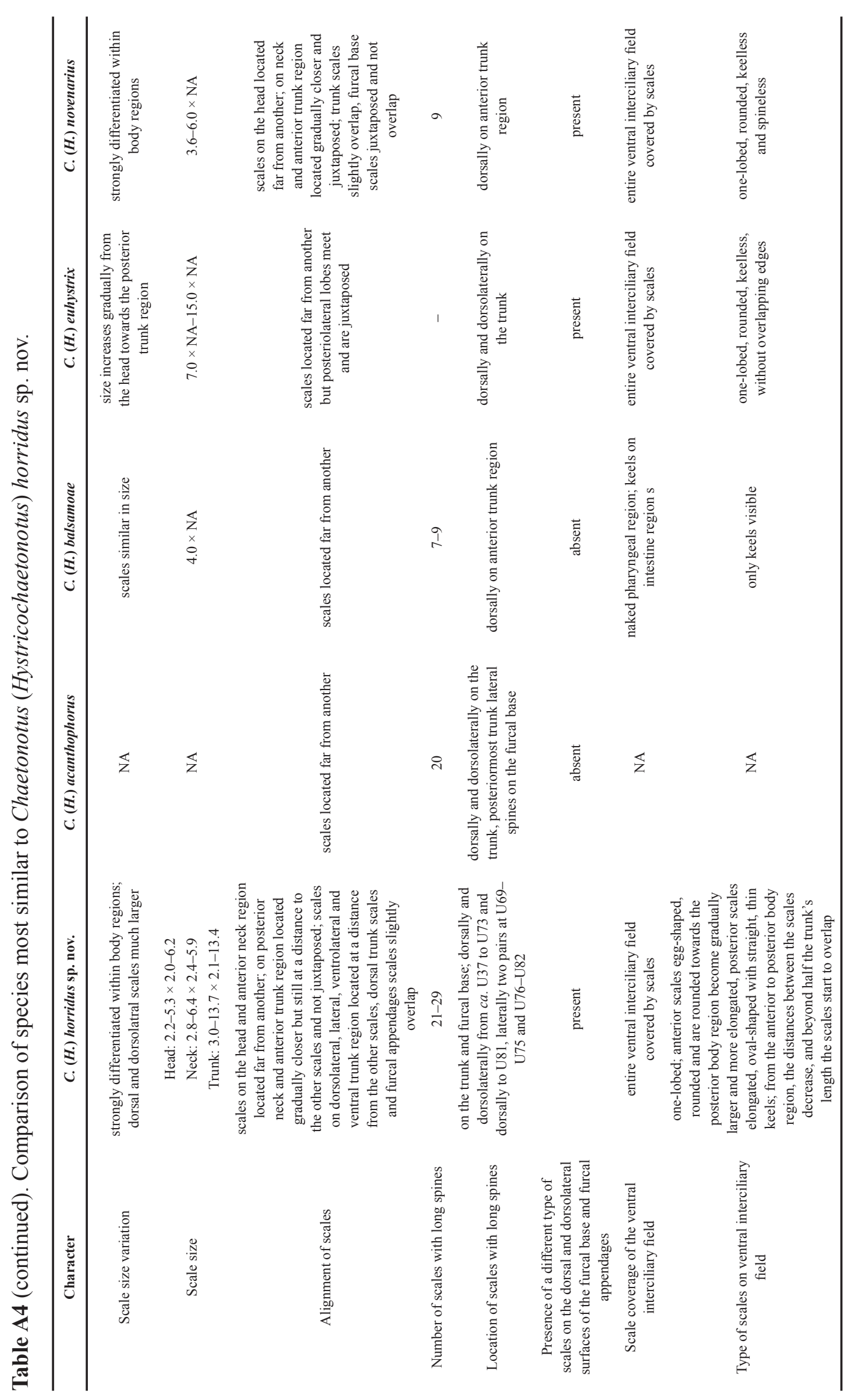




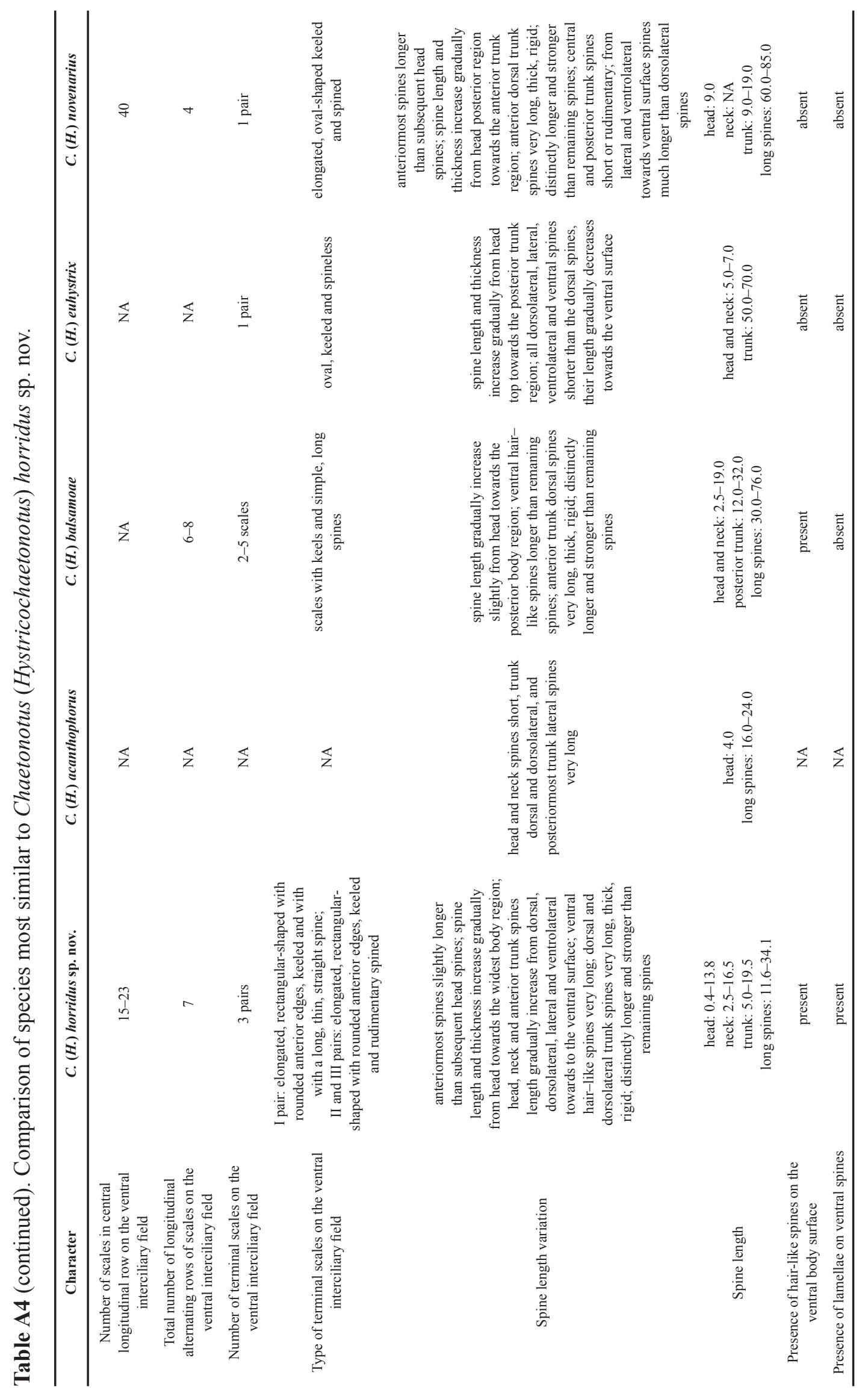




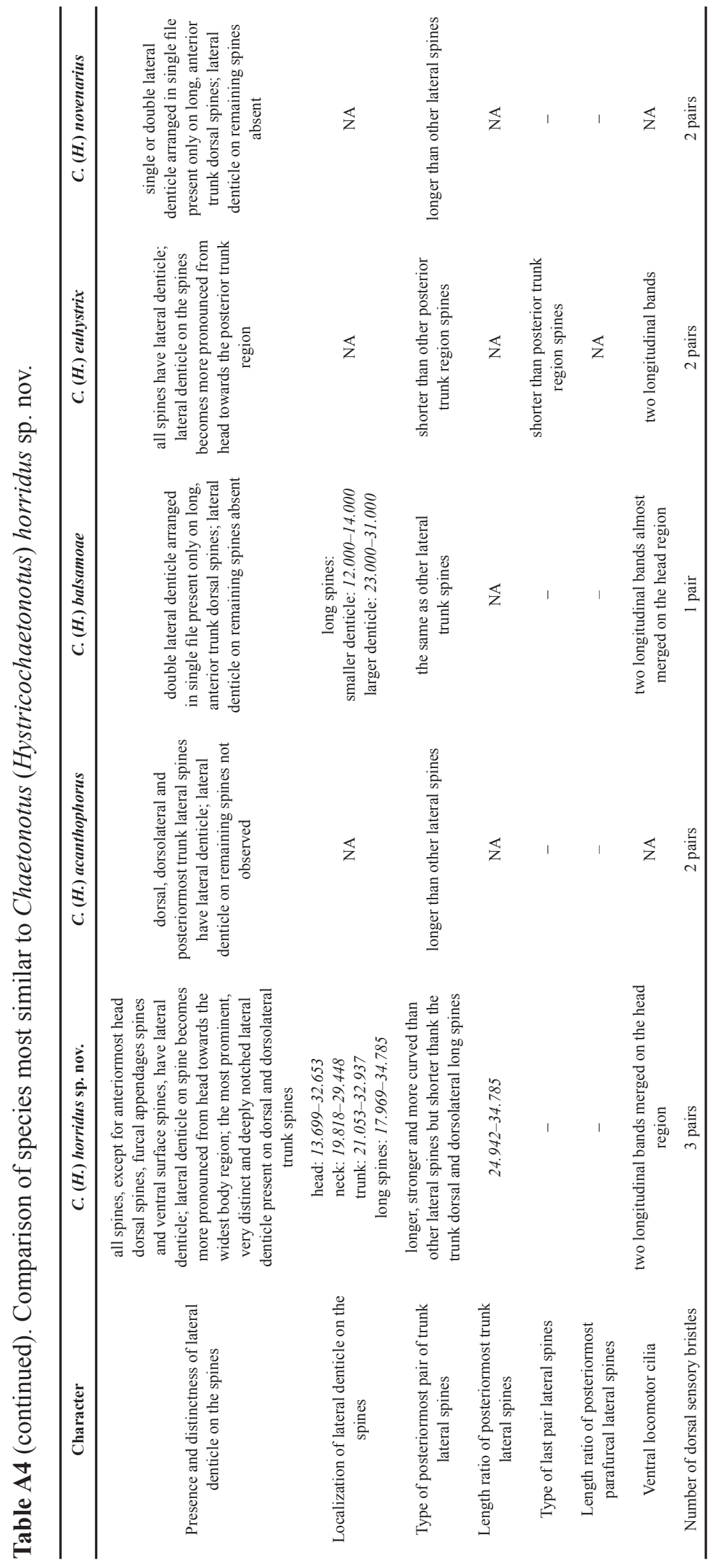




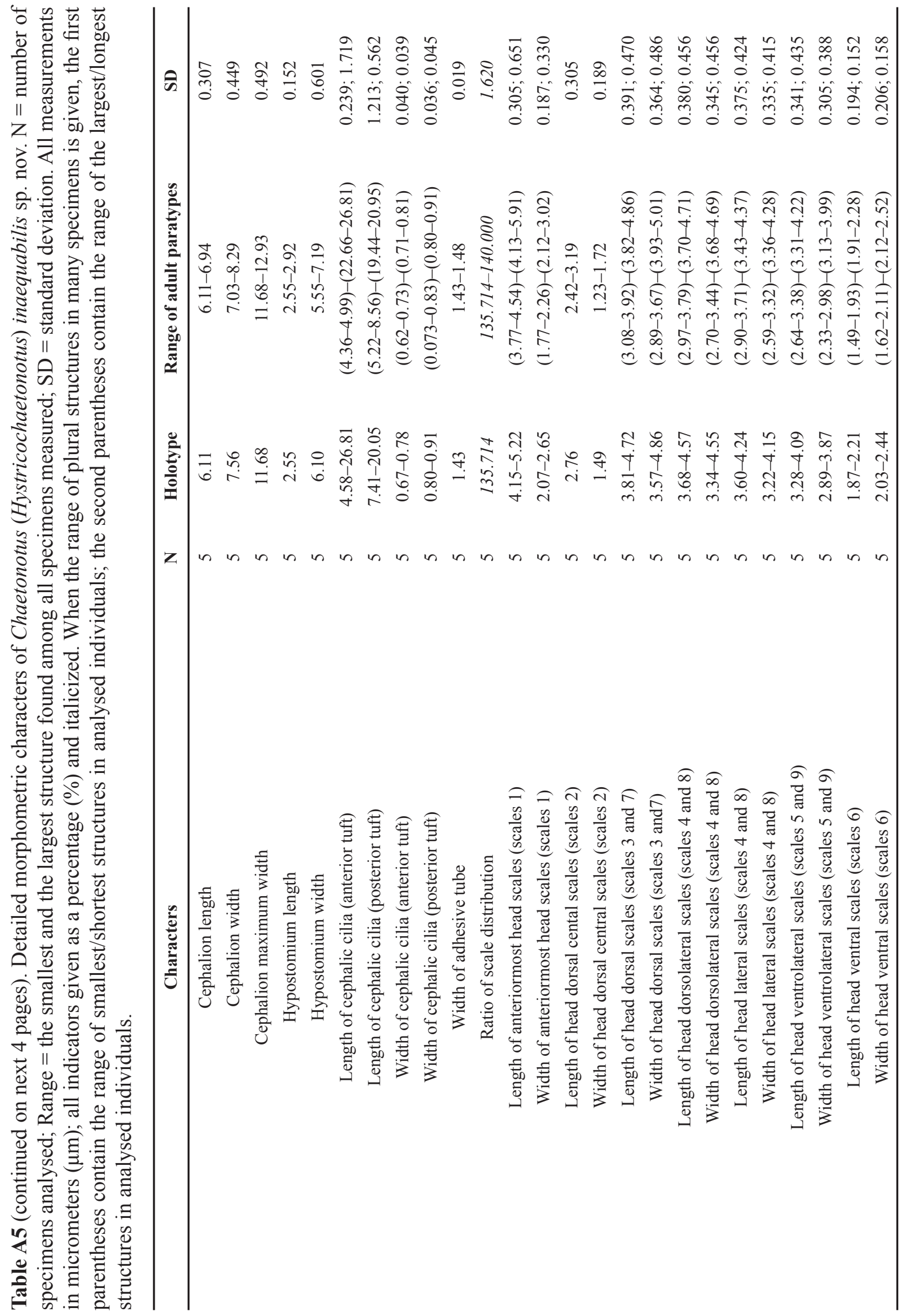




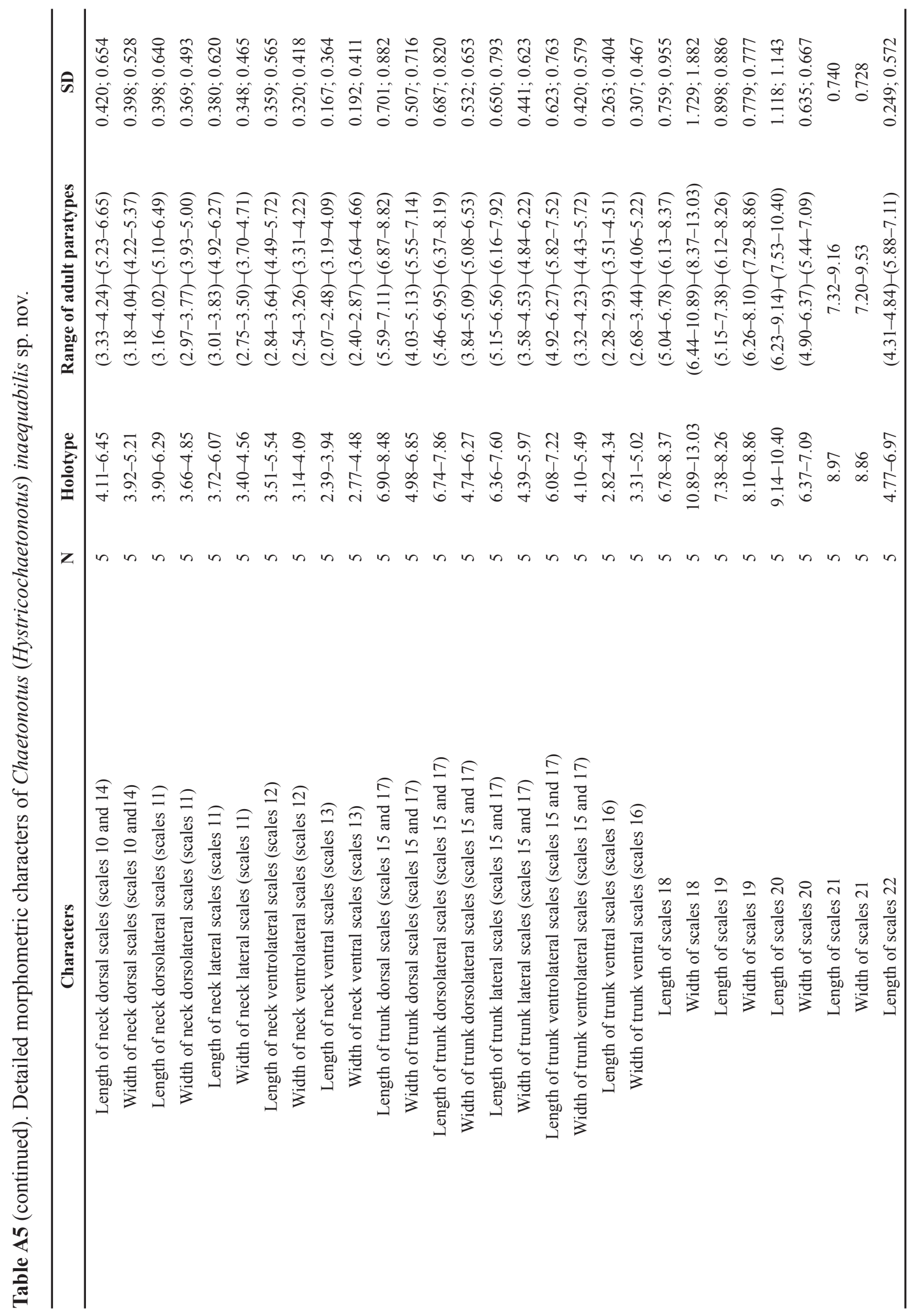




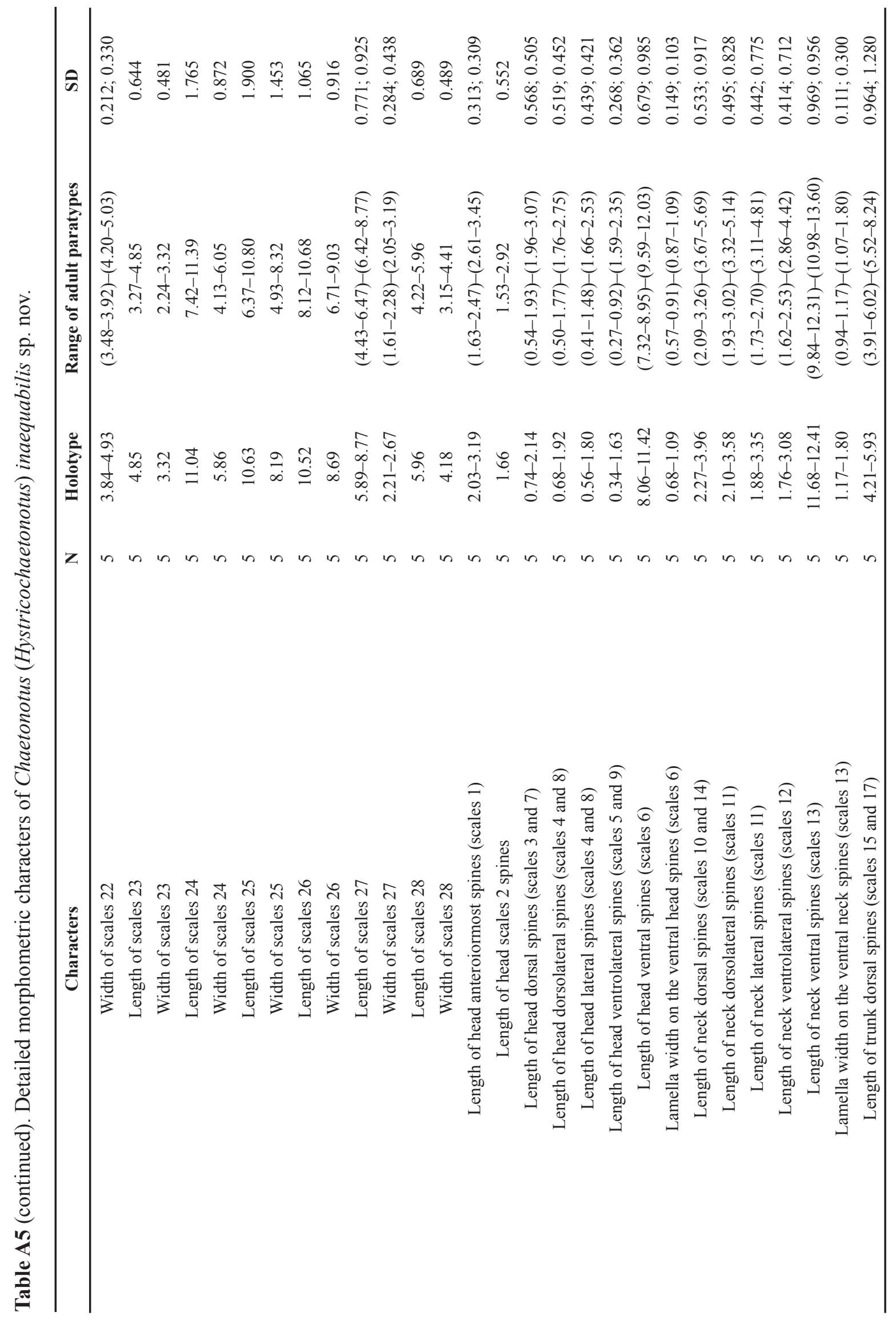




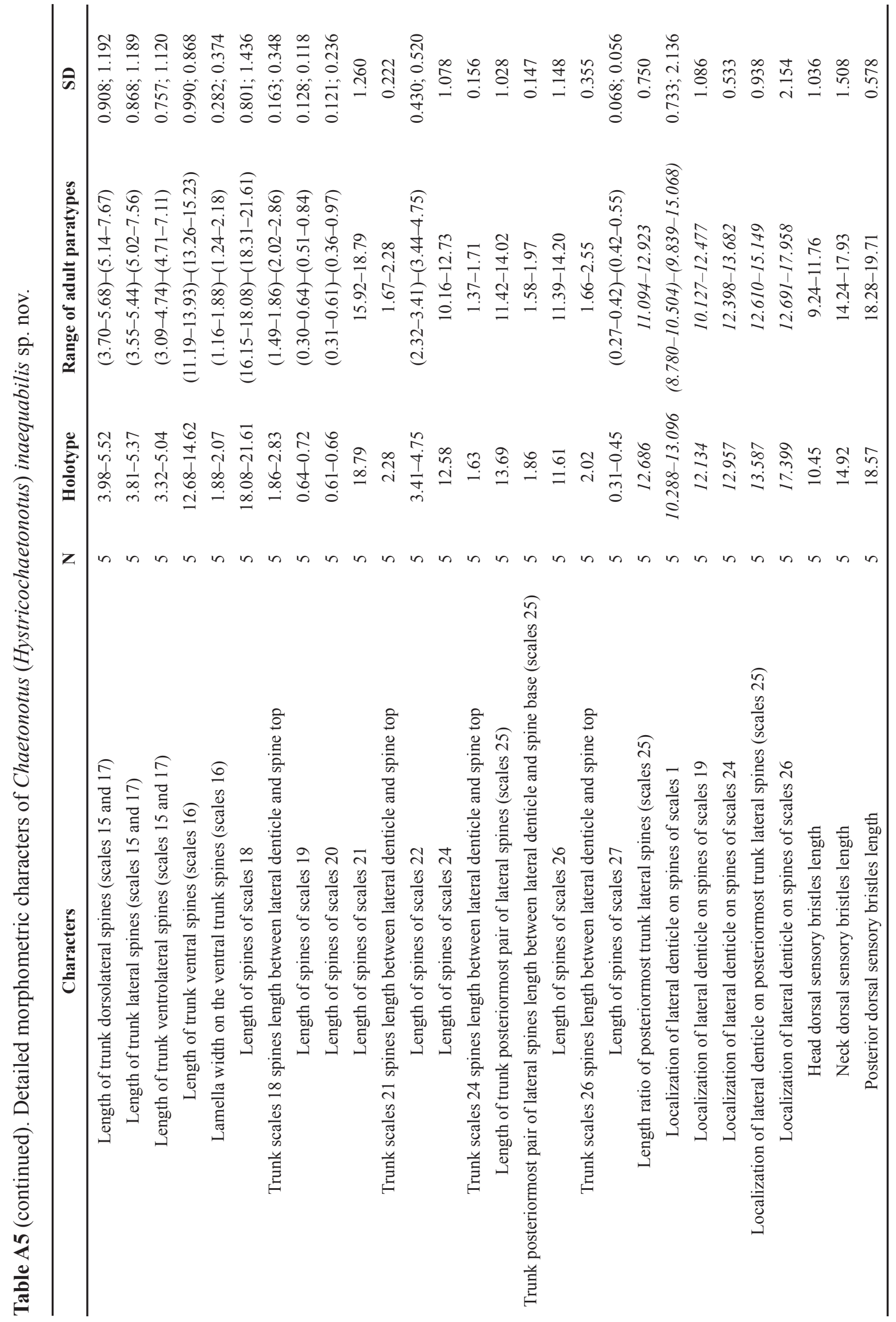




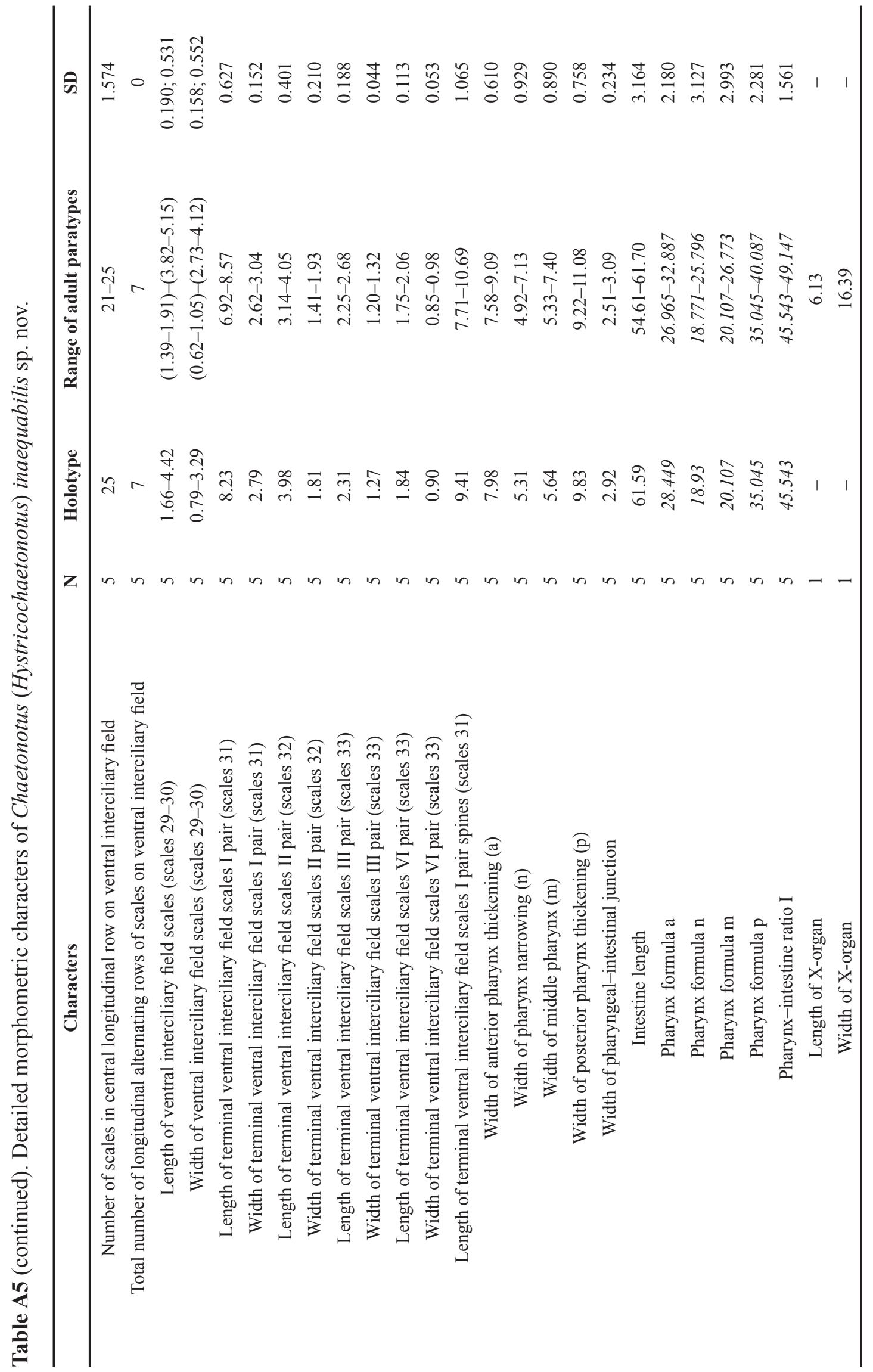




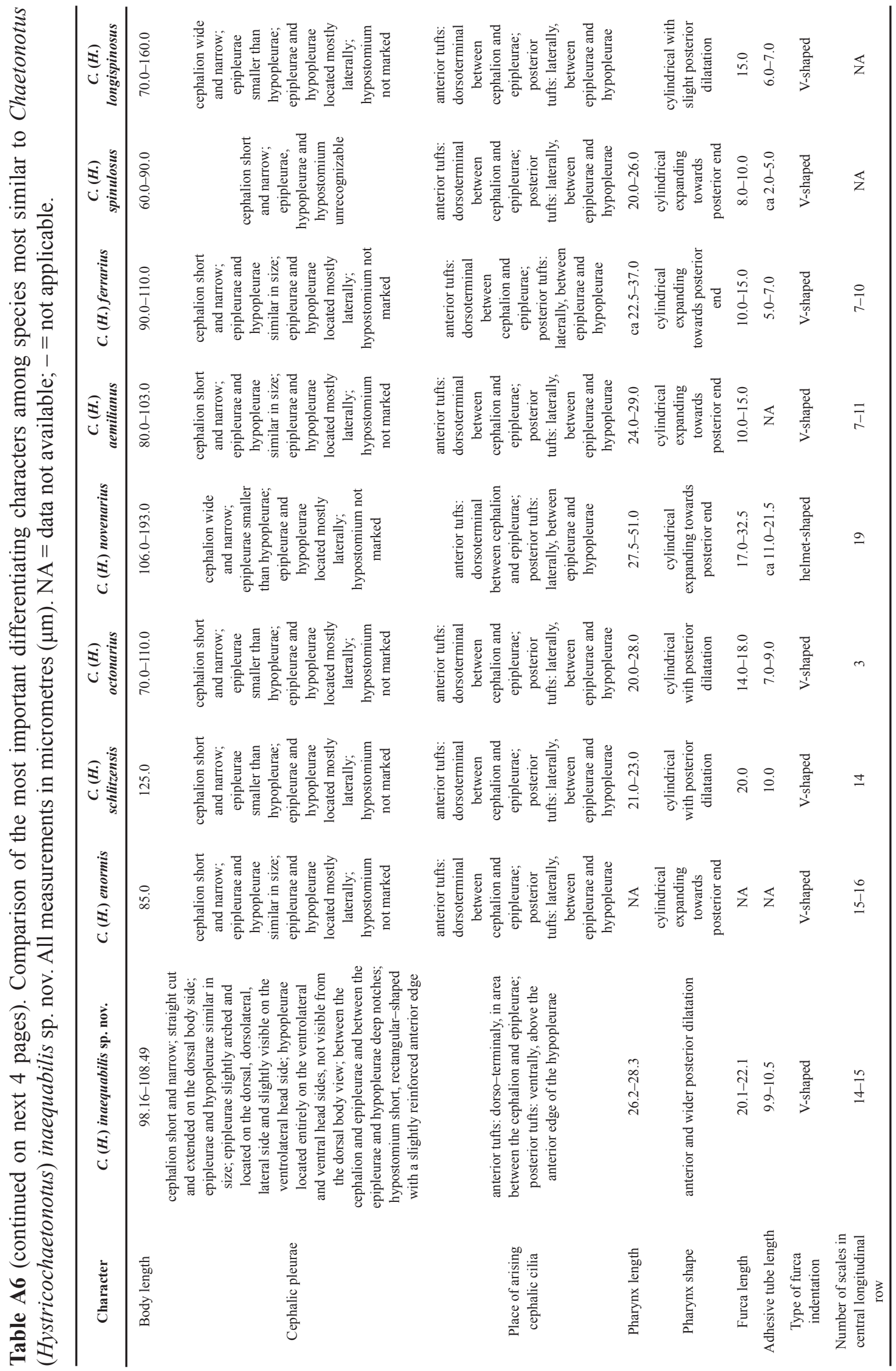




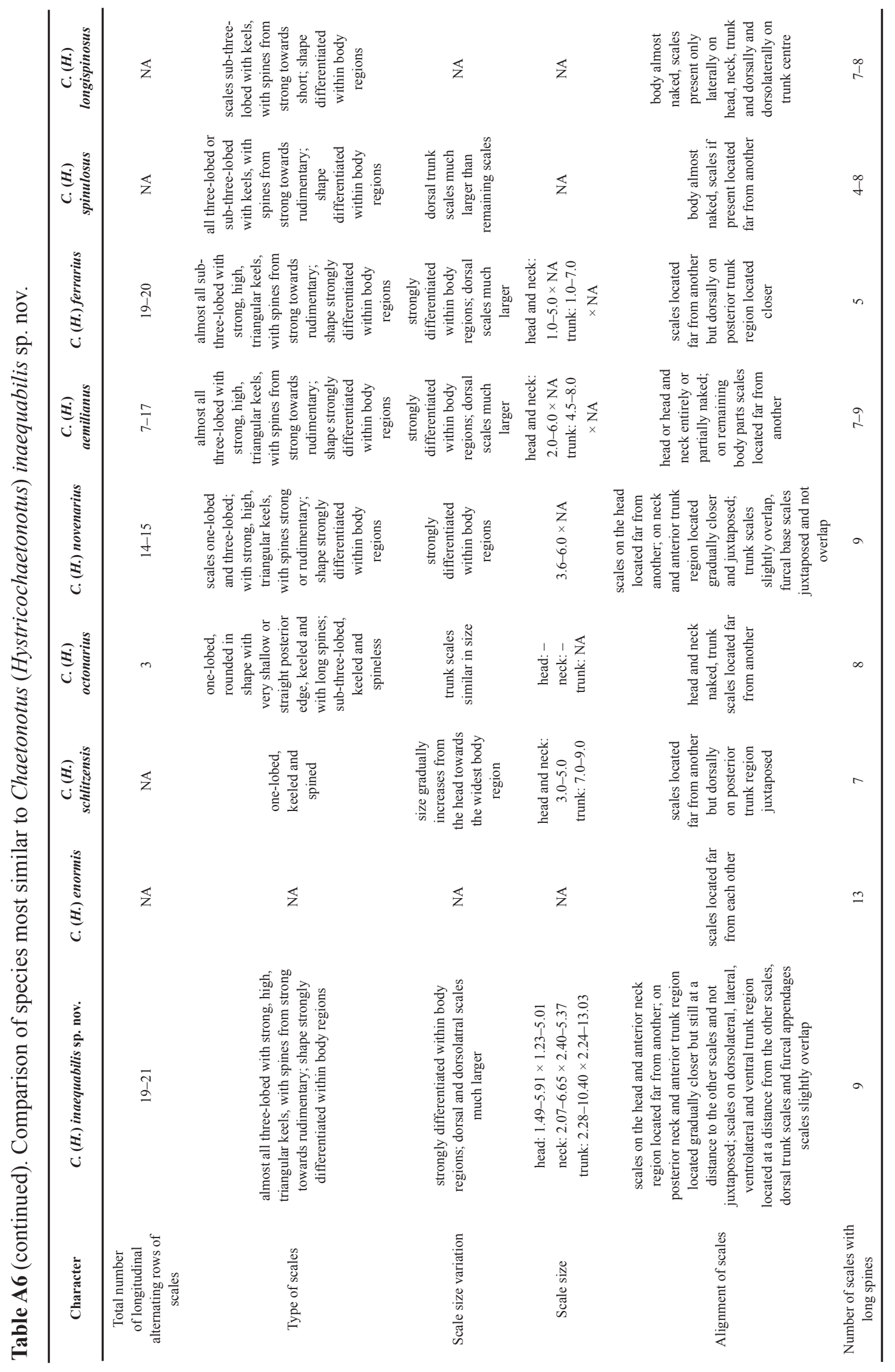




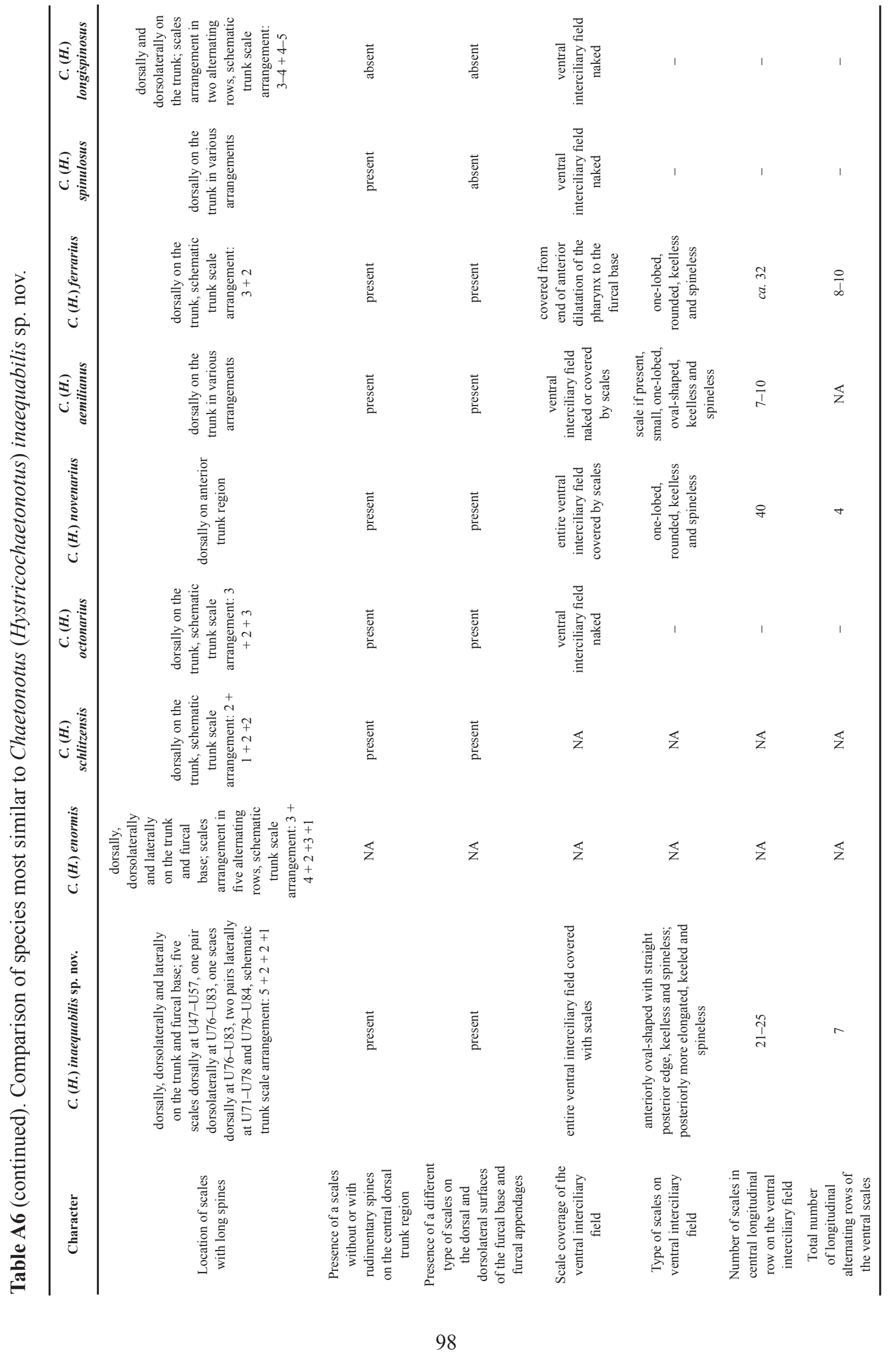




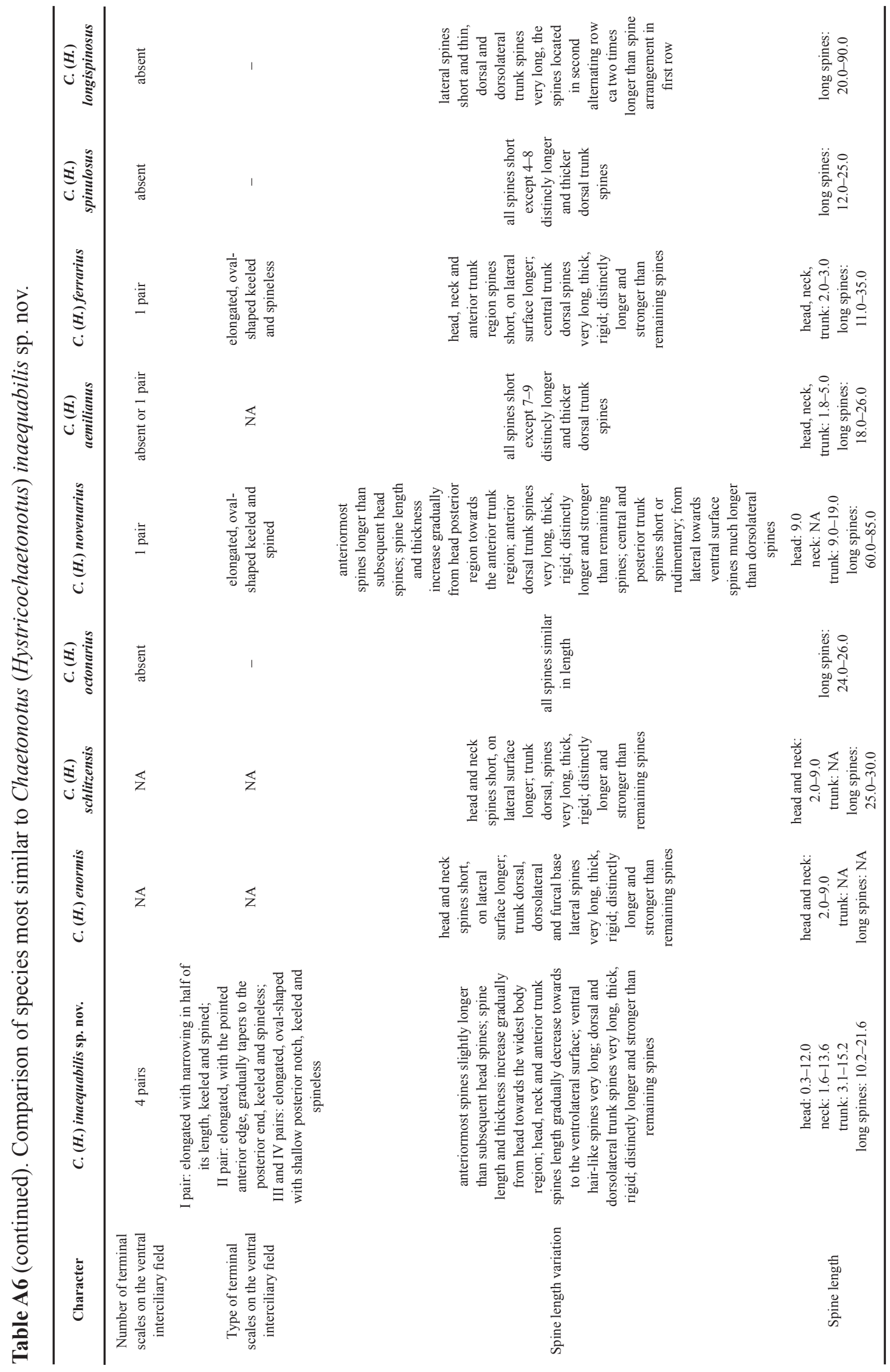




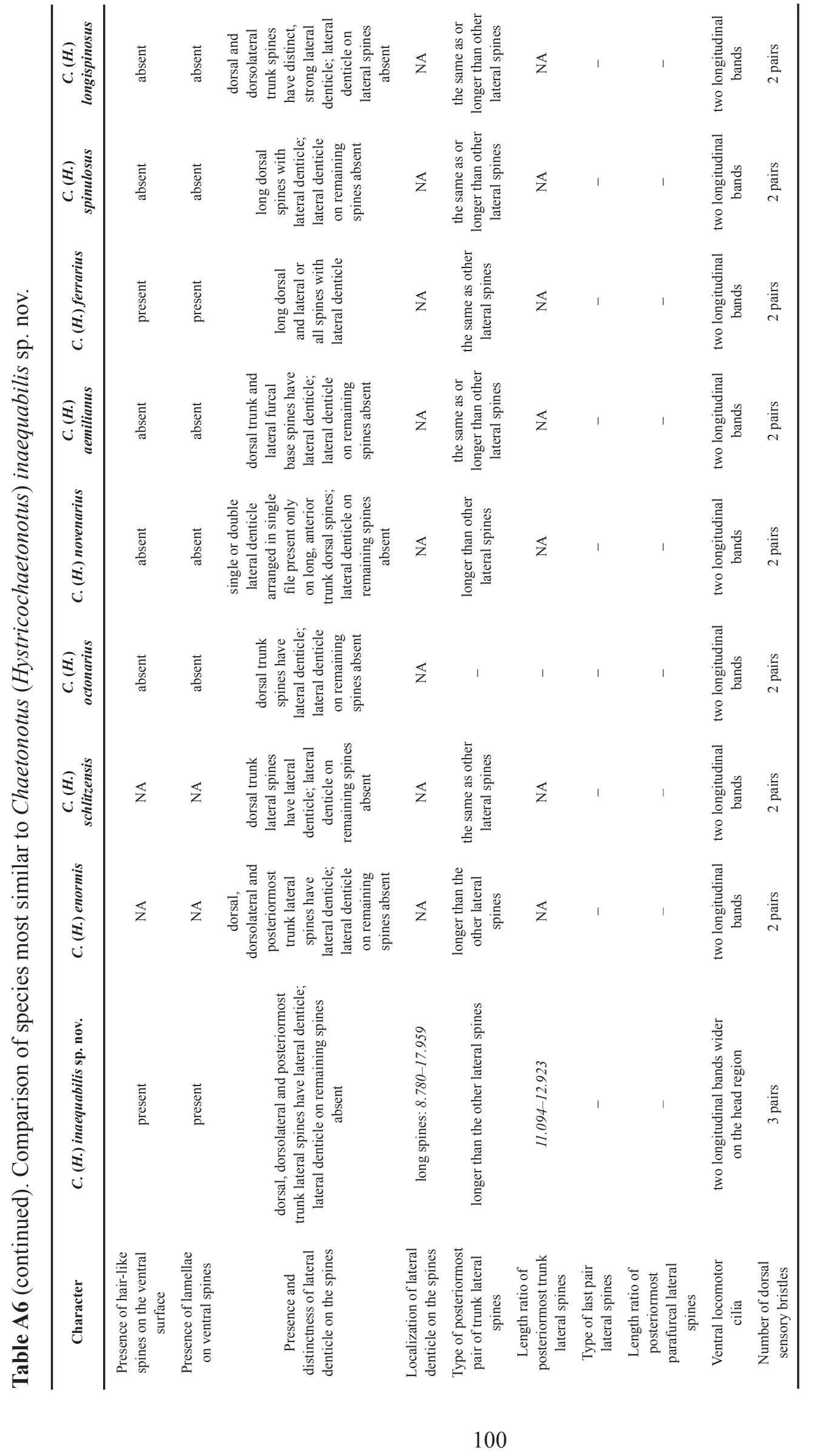

